University of Louisville

ThinkIR: The University of Louisville's Institutional Repository

$12-2014$

\title{
The impact of inflammatory and immune response-related genetic variants on prostate cancer risk among men of African descent.
}

Dominique Zilpha Jones

University of Louisville

Follow this and additional works at: https://ir.library.louisville.edu/etd

Part of the Oncology Commons

\section{Recommended Citation}

Jones, Dominique Zilpha, "The impact of inflammatory and immune response-related genetic variants on prostate cancer risk among men of African descent." (2014). Electronic Theses and Dissertations. Paper 1745.

https://doi.org/10.18297/etd/1745

This Master's Thesis is brought to you for free and open access by ThinkIR: The University of Louisville's Institutional Repository. It has been accepted for inclusion in Electronic Theses and Dissertations by an authorized administrator of ThinkIR: The University of Louisville's Institutional Repository. This title appears here courtesy of the author, who has retained all other copyrights. For more information, please contact thinkir@louisville.edu. 


\title{
THE IMPACT OF INFLAMMATORY AND IMMUNE RESPONSE-RELATED GENETIC VARIANTS ON PROSTATE CANCER RISK AMONG MEN OF AFRICAN DESCENT
}

\author{
By \\ Dominique Zilpha Jones \\ B.A., Smith College, 2010

\begin{abstract}
A Thesis
Submitted to the Faculty of the in Partial Fulfillment of the Requirements for the Degree of

Masters of Science

Department of Pharmacology and Toxicology

University of Louisville

Louisville, Kentucky
\end{abstract} \\ School of Medicine of the University of Louisville
}

December 2014 

THE IMPACT OF INFLAMMATORY AND IMMUNE RESPONSE-RELATED GENETIC VARIANTS ON PROSTATE CANCER RISK AMONG MEN OF AFRICAN DESCENT

By

Dominique Zilpha Jones

B.A., Smith College, 2010

A Thesis Approved on

October 16, 2014

by the following Thesis Committee:

LaCreis Kidd, MPH, Ph.D.

Geoffrey Clark, Ph.D.

Shirsh Barve, Ph.D.

Leila Gobeshijvili, Ph.D.

Carolyn Klinge, Ph.D.

Guy Brock, Ph.D. 


\section{DEDICATION}

This thesis is dedicated to my beloved mother, Annette Jones, my godmother, Ernestine

Hill, my family and friends

who are my source of inspiration for my interest in cancer research. 


\section{ACKNOWLEDGMENTS}

I would like to thank my mentor, Dr. LaCreis Kidd, for her guidance throughout my academic career and research at the University of Louisville. I would also like to thank the other members of my thesis committee, Dr. Geoffrey Clark, Dr. Leila Gobeshjivili, Dr. Shirish Barve, Dr. Carolyn Klinge, and Dr. Guy Brock, for their guidance, encouragement and assistance over the past years. I would like to thank my wonderful fiancée, Joseph Reed, for his encouragement, understanding and patience with me during my graduate program. I also would like to thank my family in New Jersey (Thomas Jones, Sakina Jones), North Carolina (Paula Borden, Peggy and Lovest Alexander, Dion Hill) and friends for all of their support as well. 


\section{ABSTRACT \\ THE IMPACT OF INFLAMMATORY AND IMMUNE RESPONSE-RELATED GENETIC VARIANTS ON PROSTATE CANCER RISK AMONG MEN OF AFRICAN DESCENT}

\section{Dominique Zilpha Jones}

October 16, 2014

Background: In the U.S., prostate cancer (PCA) metastasis is associated with a 5-yr survival rate of $29 \%$ and disproportionately affects men of African descent. Single nucleotide polymorphisms (SNPs) may serve as genetic markers to identify individuals at high risk of developing PCA.

Methods: We examined main and joint effects of 119 inflammatory and immune response-associated SNPs among men of African descent (535 controls, 279 cases) via logistic regression (LR) and entropy-based-multi-factor dimensionality reduction (MDR) modeling.

Results: MDR yielded highly synergistic [(TLR10, TLR6 and IRF3), (TLR2, IRAK4), $(I L 1 R 2, I L 10, I L 10 R A)]$ interaction models as the best predictors of PCA risk based upon informative information gain scores $(\mathrm{p} \leq 0.003)$. Interestingly, CCL5 [rs2107538 (AA, GA+AA), rs3817655 (GA, AA)] SNPs were strongly associated with a 43-56\% decrease in PCA risk.

Conclusion: CCL5 (rs2107538, rs3817655) reduces PCA risk by > 50\% and may serve as potential targets of PCA treatment among men of African descent. 


\section{TABLE OF CONTENTS}

PAGE

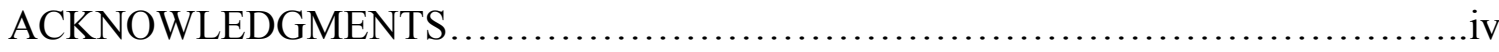

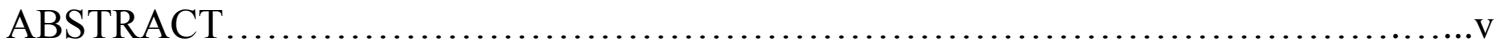

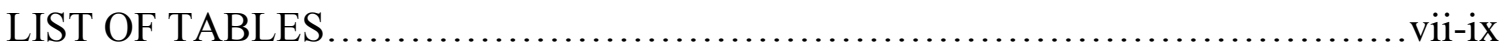

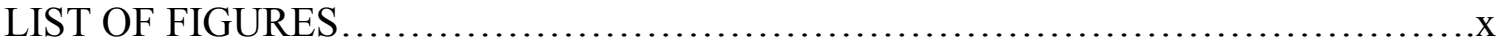

CHAPTER 1: Introduction, Hypothesis, Specific Aims.............................1-53

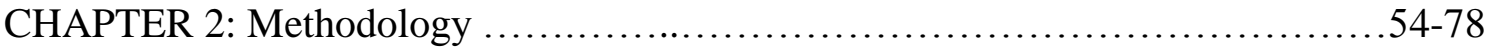

CHAPTER 3: Toll-like Receptor Signaling ....................................79-99

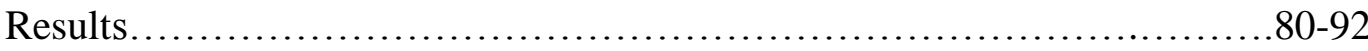

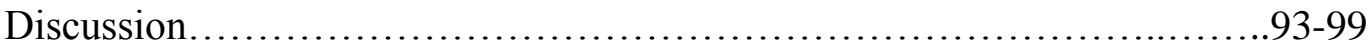

CHAPTER 4: Chemokine Signaling .........................................100-122

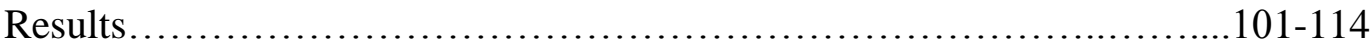

Discussion........................................................

CHAPTER 5: Cytokine Signaling ..............................................123-141

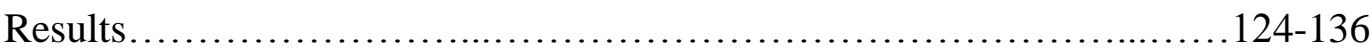

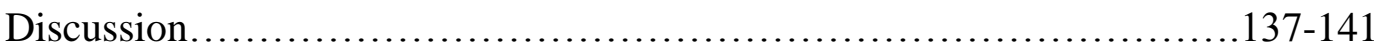

CHAPTER 6: Summary, Conclusion........................................142-146

REFERENCES.....................................................

CURRICULUM VITAE................................................ 175-183 


\section{LIST OF TABLES}

TABLE PAGE

1. Table 1. Inflammatory and Immune related gene-gene

interactions in Prostate cancer.........................................41

2. Table 2. Current Inflammatory and Immune Response Gene

Selective Drugs in Clinical Trials .................................49

3. Table 3. Study population characteristics among men of African

descent from the U.S. and Jamaica.................................55

4. Table 4. Baseline Characteristics among men of African Descent from the U.S....................................................... 56

5. Table 5. Baseline Characteristics among men from Jamaica..........57

6. Table 6. Functional consequence of TLR-associated sequence variants.......................................................... 60 .

7. Table 7. Functional Consequence of Chemokine-Associated Sequence Variants

8. Table 8. Functional Consequence of Inflammatory-Associated Sequence Variants.........................................66-71

9. Table 9a. Relationship between TLR-associated SNPS and PCA

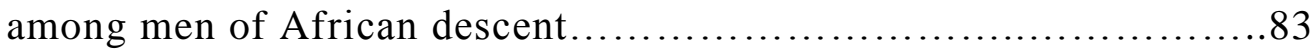

10. Table 9b. Relationship between TLR-associated SNPs and PCA risk

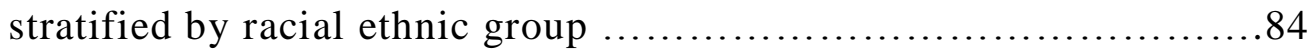


11. Table 10a. Interactions and main effects of TLR-associated SNPs as predictors of PCA using age-adjusted MDR among U.S. and Jamaican men of African Descent........................................... 87

12. Table 10b. Interactions and main effects of TLR-associated SNPs as predictors of PCA using age-adjusted MDR among U.S. men of African Descent .89

13. Table 10c. Interactions and main effects of TLR-associated SNPs as predictors of PCA using age-adjusted MDR among Jamaican men of African Descent..................................................91

14. Table 11a. Relationship between Chemokine-associated SNPs and PCA Risk among men of African Descent 103

15. Table 11b. Relationship between Chemokine-associated SNPs and PCA stratified by racial ethnic group $106-107$

16. Table 12a. Interactions and main effects of Chemokine-associated SNPs as predictors of PCA using age-adjusted MDR among men of African Descent............................................... 110

17. Table 12b. Interactions and main effects of Chemokine-associated SNPs as predictors of PCA using age-adjusted MDR among U.S. men of African Descent....................................................112

18. Table 12c. Interactions and main effects of Chemokine-associated SNPs as predictors of PCA using age-adjusted MDR among Jamaican men of African Descent 
19. Table 13a. Relationship between Inflammatory-associated SNPs and PCA Risk among men of African Descent......................126-127

20. Table 13b. Relationship between Inflammatory-associated SNPs and PCA Risk stratified by racial ethnic group............................129-130

21. Table 14a. Interactions and main effects of Inflammatory-associated SNPs as predictors of PCA using age-adjusted MDR among men of African Descent..................................................133

22. Table 14b. Interactions and main effects of Inflammatory-associated SNPs as predictors of PCA using age-adjusted MDR among U.S. men of African Descent.............................................. 135

23. Table 14c. Interactions and main effects of Inflammatory-associated SNPs as predictors of PCA using age-adjusted MDR among Jamaican men of African Descent......................................... 136 


\section{LIST OF FIGURES}

$\begin{array}{ll}\text { FIGURE } & \text { PAGE }\end{array}$

1. Figure 1. Progression of prostatic inflammation to Prostate Cancer.................4

2. Figure 2a. Acute Inflammation in Prostate Tumorigenesis ....................... 10

3. Figure 2b. Chronic Inflammation in Prostate Tumorigenesis .....................11

4. Figure 3. Toll-like receptor signaling in innate immunity $\ldots \ldots \ldots \ldots \ldots \ldots \ldots \ldots \ldots \ldots$

5. Figure 4. The effect of IL1R2 on immune cells and Prostate Cancer...............36

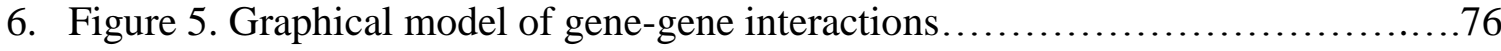

7. Figure 6. Entropy graph of gene-gene interactions........................... 78

8. Figure 7. Entropy graph of TLR gene-gene interactions among U.S. and Jamaican men of African Descent.......................................... 88

9. Figure 8. Entropy graph of TLR gene-gene interactions among U.S. men of

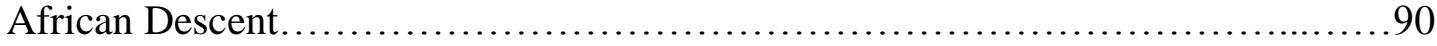

10. Figure 9. Entropy graph of TLR gene-gene interactions among Jamaican men of African Descent...................................................... 92

11. Figure 10. Entropy graph of Chemokine gene-gene interactions among U.S. and Jamaican men of African Descent......................................111

12. Figure 11. Entropy graph of Chemokine gene-gene interactions among Jamaican men of African Descent...................................... 114

13. Figure 12. Entropy graph of Cytokine gene-gene interactions among U.S. and Jamaican men of African Descent. 


\section{CHAPTER 1 \\ INTRODUCTION}

\section{Prostate cancer as a public health problem}

Prostate cancer (PCA) is a slow growing disease and one of the leading causes of cancer-related deaths among men in the U.S. and Caribbean (e.g., Jamaica). In the U.S., 1 in 6 men will develop prostate cancer in their lifetime [1]. When the disease is detected at early and treatable stages, there is a 100\% 5-year survival rate among U.S. men diagnosed with localized or regional disease [2]. However, the five-year survival rates drop drastically to $29 \%$ among U.S. men diagnosed with metastatic PCA. Among prostate cancer patients with metastatic disease, $90 \%$ and $65 \%$ of the cancer spreads to the bone and liver, respectively [3]. Metastatic PCA is aggressive and becomes nonresponsive to conventional treatments such as hormornal therapy $[4,5]$. Among PCA patients who undergo a radical prostectomy, 20-40\% of them will experience recurrent disease $[6,7]$. Although, the 5-year survival rates for regional or distant prostate cancer among Jamaican men is unknown, the $74 \%$ five-year biochemical recurrence disease free survival rate for Jamaican men with clinically organ-confined prostate cancer (tumor stage 1-2) is comparable to rates found among African-American men [8]. In addition to poor disease prognosis attributed to detection of the disease at later stages and delays in treatment, PCA is associated with a great economic burden in the United States. National 
expenditure for prostate cancer care was approximately $\$ 11.9$ billion [9], according to the 2010 U.S. National Cancer Institute (NCI) Cancer Trends Progress Report. After diagnosis, the average medical cost for U.S. patients was $\$ 48,808$, which included a direct cost of $\$ 29,417$ for prostate cancer related procedures. Medical expenses for PCA patients with Medicare insurance were slightly lower than patients on other types of insurance within the U.S. Over a 4-year follow-up period, the average medical cost was $\$ 18,168$ per prostate cancer patient on Medicare [10]. According to the PharMetrics database, patients who experienced watchful waiting care incurred a cost of $\$ 7,595$; whereas, those who underwent treatment had a direct cost of $\$ 38,745[11,12]$. In particular, treatment options for prostate cancer patients 40 years or older between years 2000 and 2005 incurred the following cost: $\$ 17,753$ for chemotherapy, $\$ 29,984$ for hormone therapy, $\$ 31,666$ for surgery, and $\$ 42,554$ for radiation therapy $[11,12]$.

\section{Determinants of Prostate Cancer}

Although the pathogenesis of prostate cancer requires further elucidation, there are a number of established and plausible PCA risk factors. Established risk factors for prostate tumorigenesis, include age, family history of prostate cancer and race $[1,13]$. Naturally, as men become older their risk for PCA increases as well. Race is a major determinant of prostate cancer as detailed in the "Prostate Cancer Health Disparities" section below.

Plausible risk factors include: hormonal imbalances (e.g., androgen, testosterone); a sedentary lifestyle (e.g., obesity); environmental exposures (e.g., intake of red meat, high-fat dairy products, polyunsaturated fats); exposure to meats-derived carcinogens detected in meats prepared well done via grilling or pan-frying [14-18]; the inheritance of genetic polymorphisms within inflammatory and immune response (e.g., toll-like 
receptor, cytokine, chemokine); chronic inflammation $[14,19,20]$. In terms of chronic inflammation, it is estimated that approximately $20 \%$ of all human cancers, including prostate cancer (PCA), are associated with chronic inflammation $[1,21,22]$. In fact, epidemiological studies revealed a higher prostate cancer susceptibility among patients with a history of prostatic inflammation compared to those without a history [23, 24].

Chronic inflammation is known to contribute to the various disease states leading to prostate cancer, including prostatic inflammation, proliferative inflammatory atrophy and prostatic intraepithelial neoplasia, as depicted in Figure 2. Prostatic inflammation may occur as the result of infection by microbial pathogens, chemical irritation caused by urine reflux, hormone imbalance, diet or environmental exposures, genetic alterations, age and autoimmunity.

Prostatic inflammation is separated into four categories: (1) acute bacterial prostatitis; (2) chronic bacterial prostatitis; (3) chronic pelvic pain syndrome; and (4) asymptomatic inflammatory prostatitis [14]. Both acute and chronic bacterial prostatitis are caused by a bacterial infection of the prostate from Escherichia coli, Enterococcus spp. (species) or sexually transmitted infections (STIs). Symptoms of bacterial prostatitis include an increase in urination, pain in the genital area, fever, chills, and burning during urination [25]. Although, the cause of chronic pelvic pain syndrome is unknown, it is categorized as either non-inflammatory or inflammatory based on the absence or presence of white blood cells in prostatic fluid [26]. Asymptomatic inflammatory prostatitis is diagnosed based on the presence of white blood cells in prostatic tissue [26]. 


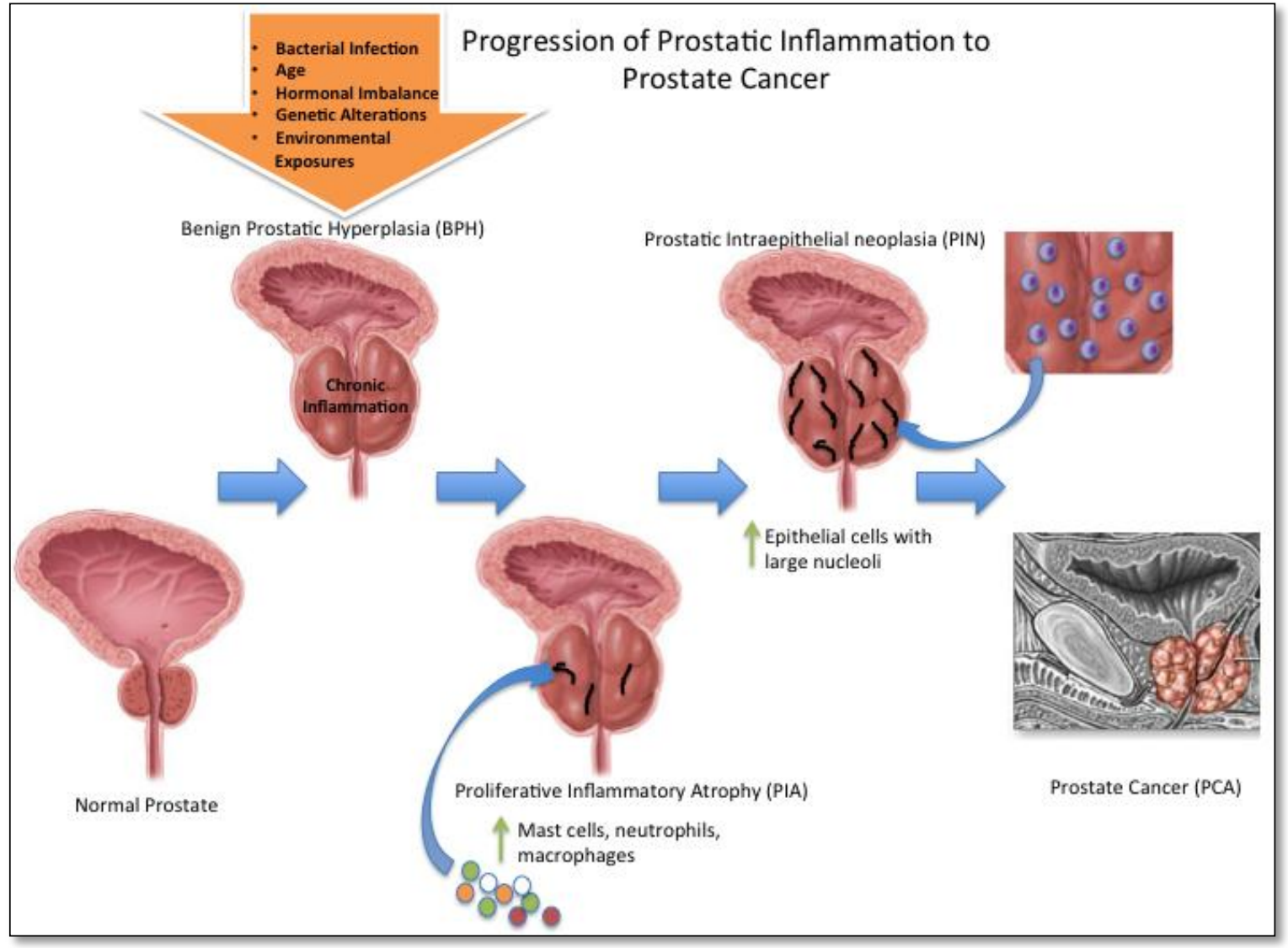

Figure 1. Progression of prostatic inflammation to prostate cancer. Chronic inflammation of the prostate may result from bacterial infection, age, hormonal imbalance, genetic alterations or environmental exposures (e.g., carcinogenic agents, diet). During inflammation, immune cells (e.g., mast cells, macrophages) travel to the site of inflammation and secrete cytokines and chemokines to recruit more immune cells. The accumulation of immune cells may lead to the formation of PIA lesions. PIA lesions may transition into PIN, which is characterized by epithelial cells with large nucleoli. High grade PIN occurs in $20-30 \%$ of prostate cancer and is regarded as a possible precursor to prostate carcinoma. 


\section{Prostate Cancer Health Disparities}

Men of African descent suffer disproportionately from PCA. African-American and Caribbean men have the highest prostate cancer incidence and mortality rates compared to their Caucasian counterparts $[1,8]$. African-American men are 1.6 times more likely to receive a prostate cancer diagnosis and 2.4 times more likely to succumb to this disease than their European-American counterparts [27]. Similarly, Jamaican men have a high incidence rate of prostate cancer in comparison to European-American men $[1,13,27,28]$. In a prostate cancer survey with more than 3,000 men on the island of Tobago in the Caribbean (i.e., $\sim 60 \%$ of male population), the prevalence of prostate cancer among men over 59 years of age was 3 times higher than European-American men [29]. In a recent report on global patterns of prostate cancer, Rebbeck and co-workers (2013) observed that African-Americans had the highest incidence rate according to the age-standardized estimates for prostate cancer compared to Caribbean and African men [30]. However, the higher PCA mortality rates observed among Caribbean men relative to African-American men may be partially attributed to limited access to early PCA detection screening protocols as well as availability of medical care and treatment. Likewise, men from African countries such as South Africa and Senegal had the largest percentage of cancer with stage T3/T4 tumors, due to limited access to healthcare and treatment $[30,31]$. Due to the limited availability of cancer statistics for African and Caribbean countries and misclassification of racial/ethnic background, some studies may not accurately depict the PCA incidence and mortality rates among men of African and Caribbean descent. 
Differences in prostate cancer screening behavior, family history, access to health care, and cancer treatment regimens cannot fully explain the tumor burden that men of African descent suffer. Some studies speculate biological differences may help to explain the higher PCA incidence among African-American men relative to European Americans. In a retrospective study, Eastham and colleagues (1998) observed that African-American men had significantly higher levels of serum PSA ( $p$-value $=0.00003)$, PSA densities ( $\mathrm{p}$-value $=0.000009)$ and inflammation in the prostate than EuropeanAmerican men [32]. Additionally, Winters and co-workers (1998) speculated higher levels of total testosterone and sex hormone binding globulin (SHBG) among young African-American men may predispose them to a higher risk of developing PCA than their Caucasian counter parts [33]. This increased risk may be attributed to enhanced cellular division in the prostate epithelium [33]. Moreover, increased apoptotic blockage via Bcl-2 expression, coupled with enhanced cellular proliferation may contribute to increased tumor volume and burden among African-American men relative to Caucasians. In fact, deVere and colleagues (1998) showed a significant relationship between Bcl-2 immunopositivity and high proliferation among African American paraffin-embedded prostatic tumor tissue $(\mathrm{p}$-value $=0.012)$ but not European-Americans [34].

Our lab and other researchers have speculated that prostate cancer health disparities may be partially attributed to dysregulation within important biological pathways involved in inflammatory and immune response signaling [35-40]. The inflammatory and immune-response signaling pathway is triggered by the detection of pathogens or damaged cells (e.g., tumor cells) via toll-like receptors (TLRs). 
Consequentially, production of cytokines and chemokines from immune cells via TLRs occur to recruit more immune cells to the site of infection or tissue damage. In fact, Wallace and colleagues (2008) observed significant differences in the mRNA expression of chemokine-related genes in prostate tumor of African- and European-American men compared to surrounding non-tumor prostate tissue [41]. For instance, the mRNA expression of $C X C R 4, C C R 7$, and $C C L 5$ were higher in prostate tumors collected from African-Americans compared to European-American men. Moreover, Reams and associates (2009) showed the gene expressions of CXCL2 and IRF4 were statistically under-expressed by 4-fold in African-American prostate tumor tissue compared to European-American tumors normalized to snap frozen non-tumor matched controls ( $\mathrm{p}$ value $\leq 0.05$ ) [42]. The differences shown in gene expression profiles between Africanand European-American men may lead to an explanation for the PCA health disparity observed among men of African descent.

\section{Role of Inflammation and immune response in prostate cancer}

Prostate tumorigenesis is largely driven by recurrent acute or chronic inflammation. During acute/chronic inflammation, inflammatory cells (e.g., mast cells, polymorphonuclear leukocytes, macrophages) produce pro- and anti-inflammatory cytokines and chemokines to launch an inflammatory response to repair tissue injury, remove pathogens and fight against infectious agents or foreign cells. Chemokines, function as chemoattractants that send signals to prostate cancer cells to migrate and metastasize to other organs in the body. In particular, the inflammatory response driven by recurrent acute or chronic inflammation can target malignant or tumor cells as emphasized in Figure 2a and 2b. Chronic inflammation results from an imbalance in the 
regulation of pro- and anti-inflammatory signals. This imbalance may favor proinflammatory signaling to trigger chronic inflammation of the prostate and ultimately lead to PCA development [43].

Acute inflammation is the immediate response of the immune system triggered by the movement of plasma and leukocytes from blood to the site of inflammation to help clear pathogens in the body, as depicted in Figure 2a. Second, chronic inflammation is a state of prolonged inflammation where active inflammation, tissue injury and repair occur simultaneously, as depicted in Figure 2b. Following exposure to viral or chemical insults to normal prostate epithelium, viral or chemical carcinogens may induce somatic changes in normal prostate cells that introduce genomic alterations such as deletions mutations, and rearrangements of oncogenes and tumor suppressor genes. In response to these DNA changes, cellular death and repair mechanisms are initiated to fix damaged cells in DNA replication and cellular proliferation. These damaged cells may produce cytokines and chemokines to recruit inflammatory cells for their destruction leading to the onset of acute inflammation. Inflammatory cells serve as the frontline of defense for the immune system during inflammation and the release of factors (e.g.,VEGF) that enhance the angiogenic phenotype of tumors. During acute inflammation, inflammatory cells such as tumor associated macrophages (TAMs) release reactive oxygen and nitrogen species that induce oxidative DNA damage. Additionally, mast cells, neutrophils and leukocytes release cytokines and chemokines to recruit more inflammatory cells to the inflamed prostatic tissue (Figure 2a). In some cells, the damage may exceed the capacity of the cellular repair mechanism and these cells transition into permanently damaged cells with uncontrolled DNA replication and cellular proliferation otherwise known as tumor cells. 
Tumor cells also produce cytokines and chemokines that attract inflammatory cells to their location. Inflammatory cells attempt to infiltrate inflamed prostatic tissue to destroy the tumor cells. Immature dendritic cells become activated and mature by engulfing antigens from the tumor cells. Mature dendritic cells travel to the lymph nodes to present tumor antigens and recruit lymphocytes to the inflamed prostatic tissue. Macrophages and lymphocytes express macrophage inhibitory factor (MIF), which is a potent cytokine that suppresses the transcriptional activity of p53. Persistent tissue damage and regeneration via reactive nitrogen and oxygen species released from inflammatory cells as well as the growing number of damaged cells leads to chronic inflammation.

During chronic inflammation, macrophages and lymphocytes such as T cells, B cells and natural killer (NK) cells are recruited to infiltrate inflamed prostatic tissue (Figure 2b). Moreover, chronic inflammation may lead to the accumulation of oncogenic mutations and promote prostate carcinoma. Unlike acute inflammation, chronic inflammation contributes to the development of an estimated $20 \%$ of adult cancers via bacterial infections, chronic non-infectious inflammatory diseases and environmental factors [14]. 


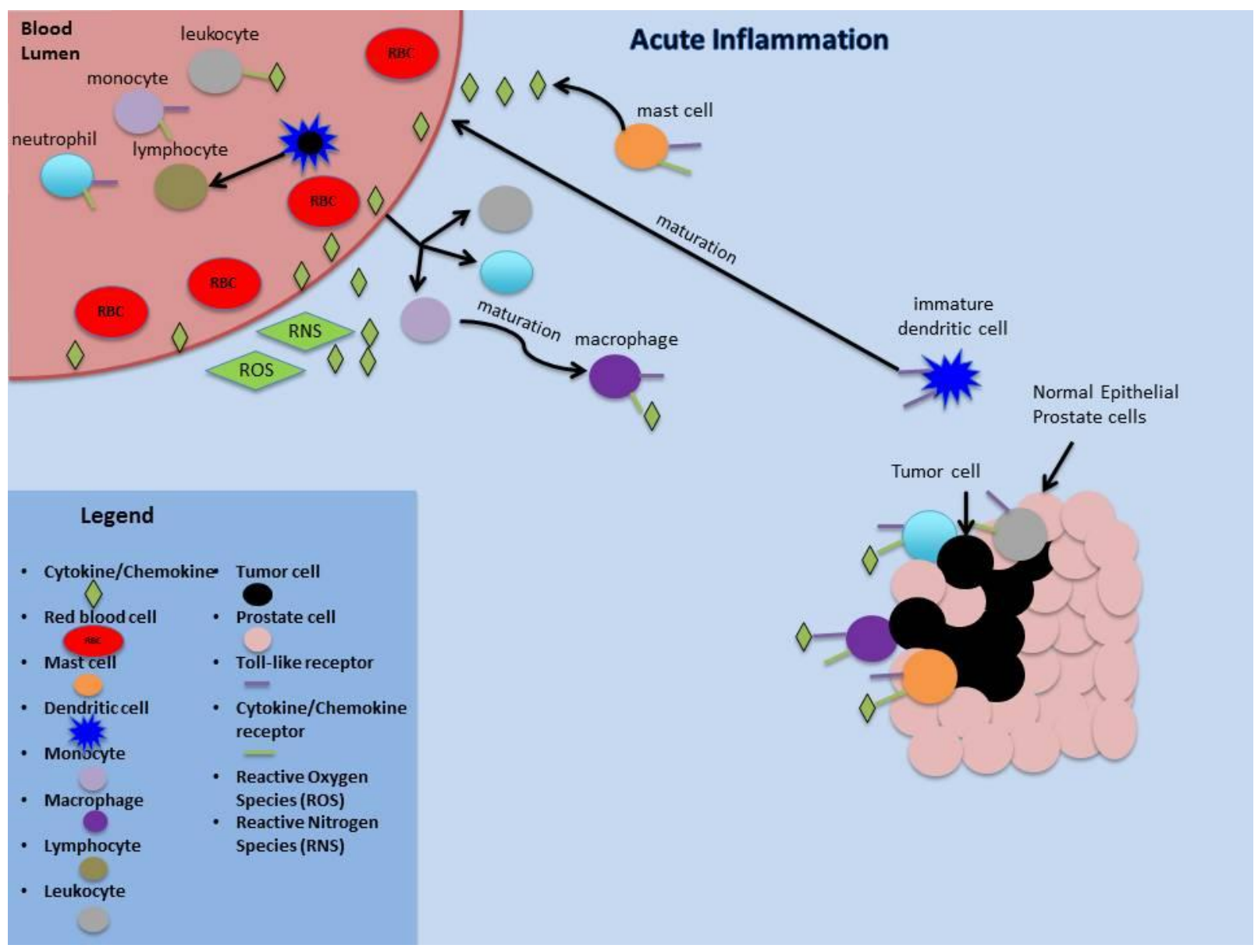

Figure 2a. Acute inflammation in prostate tumorigenesis. During acute inflammation, immune cells such mast cells, macrophages, neutrophils and leukocytes detect tumor cells through their TLRs, which recognize DAMPs (damage-associated molecular patterns) secreted from tumor cells. TLR signaling induces cytokine and chemokine production in the immune cells (e.g., mast cells, leukocytes, macrophages), which results in an increase recruitment of immune cells needed to target damaged prostatic cancer cells (tumor cells). Tumor associated macrophages secrete ROS and RNS to induce DNA damage. Immature dendritic cells engulf tumor cells to mature and travel to the lymph nodes to present tumor cell antigen to lymphocytes. 


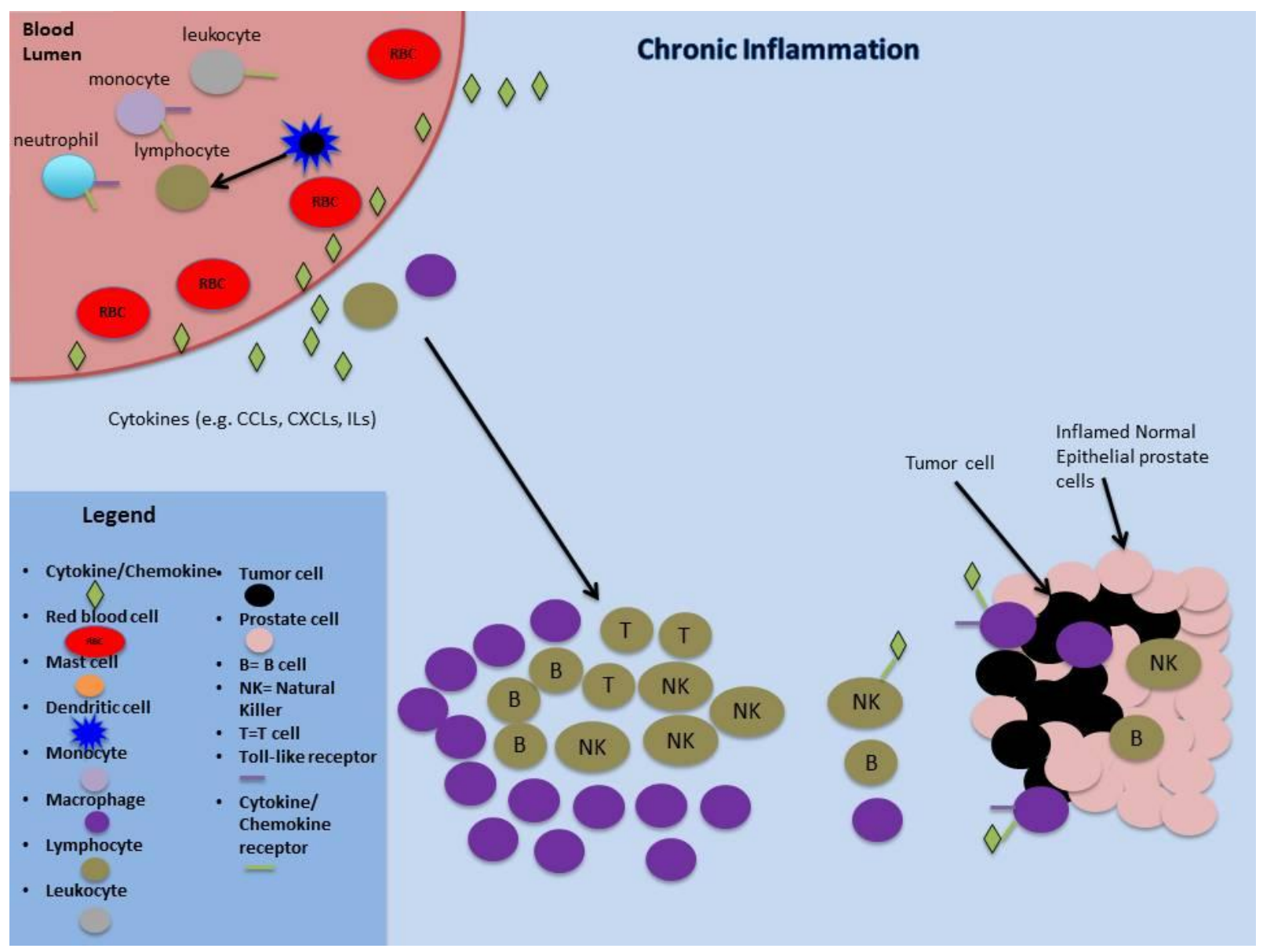

Figure 2b. Chronic Inflammation in Prostate Tumorigenesis. Primarily lymphocytes (B, T, NK cells) and macrophages are active in chronic inflammation. Cytokines and chemokines attract these immune cells to infiltrate prostatic cells and target damaged cells (tumor cells). 
Chronic inflammation of the prostate may lead to the development of PIA (proliferative inflammatory atrophic) followed by the progression of PIA to PIN (prostatic intraepithelial neoplasia) and ultimately the initiation of prostate cancer. PIA, attributed to repetitive tissue injury and damaged-induced cellular proliferation in prostate epithelium, is characterized by the formation of lesions in the peripheral zone of the prostate gland. The PIA lesions are related to increases in anti-apoptotic (e.g., Bcl-2) and proliferative signals as well as the population of mononuclear (e.g., lymphocyte, monocyte) and polymorphonuclear (e.g., neutrophils, mast cells) cells in the prostate epithelium and stromal tissue [44, 45]. IL17 positive monocytes/macrophages and other inflammatory cells accumulate in PIA lesions of radical human radical prostatectomy specimens [45]. The aforementioned immune cells exasperate PIA due to the overexpression of inflammatory cytokines. For instance, IL17 positive monocytes/macrophages accumulate in PIA lesions of human radical prostatectomy specimens [45]. IL17 plays a dual role in acute and chronic inflammation through the stimulation of IL6 (acute/chronic inflammation) and IL8 (acute inflammation) production [46]. As chronic inflammation persists in the prostate, PIA lesions can transition into PIN, a potential precursor of prostate cancer [44, 47]. High-grade PIN lesions contain abnormal cells with a large nucleus, detected in a number of prostate biopsies, and are associated with a 20-30\% increase in the risk of prostate cancer development [47, 48].

\section{Innate and Adaptive Immunity Signal Pathways in Response to Pathogens}

Chronic or recurrent exposure to pathogens or infectious agents can lead to prostatic inflammation followed by PIA, PIN and ultimately prostate carcinoma. In response to pathogens or infectious agents, the immune system has two defense 
mechanisms, innate and adaptive immunity. Innate immunity immediately triggers the activation of macrophages. During innate immunity, macrophages and mast cells nonspecifically target pathogens through the recognition of their antigens. Next, these inflammatory cells secrete soluble inflammatory mediators such as cytokines, chemokines, matrix remodeling proteases and reactive oxygen species (ROS) that attract other inflammatory cells (e.g., epithelial cells, neutrophils, monocytes, natural killer (NK) cells, dendritic cells, basophils, eosinophils) to engage pathogens at the site of infection $[49,50]$. Activated macrophages secrete cytokines (e.g., chemokines), which initiates the inflammatory response of the immune system. In addition, immature dendritic cells ingest pathogens and present receptors on their surface that recognize many common pathogens. Immature dendritic cells migrate through the lymph nodes to interact and activate lymphocytes. NK cells destroy certain groups of immature dendritic cells and promote the maturation of other dendritic cells [49]. During innate immunity, T- and Blymphocytes of adaptive immunity are exposed to foreign antigens via mature dendritic cells and develop receptors that are antigen-specific. Adaptive immunity is a complex antigen-specific defensive response to pathogens or infection and retains memory of specific antigens for future infections or invasion of pathogens. However, the effect of adaptive immunity is observed after approximately 4-7 days of infection [50]. Innate and adaptive immunity leads to the inflammatory response involved in pathogen or infectious agent induced prostate cancer development and progression. However, the focus of this study is restricted to innate immunity signaling, which involves TLRs, chemokines, and cytokines. 


\section{Innate Immune System}

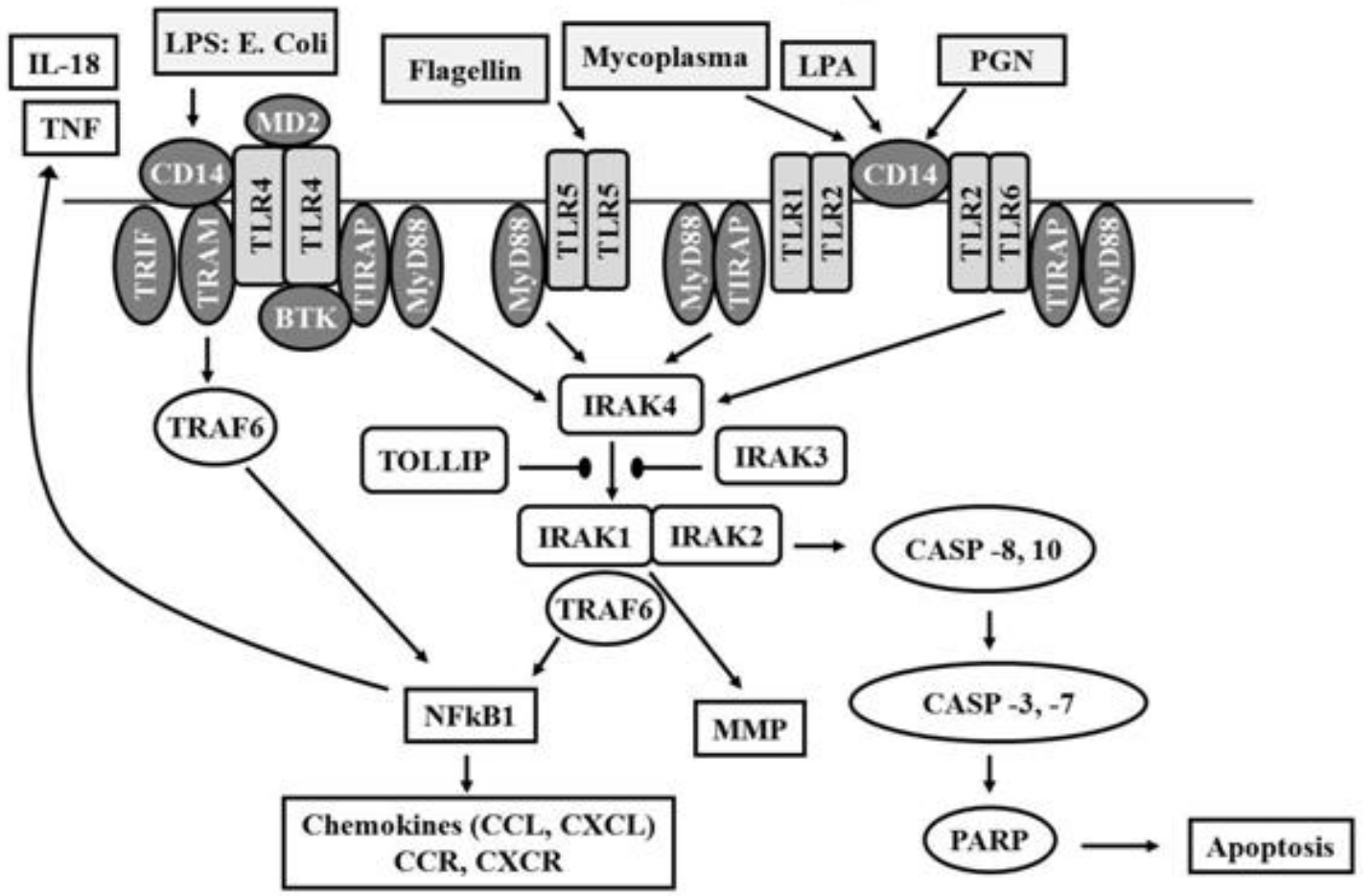

Figure 3. Toll-like receptor signaling in innate immunity. TLRs play a critical role in innate immunity through their recognition of pathogen antigens. TLR signaling induces apoptosis, and elevate the expression of MMPs, cytokines and chemokines via the activation of NFKB and IRAK4. However, TOLLIP and IRAK3 can inhibit IRAK4 signaling. 


\section{Role of TLRs, Cytokines and Chemokines in Inflammatory and Immune Response}

Toll-like receptors in relation to the inflammatory and immune response: The pattern

recognition receptor (PRR) family, which includes toll-like receptors (TLRs), plays an

essential role in regulating innate immune responses against harmful pathogens, as

depicted in Figure 3 [31]. With the assistance of extracellular accessory proteins (e.g.,

CD-14, MD-2), TLRs are activated through their recognition of pathogen-associated

molecule patterns (PAMPs) of pathogens as well as damage-associated molecular

patterns (DAMPs) released from injured epithelial cells [51]. Some human TLRs (e.g.,

TLR1, TLR2, TLR4, TLR5, and TLR6) are located on the cell surface and recognize

lipid or protein ligands; whereas, others located within the intracellular compartments

(e.g., TLR3, TLR7, and TLR9) recognize viral genetic material [31, 52].

Once activated, TLRs form complexes with adapter molecules (e.g., MyD88,

TRIM, TRIF) to recruit downstream targets (e.g., IRAK4 and TRAF6), which lead to the activation of transcription factors [e.g., nuclear factor- $\kappa \mathrm{B}(\mathrm{NF}-\kappa \mathrm{B})$ and interferon regulatory factors (IRFs)] via mitogen-activated protein kinase (MAPKs) signaling [31].

Overall, the TLR signaling cascade initiates local inflammation, which involves the secretion of inflammatory mediators, chemokines, cytokines, antibodies, major histocompatibility complex class II (MHCII) and interferons [31]. In addition, TLR

signaling leads to the maturation of dendritic cells. Immature dendritic cells phagocytize pathogens and present fragments of the pathogen on its cell surface using MHC

molecules. Mature dendritic cells induce the adaptive immune response, which is a more complex defense system against pathogens. 
Chemokines in relation to the inflammatory and immune response: Chemokines (e.g., CC, CXC, XCL, XC and CX3C), secreted via intracellular signaling through the TLR signaling pathway (i.e., TLR2/TLR4), play a pivotal role in chemotaxis, lymphocyte development, angiogenesis, host response to infection, chronic inflammation, trafficking of dendritic and lymphocytes and ultimately tumorigenesis [35]. These molecules mediate their actions through 7-transmembrane G-protein coupled receptors and serve three major physiological functions. First, chemokines are involved in the maturation and homeostasis of the immune system, as well as trafficking of memory T cells, lymphocytes, monocytes, and neutrophils to the inflammatory site. Chemokines function in a chemotactic manner to attract lymphocytes, monocytes, and neutrophils to the site of infection and into pre-malignant tissue. Chemokine receptors located on the surface of innate immune cells include neutrophils (e.g., CXCR1, CXCR2), immature dendritic cells (e.g., CCR1, CCR5) and NK cells (e.g., CCR2, CCR4, CCR5, CCR7 and CCR8) and activated maturated dendritic cells (e.g., CCR7) [53, 54]. The occurrence of chemokine production in pre-malignant tissue may increase cell survival, tissue remodeling, and angiogenesis (e.g., CXCL1, 2, 3, 5, 6, 7) to contribute to tumor development [35].

Cytokines in relation to the inflammatory and immune response: Cytokines promote tissue repair or healing with anti-inflammatory activity and exacerbate inflammation via TLR signaling pathways. Several cytokines are associated with chronic inflammation, including IL1, IL2, IL3, IL4, IL5, IL6, IL7, IL9, IL10, IL12, IL13, IL17, interferon (IFN), TGF $\beta$, and tumor necrosis factor (TNF) $\alpha$ and $\beta[36,46]$. For innate immunity, inflammatory immune cells secrete cytokines such as TNF $\alpha$, TNF $\beta$, IL1 $\beta$, IL6 IL10 IL12, 
IL17, IL18, IL22, IL23, IL25, and IFN $\alpha$, to eliminate pathogens detected within the host [55]. The subset of cytokines involved in the adaptive immunity such as IL4, IL5, IL6, IL7, IL13 induce the production of antibodies from B-lymphocytes, which destroy microorganisms and restrict area of infection. Moreover, many cytokines (e.g., IL1, IL2, IL3, IL4, IL7, IL9, IL10, IL12, interferon, transforming growth factor- $\beta$, tumor necrosis factor $\alpha$ and $\beta$ ) induce cellular responses, such as the mobilization of dendritic cells, monocytes, and T-lymphocytes, within adaptive immunity to eliminate pathogens [46, 56]. Collectively, humoral and cellular responses play an integral role in chronic inflammation, which significantly contributes toward to prostate cancer development [14, 24]. The dysregulation of inflammatory and immune response signaling pathways governed by the aforementioned toll-like receptors, chemokines, and cytokine contributes to inflammation and immune response via promotion of uncontrolled cellular proliferation, growth, invasion, and migration and ultimately leading to tumor development.

\section{Role of inflammatory and immune response pathways in relation to PCA}

\section{TLR signaling pathway and prostate cancer tumorigenesis: TLRs are a family of} transmembrane receptors that play a pivotal role in prostate cancer progression through its influence on the innate immune system via expression on immune cells and the induction of chemokine and cytokine production. In a gene expression study, human TLRs (TLR1-10) had detectable gene expression levels in normal prostate tissue [57]. In relation to prostate cancer, Varambally and co-workers (2005) observed down regulation of TLR1 gene expression in metastatic prostatic tissue compared to benign and primary localized prostate cancer tissue from the University of Michigan Prostate Specialized 
Programs of Research Excellence (SPORE) [58]. Chin and colleagues (2010) observed suppression of prostate cancer tumor growth in IFNAR1 +/+ (type I interferon) and TLR3 +/+ mice implanted with TRAMP C2 cells (i.e., transgenic mouse prostate cancer epithelial cells) compared to IFNAR1 -/- and TLR3 -/- mice, respectively [59]. Moreover, tumor suppression was observed after treatment with polyinosinic-polycytidylic acid (polyI:C), a natural agonist of TLR3 or immunostimulant, on orthotopic prostate tumors in mice. This lead to the recruitment of T-lymphocytes and NK cells via type I IFNdependent signaling. The study suggests that TLR3 agonists induce tumor suppression through the activation of the NF- $\mathrm{BB}$, MAPK and IRF3 signaling pathways via TRIF (Toll/IL-1R domain-containing adaptor inducing IFN) in immune cells. These mediators bind to receptors on the immune cells and promote immune cells to target prostate tumor cells [59].

Galli and co-workers (2010) observed that TLR2, TLR3, TLR4, TLR5, and TLR6 genes were expressed in PC3 cells (human metastatic prostate cancer cell line); however, both TLR3 and TLR5 gene and protein expression was present in LNCaP, Du-145, and PC3 cell lines (human metastatic prostate cancer cell lines) [52]. Nonetheless, TLR7, TLR8 and TLR9 genes were not expressed in PC3, Du-145 and LNCaP cell lines [52]. Unfortunately, this study fail to compare TLR expression in PCA cell lines to normal prostate cells. Stimulation of $\mathrm{LNCaP}$ and Du145 cells with poly (I:C) induce the production of chemokines (e.g., CXCL10, CCL5, CCL3 and IL8) via TLR3 and TLR5 and recruitment of leukocytes. This demonstrates that TLR signaling plays a role in chemokine production in PCA cell lines. Gonzalez-Reyes and associates (2011) observed high gene expression of TLR3, TLR4, and TLR9 in prostatic tumor tissue of 133 
European men compared to benign tissue [60]. TLR3 and TLR9 mRNA expression had a significant positive association with prostate cancer biochemical recurrence $(\mathrm{p}=0.039)$. The study speculates that elevated TLR3 and TLR 9 mRNA expression in prostate cancer tissue may induce the production of cytokines and chemokines to recruit immune cells and stimulate the release of more cytokines. The continual stimulation of cytokine and chemokine production could feed into a state of immune tolerance and initiation of a tumor microenvironment.

Interestingly, the immunohistochemical staining for TLR4 was significantly lower in high gleason score (Gleason score 4-6) prostatic adenocarcinoma stromal epithelial cells compared to normal and low gleason score (Gleason score 7-10) tissue [61]. After activation of TLR4 with LPS treatment, the gene expression of NF-kB regulated proinflammatory cytokines (e.g., IL1ß) and chemokines (e.g., IL8) was up-regulated, which contributes to an inflammatory state in Du145 cells. Moreover TLR4 signaling may increase the risk of prostate cancer via chronic inflammation. Pronounced TLR7 gene expression has been observed in normal prostate epithelial RWPE1 cells, but TLR7 expression is absent in PC3 and Du145 cells [62]. Consisted with the in vitro findings, protein expression of TLR7 was decreased in high grade PIN and adenocarcinoma of mouse prostatic tissue compared to normal prostatic tissue in mice.

Downstream signaling in the TLR pathway also plays a role in prostate cancer. IRAK4 plays a critical role in the innate immune system by relaying signals from TLRs via recruitment of IRAK1, which activates NF-kB induce pro-inflammatory response and caspases induce apoptosis. IRAK4 expression was decreased in doxcetaxel resistant Du145 and PC3 compared to non-resistant Du145 and PC3 cells [63]. Similarly, down- 
regulation of IRAK4 resulted in the resistance of U251 cells, a glioma cell line, to Temozolomide treatment [64]. Both studies suggest that IRAK4 expression modulates the sensitivity of cancer cells to chemotherapy and may serve as a good target for cancer treatments. Zhu and co-workers (2012) demonstrated in HEK293T (human embryonic kidney epithelial cell line) cells that TOLLIP inhibits the TGF $\beta$ signaling pathway, a key biological pathway in prostate tumorigenesis [65]. In prostate cancer, TGF $\beta$ functions as a tumor suppressor in the early stages of prostate cancer via suppression of cycle dependent kinases and cMyc. However, in the advanced stages, TGF $\beta$ transitions into a tumor promoter via induction of VEGF expression to promote tumor progression[66-68]. Varambally and associates (2005) observed higher gene expression of TOLLIP in metastatic prostate tissue compared to benign tissue [58]. In another study, overexpression of TOLLIP was shown to accelerate the degradation of TGF $\beta$ receptor type 1 (TGFßR1) protein [65]. In addition, TOLLIP interacts with ubiquitinated TGFßR1 via SMAD7, an inhibitory SMAD, which results in the suppression of TGF $\beta$ signaling. TOLLIP gene expression was observed in androgen sensitive (e.g., LNCaP, MDA-PCA2a) and insensitive (e.g., PC3, Du145) prostate cancer cell lines as well as prostatic cancer tissue [69]. TOLLIP may participate in the decrease of TGF $\beta$ receptor protein expression commonly seen in prostate cancer (i.e., $\mathrm{LNCaP}$ ) and malignant prostate cancer archival tissue compared to benign tissue [70]. Collectively the aforementioned studies suggest that TOLLIP may play a central role in prostate tumorigenesis however, in vitro and in vivo studies are needed to determine its role. However, no published reports have identified a strong relationship between the expression levels of TLR1 TLR6, TLR10 and IFR3 in PCA cell lines and their subsequent impact on prostate tumorigenesis. 
Chemokines, their receptors and prostate cancer : Chemokines are signaling molecules involved in the regulation of inflammation, trafficking of inflammatory cells (e.g., leukocytes, dendritic cells, neutrophils) and immune cell differentiation. These signaling molecules also play a role in cellular behaviors associated with prostate tumorigenesis. Kato and co-workers (2013) reported CCL5 treatment activates the ERK and Rac signaling pathways via one of its receptors (e.g., CCR1) in CCR1 knockdown paclitaxelresistant PC3 cells (PC3PR) compared to negative control transfected PC3PR [71]. The activation of CCR1 promotes cell invasion in PC3PR cells by increasing mRNA expression and secretion of matrix metalloproteinases, namely $M M P 2$ and $M M P 9$ [71]. Matrix metalloproteinases degrade the extracellular matrix, which is an essential step of metastasis [72]. In another study, Vaday and colleagues (2006) observed high levels of pro-inflammatory chemokines CCL5 and CCR5 in radical prostatectomy specimens compared to invasive ductal breast carcinoma as a positive control [73]. In fact, overexpression of CCL5 and CCR5 is strongly associated with aggressive prostate cancer, presumably by triggering leukocyte production and promoting cell survival, proliferation, invasion and metastasis $[22,73,74]$. CCL5 also induced cell migration and proliferation in LNCaP cells through the activation of CCR5 [73]. Moreover, another study observed that $C C L 5$ and CCR5 are highly expressed genes in prostate cancer tissue and may play a role in prostate tumorigenesis [75].

Its speculated that CCR7 gene/protein expression may mediate the cellular migration of tumor cells to the lymph nodes in various cancers including prostate cancer [76-79]. In addition to the CCL5-CCR1-CCR5 axes, some chemokines such as CXCL1 and CXCL2 influence cellular behaviors such as cell growth in prostate cancer cells. 
Killian and colleagues (2012) observed that silencing these pro-inflammatory chemokines (i.e., CXCL1 and CXCL2) inhibits cell growth and induces apoptosis in PC3, a metastatic prostate cancer cell line [80]. Similarly, Benelli and associates (2013) showed that CXCL1 transfected TRAMP-C2 cells, a transgenic mouse epithelial prostatic cell line, inhibits tumor growth in mice compared to an empty vector [81]. This report further suggests that CXCL1 may induce senescence to inhibit tumor and cell growth via CXCR2 in TRAMP-C2 cells [81]. CXCR7, another pro-inflammatory chemokine that binds to CXCL11 and CXCL12 (SDF-1a), is elevated in various cancers, including prostate cancer [82-86]. Singh and Lokeshwar (2011) demonstrated high mRNA and protein expression levels of CXCR7 in PC-3 and $\mathrm{LNCaP}$ relative to RWPE1 cells (normal immortalized prostate epithelial cell line) [85]. In addition, this study showed that CXCR7 overexpression increased cell proliferation by 23\% in RWPE1 cells. Depletion of CXCR7 in C4-2B cells, a derivative of the LNCaP cell line with androgen sensitivity, reduced tumor growth in nude mice and cell proliferation in PCA cell lines (e.g., PC3, LNCaP) [85-87]. CXCR7 promoted cell proliferation via phosphorylation of EGFR and Erk1/2 in RWCX7 cells, derivatives of RWPE1 cells that overexpress CXCR7 [85]. Singh and co-workers (2004) showed that $C C R 9$ mRNA levels were highly expressed in $\mathrm{LNCaP}$ and PC-3 cell lines in comparison to PrEC (normal prostate epithelial cell line) [88]. Treatment of LNCaP and PC-3 cells with CCL25, a known ligand of CCR9, resulted in an increase in cellular migration and invasion, as shown by flow cytometry. After CCL25 treatment, gene expression of metalloproteinases, MMP2 and MMP13, was elevated in PC-3 and LNCaP cell lines compared to untreated PC-3 and LNCaP cells. The increased expression of metalloproteinases, induced by CCL25 was 
essential to cellular invasion and migration in vitro. Chemokines contribute to prostate cancer phenotypes, including increased cellular proliferation, migration and invasion of prostate cancer cells.

Cytokines and in prostate cancer: The cytokine family, which includes chemokines, interleukins, interferons, and growth factors, plays an essential role in the development and progression of prostate cancer. Cytokines are soluble proteins, peptides or glycoproteins secreted from immune cells as signaling molecules in response to infection, foreign pathogens, and tumor cells [89-91]. Several studies reveal pro-inflammatory cytokines, involved in chronic inflammation, participate in prostate cancer progression. Salman and colleagues (2012) observed elevated secretion of pro-inflammatory cytokines from peripheral blood mononuclear cells (PBMCs) incubated with PC-3 cells (IL1 $\beta$, IL6, IL10) or LNCaP cells (IL6) compared to the incubation of PBMCs with no cancer cells [92]. The presence of prostate cancer cells induces the production of cytokines via the immune system. TGF- $\beta 1$ is a highly expressed cytokine in tumor prostate epithelial cells that was significantly associated with high vascular density and bone metastasis in prostate cancer [93]. In particular, Wikstrom and associates (1998) observed that overexpression of TGF $\beta 1$ in 73 paraffin-embedded tumors was associated with short survival rates among European PCA patients who did not receive any treatment relative to normal prostatic tissue [93]. Rodriguez-Berriguete and colleagues (2013) revealed that high protein expression of cytokines in the tumor necrosis factor family [TNF $\alpha$, TNFR1, TNF receptor-associated factor 2 (TRAF2)] were associated with high pathological prostatic tumor stage in prostatic tumor tissue relative to normal prostatic tissue [94]. In a pilot study of 93 prostate cancer patients who underwent a radical prostatectomy, 
cytokines, IL1 $\beta(\mathrm{HR}=0.431 ; 95 \% \mathrm{CI}=0.180-1.029)$ was marginally linked with a $57 \%$ decrease in biochemical progression [94]. IL6, a major cytokine, participates in chronic inflammation and prostate tumorigenesis. For instance, Chung and co-workers (1999) demonstrated a decrease in cell growth after treating hormone independent PCA cell lines (Du145, TSU and PC3) with a neutralizing polyclonal goat anti-human IL6 antibody compared with untreated cells [95]. Moreover, an independent study revealed that autocrine production of IL-6 induces a high gene and protein expression of IFR9, which is critical to the exertion of the IFNa2 anti-proliferative effect on prostate cancer cells (i.e., PC-3 and MDA PCA 2b cells) [96]. These studies confirm cytokines play a critical role in the progression of prostate cancer via cellular behaviors. In the aforementioned studies, inflammatory and immune response-associated genes and proteins were shown to participate in prostate tumorigenesis via promotion of cellular migration, proliferation and growth, which are critical biological pathways in prostate cancer.

\section{Epidemiology evidence of the relationship between variant inflammatory and}

\section{immune response related sequence variants and prostate cancer}

Over the past decade, many epidemiological studies have shown that genetic variants in inflammatory and immune response-related genes contribute to the dysregulation of critical biological pathways and ultimately leads to cancer development or disease progression. The inheritance of genetic variants in these mediators may impede their function to properly regulate the inflammatory and immune response. Some of the inflammatory and immune response-related sequence variants have been previously reported to play a role in several carcinomas, including carcinoma PCA. Although the relationship between genetic alterations and PCA is controversial [97-99], the majority of 
published reports typically focus on men of Asian or European descent. Little or no data addresses the impact of cytokine, chemokine and toll-like receptor-related sequence variants on PCA risk among men of African descent, even though this population suffers disproportionately from this disease [1, 14, 27, 100-102].

\section{TLR-associated sequence variants and PCA}

TLR-related sequence variants have been evaluated in relation inflammatory and immune response-related diseases including prostate cancer. Stevens and co-workers (2008) showed that polymorphisms in TLR1 $r s 4833095 \mathrm{CC}(\mathrm{OR}=0.64$; $95 \% \mathrm{CI}=0.47$ 0.86), TLR1 rs5743595 CC (OR=0.63; 95\% CI=0.42-0.93), TLR10 rs11096955 CC (OR $=0.78 ; 95 \% \mathrm{CI}=0.61-0.99), T L R 10 r s 11096957 \mathrm{CC}(\mathrm{OR}=0.78 ; 95 \% \mathrm{CI}=0.61-0.99)$ and were linked with a $22-58 \%$ decrease in prostate cancer susceptibility among 1,414 cases and 1,414 controls of Latin, European, and Asian descent ( $\mathrm{p}$-trend $=0.0022-0.011$ ) [97]. In six observational studies, TLR4 (rs1927911 CC, rs2149356 TT), TLR10 rs4274855 AG+AA were linked to a 1.12-6.68 fold increase in the risk of developing PCA among men of European and Asian descent [97, 98, 103-106]. In another study, inheritance of 1 copy of the risk allele for and TLR4 $r s 2149356(\mathrm{OR}=0.66 ; 95 \% \mathrm{CI}=$ 0.51-0.86) was linked to a $13-34 \%$ reduction in PCA susceptibility among European Americans (700 cases, 700 matched controls) [107]. Unfortunately, there was no relationship between prostate cancer susceptibility and possession of variant TLR signaling associated alleles TLR4 (rs1927906), TLR6 (rs1039559, rs3821985, rs5743810), and IRAK4 rs4251545 with [97, 99, 103, 104, 106-109].

The relationship between innate immunity genetic anomalies and prostate cancer susceptibility has not been met without controversy [98, 99, 103-105, 107, 108]. Under 
the recessive genetic model for TLR4 rs2149356 (i.e., TT vs.GG + GT), Chen and coworkers (2005) observed a 36\% decrease in risk of developing prostate cancer $(\mathrm{OR}=$ 0.64; 95\% CI $=0.45-0.91)$ among European men (700 cases, 700 matched controls) [107]; however, this relationship was insignificant in 3 other studies [103-105]. Moreover, inheritance of the TLR4 rs 1927911 CC genotype was linked with a 6.68-fold increase in the risk of developing prostate cancer but had a null effect in other studies [98, 103, 107]. Possession of the TLR10 rs11096955 CC, and TLR10 rs11096957 CC genotypes were associated with a 9-21\% decrease in prostate cancer susceptibility in two studies but associated with 1.20-1.25-fold increase in prostate cancer risk in another report among men of European descent [97, 106, 109]. However, these findings were null in relation to prostate cancer risk with the exception of TLR10 rs 11096955 CC genotype in one study [106]. In addition, several of the aforementioned studies that evaluated several SNPs simultaneously did not adjust their risk estimates for multiple hypotheses testing $[98,99,107,108]$. Failure to adjust for multiple comparisons may lead to an over estimation of prostate cancer susceptibility among carriers of putative high-risk alleles. Moreover, a majority of the previously mentioned studies failed to include men of African descent, despite the fact that men of African descent suffer disproportionately from prostate cancer relative to men of European and Asian descent [98, 99, 103-105, $107,108]$. In addition, some studies utilized different allelic discrimination assays such as Taqman, MassARRAY and multiplex PCR to genotype SNPs [104, 105, 107].

Furthermore, several of the aforementioned reports had evaluated different genotypes in relation to each SNP and varied in the frequency distributions across the genotypes [99, 105-107]. 
In a recent published report from our lab, we addressed some of the aforementioned concerns that often plaque most genetic epidemiology studies. First, we evaluated the role of innate immunity sequence variants among a relatively large subgroup of men of African descent (270 cases, 535 controls). Our sample size enabled us to have adequate statistical power to observe reasonable protective $(\mathrm{OR}<1.00)$ and risk $(\mathrm{OR}>1.4)$ effects. Lastly, all of our relationships were adjusted for multiple hypothesis testing using the false discovery rate (FDR), in order to adjust for false positive results. Our study was restricted to polymorphisms detected within the genes of TLRs $(1,4,6$, 10), TOLLIP and IRAK4 genes among 814 men of African descent [31]. We revealed that TLR6 rs2381289 GA $(\mathrm{OR}=1.46 ; 95 \% \mathrm{CI}=1.02-2.09)$ and TOLLIP rs5743899 AG $(\mathrm{OR}=1.59 ; 95 \% \mathrm{CI}=1.06-2.38), \mathrm{AG}+\mathrm{GG}(\mathrm{OR}=1.49 ; 95 \% \mathrm{CI}=1.02-2.18)$ genotypes modestly modified PCA risk among men of African descent from the U.S. and Jamaica. However, these sequences variants did not survive multiple hypothesis testing (FDR > 0.05). After stratification by racial/ethnic group and age-adjustment, six TLR-related sequence variants detected were modestly linked to PCA susceptibility among men of African descent from the U.S. Inheritance of IRAK4 (rs4251545 A and $r s 4251473$ A) and TLR6 rs5743818 C variants were associated with a 40-66\% reduction in PCA risk among U.S. men $\left(\chi^{2}\right.$ p-value $\left.=0.099\right)$. On the contrary, possession of both IRAK4 rs $4251545 \mathrm{GG}$ referent genotype and TLRI CT+CC genotype was associated with a 1.36-fold increase $(95 \% \mathrm{CI}=1.09-1.69)$ in prostate risk among men of European descent $(\mathrm{p}$-value $<0.01)$ [108], but IRAK4 rs4251545 had a null finding in another report [110]. However, the TOLLIP rs5743899 recessive genetic model (GG vs. AA+AG) was modestly associated with a 1.14-fold increase in PCA susceptibility $(\mathrm{OR}=1.14 ; 95 \% \mathrm{CI}=1.12-1.18)$. Among 
Jamaicans, possession of TLR6 rs $2381289 \mathrm{GA}+\mathrm{AA}\left(\mathrm{OR}_{\text {age-adj }}=2.05 ; 95 \% \mathrm{CI}=1.10\right.$ 3.78) and TLR6 rs5743818 AC+CC $\left(\mathrm{OR}_{\text {age-adj }}=1.10 ; 95 \% \mathrm{CI}=1.06-1.14\right)$ genotypes was linked to a 1.10-2.05-fold increase of PCA development. In contrast, IRF3 rs2304206 GG genotype was related to a $68 \%$ reduction $(\mathrm{OR}=0.32 ; 95 \% \mathrm{CI}=0.11-0.98)$ in $\mathrm{PCA}$ susceptibility. Notably, inheritance of the variant innate immunity alleles among Jamaicans (TLR6 rs2381289 A, IRF3 rs2304206 G) and U.S. men (IRAK4 rs4251545 A) for U.S. men did not survive multiple hypothesis testing (Bonferroni Correction p-value $>0.0016)$.

\section{Chemokine-associated sequence variants and PCA}

Genetic alterations in chemokines and their receptors have been linked to the susceptibility, development and progression of numerous cancers, including prostate cancer [111-115]. The CCL5 rs2107538 variant contributed to an increased susceptibility for different cancers [116-118]. In terms of PCA, CCL5 rs2107538 GA+AA genotype $(\mathrm{OR}=1.44 ; 95 \% \mathrm{CI}=1.09-2.38)$ was associated with an increase in prostate cancer risk among European men (296 cases, 311 controls) [116]. In a pilot study, the CXCL12 $r s 1801157(\mathrm{OR}=1.58 ; 95 \% \mathrm{CI}=1.03-2.43) \mathrm{GA}+\mathrm{AA}$ genotype was significantly associated with a 1.58-fold increase in prostate cancer risk among Japanese men (167 cases and 167 matched controls) [112]. However, there are no published reports on the main effect of CCR7 (rs3136685, rs3136687) and CCR5 rs1799988 sequence variants in relation to PCA susceptibility. Some of the aforementioned studies failed to adjust for multiple hypothesis testing [116-119], and perform power calculations to specific odd ratio detection limits [116-118, 120]. Furthermore, prior to our 2012 published report, there were no published findings on the relationship between chemokine associated 
sequence variants and PCA among African-American men.

Our lab showed that five chemokine-related sequence variants were significantly associated with prostate cancer development among men of African descent (279 cases and 535 controls) [35]. The inheritance of CCL5 (rs2107538 and rs3817655) GA, AA and GA+AA genotypes were linked with a $34-44 \%$ reduction in PCA risk in the age adjusted LR models among men of African descent [false discovery rate (FDR) $\leq$ 0.0493]. However, the inheritance of the CCR5 $r s 1799988\left(\mathrm{OR}_{\text {age adjusted }}=1.52 ; 95 \%\right.$ $\mathrm{CI}=1.02-2.26)$ recessive genetic model, $C C R 7 r s 3136685\left(\mathrm{OR}_{\text {age adjusted }}=1.66 ; 95 \%\right.$

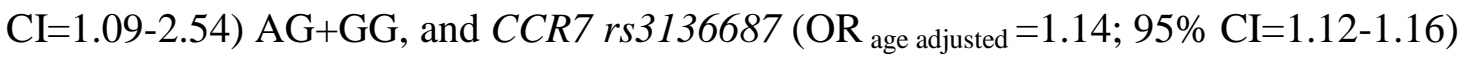
AG+GG genotypes were associated with a significant 1.14-1.66 fold increase in PCA risk within the age adjusted LR models. The CCL5 (rs2107538, rs3817655) dominant (FDR p-value $\leq 0.015)$ and CCR5 rs 1799988 recessive genetic models (FDR p-value $=0.049)$ remained significant even after adjusting for multiple hypothesis testing.

In a stratified analysis, several chemokine-chemokine receptor markers were linked to PCA susceptibility among men of African descent from the U.S. Inheritance of the $C C R 5$ rs 1799988 GG locus under the recessive genetic model ( $\mathrm{OR}_{\text {unadjusted }}=1.62$; $95 \% \mathrm{CI}=1.04-2.42)$ and the $C X C R 7 r s 1045879 \mathrm{AG}+\mathrm{GG}$ genotype $\left(\mathrm{OR}_{\text {unadjusted }}=1.54\right.$; $95 \% \mathrm{CI}=1.07-2.22)$ was associated with a $1.54-1.62$-fold increase in PCA risk among unadjusted risk models. However, possession CCL5 rs2107538 GA+AA (OR unadjusted $=$ $0.52 ; 95 \% \mathrm{CI}=0.36-0.76), \mathrm{CCL} 5 \mathrm{rs} 2280789 \mathrm{AG}+\mathrm{GG}\left(\mathrm{OR}_{\text {unadjusted }}=0.60 ; 95 \% \mathrm{CI}=0.41-\right.$ 0.89), CCL5 rs3817655 GA+AA (OR unadjusted $=0.46 ; 95 \% \mathrm{CI}=0.32-0.68), C C L 25$ $r s 2032887 \mathrm{AG}+\mathrm{GG}\left(\mathrm{OR}_{\text {unadjusted }}=0.66 ; 95 \% \mathrm{CI}=0.46-0.96\right)$ genotypes was linked with $\mathrm{a} \geq 34 \%$ reduction in PCA susceptibility. After adjusting for age, the risk estimates of the 
previously mentioned genotypes risk estimates for CCL5 ( $r s 2107538, r s 3817655)$

remained significant. However among Jamaican men, CCR5 rs 1799987, CCR5 rs 1799988, CCR7 rs3136685 and CCR9 rs1488371 loci were linked with PCA risk. In unadjusted risk models, $C C R 5$ rs $1799987 \mathrm{AA}\left(\mathrm{OR}_{\text {unadjusted }}=2.18 ; 95 \% \mathrm{CI}=1.04-4.58\right)$, CCR5 $r s 1799988 \mathrm{GG}\left(\mathrm{OR}_{\text {unadjusted }}=2.25 ; 95 \% \mathrm{CI}=1.08-4.71\right)$ and $C C R 7 r s 3136685$ $\mathrm{AG}+\mathrm{GG}\left(\mathrm{OR}_{\text {unadjusted }}=2.30 ; 95 \% \mathrm{CI}=1.05-5.07\right)$ genotypes were linked with a 2-fold increase in PCA susceptibility (P-trend $=0.034-0.086)$. On the contrary, inheritance of CCR9 rs $1488371 \mathrm{CA}+\mathrm{AA}\left(\mathrm{OR}_{\text {unadjusted }}=0.46 ; 95 \% \mathrm{CI}=0.23-0.94\right)$ genotype was associated with a 54\% reduction in PCA risk among unadjusted risk models. After adjusting for age, the risk estimates of the previously mentioned genotypes for CCR5 rs 1799987, and CCR7 rs3136685 remained significant among men of African descent. However, only CCL5 (rs2107538, rs3817655) sequence variants survived multiple hypothesis testing among U.S. men of African descent (Bonferroni Correction p-value $\leq$ 0.0012). Our study revealed strong associations between genetic variants in CCL5 among men of African descent that warrant further investigation in future studies.

Unfortunately, our findings were not in agreement with cancer-related published reports. We observed that the inheritance of CCL5 rs2107538 GA+AA genotype was associated with a $41-48 \%$ reduction in PCA susceptibility $(\mathrm{OR}=0.59 ; 95 \% \mathrm{CI}=0.44-$ 0.80 and $\mathrm{OR}_{\text {unadjusted }}=0.52 ; 95 \% \mathrm{CI}=0.36-0.76$ ) among men of African descent; however, Saenz-Lopez (2008) observed that the CCL5 rs2107538 GA+AA genotype was associated with an increase in prostate cancer risk $(\mathrm{OR}=1.44 ; 95 \% \mathrm{CI}=1.09-2.38)[116$, 118]. This variant was also an important predictor of pancreatic cancer risk $(\mathrm{OR}=2.3$; 95\% CI $=1.00-5.30$ ) for a mixed population (i.e., European, African and Asian descent) 
and oral cancer risk among Asians $(\mathrm{OR}=2.23 ; 95 \% \mathrm{CI}=1.07-4.66)[116,118][117]$. Moreover, we observed an increased PCA susceptibility affiliated with inheritance of the CCR7 (rs3136685 AG+GG, rs3136687 GA+AA) genotypes; however, a couple of studies reported a 60-62\% reduction in cancer susceptibility for multiple myeloma and chronic lymphocytic leukemia, among individuals of European descent [119, 120]. However, majority of the aforementioned studies in relation to prostate cancer susceptibility failed to include men of African descent and adjust risk estimates for multiple hypothesis testing $[116,118]$. Furthermore, the discrepancies between our study and the aforementioned reports may be attributed to differences in cancer type evaluated in relation to innate immunity genetic variants, limited sample size, genotype frequency distribution, allelic discrimination assays (i.e., PCR-RFLP) and ethnic groups included in each study population sample size and ethnic group [116-120]. In addition, a couple of epidemiological studies evaluated SNPs in relation to cancer susceptibility in populations that included women as well $[117,120]$.

\section{Cytokine-Associated Sequence Variants and PCA}

The production of cytokines can be influenced by single nucleotide polymorphisms (SNPs) in pro- and anti-inflammatory genes. Observed differences in the spectrum of cytokines expressed in an inflammatory environment or level of antitumor response within an individual can be explained by genetic variations, which leads to highor low-level production of a given cytokine [46]. Epidemiological studies evaluated the relationship between prostate cancer and several cytokine-associated gene variants, such as TNF rs1800629 (-308 G>A) among Indian men as well as IL10 rs1800871 (-819 C>T) among European American men [101, 121-128]. For instance, Berhane and associates 
(2012) showed that TNF rs 1800629 AA genotype was associated with a 1.79-fold (95\% $\mathrm{CI}=1.29-2.49)$ increase in the risk of developing prostate cancer among North Indian men (150 cases, $150 \mathrm{BPH}$ controls) [121]. In another study, TNF rs 1800629 has also been implicated in several other carcinomas (e.g., lymphoma, cervical, gastric) [129132]. However, some studies have concluded that TNF rs 1800629 was not associated with prostate cancer or other cancers among individuals of European, African and South American descent [101, 121, 133-135]. Kesarwani and associates (2009) observed that IL10 $r$ s 1800896 GA genotype $(\mathrm{OR}=2.8 ; 95 \% \mathrm{CI}=1.26-6.14)$ was associated with a 2.8 fold increase in PCA risk among North Indian men (259 cases, 159 controls) [126]. Possession of the IL1B rs $1143627 \mathrm{CC}$ genotype $(\mathrm{OR}=0.54 ; 95 \% \mathrm{CI}=0.36-0.81)$ was linked with a $46 \%$ reduction in susceptibility of PCA recurrence among U.S. men (524 matched case-control pairs) [122]. Zabaleta and associates (2008) observed IL10 $r s 1800871 \mathrm{CT}(\mathrm{OR}=0.72 ; 95 \% \mathrm{CI}=0.53-0.98), I L 10 r s 1800872 \mathrm{CA}(\mathrm{OR}=0.70 ; 95 \%$ $\mathrm{CI}=0.52-0.93)$ and $\mathrm{CA}+\mathrm{AA}(\mathrm{OR}=0.74 ; 95 \% \mathrm{CI}=0.56-0.98) 26 \%-30$ reduction in PCA risk among men of European descent (889 men) [101]. However in the same study, IL10 $r s 1800871 \mathrm{TT}(\mathrm{OR}=0.18 ; 95 \% \mathrm{CI}=0.05-0.72)$ genotype was associated with a $82 \%$ decrease in PCA susceptibility among men of African descent. However in a report from our lab, IL10 (rs1800871, rs1800872) and IL10 rs1800896 were found to have no association to PCA risk among U.S. men of African descent (193 cases and 666 controls) [40]. Inheritance of ILIA rs17561 (+4845 G>T) had a protective effect against ovarian cancer risk $(\mathrm{OR}=0.90,95 \% \mathrm{CI}=0.83-0.97)$ among European American women $(930$ cases, 1,037 controls) [136]. In addition, Balasubramanian and colleagues (2006) also showed this sequence variant had a protective effect against breast cancer risk in 
European American women (521 cases, 895 controls) as well (p-value $=0.05$ ) [137]. Sequence variant, ILIA rs $2856836, \mathrm{CT}(\mathrm{OR}=2.88 ; 95 \% \mathrm{CI}=1.58-5.27)$ and $\mathrm{CC}(\mathrm{OR}=$ $8.17 ; 95 \% \mathrm{CI}=2.23-29.9)$ genotypes were associated with $\mathrm{a} \geq 2.0$-fold increase in breast cancer risk among Korean women (209 cases, 209 controls) [138]. Although the IL1A loci $(r s 17561, r s 2856836)$ were associated with increased susceptibility to hormonerelated cancers among individuals of European and Asian descent, our lab did not observe a significant association between these markers and PCA risk among men of African descent. Furthermore, some of these studies fail to adjust for multiple hypothesis testing [121, 136, 137], and perform power calculations [121, 136, 137,138$]$.

Moreover in a recent published report, our lab observed modest associations between prostate cancer risk and the inheritance of IL1R2 rs11886877, IL8RB rs 11574752, TNF (rs1800629 and rs673) among men of African descent (279 cases and 535 controls) [36]. Among men of African descent, IL8RB rs 11574752 AA (OR age-adjusted $=38.4 ; 95 \% \mathrm{CI}=3.86-382.8), I L 1 R 2 \operatorname{rs} 11886877 \mathrm{AA}\left(\mathrm{OR}_{\text {age-adjusted }}=1.92 ; 95 \% \mathrm{CI}=\right.$ 1.11-3.32), TNF rs1800629 GA (OR age-adjusted $_{1} 1.54$; 95\% CI=1.06-2.24), and TNF rs673 $\mathrm{GA}\left(\mathrm{OR}_{\text {age-adjusted }}=1.50 ; 95 \% \mathrm{CI}=1.04-2.16\right)$ genotypes in adjusted risk estimates were associated with PCA susceptibility. However, these sequence variants did not survive multiple hypothesis testing according to the new significance level $(\alpha=0.0011)$ (Bonferroni Correction p-value > 0.0011). Upon stratification, intronic IL1R2 $r s 11886877 \mathrm{AA}\left(\mathrm{OR}_{\text {age-adjusted }}=2.75 ; 95 \% \mathrm{CI}=1.38-5.50\right), \mathrm{GA}+\mathrm{AA}\left(\mathrm{OR}_{\text {age-adjusted }}=1.82\right.$; $95 \% \mathrm{CI}=1.14-2.88)$ genotypes and recessive genetic model $(\mathrm{OR}$ age-adjusted $=2.05 ; 95 \%$ $\mathrm{CI}=1.10-3.80$ ) among U.S. men were linked to a 1.82-2.75 fold increase in risk of developing PCA within age-adjusted risk estimates. However, possession of RNASEL 
$r s 12135247 \mathrm{AG}$ genotype $\left(\mathrm{OR}_{\text {age-adjusted }}=2.10 ; 95 \% \mathrm{CI}=1.04-4.24\right)$ was associated with PCA susceptibility among Jamaican men. We adjusted all associations for multiple hypothesis testing and perform power calculations to determine odd ratio limits. Notably, none of the evaluated cytokine-associated sequence variants were associated with PCA risk (Bonferroni Correction p-value > 0.0011). Although we reported null findings, IL1R2 rs 11886877 AA and GA+AA genotypes were associated with significant risk estimates among both the total population and U.S. men in age-adjusted LR models. The IL1R2 rs 11886877 A allele may favor pro-inflammatory signals and mute the protective effect of this receptor against the tumorigenic activity of IL $1 \alpha$ and IL1 $\beta$. IL1R2 is a $68 \mathrm{kD}$ receptor pre-dominantly expressed on monocytes, B-lymphocytes, polymorphonuclear (PMN) leukocytes and prostatic tumor cells [139, 140]. Under normal conditions, this receptor functions in an anti-inflammatory or immunosuppressive manner by binding to IL $1 \alpha$ or IL1 $\beta$ to lower pro-inflammatory cytokine production from immune cells (e.g., lymphocyte, macrophage), as shown in Figure 3 [139, 141, 142]. The pro-inflammatory signal of IL1 may be decreased, due to its binding to IL1R2. However, the introduction of a sequence variant such as rs11886877 within the ILIR2 gene may render the IL1R2 protein non-functional due to instability of mRNA/protein expression. In addition, the pro-inflammatory signal of IL1 may be elevated via production of pro-inflammatory cytokines from immune cells leading to chronic inflammation (Figure 4). Furthermore, chronic inflammation may develop into PIA, which can transition to high grade PIN (HPIN) and ultimately initiate PCA development (Figure 4). Nonetheless, subsequent studies are needed to evaluate the influence of the aforementioned sequence variant on prostate tumorigenesis. Consequently, in vitro studies may be utilized to determine 
whether the IL1R2 rs11886877 AA genotype in normal prostate cells will inhibit the antiinflammatory and immunosuppressive activity of IL1R2 via IL1 $\beta$ or IL1 $\alpha$ induction. Overexpression of ILIR2 or inheritance of the $r s 11886877$ AA genotype in prostate cancer cell lines will provide information on whether or not IL1R2 is protective against cancer cells. These studies will provide more insight about the biological function of IL1R2 in prostate cells and whether IL1R2 may serve as a potential target for prostate cancer treatment. 


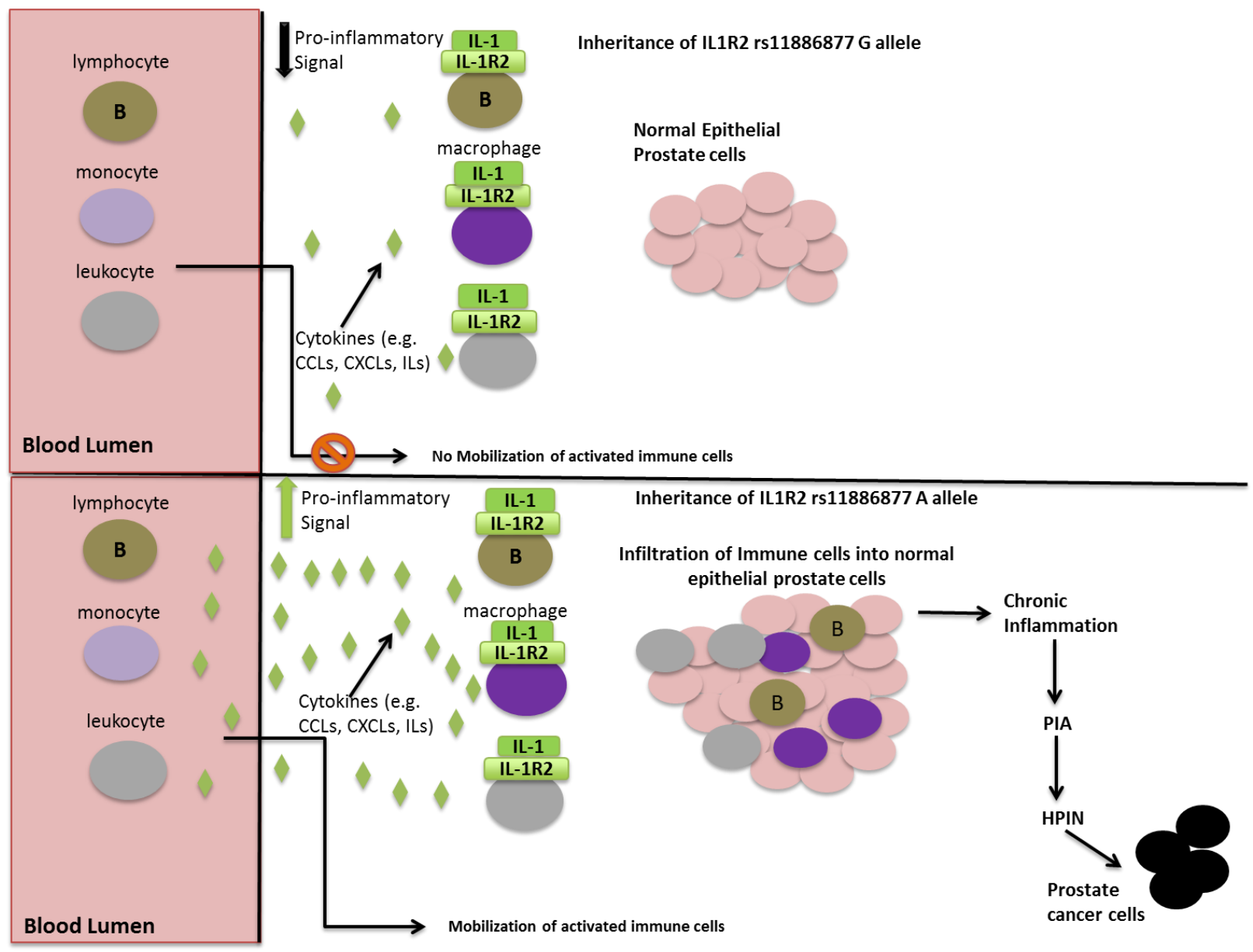

Figure 4. The effect of IL1R2 on immune cells and prostate cancer. Inheritance of IL1R2 rs 11886877 reference allele $\mathrm{G}$ does not modify prostate cancer susceptibility among men of African descent. However, the inheritance of the IL1R2 rs11886877 A allele was associated with an increase in prostate cancer risk. We proposed that rs11886877 A allele will impede function of the IL1R2 as a decoy receptor for IL1 on immune cells and allow the IL1 pro-inflammatory signal to induce the production of cytokines. Eventually immune cells will infiltrate normal epithelial prostate cells to initiate chronic inflammation that feeds into $\rightarrow$ PIA $\rightarrow$ HPIN (high grade PIN) and ultimately prostate cancer development. 
To further investigate the impact of these sequence variants on prostate cancer, we will examine the biological significance of variants through in vitro and in vivo studies in relation to prostate cancer therapies, cellular behavior (e.g., cellular proliferation, migration, invasion) and tumorigenesis. We will evaluate the gene and protein expression of CCL5, CCR5, CCR6, CCR7, CCR9, TLR2, TLR6, TLR10, IRF3, IRAK4 and ILIR2 in standard prostate cancer cell lines (e.g., PC3, Du-145, LNCaP). Next, we will evaluate the effect of target gene mimics or inhibitors on cellular behaviors in normal and cancer cell lines. Lastly, we will perform functional studies for selected genes significantly impacted by sequence variants through knockout and knockin in vivo models. Such studies will enable us toevaluate the effect of overexpression or inhibition of these genes on tumor growth in response to selected current prostate cancer therapies using state-of-art imaging techniques (e.g., Multispectral optoacoustic tomography).

\section{Combined effects and gene-gene interactions on prostate cancer susceptibility}

Gene-gene interactions aid researchers to model the complex involvement of biological pathways, and environmental factors in the etiology of prostate cancer as well as identify susceptible genes. High order interactions are difficult to detect and may lead to countless contingency tables with inadequate observations, inaccurate risk estimates and extremely wide $95 \%$ CIs. Only 4 of these published reports focused on PCA. However, 3 of the gene-gene interaction studies used logistic regression to detect interactions, and failed to predict high order (e.g., >2) gene-gene interactions in relation to PCA cancer risk. Moreover, two of the PCA genetic epidemiology studies did not have adequate statistical power to observe associations. Statistical power is the probability to correctly reject a false null hypothesis and dependent on sample size as well as size of 
effect. High statistical power decreases the probability of type II error to occur, which is the detection of no effect when there is actually an effect. Linear modeling limits logistic regression to effectively model high-order interactions with ample statistical power. Therefore, many researchers including our lab evaluate gene-gene interactions using multi-locus prediction tools [e.g., multivariate adaptive regression spline (MARS Logit), classification and regression trees (CART), computational evolution system (CES), modified logistic regression, and multifactorial dimension reduction program (MDR)] to perform intensive data mining for multivariate analyses.

Multi-locus prediction tools have both advantages and drawbacks. For instance, MARS Logit is a non-parametric method used to predict gene-gene interactions, but analyses are limited to large datasets with a bias toward the contribution of the additive genetic model to disease susceptibility [143]. CART is a nonparametric statistical method used to detect mutually exclusive and exhaustive subgroups based on common traits of a population [144]. Interestingly, CART is user friendly, provides 95\% confidence intervals and the results are easy to interpret. However, the CART analysis is unable to estimate the effect of an independent variable, which may lead to data dredging and multi-level classification trees that are difficult to interpret. CES (computational evolution system) models are biologically sound nonlinear interactions of highdimensional genetic data in 3D; however the interactions are governed by conventional mathematical models [145]. MDR is an intensive non-parametric method that randomly shuffles data to detect unbiased 1-4 factor interaction models on disease susceptibility[146]. This technique provides a cross validation consistency (CVC), and average testing accuracy (ATA or prediction score) percentages as well as permutation 
testing p-values to adjust for multiple hypothesis testing. In addition, the current version of MDR does not require an equal number cases and controls to predict high order interactions. Unlike CART, MARS Logit, logistic regression, and CES, MDR is able to adjust analyses for multiple hypothesis testing. However, MDR does not provide risk estimates and associated $95 \%$ confidence intervals.

Among peer-reviewed articles discussed in this report, 20\% (9 out of 45) of the published reports evaluated gene-gene interactions among inflammatory and immunerelated sequence variants in relation to cancer susceptibility $[40,101,102,108,112,118$, 147-149]. Genetic variants within inflammatory and immune response-related genes in relation to prostate cancer have been observed in various gene-gene interaction studies (Table 1). For instance, Sun and associates (2006) showed that the gene-gene interaction involving IRAK4 polymorphisms and TLR1 CT+CC genotype had a 1.37-9.68 fold increase in risk of developing prostate cancer among Swedish men using logistic regression [108]. Xu and colleagues (2005) reported a statistically significant four-factor gene-gene interaction model between IL10, IL1RN, TIRAP and TLR5 linked with prostate cancer risk among Sweden men (Permutation testing $\mathrm{p}$-value $=0.019$ ) using MDR [147]. Although this study controlled for multiple hypothesis testing, $\mathrm{Xu}$ and associates only evaluated gene-gene interactions among men of European descent. In the literature, a report by Duell and co-authors (2006) was one of the few studies on cytokine gene-gene interactions (e.g., CCL5-CCR5, CCL5-TNF $\alpha$, CCR5- TNF $\alpha$ ) [118].

Unfortunately, these gene-gene interactions were in relation to pancreatic cancer and not prostate cancer. Zabaleta and colleagues (2008) observed a significant two-factor genegene interaction involving IL1B-511 and IL10-592 with a 2.56-fold (95\% CI = 1.09-6.02) 
increase in prostate cancer risk among African-Americans using MARS Logit [101]. In another study, Zabaleta and colleagues (2009) showed an increase of prostate cancer risk among individuals who possessed both the $I L-1 B$ CC and $I L-10 \mathrm{GG}$ genotypes $(\mathrm{OR}=3.38$; 95\% CI=1.70-6.71) among European American men using MARS Logit [102]. However, the authors were unable to determine gene-gene interactions in relation to prostate cancer risk among African-Americans due to limited sample size. Most of the previous studies evaluated gene-gene interaction models among men of European and Asian descent, and limited analyses were performed among men of African descent. 
Table 1. Inflammatory and Immune related gene-gene interactions in Prostate cancer

\begin{tabular}{|c|c|c|c|c|c|}
\hline Gene & $\begin{array}{l}\text { Cases/ } \\
\text { Controls }\end{array}$ & Ethnicity & Disease & $\begin{array}{c}\text { Multiple } \\
\text { Hypothesis } \\
\text { Testing p-value }\end{array}$ & Reference \\
\hline $\begin{array}{l}\text { IL1B, } \\
\text { IL10 }\end{array}$ & $54 / 109$ & $\begin{array}{l}\text { African } \\
\text { American }\end{array}$ & Prostate cancer & MARS; $p=0.032$ & $\begin{array}{l}\text { Zabaleta, } 2008 \\
\text { [101] }\end{array}$ \\
\hline $\begin{array}{l}\text { IL1B, } \\
\text { IL10 }\end{array}$ & $68 / 378$ & $\begin{array}{l}\text { European } \\
\text { American }\end{array}$ & Prostate cancer & MARS; $p=n / a$ & $\begin{array}{l}\text { Zabaleta, } 2009 \\
{[102]}\end{array}$ \\
\hline $\begin{array}{l}\text { IL10, } \\
\text { IL1RN, } \\
\text { TRAP, } \\
\text { TLR5 }\end{array}$ & $1,444 / 866$ & Swedish & Prostate cancer & MDR; $p=0.019$ & $\mathrm{Xu}, 2005[147]$ \\
\hline $\begin{array}{l}\text { IRAK4, } \\
\text { TLR1 }\end{array}$ & $1,383 / 780$ & Swedish & Prostate cancer & $\mathrm{LR} ; \mathrm{p}=0.03$ & Sun, 2006 [108] \\
\hline $\begin{array}{l}\text { TLR10, } \\
\text { TLR6, } \\
\text { IRF3 }\end{array}$ & $279 / 535$ & $\begin{array}{l}\text { African } \\
\text { American, } \\
\text { Jamaican }\end{array}$ & Prostate cancer & MDR; $p=0.001$ & $\begin{array}{l}\text { Rogers, } 2013 \\
{[31]}\end{array}$ \\
\hline $\begin{array}{l}\text { TLR2, } \\
\text { IRAK4 }\end{array}$ & $279 / 535$ & $\begin{array}{l}\text { African } \\
\text { American }\end{array}$ & Prostate cancer & MDR; $p=0.001$ & $\begin{array}{l}\text { Rogers, } 2013 \\
{[31]}\end{array}$ \\
\hline $\begin{array}{l}\text { CCR7, } \\
\text { CCL5, } \\
\text { CCR9 }\end{array}$ & $279 / 535$ & $\begin{array}{l}\text { African } \\
\text { American, } \\
\text { Jamaican }\end{array}$ & Prostate cancer & MDR; $p=0.001$ & $\begin{array}{l}\text { Jones, } 2011 \\
{[150]}\end{array}$ \\
\hline $\begin{array}{l}\text { CCR6, } \\
\text { CCL5, } \\
\text { CCR9 }\end{array}$ & $279 / 535$ & $\begin{array}{l}\text { African } \\
\text { American }\end{array}$ & Prostate cancer & MDR; $p=0.001$ & $\begin{array}{l}\text { Kidd, } 2012 \\
\text { Unpublished } \\
\text { data }\end{array}$ \\
\hline $\begin{array}{l}\text { CCR6, } \\
\text { CCR4, } \\
\text { CXCR7 }\end{array}$ & $279 / 535$ & Jamaican & Prostate cancer & MDR; $p=0.017$ & $\begin{array}{l}\text { Kidd, } 2012 \\
\text { Unpublished } \\
\text { data }\end{array}$ \\
\hline
\end{tabular}

n/a: Not available 
To overcome the challenges and gaps of the aforementioned studies, our lab evaluated complex interactions among 119 inflammatory and immune response sequence variants in relation to PCA among men of African descent. We evaluated 1-, 2- and 3factor gene-gene interaction models among 119 inflammatory and immune responserelated sequence variants using a supercomputer with 24 computer processing units (CPUs). Gene-gene interactions were examined using MDR to identify interaction models with high cross validation consistency values, ranging between $80-100 \%$, and accurate prediction scores (e.g., ATA $\geq 50 \%$ ). As previously reported, our lab used multifactor-dimensionality reduction coupled with entropy graphs to identify, validate and visualize joint effects of inflammatory and immune response sequence variants as PCA predictors. MDR is a non-parametric method designed to detect higher order genegene interactions involving 2 or more loci with relatively small sample sizes ( $\geq 200$ cases, $\geq 200$ controls) for case-control studies, which is beyond the capacity of LR. It also has adequate statistical power to detect significant 2-4-factor gene-gene interactions in the presence of small sizes (200 cases, 200 controls). MDR analyses can be adjusted for multiple hypothesis testing using permutation testing, which minimizes spurious findings due to chance. In addition, this non-parametric method has the capacity to adjust for cofounders (e.g., age) and utilizes entropy graphs to interpret the effect of gene-gene interactions. Entropy graphs indicate which factors within a gene-gene interaction is synergistic or not through connecting color-coded lines between each SNP. The color scheme is as follows: red (highly synergistic), orange (moderately synergistic), green (moderately redundant), blue (highly redundant), and gold (neither synergistic/redundant). 
The current version of MDR does not require an equal number cases and controls to predict high order interactions. For instance, our lab reported on gene-gene interactions among inflammatory and immune response-related sequence variants among men of African descent [31]. We observed that the age-adjusted three-factor (TLR10 rs 11096957 , TLR6 rs2381289, IRF3 rs2304206) interaction model was the best predictor of prostate cancer risk due to its high prediction accuracy score (ATA) of 65\% and cross validation value (CVC) of 100\% among men of African descent from the U.S. and Jamaica (Permutation testing $\mathrm{p}$-value $=0.001)$ [31]. The synergy of this three-factor model was primarily driven by the information gain scores of TLR6 rs2381289 $(\mathrm{IG}=1.71 \%)$ and the pairwise interaction between TLR10 rs1 1096957 and IRF3 rs2304206 (IG = 1.75\%) (see Chapter 3 Results). However when MDR analysis was restricted to U.S. men, the ageadjusted 2-factor model, IRAK4 rs4251545 and TLR2 rs1898830, was found to be the best predictor of prostate cancer risk based upon 100\% CVC and 62\% ATA values (Permutation testing $\mathrm{p}$-value $=0.001)$. The MDR-based entropy graph displayed a highly synergistic pairwise interaction between IRAK4 rs4251545 and TLR2 rs 1898830 with an information gain (IG) score of 2.33\%. Due to the information score exceeding the mutual information gain scores of each loci, this information gain score was regarded as informative. For the Jamaican men, only the one-factor model of TLR6 rs2381289 survived multiple hypothesis testing and therefore selected as the best predictor of PCA susceptibility. MDR analysis for chemokine-associated sequence variants showed that the age-adjusted three-factor model (CCR7 rs3136685, CCL5 rs3817655, CCR9 rs41289608) was selected as the best interaction model based upon 100\% CVC and 67\% ATA values among men of African descent (see Chapter 4 Results). However within this interaction, 
the MDR entropy-based graph revealed no strong synergistic interaction due to none of the pairwise interactions yielding informative information information gain scores. Similarly, the age-adjusted three-factor model (CCR6 rs3093024, CCL5 rs3817655, CCR9 rs41289608) among U.S. men were statistically significant with 69\% ATA score and $100 \% \mathrm{CVC}$ value in relation to prostate cancer (Permutation testing $\mathrm{p}$-value $=0.001$ ) Moreover, the age-adjusted three-factor model (CCR6 rs3093024, CCR4 rs6550178, CXCR7 rs7559855) was associated with a 90\% CVC value and 70\% ATA score among Jamaican men $($ Permutation p-value $=0.017)$. Within this interaction, the MDR entropybased graph showed a moderately synergistic interaction between SNPs in CCR6 and CXCR7 with an informative pairwise interaction IG score of $3.41 \%$ and CCR 4 rs6550178 with the highest individual IG score of $8.2 \%$.

Among the cytokine-associated gene-gene interactions, a three-factor model (IL1R2 rs11886877, IL10 rs1800896, IL10RA rs4252243) was selected as the best predictor of PCA risk among men of African descent based upon a 61\% ATA score (Permutation testing p-value $=0.003)($ see Chapter 5 Results $)$. This model displayed a highly synergistic interaction with an informative IG score of $0.86 \%$ for the pairwise interaction between IL1R2 rs11886877 and IL10 rs1800896. MDR analysis restricted to U.S. men showed a significant three-factor interaction model (IL1B rs 1143627, ILIA rs 1800587, ILIRN rs315951) with a 100\% CVC value and 67\% ATA score (Permutation testing $\mathrm{p}$-value $=0.001)$. The synergy of this three-factor interaction model was based upon an informative mutual information gain score for ILIB rs 1143627 and ILIA rs1800587 pairwise interaction $(\mathrm{IG}=1.93 \%$ ) (Data not shown). Among Jamaican men, the two-factor model (ILIRN rs315951 and IL1RI rs949963) was selected as the best 
predictor of PCA risk with a $100 \% \mathrm{CVC}$ value, $65 \%$ ATA score, permutation testing pvalue of 0.008 and informative pairwise mutual information gain score of $4.77 \%$ (Data not shown). However, interaction models predicted in relation to prostate cancer for Jamaican men must be further validated due to limited sample size of Jamaican population.

Gene-gene interactions among genetic variants are essential to understanding the complex genetic architecture of prostate cancer. Further investigation of these interactions using a pooled multi-center study may lead to the identification of polymorphisms related to PCA risk within racially/ethnically diverse subgroups and disease progression. Such efforts may lead to the detection of validation of SNP signatures that may help to explain the higher PCA tumor burden among men of African descent relative to their Caucasian counterparts. To further investigate whether modification of a combination of gene targets (e.g., CCL5, CCR5) may impact PCA behavior (e.g., cell migration, proliferation, invasion, metastasis) using appropriate in vitro and in vivo studies. Moreover, it will also be very valuable to assess the effect of altered expression (i.e., overexpression or knockout) of inflammatory and immune response associated gene products (e.g., TLR, chemokine, cytokine) in prostate tumorigenesis. For instance silencing of CXCL1 and CXCL2 inhibits cell growth and induces apoptosis in PC3 cells [80]. Ultimately, the investigation of inflammatory and immune-response associated genes will help to understand how these genes play a role in prostate tumorigenesis.

\section{Significance}


Currently, physicians diagnose patients with prostate cancer based upon tumor biopsies (e.g., needle or TUR), pathological analyses of tumor traits (e.g., tumor size, grade, stage), a blood test (e.g., PSA levels) and digital rectal exams. However, these standard methods fail to accurately distinguish between non-aggressive and aggressive disease. The inability of physicians to determine which patients should receive a biopsy and aggressive therapy will lead to unnecessary and costly clinical management of prostate cancer. The identification of high-risk alleles associated with inflammatory and immune-response genetic variants may help to improve early detection of PCA and ultimately aggressive disease. In addition, genetic variants may be used to develop a genetic kit, which consist of a high risk SNP panel, to identify high-risk individuals who should receive aggressive prostate cancer therapy. The development of genetic kits will be very marketable for translational medicine and may prove to replace or enhance current diagnostic techniques. In addition, scientists will want to understand the effect of conventional drugs on people with high-risk alleles. Ultimately, genetic kits may help reduce the use of invasive diagnostic techniques (e.g., tissue biopsy) for cancer diagnosis, improve the decisions of physician about treatment options for patients, and guide the discovery of new therapeutic targets.

Over the years, cancer researchers have utilized genetic alterations associated with inflammatory and immune response genes to identify potential therapeutic agents and treatment strategies for cancer. Drug agonists and antagonists of toll-like receptors, chemokines, and cytokines are being evaluated in various clinical trials as potential anticancer therapeutic strategies, as summarized in Table 2. TLR signaling plays a critical role in immune response surveillance, which detect pathogens and tumor cells. TLR 
agonists have been studied as anti-tumor drugs in relation to tumorigenesis. For instance, Sohn and associates (2014) observed that TLR7 agonist, imiquimod, induces apoptosis in the squamous cell carcinoma cell line, SCC12, through the suppression of A20 protein expression and activation of JNK [151]. TLR7 agonists, imiquimod and loxoribine, stimulate pro-inflammatory cytokine (IL6) and chemokine (CXCL1, CXCL2, CCL2) production in TRAMP-C2 cells (mouse prostate cancer cell line) via elevation of TLR7 gene and protein expression [62]. In particular, loxoribine was shown to inhibit the growth of TRAMP-C2 cells primarily through TLR7 signaling. Thus, TLR7 agonists may possess anti-tumorigenic activity against prostate cancer tumorigenesis. TLR9 is a member of the innate immune system, which makes it a great target for candidate anticancer therapeutic agents. Wakayama Medical University conducted a Phase I and II clinical trial to treat advanced recurrent esophageal cancer patients with a combination of novel tumor specific epitope peptides and TLR9 agonist, CpG7909 (Trial \#:

NCT00669292). Several studies have shown elevated TLR9 protein expression in poorly differentiated prostatic tumors and strongly associated with poor prognosis of prostate cancer $[152,153]$. Moreover, the TLR9 agonist, CpG-ODN, stimulates PC3 cells to secrete immunosuppressive cytokines, IL8 and TGF $\beta 1[154]$.

The National Center of Tumor Diseases in Heidelberg, Germany has a Phase I clinical trial in progress studying the effect of CCR5 blockage on tumor cells in colorectal metastases. CCR5 inhibitor, maraviroc, is used to treat colorectal cancer metastasis in 12 patients with an 8-week follow-up time (Trial \#: NCT01736813). Ochoa and co-workers (2013) demonstrated that maraviroc reduces liver injury, weight loss and tumor size in CDE-treated mice with hepatocellular carcinoma [155]. In another study, 
Velasco and colleagues (2012) observed that CCR5 antagonists (maraviroc and vicriviroc) decreased both cellular invasion and tumor metastases on the lung in breast cancer metastasis in vivo using NOD/SCID mice [156]. In a non-randomized Phase I/II clinical trial completed in 2010, Biokine Therapeutics Ltd evaluated a CXCR4 antagonist, BKT-140, as a novel treatment against multiple myeloma (Trial\# NCT01010880). BKT-140 has a synergistic effect with Granulocyte-colony stimulating factor (G-CSF) to mobilize white blood cells and reduce anemic episodes.

Expansion of the knowledge on the role of inflammatory and immune responserelated genes in prostate cancer tumorigenesis will provide guidance in the design of personalized medicine for cancer patients. Nonetheless, observational studies must evaluate all possible inflammatory and immune response signaling pathway targets. Further investigation of the inflammatory and immune-response signaling pathway may lead to the identification of novel and more effective targets to improve clinical management of prostate cancer. 
Table 2. Current Inflammatory and Immune Response Gene Selective Drugs in Clinical Trials

\begin{tabular}{|c|c|c|c|c|}
\hline Target & Compound & Company & Status & Trial \# \\
\hline CCR5 & Maraviroc & $\begin{array}{l}\text { National Center for Tumor } \\
\text { Diseases, Heidelberg }\end{array}$ & Phase I & NCT01736813 \\
\hline CXCR4 & BKT140 & Biokine Therapeutics Ltd & Phase I/II & NCT01010880 \\
\hline TLR & $\begin{array}{l}\text { gp100, R848 } \\
\text { gel, MAGE-3 }\end{array}$ & $\begin{array}{l}\text { M.D. Anderson Cancer } \\
\text { Center }\end{array}$ & Phase II & NCT00960752 \\
\hline TLR7 & Imiquimod & $\begin{array}{l}\text { New York University School } \\
\text { of Medicine }\end{array}$ & Phase I/II & NCT01421017 \\
\hline TLR8 & VTX-2337 & University of Washington & Phase I & NCT01334177 \\
\hline TLR9 & CpG7909 & $\begin{array}{l}\text { Wakayama Medical } \\
\text { University }\end{array}$ & Phase I/II & NCT00669292 \\
\hline IL15 & IL15 & $\begin{array}{l}\text { National Institutes of Health } \\
\text { Clinical Center, National } \\
\text { Cancer Institute }\end{array}$ & Phase I/II & NCT01369888 \\
\hline
\end{tabular}


The following sections of this master's thesis will be organized into chapters 2 through 6. Chapter 2 describes the methods used to analyze main and joint effects of inflammatory and immune response related sequence variants. Next, research findings will be divided into 3 separate chapters for each signaling pathway. Chapter 3 describes the key logistic regression modeling and MDR analysis findings for the toll-like receptor signaling pathway. Chapter 4 highlights the key logistic regression and MDR analysis findings for the chemokine signaling pathway. Chapter 5 describes the key logistic regression modeling and MDR analysis findings for the cytokine signaling pathway. Lastly, Chapter 6 consists of the master's thesis summary, conclusion and clinical relevance. 


\section{Research Hypothesis}

The proposed research hypothesizes that the inheritance of one or more high-risk alleles in inflammatory and immune response genes involved in the toll-like receptor, chemokine and cytokine signaling pathways will modify prostate cancer susceptibility among men of African descent. 


\section{Specific Aims}

The following two specific aims will test the proposed research hypothesis:

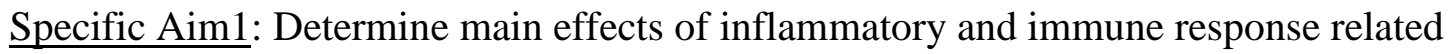
sequence variants on prostate cancer susceptibility among men of African descent. Sequence variants within inflammatory and immune response genes may influence the interaction among the toll-like receptor, cytokine-cytokine receptor and chemokine-chemokine receptor signaling pathways. These variants may impact tolllike receptor surveillance in innate immunity, chemokine and cytokine production during chronic inflammation and mobilization of inflammatory immune cells within the inflammatory and immune response signaling pathway. Regulation of the toll-like receptor, chemokine and cytokine signaling pathways are pivotal to the balance between anti- and pro-inflammatory signals released from immune cells. Genetic alterations that interfere with the operation of the inflammatory and immune response pathways may elevate pro-inflammatory signals leading to chronic prostatitis (chronic inflammation) and initiation of prostate cancer development.

Specific Aim 2: Evaluate gene-gene interactions among inflammatory and immune response related sequence variants among U.S. and Jamaican men. The effect of single sequence variants may not fully explain the role of inflammatory and immune response-related genes in prostate cancer development and progression. Therefore, the investigation of multiple sequence variants is needed to identify important PCA predictors. Multi-locus tools such as MDR can detect high order $(\geq 2)$ interactions among sequence variants to elucidate the complexity of the roles these pathways and target genes predispose individual to prostate cancer risk. The interplay between 
genes within the inflammatory and immune response pathway will provide insight to the complex mechanisms that feed into prostate cancer development. Gene-gene interactions can negatively or positively influence the translation of protein product and expression on various cell types. Immune cells (e.g., macrophages, leukocytes) express toll-like receptors on the extracellular membrane to detect bacterial infection and pathogens. Cytokine and chemokine receptors are also expressed on immune cells and utilized to detect their respective ligands and direct cell-cell communications. The inheritance of sequence variants within inflammatory and immune response associated genes may render non-functional proteins. 


\section{CHAPTER 2}

\section{METHODOLOGY}

\section{Study Population}

The current study consisted of two independent case-control study sets with participants from the Prostate Cancer Clinical Outcome $\left(\mathrm{PC}^{2} \mathrm{O}\right)$ Study and the Prostate Cancer CaseControl study (Table 3, 4, and 5). Among all 814 men of African descent, germ-line DNA samples were collected for 279 PCA cases and 535 disease-free men, as shown in Table 1. In the $\mathrm{PC}^{2} \mathrm{O}$ Study, 603 unrelated men of African descent were recruited from Columbia, South Carolina and Howard University Hospital (HUH) Division of Urology in Washington, D.C. or related PCA screening programs between 2001 and 2005. This population of men of African descent (i.e., self-reported African Americans, East African Americans, West African Americans, and Afro-Caribbean Americans) consisted of 170 incident PCA cases and 433 controls (Table 4). Between March 2005 and July 2007, two hundred twenty-one unrelated Jamaican men were recruited and consecutively enrolled into a prostate cancer case-control study (109 prostate cancer cases, 102 controls) during their first time visit at urology clinics (Table 5). Details on case and control ascertainment and inclusion criteria for both sub-populations have ben detailed elsewhere [157, 158]. 
Table 3. Study population characteristics among men of African descent from the U.S. and Jamaica.

\begin{tabular}{|c|c|c|c|}
\hline Characteristics & Cases & Controls & p value ${ }^{a}$ \\
\hline Number of Participants, $n$ & 279 & 535 & --- \\
\hline $\begin{array}{l}\text { Age at enrollment (yrs), } \\
\text { Median (range) }\end{array}$ & $67(45-91)$ & $53(27-89)$ & $<0.0001$ \\
\hline $\begin{array}{l}\text { Family History of Prostate } \\
\text { Cancer }{ }^{\mathrm{b}}, \mathrm{n}(\%) \\
\text { Yes } \\
\text { No } \\
\text { Missing } \\
\end{array}$ & $\begin{array}{c}35(16.1) \\
182(83.9) \\
62(22.2) \\
\end{array}$ & $\begin{array}{r}21(12.5) \\
147(87.5) \\
367(68.6) \\
\end{array}$ & 0.316 \\
\hline PSA (ng/ml), median (range) & $11.7(0.01-10,000)$ & $0.9(0.0-4.0)$ & $<0.0001$ \\
\hline $\begin{array}{l}\text { PSA }^{\mathrm{b}}(\mathrm{ng} / \mathrm{ml}), \mathrm{n}(\%) \\
\quad<4 \\
\quad \geq 4 \\
\quad \text { Missing }\end{array}$ & $\begin{array}{r}37(13.8) \\
231(86.2) \\
11(0.04) \\
\end{array}$ & $\begin{array}{c}517(99.8) \\
1(0.2) \\
17(0.03) \\
\end{array}$ & $<0.0001$ \\
\hline $\begin{array}{l}\text { Gleason Score }^{\mathrm{b}}, \mathrm{n}(\%) \\
\quad 4 \\
5 \\
6 \\
7 \\
8 \\
9 \\
10 \\
\text { Missing } \\
\end{array}$ & $\begin{array}{c}12(5.6) \\
14(6.5) \\
74(34.2) \\
70(32.4) \\
18(8.3) \\
22(10.2) \\
6(2.8) \\
63(22.6) \\
\end{array}$ & & \\
\hline $\begin{array}{l}\text { Global WAA }{ }^{\mathrm{b}} \text {, median } \\
\text { (range) }\end{array}$ & $0.79(0.25-0.94)$ & $0.767(0.25-0.95)$ & 0.107 \\
\hline
\end{tabular}

Abbreviations: PSA, prostate specific antigen; WAA, West African Ancestry; ${ }^{\mathrm{a} C h i-s q u a r e}$ test of homogeneity was used to determine whether the prevalence of family history or high PSA levels (PSA $\geq 4 \mathrm{ng} / \mathrm{mL}$ ) vary between cases and controls; ${ }^{b}$ Wilcoxon Sum Rank Test was used to examine whether differences exist within the median age (yrs), PSA (ng/ml) and Global WAA between cases and controls. 
Table 4. Baseline Characteristics among men of African Descent from the U.S.

\begin{tabular}{|c|c|c|c|}
\hline Characteristics & Cases & Controls & $\mathrm{p}$ value $^{\mathrm{a}}$ \\
\hline Number of Participants, $n$ & 170 & 433 & --- \\
\hline Age at diagnosis (yrs), Median (range) & $65(45-91)$ & $51(27-89)$ & $<0.0001$ \\
\hline \multicolumn{4}{|l|}{ Family History of Prostate Cancer ${ }^{\mathrm{b}}, \mathrm{n}(\%)$} \\
\hline Yes & $18(16.7)$ & $9(13.6)$ & 0.592 \\
\hline No & $90(83.3)$ & $57(86.4)$ & \\
\hline Missing & $62(36.5)$ & $367(84.8)$ & \\
\hline $\mathrm{PSA}^{\mathrm{b}}(\mathrm{ng} / \mathrm{ml})$, median (range) & $7.0(0.01-5,000)$ & $0.9(0.0-3.9)$ & $<0.0001$ \\
\hline \multicolumn{4}{|l|}{ PSA (ng/ml), n (\%) } \\
\hline$<4$ & $37(23.1)$ & $416(100.0)$ & $<0.0001$ \\
\hline$\geq 4$ & $123(76.9)$ & $0(0.0)$ & \\
\hline Missing & $10(5.9)$ & $17(1.6)$ & \\
\hline \multicolumn{4}{|l|}{ Gleason Score $^{\mathrm{b}}, \mathrm{n}(\%)$} \\
\hline 4 & $12(11.1)$ & & \\
\hline 5 & $14(13.0)$ & & \\
\hline 6 & $29(26.9)$ & & \\
\hline 7 & $32(29.6)$ & & \\
\hline 8 & $5(4.6)$ & & \\
\hline 9 & $12(11.1)$ & & \\
\hline 10 & $4(3.7)$ & & \\
\hline Missing & $62(36.5)$ & & \\
\hline Global WAA $^{\mathrm{b}}$, mean (SD) & $0.79(0.25-0.94)$ & $0.77(0.25-0.94)$ & 0.107 \\
\hline
\end{tabular}

Abbreviations: PSA, prostate specific antigen; ${ }^{\mathrm{a}}$ Differences in frequencies were tested by a Chi-square test of homogeneity or Fisher's Exact Test; 'Differences in median age (yrs) between cases and controls were tested using the Wilcoxon Sum Rank test. 
Table 5. Baseline Characteristics among men from Jamaica

\begin{tabular}{|lccc|}
\hline Characteristics & Cases & Controls & p value \\
\hline Number of Participants, $\mathrm{n}$ & 109 & 102 & --- \\
\hline Age at diagnosis (yrs), Median (range) & $70(49-80)$ & $60(40-80)$ & $<0.0001$ \\
\hline Family History of Prostate Cancer ${ }^{\mathrm{b}}, \mathrm{n}(\%)$ & & & \\
$\quad$ Yes & $17(15.6)$ & $12(11.8)$ & 0.272 \\
No & $92(84.4)$ & $90(88.2)$ & \\
Missing & $0(0.0)$ & $0(0.0)$ & \\
\hline PSA $^{\mathrm{b}}$ (ng/ml), median (range) & $35.0(4.0-10,000)$ & $1.2(0.2-4.0)$ & $<0.0001$ \\
\hline PSA (ng/ml), n (\%) & $0(0.0)$ & & \\
$<4$ & $108(100.0)$ & $101(99.0)$ & \\
$\geq 4$ & $0(0.0)$ & 0.0001 \\
Missing & & & \\
Gleason Score ${ }^{\mathrm{b}}, \mathrm{n}(\%)$ & -- & & \\
4 & --- & & \\
5 & $45(41.7)$ & & \\
6 & $38(35.2)$ & & \\
7 & $13(12.0)$ & & \\
8 & $10(9.3)$ & & \\
9 & $2(1.8)$ & & \\
10 & $1(0.01)$ & & \\
Missing & & & \\
\hline
\end{tabular}

Abbreviations: PSA, prostate specific antigen; ${ }^{\mathrm{a}}$ Differences in frequencies were tested by a Chi-square test of homogeneity or Fisher's Exact Test; ${ }^{b}$ Differences in median age (yrs) between cases and controls were tested using the Wilcoxon sum Rank test. 


\section{Criteria for Inflammatory and Immune Response Gene and SNP selection}

Inflammatory and immune response-associated genes and SNPs were selected using one or more of following criteria: (1) epidemiological or molecular biological evidence from published reports indicating a relationship between the SNP/gene with cancer or inflammatory/immune response related diseases; (2) commonly studied loci; (3) marked disparities in genotype frequency comparing men of African descent to their Caucasian counterparts (i.e., $\pm 10 \%$ change); (4) evidence demonstrating a link between the SNPs and alterations in mRNA expression/stability or protein expression/structure or function using in silico tools (e.g., SNPinfo) or published reports (http://snpinfo.niehs.nih.gov/snpfunc.htm); and (5) a minor allele frequency $\geq 1 \%$ reported in the National Center for Biotechnology Information (NCBI) Entrez SNP, (www.ncbi.nlm.nih.gov). On average, a majority of the SNPs had minor allele frequencies ranging from 22-27\%. However, eight SNPs with allele frequencies greater than $1 \%$ but less than $5 \%$ were included in the analysis to explore whether rare SNPs would lead to substantial gains in effect sizes (i.e., 2-3 fold increases in risk) and contribute to the missing genetic heritability $[159,160]$. The SNPinfo webserver enabled us to annotate and/or predict the functional consequence of inflammatory and immune response associated sequence variants on altered alleles relative to referent alleles, as summarized in the Functional Consequence Tables 6-8.

\section{Quality Control Assurance and Data Management of Genotype data}

At the onset of the project, allelic discrimination focused on inflammatory and immune response associated SNPs among men of African Descent. To minimize misclassification bias, laboratory technicians were blinded to the case status of study 
participants. Each batch of up to 96 samples included four non-DNA template controls and eight duplicate samples, which enabled us to calculate the percent contamination (i.e., $0 \%$ ) and concordance rates (i.e., 100\%) per batch and for the entire data set, respectively. Genotype call rates were calculated separately for each SNP and study participant. Lastly, we tested whether the distribution of the genotypes among diseasefree individuals had significant departures from the Hardy-Weinberg equilibrium (HWE).

Prior to performing marker statistics, we excluded subjects who had genotype call rates that were $<90 \%$. To ensure high quality data, nine SNPs were excluded from the final analysis if: the distribution of the genotypes among controls deviated substantially from the Hardy-Weinberg Equilibrium, using a conservative significance level cut-off value of $\mathrm{P} \leq 0.005$; they had a minor allele frequency that was $<1 \%$; or the genotype call rates fell below 95\%. Following data clean up, 119 inflammatory and immune-related SNPs were included in the final analysis consisting of 814 men of African descent (279 cases, 535 controls). All quality control analyses and data management was performed using Golden Helix's SNP Variation Software 7.0 (Bozeman, MT).

\section{Genetic Analysis of Variant Inflammatory and Immune Response-Associated SNPs}

De-identified germ-line DNA was obtained from incident PCA male cases $(\mathrm{n}=$ 279) and controls $(\mathrm{n}=535)$. SNPs detected in TLRs $(1,2,4,6$, and 10), IRAK4, TOLLIP, IRF3, CCLs (1,2,5,7,11,17,21,24,25, and 26), CCRs (4,5,6, 7, and 9), CXCL12, CXCRs (5 and 7), ILs $(1,8,10), T N F, R N A S E L$ were genotyped using Illumina's GoldenGate genotyping assay system combined with Veracode Technology (Illumina, Inc., San Diego, CA). Allelic discrimination was performed using a BeadXpress Reader (Illumina, Inc., San Diego, CA) according to the manufacturer's instructions [161]. 
Table 6. Functional consequence of TLR-associated sequence variants ${ }^{\mathrm{a}}$.

\begin{tabular}{|c|c|c|c|c|c|c|c|c|c|c|c|c|}
\hline $\begin{array}{c}\text { Gene } \\
\text { dbSNPID } \\
\text { Location }\end{array}$ & Allele & Chr & $\begin{array}{l}\text { Nucleotide } \\
\text { Change }\end{array}$ & $\begin{array}{l}\text { Amino acid } \\
\text { change }\end{array}$ & $\begin{array}{c}\text { Predicted } \\
\text { Functional } \\
\text { Consequence }\end{array}$ & Major & Minor & $\begin{array}{c}\text { NCBI } \\
\text { EA }\end{array}$ & $\begin{array}{c}\text { NCBI } \\
\text { AA }\end{array}$ & $\begin{array}{c}\text { Current } \\
\text { MAF Study } \\
\text { Total } \\
\text { Population }\end{array}$ & $\begin{array}{c}\text { Current } \\
\text { MAF Study } \\
\text { U.S. }\end{array}$ & $\begin{array}{c}\text { Current } \\
\text { MAF Study } \\
\text { Jamaican }\end{array}$ \\
\hline $\begin{array}{l}\text { IRAK4 } \\
\text { rs4251467 } \\
\text { Intron 3 }\end{array}$ & $\mathrm{C} / \mathrm{T}$ & 12 & $\mathrm{C}>\mathrm{T}$ & & & $\mathrm{T}$ & $\mathrm{C}$ & 0.932 & 0.926 & 0.062 & 0.058 & 0.078 \\
\hline $\begin{array}{l}\text { IRAK4 } \\
\text { rs4251473 } \\
\text { Intron 5 }\end{array}$ & $\mathrm{A} / \mathrm{C}$ & 12 & $\mathrm{~A}>\mathrm{C}$ & & & $\mathrm{C}$ & A & 0.951 & 0.76 & 0.202 & 0.204 & 0.195 \\
\hline $\begin{array}{l}\text { IRAK4 } \\
\text { rs4251520 } \\
\text { Intron } 9 \\
\end{array}$ & $\mathrm{C} / \mathrm{T}$ & 12 & $\mathrm{C}>\mathrm{T}$ & & & $\mathrm{T}$ & $\mathrm{C}$ & 0.88 & 0.812 & 0.184 & 0.176 & 0.220 \\
\hline $\begin{array}{l}\text { IRAK4 } \\
\text { rs4251545 } \\
\text { Exon } 8\end{array}$ & $\mathrm{~A} / \mathrm{G}$ & 12 & $A>G$ & Ala $>\mathrm{Thr}$ & $\begin{array}{l}\text { Splice Site } \\
\text { benign }\end{array}$ & $\mathrm{G}$ & A & 0.937 & 0.625 & 0.300 & 0.304 & 0.282 \\
\hline $\begin{array}{l}\text { IRF3 } \\
\text { rs2304206 } \\
\text { 5’UTR }\end{array}$ & & 19 & $G>A$ & & TFBS & & & 0.727 & 0.421 & 0.384 & 0.388 & 0.368 \\
\hline $\begin{array}{l}\text { IRF3 } \\
\text { rs968457 } \\
\text { Near Gene'5 }\end{array}$ & $\mathrm{T} / \mathrm{C}$ & 19 & $\mathrm{~T}>\mathrm{C}$ & & $\begin{array}{l}\text { Splice Site } \\
\text { nsSNP, benign }\end{array}$ & $\mathrm{C}$ & $\mathrm{T}$ & 1 & 0.85 & 0.080 & 0.070 & 0.123 \\
\hline $\begin{array}{l}\text { TLR1 } \\
\text { rs3923647 } \\
\text { Exon 1 }\end{array}$ & $\mathrm{T} / \mathrm{A}$ & 4 & $\mathrm{~T}>\mathrm{A}$ & & $\begin{array}{l}\text { nsSNP } \\
\text { probably } \\
\text { damaging }\end{array}$ & $\mathrm{T}$ & A & 0.913 & 0.917 & 0.068 & 0.058 & 0.109 \\
\hline $\begin{array}{l}\text { TLR1 } \\
\text { rs4624663 } \\
\text { 3'UTR }\end{array}$ & $\mathrm{T} / \mathrm{C}$ & 4 & $\mathrm{~T}>\mathrm{C}$ & & & $\mathrm{T}$ & $\mathrm{C}$ & 0.973 & 0.938 & 0.068 & 0.064 & 0.089 \\
\hline $\begin{array}{l}\text { TLR1 } \\
\text { rs4833095 } \\
\text { Exon 1 }\end{array}$ & $\mathrm{C} / \mathrm{T}$ & 4 & $\mathrm{C}>\mathrm{T}$ & & nsSNP & $\mathrm{C}$ & $\mathrm{T}$ & 0.273 & 0.646 & 0.198 & 0.208 & 0.152 \\
\hline $\begin{array}{l}\text { TLR1 } \\
\text { rs5743595 } \\
\text { Intron } 2\end{array}$ & $\mathrm{G} / \mathrm{A}$ & 4 & $\mathrm{G}>\mathrm{A}$ & & & A & G & 0.753 & 0.958 & 0.029 & 0.033 & 0.010 \\
\hline $\begin{array}{l}\text { TLR1 } \\
\text { rs5743604 } \\
\text { Intron } 3\end{array}$ & $\mathrm{G} / \mathrm{A}$ & 4 & $\mathrm{G}>\mathrm{A}$ & & & A & G & 0.729 & 0.542 & 0.450 & 0.470 & 0.368 \\
\hline $\begin{array}{l}\text { TLR2 } \\
\text { rs1898830 } \\
\text { Intron 1 }\end{array}$ & $\mathrm{A} / \mathrm{G}$ & 4 & $A>G$ & & & A & $\mathrm{G}$ & 0.628 & 0.833 & 0.136 & 0.359 & 0.327 \\
\hline $\begin{array}{l}\text { TLR2 } \\
\text { rs3804099 } \\
\text { Exon 1 }\end{array}$ & $\mathrm{C} / \mathrm{T}$ & 4 & $\mathrm{C}>\mathrm{T}$ & & & $\mathrm{C}$ & $\mathrm{T}$ & 0.586 & 0.354 & 0.382 & 0.256 & 0.181 \\
\hline $\begin{array}{l}\text { TLR2 } \\
\text { rs7656411 } \\
\text { Near Gene'3 }\end{array}$ & $\mathrm{G} / \mathrm{T}$ & 4 & $\mathrm{G}>\mathrm{T}$ & & & G & $\mathrm{T}$ & 0.792 & -- & 0.423 & 0.017 & 0.015 \\
\hline
\end{tabular}




\begin{tabular}{|c|c|c|c|c|c|c|c|c|c|c|c|c|}
\hline $\begin{array}{c}\text { Gene } \\
\text { dbSNPID } \\
\text { Location }\end{array}$ & Allele & Chr & $\begin{array}{c}\text { Nucleotide } \\
\text { Change }\end{array}$ & $\begin{array}{c}\text { Amino acid } \\
\text { change }\end{array}$ & $\begin{array}{c}\text { Predicted } \\
\text { Functional } \\
\text { Consequence }\end{array}$ & Major & Minor & $\begin{array}{c}\text { NCBI } \\
\text { EA }\end{array}$ & $\begin{array}{c}\text { NCBI } \\
\text { AA }\end{array}$ & $\begin{array}{c}\text { Current } \\
\text { MAF Study } \\
\text { Total } \\
\text { Population }\end{array}$ & $\begin{array}{c}\text { Current } \\
\text { MAF Study } \\
\text { U.S. }\end{array}$ & $\begin{array}{l}\text { Current } \\
\text { MAF Study } \\
\text { Jamaican }\end{array}$ \\
\hline $\begin{array}{l}\text { TLR2 } \\
\text { rs7656411 } \\
\text { Near Gene'3 }\end{array}$ & $\mathrm{G} / \mathrm{T}$ & 4 & $\mathrm{G}>\mathrm{T}$ & & & G & $\mathrm{T}$ & 0.792 & -- & 0.423 & 0.017 & 0.015 \\
\hline $\begin{array}{l}\text { TLR4 } \\
\text { rs2149356 } \\
\text { Intron 3 }\end{array}$ & & 9 & $\mathrm{~T}>\mathrm{G}$ & & & & & 0.707 & 0.304 & 0.242 & 0.370 & 0.340 \\
\hline $\begin{array}{l}\text { TLR4 } \\
\text { rs1927906 } \\
\text { Near Gene'3 }\end{array}$ & $\mathrm{T} / \mathrm{C}$ & 9 & $\mathrm{~T}>\mathrm{C}$ & & & $\mathrm{T}$ & $\mathrm{C}$ & 0.94 & 0.604 & 0.449 & 0.191 & 0.186 \\
\hline $\begin{array}{l}\text { TLR4 } \\
\text { rs1927911 } \\
\text { Intron 1 }\end{array}$ & G/A & 9 & $\mathrm{G}>\mathrm{A}$ & & & G & A & 0.743 & 0.542 & 0.353 & 0.256 & 0.196 \\
\hline $\begin{array}{l}\text { TLR4 } \\
\text { rs4986791 } \\
\text { Exon 3 }\end{array}$ & $\mathrm{C} / \mathrm{T}$ & 9 & $C>T$ & & $\begin{array}{l}\text { nsSNP } \\
\text { possibly } \\
\text { damaging }\end{array}$ & $\mathrm{C}$ & $\mathrm{T}$ & 0.959 & 0.938 & 0.017 & 0.070 & 0.083 \\
\hline $\begin{array}{l}\text { TLR4 } \\
\text { rs5030710 } \\
\text { Exon } 3\end{array}$ & $\mathrm{C} / \mathrm{T}$ & 9 & $\mathrm{C}>\mathrm{T}$ & & Splice Site & $\mathrm{T}$ & $\mathrm{C}$ & 1.000 & 0.729 & 0.149 & 0.097 & 0.025 \\
\hline $\begin{array}{l}\text { TLR6 } \\
\text { rs1039559 } \\
\text { Intron 1 }\end{array}$ & $\mathrm{G} / \mathrm{A}$ & 4 & $G>A$ & & TFBS & A & $\mathrm{G}$ & 0.513 & 0.771 & 0.190 & 0.227 & 0.255 \\
\hline $\begin{array}{l}\text { TLR6 } \\
\text { rs2381289 } \\
\text { 3'UTR }\end{array}$ & $\mathrm{G} / \mathrm{A}$ & 4 & $G>A$ & & & G & A & 0.587 & 0.771 & 0.245 & 0.494 & 0.435 \\
\hline $\begin{array}{l}\text { TLR6 } \\
\text { rs3821985 } \\
\text { Exon 1 }\end{array}$ & $\mathrm{G} / \mathrm{C}$ & 4 & $\mathrm{G}>\mathrm{C}$ & & & $\mathrm{C}$ & G & 0.722 & 0.423 & 0.364 & 0.493 & 0.436 \\
\hline $\begin{array}{l}\text { TLR6 } \\
\text { rs5743810 } \\
\text { Exon 1 }\end{array}$ & $\mathrm{G} / \mathrm{A}$ & 4 & $\mathrm{G}>\mathrm{A}$ & & $\begin{array}{l}\text { nsSNP } \\
\text { benign }\end{array}$ & G & A & 0.588 & 0.907 & 0.072 & 0.031 & 0.015 \\
\hline $\begin{array}{l}\text { TLR6 } \\
\text { rs5743818 } \\
\text { Exon 1 } \\
\end{array}$ & $\mathrm{C} / \mathrm{A}$ & 4 & $C>A$ & & & A & $\mathrm{C}$ & 0.761 & 0.839 & 0.083 & 0.032 & 0.025 \\
\hline $\begin{array}{l}\text { TLR10 } \\
\text { rs10776483 } \\
\text { Exon 1 }\end{array}$ & $\mathrm{G} / \mathrm{A}$ & 4 & $G>A$ & & & A & G & 0.707 & -- & 0.232 & 0.134 & 0.142 \\
\hline $\begin{array}{l}\text { TLR10 } \\
\text { rs11096955 } \\
\text { Exon 1 }\end{array}$ & $\mathrm{T} / \mathrm{G}$ & 4 & $\mathrm{~T}>\mathrm{G}$ & & $\begin{array}{l}\text { nsSNP } \\
\text { benign }\end{array}$ & $\mathrm{T}$ & G & 0.408 & -- & 0.492 & 0.382 & 0.382 \\
\hline $\begin{array}{l}\text { TLR10 } \\
\text { rs11096957 } \\
\text { Exon 1 }\end{array}$ & $\mathrm{T} / \mathrm{G}$ & 4 & $\mathrm{~T}>\mathrm{G}$ & & $\begin{array}{l}\text { nsSNP } \\
\text { possibly } \\
\text { damaging }\end{array}$ & G & $\mathrm{T}$ & 0.408 & -- & 0.493 & 0.424 & 0.421 \\
\hline $\begin{array}{l}\text { TLR10 } \\
\text { rs11466640 } \\
\text { Intron 1 }\end{array}$ & $\mathrm{G} / \mathrm{A}$ & 4 & $\mathrm{G}>\mathrm{A}$ & & & G & A & 0.757 & 0.957 & 0.028 & 0.098 & 0.079 \\
\hline
\end{tabular}




\begin{tabular}{|c|c|c|c|c|c|c|c|c|c|c|c|c|}
\hline $\begin{array}{c}\text { Gene } \\
\text { dbSNPID } \\
\text { Location }\end{array}$ & Allele & Chr & $\begin{array}{l}\text { Nucleotide } \\
\text { Change }\end{array}$ & $\begin{array}{l}\text { Amino acid } \\
\text { change }\end{array}$ & $\begin{array}{c}\text { Predicted } \\
\text { Functional } \\
\text { Consequence }\end{array}$ & Major & Minor & $\begin{array}{c}\text { NCBI } \\
\text { EA }\end{array}$ & $\begin{array}{c}\text { NCBI } \\
\text { AA }\end{array}$ & $\begin{array}{c}\text { Current } \\
\text { MAF Study } \\
\text { Total } \\
\text { Population }\end{array}$ & $\begin{array}{c}\text { Current } \\
\text { MAF Study } \\
\text { U.S. }\end{array}$ & $\begin{array}{c}\text { Current } \\
\text { MAF Study } \\
\text { Jamaican }\end{array}$ \\
\hline $\begin{array}{l}\text { TLR10 } \\
\text { rs4274855 } \\
\text { 5'UTR } \\
\end{array}$ & $\mathrm{T} / \mathrm{C}$ & 4 & $\mathrm{~T}>\mathrm{C}$ & & & $\mathrm{C}$ & $\mathrm{T}$ & 0.747 & 0.958 & 0.031 & 0.455 & 0.425 \\
\hline $\begin{array}{l}\text { TOLLIP } \\
\text { rs3168046 } \\
\text { 3'UTR }\end{array}$ & $\mathrm{G} / \mathrm{A}$ & 11 & $\mathrm{G}>\mathrm{A}$ & & miRNA & G & A & 0.568 & 0.568 & 0.422 & 0.428 & 0.397 \\
\hline $\begin{array}{l}\text { TOLLIP } \\
\text { rs57433867 } \\
\text { Intron } 1\end{array}$ & $\mathrm{G} / \mathrm{A}$ & 11 & $\mathrm{G}>\mathrm{A}$ & & & A & G & 0.92 & 0.854 & 0.201 & 0.202 & 0.197 \\
\hline $\begin{array}{l}\text { TOLLIP } \\
\text { rs5743899 } \\
\text { Intron 1 } \\
\end{array}$ & $\mathrm{T} / \mathrm{C}$ & 11 & $\mathrm{~T}>\mathrm{C}$ & & & $\mathrm{T}$ & $\mathrm{C}$ & 0.892 & 0.652 & 0.428 & 0.419 & 0.465 \\
\hline
\end{tabular}

Abbreviations: Chr, chromosome; UTR, untranslated region; TFBS, transcription factor binding site, miRNA, micro RNA; nsSNP, nonsynonymous SNP; EA, European-American; AA, African-American; ${ }^{\text {a}}$ TLR-related SNPs were analyzed among men of African Descent. 
Table 7. Functional Consequence of Chemokine-Associated Sequence Variants ${ }^{\mathrm{a}}$.

\begin{tabular}{|c|c|c|c|c|c|c|}
\hline $\begin{array}{c}\text { Gene } \\
\text { dbSNP ID } \\
\text { Location }\end{array}$ & Chr & Location & Nucleotide & $\begin{array}{l}\text { Amino Acid } \\
\text { Change }\end{array}$ & $\begin{array}{c}\text { Predicted } \\
\text { Functional } \\
\text { Consequence }\end{array}$ & Current Study MAF \\
\hline $\begin{array}{c}\text { CCR6 } \\
\text { rs } 1012656 \\
\end{array}$ & 6 & 5'UTR & & & TFBS & $\mathrm{C}=19.5$ \\
\hline $\begin{array}{c}\text { CCL2 } \\
\text { rs1024611 } \\
\end{array}$ & 17 & Near gene $5^{\prime}$ & & & TFBS & $\mathrm{C}=19.7$ \\
\hline $\begin{array}{c}\text { CXCR7 } \\
\text { rs1045879 }\end{array}$ & 2 & Exon 1 & $\mathrm{~T}>\mathrm{C}$ & Leu266Leu & & $\mathrm{G}=30.7$ \\
\hline $\begin{array}{c}\text { CCL17 } \\
\text { rs11076191 }\end{array}$ & 16 & Intron 1 & & & TFBS & $\mathrm{A}=2.3$ \\
\hline $\begin{array}{c}\text { CCL21 } \\
\text { rs11574914 }\end{array}$ & 9 & Near gene 5, & & & TFBS & $A=9.1$ \\
\hline $\begin{array}{c}\text { CCL21 } \\
\text { rs11574915 }\end{array}$ & 9 & 5'UTR & & & TFBS, Splicing & $\mathrm{C}=10.6$ \\
\hline $\begin{array}{c}\text { CCL21 } \\
\text { rs11574916 }\end{array}$ & 9 & 3'UTR & & & TFBS, miRNA & $A=5.5$ \\
\hline $\begin{array}{c}\text { CCR9 } \\
\text { rs12721497 }\end{array}$ & 3 & Exon 3 & $\mathrm{G}>\mathrm{A}$ & Met284Val & nsSNP, benign & $\mathrm{G}=1.9$ \\
\hline $\begin{array}{c}C C R 9 \\
r s 1488371\end{array}$ & 3 & Intron 2 & & & & $A=15.6$ \\
\hline $\begin{array}{c}\text { CCR6 } \\
\text { rs } 1556413\end{array}$ & 6 & Near gene $5^{\prime}$ & & & TFBS & $\mathrm{A}=20.2$ \\
\hline $\begin{array}{c}\text { CCL7 } \\
\text { rs17809012 } \\
\end{array}$ & 17 & Near gene 5, & & & TFBS & $\mathrm{G}=34.6$ \\
\hline $\begin{array}{c}\text { CXCL12 } \\
\text { rs } 17880777\end{array}$ & 10 & Near gene 5, & & & TFBS & $\mathrm{C}=17.4$ \\
\hline $\begin{array}{c}\text { CCR5 } \\
\text { rs1799987 }\end{array}$ & 3 & Intron 1 & & & TFBS & $A=40.3$ \\
\hline $\begin{array}{c}\text { CCR5 } \\
r s 1799988 \\
\end{array}$ & 3 & 5'UTR & & & TFBS & $G=41.9$ \\
\hline $\begin{array}{c}\text { CCR5 } \\
\text { rs1800024 }\end{array}$ & 3 & Intron 2 & & & TFBS & $A=19.8$ \\
\hline $\begin{array}{c}\text { CXCL12 } \\
\text { rs1801157 } \\
\end{array}$ & 10 & 3'UTR & & & $\underline{\operatorname{miRNA}}$ & $A=6.3$ \\
\hline $\begin{array}{c}\text { CCR6 } \\
\text { rs2023305 } \\
\end{array}$ & 6 & Near gene $5^{\prime}$ & & & TFBS & $A=16.8$ \\
\hline
\end{tabular}




\begin{tabular}{|c|c|c|c|c|c|c|}
\hline $\begin{array}{c}\text { Gene } \\
\text { dbSNP ID } \\
\text { Location }\end{array}$ & Chr & Location & Nucleotide & $\begin{array}{l}\text { Amino Acid } \\
\text { Change }\end{array}$ & $\begin{array}{c}\text { Predicted } \\
\text { Functional } \\
\text { Consequence }\end{array}$ & Current Study MAF \\
\hline $\begin{array}{c}\text { CCL25 } \\
\text { rs2032887 }\end{array}$ & 19 & Exon 3 & $\mathrm{G}>\mathrm{A}$ & His101 Arg & $\begin{array}{l}\text { Splicing, } \\
\text { probably } \\
\text { damaging }\end{array}$ & $\mathrm{G}=27.4$ \\
\hline $\begin{array}{c}\text { CCL5 } \\
\text { rs2107538 }\end{array}$ & 17 & Near gene 5, & & & TFBS & $A=46.6$ \\
\hline $\begin{array}{c}\text { CCR5 } \\
\text { rs2227010 }\end{array}$ & 3 & Near gene 5 , & & & TFBS & $\mathrm{G}=19.8$ \\
\hline $\begin{array}{c}\text { CCL17 } \\
\text { rs223895 }\end{array}$ & 16 & Intron 1 & & & & $\mathrm{~A}=29.9$ \\
\hline $\begin{array}{c}\text { CCL5 } \\
\text { rs2280789 }\end{array}$ & 17 & Intron 1 & & & TFBS & $\mathrm{G}=22.3$ \\
\hline $\begin{array}{c}\text { CCL1 } \\
\text { rs2282691 }\end{array}$ & 17 & Intron 2 & & & & $\mathrm{~A}=46.2$ \\
\hline $\begin{array}{c}\text { CCR9 } \\
\text { rs2286486 }\end{array}$ & 3 & Near gene 5 , & & & TFBS & $\mathrm{G}=25.9$ \\
\hline $\begin{array}{c}\text { CCL24 } \\
\text { rs2302004 }\end{array}$ & 7 & Intron 1 & & & TFBS & $\mathrm{G}=41.9$ \\
\hline $\begin{array}{c}\text { CCL26 } \\
\text { rs2302009 }\end{array}$ & 7 & 3'UTR & & & miRNA & $\mathrm{C}=40.7$ \\
\hline $\begin{array}{l}\text { CXCL12 } \\
\text { rs266093 }\end{array}$ & 10 & 3'UTR & & & miRNA & $\mathrm{G}=42.9$ \\
\hline $\begin{array}{c}\text { CCL21 } \\
\text { rs2812378 }\end{array}$ & 9 & Near gene 5 , & & & TFBS & $\mathrm{G}=41.9$ \\
\hline $\begin{array}{c}\text { CXCL12 } \\
\text { rs2839685 }\end{array}$ & 10 & Near gene 5 , & & & TFBS & $\mathrm{A}=31.4$ \\
\hline $\begin{array}{c}\text { CXCL12 } \\
\text { rs2839695 }\end{array}$ & 10 & 3'UTR & & & miRNA & $\mathrm{G}=17.5$ \\
\hline $\begin{array}{c}\text { CCR6 } \\
\text { rs3093023 }\end{array}$ & 6 & Near gene 5 , & & & & $\mathrm{A}=13.8$ \\
\hline $\begin{array}{c}\text { CCR6 } \\
\text { rs3093024 }\end{array}$ & 6 & Intron 1 & & & & $\mathrm{~A}=32.3$ \\
\hline $\begin{array}{c}C C R 7 \\
r s 3136685\end{array}$ & 17 & Intron 1 & & & & $G=49.5$ \\
\hline
\end{tabular}




\begin{tabular}{|c|c|c|c|c|c|c|}
\hline $\begin{array}{c}\text { Gene } \\
\text { dbSNP ID } \\
\text { Location }\end{array}$ & Chr & Location & Nucleotide & $\begin{array}{l}\text { Amino Acid } \\
\text { Change }\end{array}$ & $\begin{array}{c}\text { Predicted } \\
\text { Functional } \\
\text { Consequence }\end{array}$ & Current Study MAF \\
\hline $\begin{array}{c}\text { CCR7 } \\
\text { rs3136687 }\end{array}$ & 17 & Intron 1 & & & & $\mathrm{~A}=44.4$ \\
\hline $\begin{array}{c}\text { CCL5 } \\
\text { rs3817655 }\end{array}$ & 17 & Intron 2 & & & TFBS & $A=46.5$ \\
\hline $\begin{array}{c}\text { CCR9 } \\
\text { rs41289608 }\end{array}$ & 3 & 5'UTR & & & TFBS, Splicing & $A=36$ \\
\hline $\begin{array}{c}\text { CCL11 } \\
\text { rs4795896 }\end{array}$ & 17 & Near gene 5 , & & & TFBS & $\mathrm{G}=4.8$ \\
\hline $\begin{array}{c}\text { CXCR5 } \\
\text { rs523604 }\end{array}$ & 11 & Intron 1 & & & & $\mathrm{~A}=34.9$ \\
\hline $\begin{array}{c}\text { CCR4 } \\
\text { rs6550178 }\end{array}$ & 3 & Intron 1 & & & TFBS & $A=17.2$ \\
\hline $\begin{array}{c}\text { CCL25 } \\
\text { rs7259568 }\end{array}$ & 19 & Near gene 5 , & & & TFBS & $A=9.3$ \\
\hline $\begin{array}{c}\text { CXCR7 } \\
\text { rs7559855 }\end{array}$ & 2 & Intron 1 & & & & $\mathrm{~A}=38.5$ \\
\hline $\begin{array}{c}\text { CCR9 } \\
\text { rs7613548 }\end{array}$ & 3 & Near gene 5 , & & & TFBS & $A=44$ \\
\hline $\begin{array}{c}\text { CCR4 } \\
\text { rs7632357 }\end{array}$ & 3 & Near gene 5 , & & & TFBS & $\mathrm{C}=41.6$ \\
\hline
\end{tabular}

Abbreviations: Chr, chromosome; UTR, untranslated region; TFBS, transcription factor binding site, miRNA, micro RNA; nsSNP, nonsynonymous SNP; ${ }^{a}$ Forty-three chemokine-related SNPs were analyzed among men of African Descent. SNPs denoted in bold had significant risk estimates associated with PCA risk in the total population. Italicized SNPs were significantly associated with PCA risk in the Jamaican population. Columns shaded in gray symbolize SNPs that were significantly associated with PCA risk in the U.S. population. 
Table 8. Functional Consequence of Inflammatory-Associated Sequence Variants.

\begin{tabular}{|c|c|c|c|c|c|c|c|}
\hline $\begin{array}{l}\text { Gene } \\
\text { dbSNPID } \\
\text { Location } \\
\text { Functional } \\
\text { Consequence }\end{array}$ & $\begin{array}{l}\text { NCBI } \\
\text { Nucleotide } \\
\text { Change } \\
\text { (Major> } \\
\text { Minor } \\
\text { allele) }\end{array}$ & $\begin{array}{l}\text { NCBI } \\
\text { AA } \\
\text { MAF } \\
(\%)\end{array}$ & $\begin{array}{l}\text { NCBI } \\
\text { AA } \\
\text { Major/Major, } \\
\text { Major/Minor, } \\
\text { Minor/Minor } \\
\text { Genotypes n(\%) }\end{array}$ & $\begin{array}{l}\text { Current } \\
\text { Study } \\
\text { Nucleotide } \\
\text { Change } \\
\text { (Major> } \\
\text { Minor allele) } \\
\end{array}$ & $\begin{array}{l}\text { Current Study } \\
\text { AA } \\
\text { MAF (\%) }\end{array}$ & $\begin{array}{l}\text { Current Study } \\
\text { AA } \\
\text { Major/Major, } \\
\text { Major/Minor, } \\
\text { Minor/Minor } \\
\text { Genotypes n (\%) }\end{array}$ & $\begin{array}{l}\text { Overall } \\
\chi^{2} \text { p-value } \\
\text { NCBI AAs vs } \\
\text { Current Study } \\
\text { AAs }{ }^{\dagger \dagger}\end{array}$ \\
\hline $\begin{array}{l}\text { IL10RB } \\
\text { rs1058867* } \\
\text { 3’UTR } \\
\text { miRNA } \\
\end{array}$ & $\mathrm{G}>\mathrm{A}$ & $\mathrm{A}=37.9$ & $\begin{array}{l}26(42.0) \\
25(40.3) \\
11(17.7)\end{array}$ & $\mathrm{G}>\mathrm{A}$ & $\mathrm{A}=33.9$ & $\begin{array}{l}239(44.6) \\
229(42.9) \\
67(12.5)\end{array}$ & 0.514 \\
\hline $\begin{array}{l}\text { IL1B } \\
\text { rs1071676* } \\
\text { 3'UTR } \\
\text { miRNA } \\
\text { (miRanda and } \\
\text { Sanger) } \\
\end{array}$ & $G>C$ & $\mathrm{C}=14.6$ & $\begin{array}{l}19(79.2) \\
3(12.5) \\
2(8.30)\end{array}$ & $\mathrm{G}>\mathrm{C}$ & $\mathrm{C}=16.1$ & $\begin{array}{l}378(70.7) \\
142(26.5) \\
15(2.80)\end{array}$ & 0.106 \\
\hline $\begin{array}{l}\text { IL1R2 } \\
\text { rs11123902* } \\
\text { Intron 1 }\end{array}$ & $A>C$ & $\mathrm{C}=31.8$ & $\begin{array}{l}10(45.5) \\
10(45.5) \\
2(9.10) \\
\end{array}$ & $A>C$ & $\mathrm{C}=30.7$ & $\begin{array}{l}258(48.2) \\
225(42.1) \\
52(9.70) \\
\end{array}$ & 0.949 \\
\hline $\begin{array}{l}\text { IL8RB } \\
\text { rs1126579* } \\
\text { 3'UTR } \\
\text { miRNA } \\
\end{array}$ & $C>T$ & $\mathrm{~T}=14.5$ & $\begin{array}{l}46(74.2) \\
14(22.6) 2 \\
(3.20)\end{array}$ & $\mathrm{G}>\mathrm{A}^{\dagger}$ & $\mathrm{A}=13.8$ & $\begin{array}{l}402(75.1) \\
118(22.1) \\
15(2.80)\end{array}$ & 0.886 \\
\hline $\begin{array}{l}\text { IL1B } \\
\text { rs1143627* } \\
\text { Near gene 5' } \\
\text { TFBS } \\
\end{array}$ & $\mathrm{C}>\mathrm{T}$ & $\mathrm{T}=37.5$ & $\begin{array}{l}12(50.0) \\
6(25.0) \\
6(25.0)\end{array}$ & $\mathrm{G}>\mathrm{A}^{\dagger}$ & $A=39.6$ & $\begin{array}{l}194(36.3) \\
256(48.2) \\
83(15.5)\end{array}$ & 0.063 \\
\hline $\begin{array}{l}\text { IL1B } \\
\text { rs1143634* }\end{array}$ & $\mathrm{C}>\mathrm{T}$ & $\mathrm{T}=12.9$ & $\begin{array}{l}47(75.8) \\
14(22.6) \\
1(1.60) \\
\end{array}$ & $\mathrm{G}>\mathrm{A}^{\dagger}$ & $\mathrm{A}=15.5$ & $\begin{array}{l}381(71.2) \\
142(26.5) \\
12(2.30) \\
\end{array}$ & 0.833 \\
\hline $\begin{array}{l}\text { IL8RB } \\
\text { rs11574752* } \\
\text { 3'UTR } \\
\text { miRNA } \\
\end{array}$ & $\mathrm{G}>\mathrm{A}$ & $\mathrm{A}=10.4$ & $\begin{array}{l}19(79.2) \\
5(20.8) \\
0(0.00)\end{array}$ & $\mathrm{G}>\mathrm{A}$ & $\mathrm{A}=9.40$ & $\begin{array}{l}435(81.3) \\
99(18.5) \\
1(0.20)\end{array}$ & 0.798 \\
\hline $\begin{array}{l}\text { IL1R2 } \\
\text { rs11886877 } \\
\text { Intron 1 }\end{array}$ & --- & --- & --- & $G>A$ & $\mathrm{~A}=35.8$ & $\begin{array}{l}211(39.4) \\
265(49.5) \\
59(11.1) \\
\end{array}$ & \\
\hline
\end{tabular}




\begin{tabular}{|c|c|c|c|c|c|c|c|}
\hline $\begin{array}{l}\text { Gene } \\
\text { dbSNPID } \\
\text { Location } \\
\text { Functional } \\
\text { Consequence }\end{array}$ & $\begin{array}{l}\text { NCBI } \\
\text { Nucleotide } \\
\text { Change } \\
\text { (Major> } \\
\text { Minor } \\
\text { allele) }\end{array}$ & $\begin{array}{l}\text { NCBI } \\
\text { AA } \\
\text { MAF } \\
(\%)\end{array}$ & $\begin{array}{l}\text { NCBI } \\
\text { AA } \\
\text { Major/Major, } \\
\text { Major/Minor, } \\
\text { Minor/Minor } \\
\text { Genotypes n(\%) }\end{array}$ & $\begin{array}{l}\text { Current } \\
\text { Study } \\
\text { Nucleotide } \\
\text { Change } \\
\text { (Major> } \\
\text { Minor allele) }\end{array}$ & $\begin{array}{l}\text { Current Study } \\
\text { AA } \\
\text { MAF (\%) }\end{array}$ & $\begin{array}{l}\text { Current Study } \\
\text { AA } \\
\text { Major/Major, } \\
\text { Major/Minor, } \\
\text { Minor/Minor } \\
\text { Genotypes n (\%) }\end{array}$ & $\begin{array}{l}\text { Overall } \\
\chi^{2} \text { p-value } \\
\text { NCBI AA vs } \\
\text { Current Study } \\
\text { AA } A^{\dagger \dagger}\end{array}$ \\
\hline $\begin{array}{l}\text { RNASEL } \\
\text { rs12135247** } \\
\text { 3'UTR } \\
\text { TFBS, miRNA }\end{array}$ & $\mathrm{T}>\mathrm{C}$ & $C=16.3$ & $\begin{array}{l}33(67.3) \\
16(32.7) \\
0(0.00)\end{array}$ & $\mathrm{A}>\mathrm{G}^{\dagger}$ & $\mathrm{G}=17.9$ & $\begin{array}{l}368(68.8) \\
142(26.5) \\
25(4.70)\end{array}$ & 0.226 \\
\hline $\begin{array}{l}\text { IL1R2 } \\
\text { rs12328606** } \\
\text { Near gene } 5 ' \\
\text { TFBS } \\
\end{array}$ & $\mathrm{C}>\mathrm{T}$ & $\mathrm{T}=11.2$ & $\begin{array}{l}38(77.6) \\
11(22.4) \\
0(0.00)\end{array}$ & $\mathrm{G}>\mathrm{A}^{\dagger}$ & $\mathrm{A}=13.5$ & $\begin{array}{l}405(75.7) \\
116(21.7) \\
14(2.60)\end{array}$ & 0.798 \\
\hline $\begin{array}{l}\text { IL1A } \\
\text { rs1304037* } \\
\text { 3'UTR } \\
\text { miRNA }\end{array}$ & $A>G$ & $\mathrm{G}=39.6$ & $\begin{array}{r}8(33.3) \\
13(54.2) \\
3(12.5)\end{array}$ & $A>G$ & $\mathrm{G}=41.1$ & $\begin{array}{l}191(35.7) \\
248(46.4) \\
96(17.9)\end{array}$ & 0.760 \\
\hline $\begin{array}{l}\text { IL1B } \\
\text { rs16944* } \\
\text { Near gene 5' } \\
\text { TFBS }\end{array}$ & $A>G$ & $\mathrm{G}=39.0$ & $\begin{array}{l}18(30.5) \\
36(61.0) \\
5(8.50)\end{array}$ & $A>G$ & $\mathrm{G}=45.1$ & $\begin{array}{l}156(29.2) \\
275(51.4) \\
104(19.4)\end{array}$ & 0.108 \\
\hline $\begin{array}{l}\text { IL1A } \\
\text { rs17561* } \\
\text { Exon } 4 \\
\text { Splicing (ESE or } \\
\text { ESS), nsSNP, } \\
\text { benign }\end{array}$ & $\mathrm{G}>\mathrm{T}$ & $\mathrm{T}=15.3$ & $\begin{array}{r}44(71.0) \\
17(27.4) \\
1(1.60)\end{array}$ & $\mathrm{C}>\mathrm{A}^{\dagger}$ & $A=18.6$ & $\begin{array}{l}358(66.9) \\
155(29.0) \\
22(4.10)\end{array}$ & 0.698 \\
\hline $\begin{array}{l}\text { TNF } \\
\text { rs1799964* } \\
\text { Near gene 5' } \\
\text { TFBS }\end{array}$ & $\mathrm{T}>\mathrm{C}$ & $\mathrm{C}=12.9$ & $\begin{array}{l}46(74.2) \\
16(25.8) \\
0(0.00)\end{array}$ & $A>G^{\dagger}$ & $\mathrm{G}=16.5$ & $\begin{array}{l}374(69.9) \\
145(27.1) \\
16(3.00)\end{array}$ & 0.492 \\
\hline $\begin{array}{l}\text { IL1A } \\
\text { rs1800587* } \\
\text { 5'UTR } \\
\text { TFBS, Splicing } \\
\text { (ESE or ESS) }\end{array}$ & $\mathrm{C}>\mathrm{T}$ & $\mathrm{T}=39.1$ & $\begin{array}{l}9(39.1) \\
10(43.5) \\
4(17.4)\end{array}$ & $\mathrm{G}>\mathrm{A}^{\dagger}$ & $\mathrm{A}=41.8$ & $\begin{array}{l}183(34.2) \\
257(48.0) \\
95(17.8)\end{array}$ & 0.885 \\
\hline
\end{tabular}




\begin{tabular}{|c|c|c|c|c|c|c|c|}
\hline $\begin{array}{l}\text { Gene } \\
\text { dbSNPID } \\
\text { Location } \\
\text { Functional } \\
\text { Consequence }\end{array}$ & $\begin{array}{l}\text { NCBI } \\
\text { Nucleotide } \\
\text { Change } \\
\text { (Major> } \\
\text { Minor } \\
\text { allele) }\end{array}$ & $\begin{array}{l}\text { NCBI } \\
\text { AA } \\
\text { MAF } \\
(\%)\end{array}$ & $\begin{array}{l}\text { NCBI } \\
\text { AA } \\
\text { Major/Major, } \\
\text { Major/Minor, } \\
\text { Minor/Minor } \\
\text { Genotypes n(\%) }\end{array}$ & $\begin{array}{l}\text { Current } \\
\text { Study } \\
\text { Nucleotide } \\
\text { Change } \\
\text { (Major> } \\
\text { Minor allele) }\end{array}$ & $\begin{array}{l}\text { Current Study } \\
\text { AA } \\
\text { MAF (\%) }\end{array}$ & $\begin{array}{l}\text { Current Study } \\
\text { AA } \\
\text { Major/Major, } \\
\text { Major/Minor, } \\
\text { Minor/Minor } \\
\text { Genotypes n (\%) }\end{array}$ & $\begin{array}{l}\text { Overall } \\
\chi^{2} \text { p-value } \\
\text { NCBI AA vs } \\
\text { Current Study } \\
\text { AA }^{\dagger \dagger}\end{array}$ \\
\hline $\begin{array}{l}\text { TNF } \\
\text { rs1800629* } \\
\text { Near gene 5, } \\
\text { TFBS } \\
\end{array}$ & $\mathrm{G}>\mathrm{A}$ & $\mathrm{A}=13.7$ & $\begin{array}{l}46(74.2) \\
15(24.2) \\
1(1.60)\end{array}$ & $\mathrm{G}>\mathrm{A}$ & $\mathrm{A}=16.9$ & $\begin{array}{l}368(68.8) \\
153(28.6) \\
14(2.60)\end{array}$ & 0.752 \\
\hline $\begin{array}{l}\text { IL10 } \\
\text { rs1800871* } \\
\text { Near gene } \\
\text { 5’TFBS } \\
\end{array}$ & $\mathrm{C}>\mathrm{T}$ & $\mathrm{T}=36.3$ & $\begin{array}{l}28(45.2) \\
23(37.1) \\
11(17.7)\end{array}$ & $\mathrm{G}>\mathrm{A}^{\dagger}$ & $\mathrm{A}=40.7$ & $\begin{array}{l}188(35.0) \\
258(48.0) \\
89(17.0)\end{array}$ & 0.219 \\
\hline $\begin{array}{l}\text { IL10 } \\
\text { rs1800872** } \\
\text { Near gene 5, } \\
\text { TFBS }\end{array}$ & $\mathrm{C}>\mathrm{A}$ & $\mathrm{A}=38.8$ & $\begin{array}{l}19(38.8) \\
22(44.9) \\
8(16.3)\end{array}$ & $\mathrm{C}>\mathrm{A}$ & $A=40.7$ & $\begin{array}{l}188(35.0) \\
258(48.0) \\
89(17.0)\end{array}$ & 0.874 \\
\hline $\begin{array}{l}\text { IL10 } \\
\text { rs1800893* } \\
\text { Near gene } 5 \\
\text { TFBS } \\
\end{array}$ & $\mathrm{G}>\mathrm{A}$ & $A=37.1$ & $\begin{array}{l}22(35.5) \\
34(54.8) \\
6(9.70)\end{array}$ & $\mathrm{G}>\mathrm{A}$ & $A=36.4$ & $\begin{array}{l}216(40.4) \\
248(46.4) \\
71(13.2)\end{array}$ & 0.419 \\
\hline $\begin{array}{l}\text { IL10 } \\
\text { rs1800896* } \\
\text { Near gene 5, } \\
\text { TFBS } \\
\end{array}$ & $A>G$ & $\mathrm{G}=40.5$ & $\begin{array}{l}7(33.3) \\
11(52.4) \\
3(14.3)\end{array}$ & $A>G$ & $\mathrm{G}=33.3$ & $\begin{array}{l}243(45.4) \\
228(42.6) \\
64(12.0)\end{array}$ & 0.491 \\
\hline $\begin{array}{l}\text { IL1R1 } \\
\text { rs2192752* } \\
\text { Near gene 5, } \\
\text { TFBS } \\
\end{array}$ & $\mathrm{A}>\mathrm{C}$ & $\mathrm{C}=4.80$ & $\begin{array}{l}56(90.3) \\
6(9.70) \\
0(0.00)\end{array}$ & $A>C$ & $\mathrm{C}=5.60$ & $\begin{array}{l}477(89.1) \\
56(10.5) \\
2(0.40)\end{array}$ & 1.000 \\
\hline $\begin{array}{l}\text { IL8 } \\
\text { rs2227532* } \\
\text { Near gene 5' } \\
\text { TFBS }\end{array}$ & $\mathrm{T}>\mathrm{C}$ & $\mathrm{C}=9.70$ & $\begin{array}{l}50(80.6) \\
12(19.4) \\
0(0.00)\end{array}$ & $\mathrm{A}>\mathrm{G}^{\dagger}$ & $\mathrm{G}=8.60$ & $\begin{array}{l}448(83.7) \\
82(15.3) \\
5(1.00)\end{array}$ & 0.690 \\
\hline $\begin{array}{l}\text { IL8 } \\
\text { rs2227538* } \\
\text { 5'UTR } \\
\text { TFBS, Splicing } \\
\text { (ESE or ESS) }\end{array}$ & $\mathrm{C}>\mathrm{T}$ & $\mathrm{T}=17.7$ & $\begin{array}{l}41(66.1) \\
20(32.3) \\
1(1.60)\end{array}$ & $\mathrm{G}>\mathrm{A}^{\dagger}$ & $\mathrm{A}=23.2$ & $\begin{array}{l}323(60.4) \\
176(32.9) \\
36(6.70)\end{array}$ & 0.291 \\
\hline
\end{tabular}




\begin{tabular}{|c|c|c|c|c|c|c|c|}
\hline $\begin{array}{l}\text { Gene } \\
\text { dbSNPID } \\
\text { Location } \\
\text { Functional } \\
\text { Consequence }\end{array}$ & $\begin{array}{l}\text { NCBI } \\
\text { Nucleotide } \\
\text { Change } \\
\text { (Major> } \\
\text { Minor } \\
\text { allele) }\end{array}$ & $\begin{array}{l}\text { NCBI } \\
\text { AA } \\
\text { MAF } \\
(\%)\end{array}$ & $\begin{array}{l}\text { NCBI } \\
\text { AA } \\
\text { Major/Major, } \\
\text { Major/Minor, } \\
\text { Minor/Minor } \\
\text { Genotypes n(\%) }\end{array}$ & $\begin{array}{l}\text { Current } \\
\text { Study } \\
\text { Nucleotide } \\
\text { Change } \\
\text { (Major> } \\
\text { Minor allele) }\end{array}$ & $\begin{array}{l}\text { Current Study } \\
\text { AA } \\
\text { MAF (\%) }\end{array}$ & $\begin{array}{l}\text { Current Study } \\
\text { AA } \\
\text { Major/Major, } \\
\text { Major/Minor, } \\
\text { Minor/Minor } \\
\text { Genotypes n (\%) }\end{array}$ & $\begin{array}{l}\text { Overall } \\
\chi^{2} \text { p-value } \\
\text { NCBI AA vs } \\
\text { Current Study } \\
\text { AA }^{\dagger \dagger}\end{array}$ \\
\hline $\begin{array}{l}\text { IL8 } \\
\text { rs2227545* } \\
\text { 3'UTR } \\
\text { miRNA }\end{array}$ & $\mathrm{A}>\mathrm{C}$ & $\mathrm{C}=8.70$ & $\begin{array}{l}19(82.6) \\
4(17.4) \\
0(0.00)\end{array}$ & $\mathrm{A}>\mathrm{C}$ & $\mathrm{C}=8.50$ & $\begin{array}{l}449(83.9) \\
81(15.1) \\
5(1.00)\end{array}$ & 0.812 \\
\hline $\begin{array}{l}\text { IL10RA } \\
\text { rs2229113* } \\
\text { Exon } 7 \\
\text { nsSNP, probably } \\
\text { damaging }\end{array}$ & $G>A$ & $\mathrm{~A}=20.5$ & $\begin{array}{l}14(63.7) \\
7(31.8) \\
1(4.50)\end{array}$ & $\mathrm{G}>\mathrm{A}$ & $\mathrm{A}=18.8$ & $\begin{array}{l}355(66.4) \\
159(29.7) \\
21(3.90)\end{array}$ & 0.782 \\
\hline $\begin{array}{l}\text { IL10RB } \\
\text { rs2834167* } \\
\text { Exon } 2 \\
\text { Splicing (ESE or } \\
\text { ESS), nsSNP, } \\
\text { benign }\end{array}$ & $A>G$ & $\mathrm{G}=16.9$ & $\begin{array}{l}44(71.0) \\
15(24.2) \\
3(4.80)\end{array}$ & $A>G$ & $\mathrm{G}=11.0$ & $\begin{array}{l}423(79.1) \\
106(19.8) \\
6(1.10)\end{array}$ & 0.050 \\
\hline $\begin{array}{l}\text { IL1A } \\
\text { rs2856836* } \\
\text { 3'UTR } \\
\text { miRNA }\end{array}$ & $\mathrm{T}>\mathrm{C}$ & $\mathrm{C}=17.4$ & $\begin{array}{l}16(69.6) \\
6(26.1) \\
1(4.30)\end{array}$ & $\mathrm{A}>\mathrm{G}^{\dagger}$ & $\mathrm{G}=18.6$ & $\begin{array}{l}358(66.9) \\
155(29.0) \\
22(4.10)\end{array}$ & 1.000 \\
\hline $\begin{array}{l}\text { IL10RA } \\
\text { rs3135932* } \\
\text { Exon 5 } \\
\text { Splicing (ESE or } \\
\text { ESS), nsSNP, } \\
\text { benign }\end{array}$ & $A>G$ & $\mathrm{G}=2.10$ & $\begin{array}{l}23(95.8) \\
1(4.20) \\
0(0.00)\end{array}$ & $A>G$ & $\mathrm{G}=2.60$ & $\begin{array}{l}508(95.0) \\
26(4.80) \\
1(0.20)\end{array}$ & 1.000 \\
\hline $\begin{array}{l}\text { IL1RN } \\
\text { rs315951* } \\
\text { 3'UTR } \\
\text { miRNA }\end{array}$ & $C>G$ & $\mathrm{G}=47.9$ & $\begin{array}{l}8(33.3) \\
9(37.5) \\
7(29.2)\end{array}$ & $\mathrm{C}>\mathrm{G}$ & $\mathrm{C}=48.0$ & $\begin{array}{l}119(26.9) \\
268(50.1) \\
123(23.0)\end{array}$ & 0.482 \\
\hline $\begin{array}{l}\text { RNASEL } \\
\text { rs3738579* } \\
\text { 5'UTR } \\
\text { TFBS, Splicing } \\
\text { (ESE or ESS) }\end{array}$ & $\mathrm{T}>\mathrm{C}$ & $\mathrm{C}=16.7$ & $\begin{array}{l}14(66.7) \\
7(33.3) \\
0(0.00)\end{array}$ & $\mathrm{A}>\mathrm{G}^{\dagger}$ & $\mathrm{G}=12.3$ & $\begin{array}{l}411(76.8) \\
116(21.7) \\
8(1.50)\end{array}$ & 0.474 \\
\hline
\end{tabular}




\begin{tabular}{|c|c|c|c|c|c|c|c|}
\hline $\begin{array}{l}\text { Gene } \\
\text { dbSNPID } \\
\text { Location } \\
\text { Functional } \\
\text { Consequence }\end{array}$ & $\begin{array}{l}\text { NCBI } \\
\text { Nucleotide } \\
\text { Change } \\
\text { (Major> } \\
\text { Minor } \\
\text { allele) }\end{array}$ & $\begin{array}{l}\text { NCBI } \\
\text { AA } \\
\text { MAF } \\
(\%)\end{array}$ & $\begin{array}{l}\text { NCBI } \\
\text { AA } \\
\text { Major/Major, } \\
\text { Major/Minor, } \\
\text { Minor/Minor } \\
\text { Genotypes n(\%) }\end{array}$ & $\begin{array}{l}\text { Current } \\
\text { Study } \\
\text { Nucleotide } \\
\text { Change } \\
\text { (Major> } \\
\text { Minor allele) }\end{array}$ & $\begin{array}{l}\text { Current Study } \\
\text { AA } \\
\text { MAF (\%) }\end{array}$ & $\begin{array}{l}\text { Current Study } \\
\text { AA } \\
\text { Major/Major, } \\
\text { Major/Minor, } \\
\text { Minor/Minor } \\
\text { Genotypes n (\%) }\end{array}$ & $\begin{array}{l}\text { Overall } \\
\chi^{2} \text { p-value } \\
\text { NCBI AA vs } \\
\text { Current Study } \\
\text { AA } A^{\dagger \dagger}\end{array}$ \\
\hline $\begin{array}{l}\text { IL1R1 } \\
\text { rs3917225* } \\
\text { Near gene 5' } \\
\text { TFBS }\end{array}$ & $\mathrm{A}>\mathrm{G}$ & $\mathrm{G}=12.3$ & $\begin{array}{l}49(80.3) \\
9(14.8) \\
3(4.90)\end{array}$ & $A>G$ & $\mathrm{G}=9.10$ & $\begin{array}{l}438(81.9) \\
97(18.1) \\
0(0.00)\end{array}$ & 0.001 \\
\hline $\begin{array}{l}\text { IL8 } \\
\text { rs4073* } \\
\text { Near gene 5' } \\
\text { TFBS }\end{array}$ & $\mathrm{A}>\mathrm{T}$ & $\mathrm{T}=26.6$ & $\begin{array}{l}34(54.8) \\
23(37.1) \\
5(8.10)\end{array}$ & $\mathrm{T}>\mathrm{A}$ & $A=20.9$ & $\begin{array}{l}335(62.6) \\
176(32.9) \\
24(4.50)\end{array}$ & 0.262 \\
\hline $\begin{array}{l}\text { IL1R2 } \\
\text { rs4141134** } \\
\text { Near gene 5' } \\
\text { TFBS }\end{array}$ & $\mathrm{T}>\mathrm{C}$ & $\mathrm{C}=11.2$ & $\begin{array}{l}39(79.6) \\
9(18.4) \\
1(2.00)\end{array}$ & $\mathrm{A}>\mathrm{G}^{\dagger}$ & $\mathrm{G}=13.7$ & $\begin{array}{l}399(74.6) \\
125(23.4) \\
11(2.00)\end{array}$ & 0.660 \\
\hline $\begin{array}{l}\text { IL1RN } \\
\text { rs4251961* } \\
\text { Near gene 5' } \\
\text { TFBS }\end{array}$ & $\mathrm{T}>\mathrm{C}$ & $C=20.2$ & $\begin{array}{l}37(59.7) \\
25(40.3) \\
0(0.00)\end{array}$ & $\mathrm{A}>\mathrm{G}^{\dagger}$ & $\mathrm{G}=17.9$ & $\begin{array}{l}367(68.6) \\
145(27.1) \\
23(4.30)\end{array}$ & 0.035 \\
\hline $\begin{array}{l}\text { IL10RA } \\
\text { rs4252243* } \\
\text { Near gene } 5^{\prime} \\
\text { TFBS }\end{array}$ & $\mathrm{C}>\mathrm{T}$ & $\mathrm{T}=32.5$ & $\begin{array}{l}9(45.0) \\
9(45.0) \\
2(10.0)\end{array}$ & $G>A^{\dagger}$ & $A=27.5$ & $\begin{array}{l}271(50.7) \\
234(43.7) \\
30(5.60)\end{array}$ & 0.522 \\
\hline $\begin{array}{l}\text { IL8RB } \\
\text { rs4674257** } \\
\text { Near gene } 5 ' \\
\text { TFBS }\end{array}$ & $\mathrm{G}>\mathrm{A}$ & $A=25.0$ & $\begin{array}{l}14(58.3) \\
8(33.3) \\
2(8.30)\end{array}$ & $\mathrm{G}>\mathrm{A}$ & $A=20.1$ & $\begin{array}{l}347(64.9) \\
161(30.10) \\
27(5.00)\end{array}$ & 0.468 \\
\hline $\begin{array}{l}\text { IL8RB } \\
\text { rs4674259* } \\
\text { 5'UTR } \\
\text { TFBS }\end{array}$ & $A>G$ & $\mathrm{G}=23.9$ & $\begin{array}{l}12(52.2) \\
11(47.8) \\
0(0.00)\end{array}$ & $A>G$ & $\mathrm{G}=20.0$ & $\begin{array}{l}349(65.0) \\
158(30.0) \\
28(5.00)\end{array}$ & 0.176 \\
\hline $\begin{array}{l}\text { RNASEL } \\
\text { rs486907* } \\
\text { Exon 1 } \\
\text { nsSNP, benign }\end{array}$ & $\mathrm{G}>\mathrm{A}$ & $A=16.7$ & $\begin{array}{l}16(66.7) \\
8(33.3) \\
0(0.00)\end{array}$ & $\mathrm{G}>\mathrm{A}$ & $A=13.2$ & $\begin{array}{l}402(75.1) \\
125(23.4) \\
8(1.50)\end{array}$ & 0.528 \\
\hline
\end{tabular}




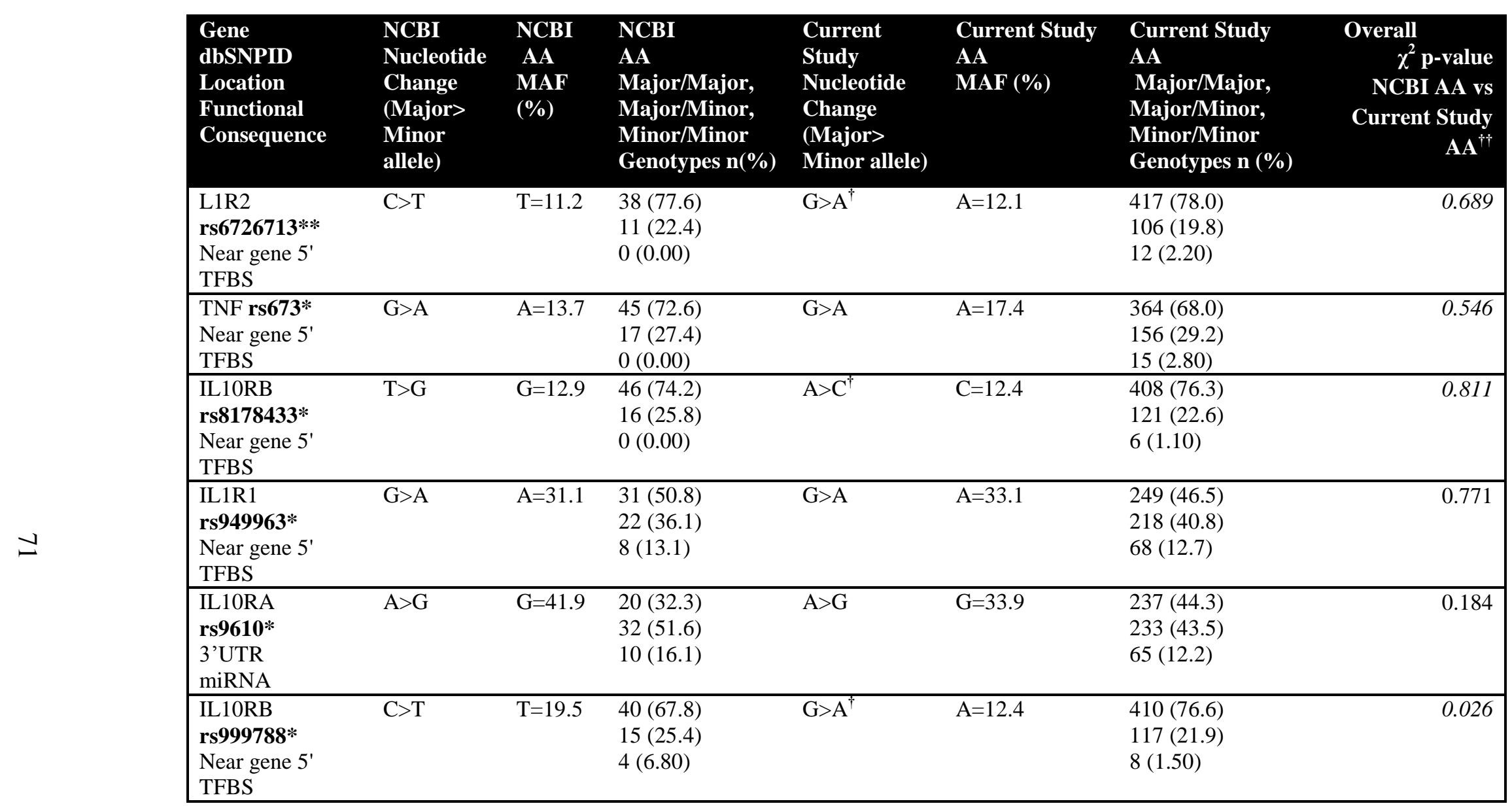

${ }^{\dagger}$ The nucleotide change may vary relative to that reported in NCBI depending on whether the genotyping was performed using the sense or antisense DNA strand.

${ }^{\dagger}$ The chi-square test was used to assess differences in the overall genotype frequencies comparing men of African descent as reported in NCBI to those in the total population from the current study. P-values generated from the Fisher's exact test (in italics) were used when expected genotype counts were $<5$ for either cases or controls. Abbreviations: UTR, untranslated region; TFBS, transcription factor binding site; nsSNP, non-synonymous coding SNP; miRNA, microRNA binding site;; MAF, Minor Allele Frequency NCBI, National Center for Biotechnology Information Entrez SNP

*NCBI AFR1 or African American Population Panel

**NCBI ASW Population Panel 


\section{Ancestry markers}

Cases and controls were genotyped with a set of 100 genome-wide ancestry informative markers to correct for potential population stratification among our admixed population of self-reported African-Americans, West African-Americans, East AfricanAmericans, Afro-Caribbean-Americans, as previously described [162, 163]. Individual genetic ancestry was determined using 100 ancestry identification markers (AIMs) for West African and European genetic ancestry as well as genotype data using the Bayesian Markov Chain-Monte Carlo method implemented in the STRUCTURE 2.1 program [162, 164]. Study participants were grouped from lowest to highest genetic West African Ancestry, with scores ranging from 0-100\%. These 100 markers were assembled using DNA from self-identified African-Americans (Coriell Institute for Medical Research, $\mathrm{n}=$ 96), Yoruban West Africans (HapMap, $\mathrm{n}=60$ ), West Africans (Bantu and Nilo Saharan speakers, $n=72$ ), Europeans (New York City, $n=24)$, and CEPH Europeans (HapMap Panel, $n=60$ ), as previously reported [163]. Individuals with a West African ancestry (WAA) score $\geq 25 \%$ and available inflammatory and immune response associated sequence variants were included in the final analysis.

\section{Statistical Analysis for Single Gene Effects}

Logistic regression (LR) modeling analyses were used to evaluate the relationship between 119 inflammatory and immune response SNPs among men of African descent and PCA risk. For each SNP, we examined the frequency differences in the distribution of homozygous major, heterozygous, or homozygous minor genotypes between cases and controls using the chi-square $\left(\chi^{2}\right)$ test of homogeneity. Odds ratios (OR) and corresponding 95\% confidence intervals (CI) for PCA risk in association with 
inflammatory and immune response-related SNPs were estimated using unconditional multivariate after adjusting for potential confounders (e.g., age, PSA, WAA). Confounders were kept in the LR model if they significantly changed the risk estimates by $\pm 20 \%$ compared to the unadjusted model. LR analyses for genetic variants and PCA risk were conducted using the major or common genotype as the referent category. Chisquare test and LR analyses were performed using SAS 9.3 (SAS Institute Inc., Cary, NC) and SVS software 7.0 (Golden Helix, Inc., Bozeman, MT). Adjustment for multiple hypothesis testing was achieved using false discovery rate (FDR) or Bonferroni Correction with a significance level of 0.05 and 0.001 , respectively.

\section{Statistical Power for Single Gene Effects}

We calculated the odds of developing PCA among carriers of at least one or more minor allele among 119 inflammatory and immune response-associated sequence variants based on the average MAF 22-27\%, a PCA disease prevalence of $0.740 \%$, a significance level $(\alpha)$ of $5 \%$, and $100 \%$ linkage disequilibrium (LD) between the casual and predisposing variant. We assumed the causal SNP was in complete linkage disequilibrium with the predisposing variant $\left(r^{2}=1.0\right)$ and a co-dominant genetic model with 1 degree of freedom (df). According to our sample size for the combined population (279 cases, 535 controls), U.S. (170 cases, 433 controls) and Jamaican men (109 cases, 102 controls), we had $>80 \%$ power to detect odds ratios (ORs) of $\geq 1.4, \geq 1.6, \geq 1.9$ for TLRs, $\geq 1.5, \geq 1.55, \geq 2.0$ for chemokines and $\geq 1.4, \geq 1.6, \geq 1.8$ for cytokines in relation to PCA risk, respectively. Statistical power calculations were performed using Power for Genetic Association Version 2 Software, as described previously [165]. 


\section{Analysis of Gene-Gene Interactions Using Multi-factor Dimensionality Reduction}

To evaluate the single- and joint- modifying effects of 119 candidate inflammatory and immune response sequence variants within a large dataset is computationally challenging. In order to overcome this problem, open source and freely available Multi-factor Dimensionality Reduction (MDR) 2.0 was used to detect and characterize all possible one-, two-, and three-way interaction models in relation to PCA (http://www.epistasis.org/) [166]. To reduce computation time needed to process thousands of SNP combinations in relation to PCA risk, we distributed MDR on a workstation with 12 hyper-threaded cores across two central processing units (total of 24 simultaneous threads of execution) and 24 GB of RAM. Although MDR has been described elsewhere, for convenience we provide a brief summary. With MDR, genetic information is reduced to a one-dimensional multi-locus genotype variable shown in Figure 5 [167, 168]. Information from various disease loci were grouped and labeled as "high risk" or "low risk" based on whether or not the control ratio met or exceeded a particular threshold. Subsequently, the resulting one-dimensional multi-locus genotype variable was examined for its capacity to categorize and predict disease outcome through cross-validation and permutation testing procedures. A 10-fold cross-validation was achieved by dividing the entire dataset into a training set and an independent testing set. The training set involved $9 / 10^{\text {ths }}$ of the data; the remaining $1 / 10^{\text {th }}$, known as the independent testing set, was evaluated against the training set. Evaluation of each independent testing set predicted average testing accuracy values for each MDR model. The greatest cross validation consistency (i.e., $\mathrm{CVC} \geq 8 / 10$ ) and highest prediction accuracy score [i.e., Average Testing Accuracy (ATA)] were selected as the best 
predictors of disease outcome. Sensitivity and specificity were determined as functions of true negatives (TN), false positives (FP), and false negatives (FN). Sensitivity, specificity and balanced accuracy values were calculated as follows: sensitivity $=(\mathrm{TP}) /(\mathrm{TP}+\mathrm{FN})$; specificity $=(\mathrm{TN}) /(\mathrm{FP}+\mathrm{TN}) ;$ and balanced accuracy $=($ sensitivity + specificity $) / 2$. ATAs were averaged across all 10 pieces of the data, in order to provide an estimate of the predictive ability of the loci in relation to the outcome of interest. We used crossvalidation consistency (CVC) to determine the degree to which the same best MDR model was selected across the 10 divisions of the data. Models with a CVC of $\geq 8 / 10$ using a 10-fold cross-validation were considered more carefully. CVCs and ATAs were calculated across 1,000 random seeds to ensure reproducibility in model selection. If the MDR model met the CVC criteria, we selected models that had the highest ATAs. Multiple hypothesis testing was controlled by CVC in combination with permutation testing. Permutation testing results $\leq 0.05$, generated using random seed 500 , were considered statistically significant. Age-group covariate effects were removed by integrating over- and under-sampling methods. 


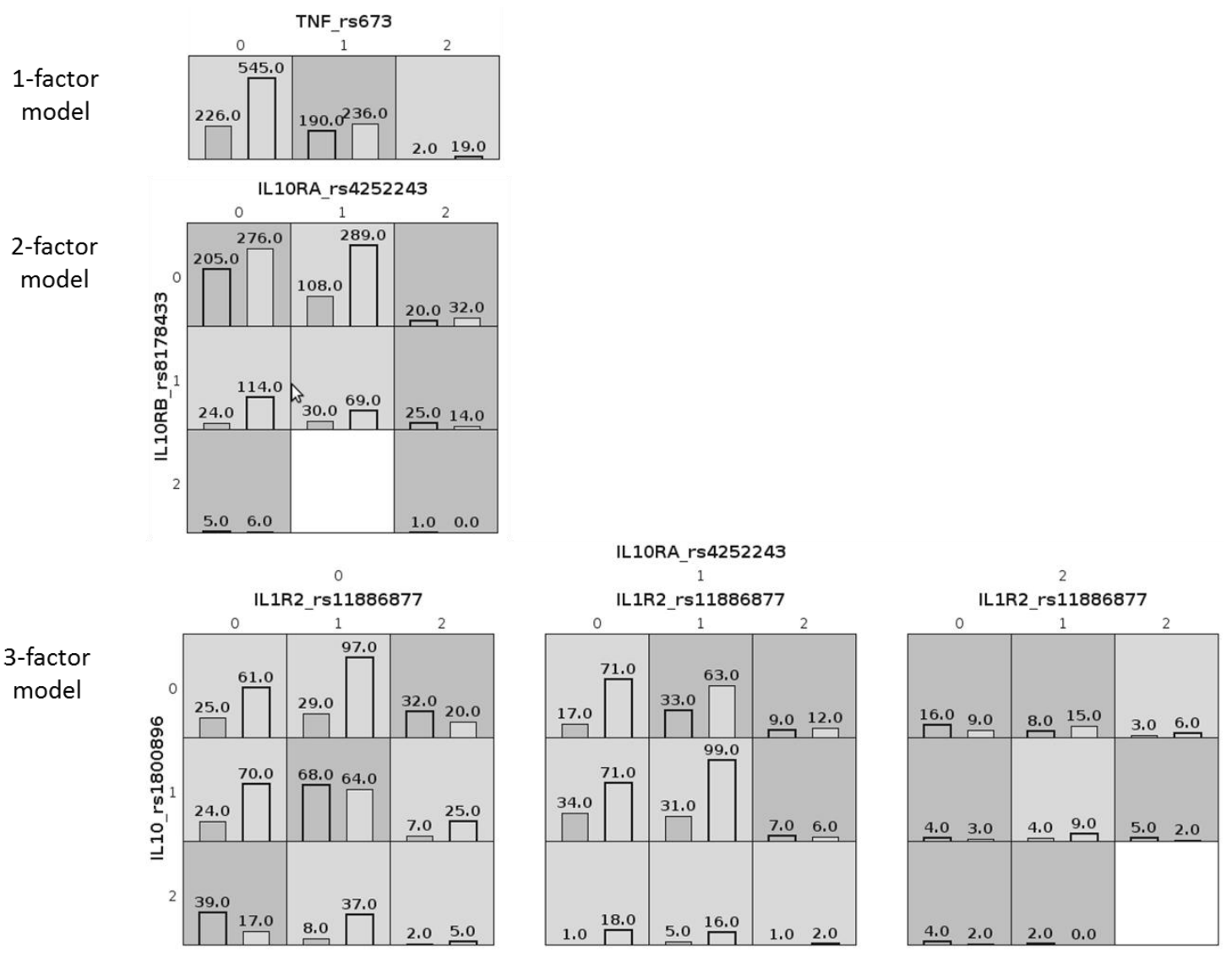

Figure 5. Graphical model of gene-gene interactions. MDR analysis reduces genetic data into a one-dimensional variable. The graphical model is an example of a 1-, 2- and 3-factor interaction graphical models using Random Seed 500. For each model, the major/major homozygous genotype (0), heterozygous genotype (1) and minor/minor homozygous genotypes (2) are shown. In each square, darker gray bars represent cases and lighter gray bars represent controls. 


\section{Visualization of Interaction Models Using Hierarchical Interaction Entropy Graphs}

Hierarchical interaction entropy graphs, based on information theory, were used to visualize and interpret complex interactions among selected SNPs and PCA risk [169172]. With this approach, individual and all possible pairwise loci are assigned a joint or mutual information percentage score based on disease risk, respectively. Joint mutual information and mutual information gain scores are based on a number system, ranging from $0-100 \%$. However, these scores rarely exceed 5-6\%. When the pairwise or joint mutual information exceeds the mutual information gain scores, then the pairwise interaction is considered more informative in relation to prostate cancer risk when compared to each locus considered separately. Potential interactions are assessed using interaction entropy graphs, which uses a color-coding system to depict redundant or synergistic interactions. Within the entropy graph, lines depicted between SNP pairs that are color-coded red, orange, green, blue, and gold represent highly synergistic, moderately synergistic, moderately redundant, highly redundant, and neither synergistic/redundant pairwise interaction models, respectively, as depicted in Figure 6. All entropy-based analyses were conducted using Orange software [173]. 


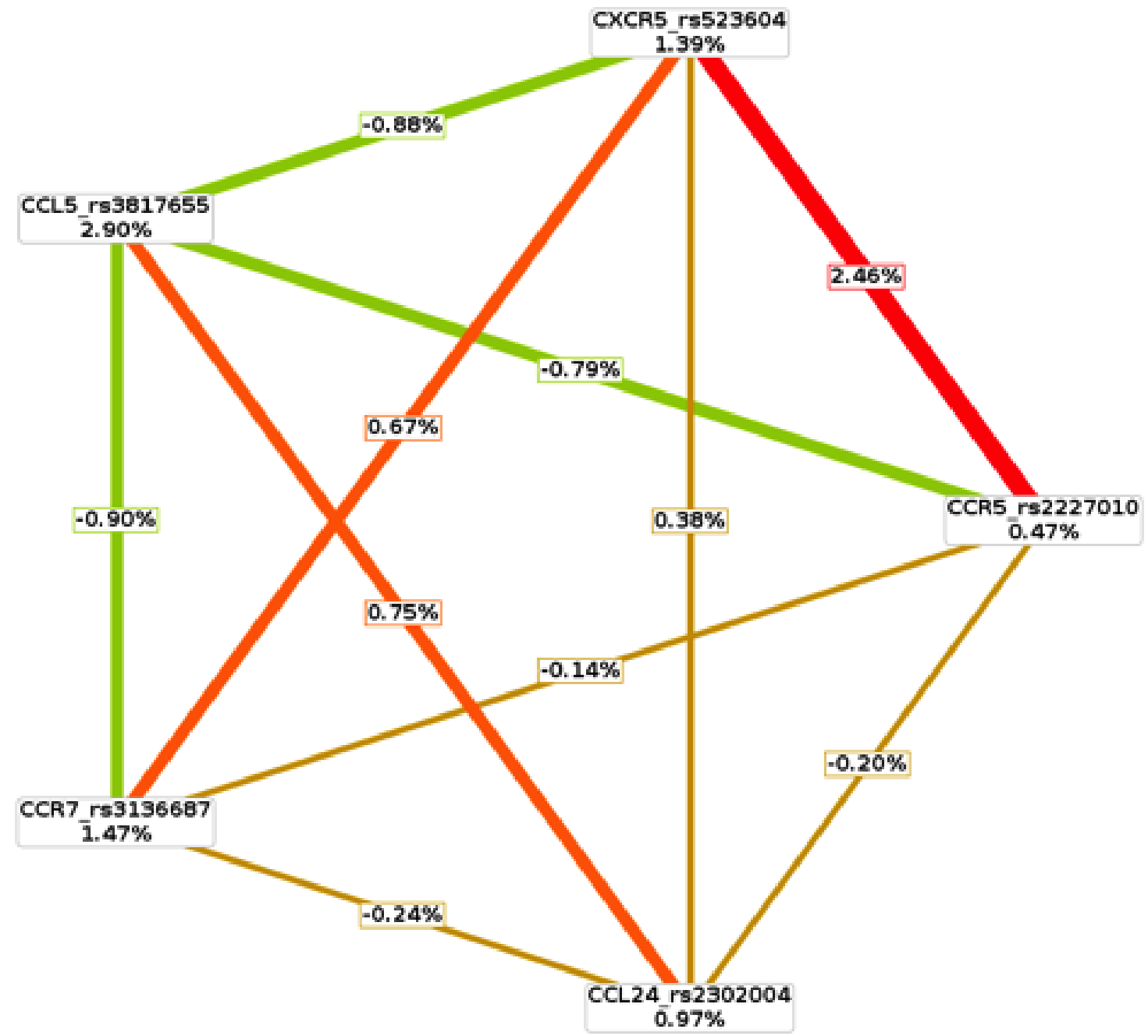

Figure 6. Entropy graph of gene-gene interactions. MDR analysis produce an entropy graph to demonstrate if a gene-gene interaction has a synergistic effect or not. The lines between SNPs display a pairwise mutual information gain score representative of the interaction and are color-coded in the following manner: red (highly synergistic), orange (moderately synergistic), green (moderately redundant), blue (highly redundant), and gold (neither synergistic/redundant). Each SNP displays the mutual information gain score underneath its name. 


\section{CHAPTER 3}

\section{TOLL-LIKE RECEPTOR-ASSOCIATED SEQUENCE VARIANTS AND PROSTATE CANCER RISK AMONG MEN OF AFRICAN DESCENT}

Among inflammatory and immune response regulators, toll-like receptors (TLRs) have a critical role in innate immune responses against chronic/recurrent inflammation, a major contributor to PCA development. However, it remains unclear whether sequence variants within TLR genes influence PCA risk among men of African descent. Therefore, we evaluated the impact of 32 TLR associated single-nucleotide polymorphisms (SNPs) on PCA risk among African Americans and Jamaicans. SNP profiles of 814 subjects were evaluated using Illumina's Veracode genotyping platform. Single and combined effects of SNPs in relation to PCA risk were assessed using age-adjusted logistic regression and entropy-based multifactor dimensionality reduction (MDR) models. Seven sequence variants detected in TLR6, TOLLIP (Toll-interacting protein), IRAK4 (interleukin-1 receptor-associated kinase 4) and IRF3 (interferon regulatory factor 3) were marginally associated with PCA [31]. However, none of these effects remained significant after adjusting for multiple hypothesis testing. Nevertheless, MDR modeling revealed a complex interaction between IRAK4 rs4251545 and TLR2 rs1898830 as a significant predictor of PCA risk among US men (Permutation testing p-value $=0.001$ ). However, these genetic susceptibilities detected within the $T L R$ signaling pathway require further assessment and validation to provide a better understanding of their influence on PCA risk among men of African descent. 


\section{Results}

\section{Population Description}

The demographic and other pertinent characteristics of cases and controls for the entire study population and each study center are summarized in Table 3-5. Overall, men diagnosed with prostate cancer were 14 years older and had higher PSA levels than controls $(\mathrm{P}<0.0001)$. Among controls, Jamaican men were about 9 years older and had higher PSA levels $(\mathrm{P}<0.0001)$ and as well as higher median Gleason scores $(\mathrm{P}=0.018)$ than U.S. men. As summarized in Table 3, there were no significant differences in family history of PCA with respect to the following: (1) cases to controls from the total population $(\mathrm{P}=0.316)$ (Table 3), U.S. alone $(\mathrm{P}=0.592)$ (Table 4), or Jamaica alone $(\mathrm{P}=$ 0.272) (Table 5), and (2) controls $(\mathrm{P}=0.757)$ or cases $(\mathrm{P}=0.830)$ comparing the two study centers (data not shown). Among African-Americans, the degree of West African ancestry did not vary by disease-status, as shown in Table 4 [162-164]; however, no such data was collected for the Jamaican men.

\section{Minor allele and genotype frequency among men of African descent from the U.S. and}

Jamaica

Overall, the average minor allele frequency (MAF) for $T L R$-associated SNPs among disease-free U.S. and Jamaican men combined was $23.3 \%$ [standard deviation $(\mathrm{SD})=15.8]$. When stratified by study site, the MAFs for U.S. and Jamaican men were $23.3 \%(\mathrm{SD}=16.1)$ and $21.9 \%(\mathrm{SD}=14.9)$, respectively. When the $T L R$-associated SNPs among the total population (i.e., U.S. and Jamaican men combined) were analyzed, $87.5 \%$ had minor allele frequencies $\geq 5 \%$. 


\section{Association between TLR-associated sequence variants and prostate cancer risk}

Three TLR-associated markers (TLR6 rs2381289, TOLLIP rs3168046, and TOLLIP rs5743899) were modestly linked with PCA susceptibility for the total population under the age-adjusted LR models, as shown in Table 9a. In particular, possession of the TLR6 rs2381289 GA or TOLLIP rs5743899 AG+GG genotypes was associated with a 1.46-1.49 fold increase in the risk of developing PCA. In contrast, TOLLIP rs3168046 AA carriers had a significant $42 \%$ reduction in PCA susceptibility $\left(\mathrm{OR}_{\text {age-adjusted }}=0.58 ; 95 \% \mathrm{CI}=0.35,0.98\right)$. However, none of these markers remained significant after adjusting for multiple hypothesis testing (FDR p-value > 0.05).

Upon stratification by study center, six of the 32 candidate $T L R$-associated SNPs were identified as modestly significant determinants of PCA risk after adjusting for age, as shown in Table 9b. Within the U.S. population, a nominal 40-66\% reduction in PCA susceptibility was observed among men who possessed one or more IRAK4 (rs4251545 A and $r s 4251473 \mathrm{~A}$ ) or TLR6 rs5743818 C minor alleles; however, the relationship was strongest for carriers of the IRAK4 rs 4251545 AA genotype $\left(\mathrm{OR}_{\text {age-adjusted }}=0.34 ; 95 \% \mathrm{CI}\right.$ $=0.13,0.91)$. Moreover, the TOLLIP rs5743899 locus, under the recessive genetic model (GG versus AG+AA), was modestly associated with a 1.14 fold increase in the risk of developing PCA $\left(\mathrm{OR}_{\text {age-adjusted }}=1.14 ; 95 \% \mathrm{CI}=1.12,1.18\right)$. Among Jamaican men, $I R F 3$ rs2304206, TLR6 rs2381289, and TLR6 rs5743818 were marginally associated with PCA risk. For instance, inheritance of the $I R F 3$ rs $2304206 \mathrm{GG}$ genotype $\left(\mathrm{OR}_{\text {age-adjusted }}=0.32\right.$; $95 \% \mathrm{CI}=0.10,0.98)$ was linked to a modestly significant $68 \%$ reduction in PCA susceptibility. On the other hand, there was a 1.10-2.0-fold increase in PCA risk associated with inheriting the $T L R 6 r s 2381289 \mathrm{GA}+\mathrm{AA}\left(\mathrm{OR}_{\text {age-adjusted }}=2.05 ; 95 \% \mathrm{CI}=\right.$ 
$1.10,3.78)$ or $T L R 6$ rs5743818 $A C+C C \mathrm{GA}\left(\mathrm{OR}_{\text {age-adjusted }}=1.10 ; 95 \% \mathrm{CI}=1.06,1.14\right)$ genotypes. Notably, additive genetic models for IRF3 rs2304206 and TLR6 rs2381289 were significantly related to prostate cancer risk, which was modestly suggestive of a significant dose-response effect in relation to the number of inherited minor alleles ( $\mathrm{P}$ trend $\geq 0.0193)$. According to the new significance level $(\alpha=0.0016)$, these modest associations did not persist after adjustments for multiple hypothesis testing among U.S. men and Jamaican men, respectively (Bonferroni Correction p-value $\geq 0.033$, p-value $\geq$ $0.014)$. 
Table 9a. Relationship between TLR-associated SNPS and prostate cancer risk among men of African descent.

\begin{tabular}{|c|c|c|c|c|c|c|c|c|}
\hline $\begin{array}{c}\text { Gene } \\
\text { (Allele, position, } \\
\text { function) }\end{array}$ & Genotype & $\begin{array}{l}\text { Cases } \\
\text { n }(\%)\end{array}$ & $\begin{array}{c}\text { Controls } \\
\mathbf{n}(\%)\end{array}$ & $\begin{array}{l}\text { Unadjusted } \\
\text { OR }(95 \% \text { CI })\end{array}$ & $\begin{array}{l}\text { Age Adjusted } \\
\text { OR }(95 \% \text { CI })\end{array}$ & $\begin{array}{c}\text { Chi-square }\left(\chi^{2}\right) \\
\text { p-value }\end{array}$ & p-trend & $\begin{array}{c}\text { FDR } \\
\text { p-value }\end{array}$ \\
\hline $\begin{array}{l}\text { TLR6 } \\
r s 2381289 \\
\text { 3'UTR }\end{array}$ & $\begin{array}{c}\mathrm{GG} \\
\mathrm{GA} \\
\mathrm{AA} \\
\mathrm{GA}+\mathrm{AA} \\
\mathrm{AA} \mathrm{vs}(\mathrm{GG}+\mathrm{AG})\end{array}$ & $\begin{array}{c}140(50.4) \\
124(44.6) \\
14(5.04) \\
138(49.64)\end{array}$ & $\begin{aligned} 302 & (56.7) \\
200 & (37.7) \\
30 & (5.63) \\
230 & (43.33)\end{aligned}$ & $\begin{array}{l}1.00 \text { (referent) } \\
1.33(0.98,1.80) \\
1.00(0.52,1.96) \\
1.28(0.96,1.72) \\
0.88(0.46,1.70)\end{array}$ & $\begin{array}{l}1.00 \text { (referent) } \\
\mathbf{1 . 4 6}(\mathbf{1 . 0 2}, \mathbf{2 . 0 9}) \\
1.20(0.52,2.76) \\
1.43(1.00,2.00) \\
1.02(0.46,2.29)\end{array}$ & $\begin{array}{l}0.164 \\
\mathbf{0 . 0 6 2} \\
0.984 \\
\mathbf{0 . 0 8 8} \\
0.724\end{array}$ & 0.198 & $\begin{array}{l}1.000 \\
0.853\end{array}$ \\
\hline $\begin{array}{l}\text { TOLLIP } \\
\text { rs3168046 } \\
\text { 3'UTR } \\
\text { miRNA }\end{array}$ & $\begin{array}{c}\text { GG } \\
\text { GA } \\
\text { AA } \\
\text { GA+AA } \\
\text { AA vs (GG+AG) }\end{array}$ & $\begin{array}{r}104(37.3) \\
131(46.9) \\
44(15.8) \\
175(62.7)\end{array}$ & $\begin{array}{l}189(35.4) \\
239(44.8) \\
106(19.9) \\
345(64.7)\end{array}$ & $\begin{array}{l}1.00 \text { (referent) } \\
1.00(0.72,1.40) \\
0.75(0.49,1.15) \\
0.92(0.68,1.24) \\
0.76(0.51,1.11)\end{array}$ & $\begin{array}{l}1.00 \text { (referent) } \\
0.85(0.58,1.25) \\
\mathbf{0 . 5 8}(\mathbf{0 . 3 5}, \mathbf{0 . 9 8}) \\
0.76(0.54,1.10) \\
0.64(0.40,1.02)\end{array}$ & $\begin{array}{l}0.363 \\
0.981 \\
0.194 \\
0.596 \\
0.155\end{array}$ & 0.261 & $\begin{array}{l}1.000 \\
1.000\end{array}$ \\
\hline $\begin{array}{l}\text { TOLLIP } \\
\text { rs5743899 } \\
\text { Intron } 1\end{array}$ & $\begin{array}{c}\text { AA } \\
\text { AG } \\
\text { GG } \\
\text { AG+GG } \\
\text { GG vs }(\mathrm{AA}+\mathrm{AG})\end{array}$ & $\begin{array}{r}85(30.8) \\
140(50.7) \\
51(18.5) \\
191(69.2)\end{array}$ & $\begin{array}{l}187(35.2) \\
235(44.2) \\
110(20.7) \\
345(64.9)\end{array}$ & $\begin{array}{l}1.00 \text { (referent) } \\
1.31(0.94,1.82) \\
1.02(0.67,1.55) \\
1.22(0.89,1.66) \\
0.87(0.60,1.26)\end{array}$ & $\begin{array}{l}1.00 \text { (referent) } \\
\mathbf{1 . 5 9}(\mathbf{1 . 0 6}, \mathbf{2 . 3 8}) \\
1.29(0.78,2.14) \\
\mathbf{1 . 4 9}(\mathbf{1 . 0 2}, \mathbf{2 . 1 8}) \\
0.98(0.64,1.53)\end{array}$ & $\begin{array}{l}0.208 \\
0.109 \\
0.926 \\
0.215 \\
0.458\end{array}$ & 0.686 & $\begin{array}{l}0.884 \\
0.756\end{array}$ \\
\hline
\end{tabular}

The chi-square $\left(\chi^{2}\right)$ test p-values were used to determine the difference in the genotype frequencies between cases and controls. *Fisher's p-values were calculated when expected genotype counts were $<5$ for either cases and controls. Significant odd ratios (ORs) and $95 \%$ confidence interval (CI) are indicated in boldface. Abbreviations: UTR, untranslated region; miRNA, microRNA binding site; FDR, false discovery rate. 
Table 9b. Relationship between TLR-associated SNPs and PCA risk stratified by racial/ethnic group.

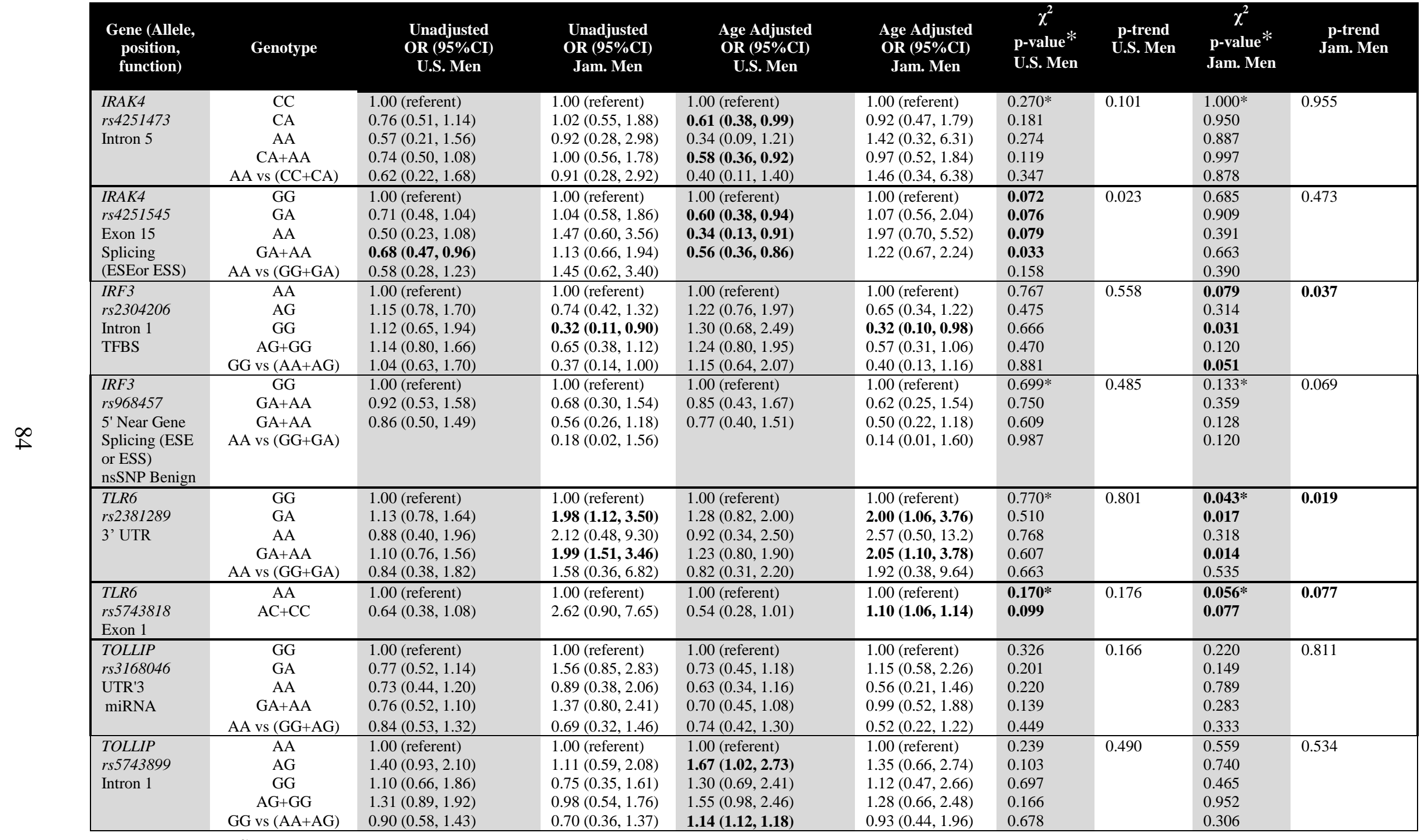

The chi-square ${ }^{\left({ }^{2}\right)}$ test p-values were used to determine the difference in the genotype frequencies between cases and controls. *Fisher's p-values were calculated when expected genotype counts were $<5$ for either cases and controls. Significant odd ratios (ORs) and $95 \%$ confidence interval (CI) are indicated in boldface. Abbreviations: UTR, untranslated region; TFBS, transcription factor binding site; ESE exonic splicing enhancer; ESS, exonic splicing silencers; miRNA, microRNA binding site; nsSNP, non-synonymous coding SNP; Jam, Jamaican. 


\section{Analysis of gene-gene interactions using Multi-factor Dimensionality Reduction}

MDR modeling was used to efficiently assess and validate age-adjusted genegene interactions in relation to PCA risk for the total population, U.S. men alone, and Jamaican men alone [31]. The top one-, two-, and three-way interaction models for the total population, involving U.S. and Jamaican men combined, displayed 100\% cross validation consistency (CVC) values, 57-65\% average testing accuracy (ATA) scores, and permutation $\mathrm{p}$-values $=0.001$ (Table 10a). However, the three-way interaction among TLR6 rs2381289, TLR10 rs11096957, and IRF3 rs2304206 was selected as the best PCA predictor for men of African descent, since this model had the highest average testing accuracy $(\mathrm{ATA}=0.6505)$. This three-way interaction was primarily driven by a highly synergistic relationship between TL10 rs11096957 and IRF3 rs2304206 due to its pairwise mutual information gain score $(\mathrm{IG}=1.32 \%)$, which was higher than the mutual IG scores for each variant (Figure 7).

CVC and ATA scores for all 1-, 2-, and 3-factor models among U.S. men were significant and characterized as $90-100 \%$ and $57-62 \%$, respectively, as described in Tables 10b. However, interaction between TLR2 rs 1898830 and IRAK4 rs4251545 was chosen as the best PCA predictor, based on a stronger CVC (100\%) value as well as ATA $(61.94 \%)$ score and lower permutation testing value (Permutation testing $\mathrm{p}$-value $=$ 0.001 ) relative to the best three-factor model (Permutation $\mathrm{p}$-value $=0.015$ ). Moreover, the two-way interaction was highly synergistic since the pairwise mutual information gain score $(2.33 \%)$ exceeded the mutual information gain scores for TLR2 rs 1898830 alone (0.04\%) and IRAK4 rs4251545 alone (1.30\%), as shown in Figure 8. 
For the Jamaican population, the one-way model containing the TLR6 rs 2381289 loci was the best PCA-related MDR model based on a $62.7 \%$ prediction accuracy score (Permutation testing $\mathrm{p}$-value $=0.018$ ). Although the three- factor model had high CVC scores $(\geq 80 \%)$, this model failed to reach statistical significance (Table 10c). 
Table 10a. Interactions and main effects of TLR-associated SNPs as predictors of PCA using age-adjusted MDR among U.S. and Jamaican men of African Descent.

\begin{tabular}{|c|c|c|c|c|}
\hline $\begin{array}{l}\text { Best Model } \\
\text { (dbSNPID\#) }\end{array}$ & Interactions & $\begin{array}{c}\text { Cross } \\
\text { Validation } \\
\text { Consistency } \\
\text { (CVC) }\end{array}$ & $\begin{array}{l}\text { Average } \\
\text { Testing } \\
\text { Accuracy } \\
\text { (ATA) }\end{array}$ & $\begin{array}{c}\text { Permutation } \\
\text { Testing } \\
p \text {-value }\end{array}$ \\
\hline$\frac{\text { One Factor }}{\text { TLR6 rs } 2381289}$ & 32 & $10 / 10$ & 0.572 & 0.001 \\
\hline $\begin{array}{l}\text { Two Factor } \\
\text { TLR10 rs } 11096957 \\
\text { TLR6 rs } 2381289\end{array}$ & 496 & $10 / 10$ & 0.611 & 0.001 \\
\hline $\begin{array}{l}\text { Three Factor } \\
\text { TLR10 rs11096957 } \\
\text { TLR6 rs } 2381289 \\
\text { IRF3 rs } 2304206\end{array}$ & 4960 & $10 / 10$ & 0.650 & 0.001 \\
\hline
\end{tabular}

*Analysis was restricted to 279 cases and 535 controls. Interaction models were adjusted for multiple hypothesis testing with 1,000 permutations. 


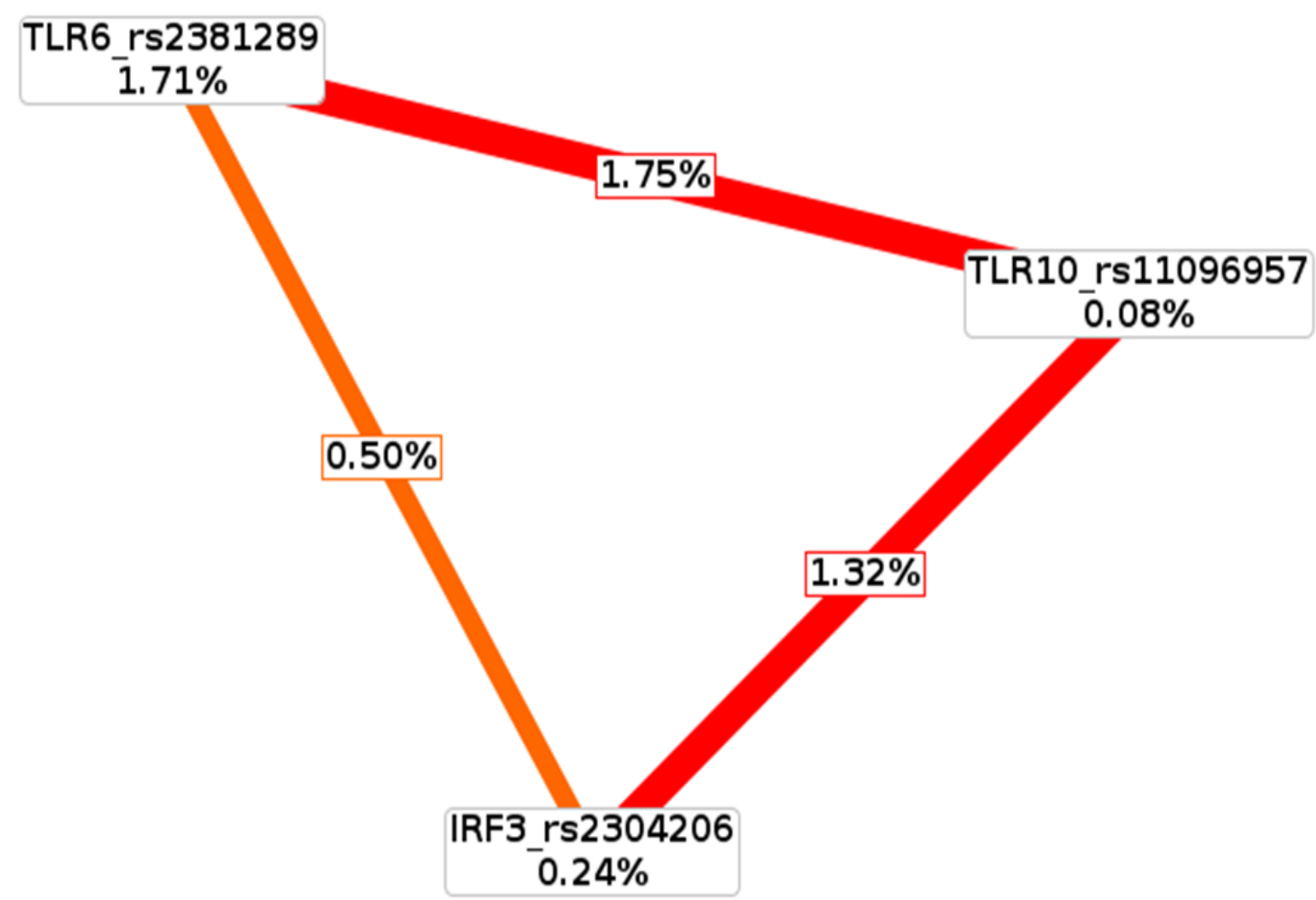

Figure 7. Entropy graph of TLR gene-gene interactions among U.S. and Jamaican men of African Descent. MDR analysis revealed a significant three-factor interaction (TLR10, TLR6 and IRF3) model with a pairwise mutual information gain score of $3.57 \%, 100 \% \mathrm{CVC}$ and $65 \%$ ATA values (Permutation $\mathrm{p}$-value $=0.001$ ). A highly synergistic relationship was observed for TLR6 rs2381289-TLR10 rs1109657 and TLR10 rs1109657IRF3 rs2304206 interactions represented by a red line. 
Table 10b. Interactions and main effects of TLR-associated SNPs as predictors of PCA using age-adjusted MDR among U.S. men of African Descent.

\begin{tabular}{|lcccc|}
\multicolumn{1}{c}{$\begin{array}{c}\text { Best } \\
\text { Model } \\
\text { (dbSNPID\#) }\end{array}$} & Interactions & $\begin{array}{c}\text { Cross } \\
\text { Validation } \\
\text { Consistency } \\
\text { (CVC) }\end{array}$ & $\begin{array}{c}\text { Average } \\
\text { Testing } \\
\text { Accuracy } \\
\text { (ATA) }\end{array}$ & $\begin{array}{c}\text { Permutation } \\
\text { Testing } \\
\text {-value }\end{array}$ \\
\hline $\begin{array}{l}\text { One Factor } \\
\text { IRAK4 rs4251473 }\end{array}$ & 32 & $10 / 10$ & 0.574 & 0.179 \\
\hline $\begin{array}{l}\text { Two Factor } \\
\text { TLR2 rs } 1898830\end{array}$ & 496 & $10 / 10$ & 0.619 & 0.001 \\
IRAK4 rs4251545 & & & & 0.015 \\
\hline $\begin{array}{l}\text { Three Factor } \\
\text { TLR6 rs3821985 }\end{array}$ & 4960 & $9 / 10$ & 0.618 & \\
\hline $\begin{array}{l}T L R 4 \text { rs } 1927906 \\
T L R 2 ~ r s 3804099\end{array}$ & & & & \\
\hline
\end{tabular}

*Analysis was restricted to 279 cases and 535 controls. Interaction models were adjusted for multiple hypothesis testing with 1,000 permutations. 


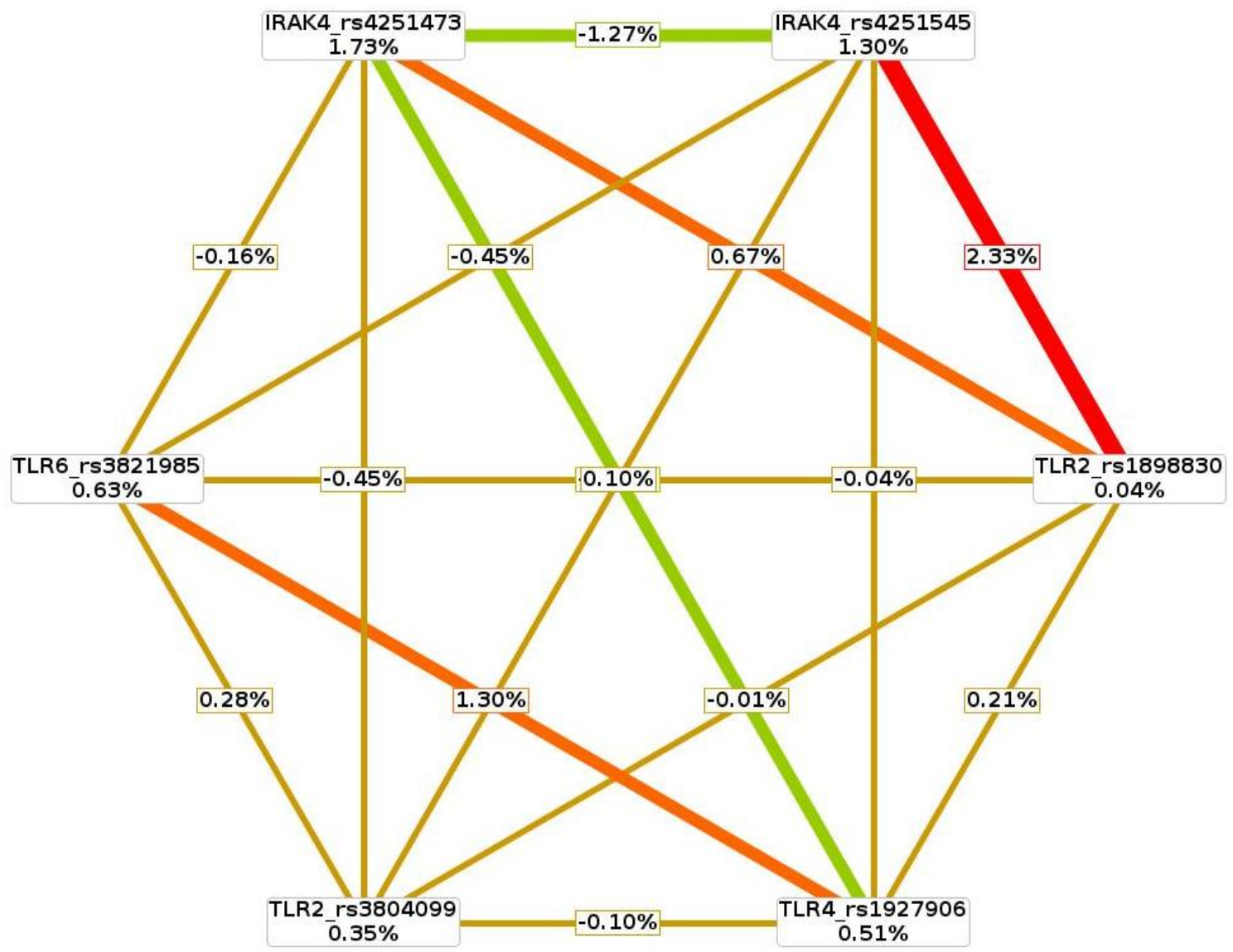

Figure 8. Entropy graph of TLR gene-gene interactions among U.S. men of African Descent. MDR analysis revealed a significant and highly synergistic (red line) two-factor interaction (TLR2 and IRAK4) model with a pairwise information gain score of $2.33 \%, 100 \% \mathrm{CVC}$ and $61.9 \%$ ATA values. The threefactor interaction between TLR6 rs3821985, TLR4 rs1927906 and TLR2

rs3804099 was shown as a good predictor of prostate cancer risk with a $90 \%$ and $61.8 \%$ ATA values $(\mathrm{p}=0.015)$. 
Table 10c. Interactions and main effects of TLR-associated SNPs as predictors of PCA using age-adjusted MDR among Jamaican men of African Descent.

\begin{tabular}{|c|c|c|c|c|}
\hline $\begin{array}{l}\text { Best Model } \\
\text { dbSNPID \# }\end{array}$ & Interactions & $\begin{array}{c}\text { Cross } \\
\text { Validation } \\
\text { Consistency } \\
\text { (CVC) }\end{array}$ & $\begin{array}{l}\text { Average } \\
\text { Testing } \\
\text { Accuracy } \\
\text { (ATA) }\end{array}$ & $\begin{array}{c}\text { Permutation } \\
\text { Testing } \\
p \text {-value }\end{array}$ \\
\hline$\frac{\text { One Factor }}{T L R 6 r s 2381289}$ & 32 & $10 / 10$ & 0.627 & 0.018 \\
\hline $\begin{array}{c}\frac{\text { Two Factor }}{\text { TLR6 rs } 2381289} \\
\text { TOLLIP rs3168046 }\end{array}$ & 496 & $7 / 10$ & 0.646 & 0.203 \\
\hline $\begin{array}{c}\text { Three Factor } \\
\text { TLR10 rs } 11096955 \\
\text { TLR4 rs } 1927911 \\
\text { TOLLIP rs } 5743899\end{array}$ & 4960 & $10 / 10$ & 0.639 & 0.174 \\
\hline
\end{tabular}

*Analysis was restricted to 279 cases and 535 controls. Interaction models were adjusted for multiple hypothesis testing with 1,000 permutations. 


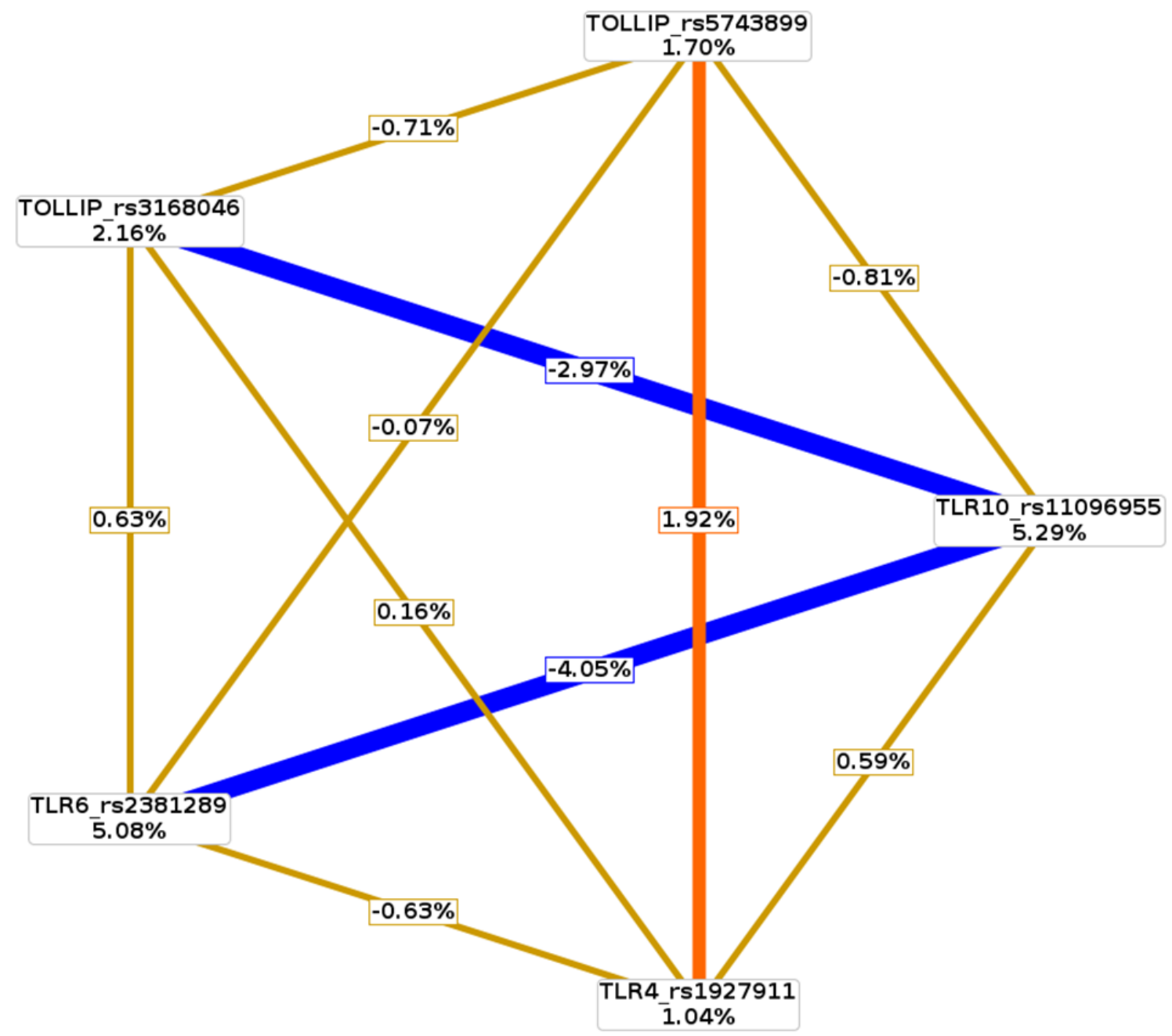

Figure 9. Entropy graph of TLR gene-gene interactions among Jamaican men of African Descent. MDR analysis revealed a significant one-factor (TLR6) model with a mutual information gain score of $5.08 \%, 100 \%$ CVC and $62.7 \%$ ATA values. However, two- and three- factor interaction models did not survive multiple hypothesis testing. 


\section{Discussion}

Dysregulation and genetic alterations in immune system function are linked to many cancers. In particular, it is estimated that approximately $20 \%$ of all human cancers, including prostate cancer (PCA), are associated with chronic inflammation $[174,175]$. TLR activation, a key initiator of inflammation and dysregulation of TLR-responsive pathways, has been associated with cancer susceptibility. Consequently, we evaluated 32 $T L R$-associated sequence variants to determine their individual and joint modifying effects on PCA risk among 279 cases and 535 disease free men of African descent [31]. We evaluated the impact of select polymorphic TLR-related genes (i.e., TLR1, TLR 2, TLR 4,TLR 6,TLR10, IRAK4, IRF3, and TOLLIP) on PCA susceptibility among men of African descent. Out of the 32 minor variant alleles, 3 loci (TLR6 rs2381289, TLR6 rs5743818, TOLLIP rs5743899) displayed a 1.14-2.05 fold increase in PCA risk after adjusting for age; whereas, 4 markers (TOLLIP rs3168046, IRAK4 rs4251473, IRAK4 $r s 4251545, I R F 3$ rs2304206) were linked to a 39-68\% reduction in PCA risk. Among U.S. men, there was a nominal 40-66\% reduction in PCA susceptibility among those who possessed one or more IRAK4 (rs4251545 A, rs4251473 A) or TLR6 rs5743818 C minor alleles. Similar to the total population, the TOLLIP rs5743899 SNP under the recessive genetic model (GG versus AG+AA) was modestly associated with a 1.14 fold increase in the risk of developing PCA $\left(\mathrm{OR}_{\text {age-adjusted }}=1.14 ; 95 \% \mathrm{CI}=1.12,1.18\right)$ among men of African descent from the U.S. The TOLLIP rs3168046 GA was unique to the total population; whereas, 3 markers [IRAK4 rs4251473 (CA, CA+AA), IRAK4 rs4251545 (GA, AA GA+AA), TLR6 rs2381289 (GA, GA+AA)] were unique to the U.S. men. Among Jamaicans, both the IRF3 rs2304206 and TLR6 rs2381289 loci were significant 
under the additive genetic model. IRF3 rs2304206 GG genotype was linked to a $68 \%$ reduction $(\mathrm{OR}$ age-adjusted $=0.32 ; 95 \% \mathrm{CI}=0.10,0.98)$ in PCA risk among Jamaican men (Table 9b). In addition, inheritance of TLR6 rs2381289 GA and GA+AA genotypes were associated to a 2 -fold increase in PCA susceptibility among Jamaican men $\left(\chi^{2}\right.$ p-value $=$ 0.014-0.017). However, TLR6 (rs2381289, rs5743818), IRAK4 rs4251473, TOLLIP (rs3168046, rs5743899), and IRF3 (rs2304206, rs968457) have never been studied in relation to cancer in the literature. Nonetheless, selected TLR-related sequence variants in the current study did not survive multiple hypothesis testing according to the new significance level $(\alpha=0.0016)$ (Bonferroni Correction $p$-value $>0.0016)$.

Collectively, 10 studies evaluated 14 out of the 32 SNPs examined in our study [97-99, 103-109]. In the Cancer of the Prostate Study (CAPS), inheritance of one or more $T L R 1$ rs4833095 (OR = 1.28; $95 \% \mathrm{CI}=1.12-1.44)$ and $T L R 10$ rs11096955 (OR = 1.16; 95\% CI = 1.02-1.30), TLR10 rs $11096957(\mathrm{OR}=1.16 ; 95 \% \mathrm{CI}=1.02-1.30)$ minor alleles were associated with an increase in prostate cancer risk among European Americans [99, 105]. However, the American Cancer Society Cancer Prevention II Nutrition Cohort (CPS-II) study reported protective effects for TLR1 rs4833095 CC (OR $=0.64 ; 95 \% \mathrm{CI}=0.47-0.86), T L R 10 \operatorname{rs} 11096955 \mathrm{CC}(\mathrm{OR}=0.78 ; 95 \% \mathrm{CI}=0.61-0.99)$ and TLR10 rs $11096957 \mathrm{CC}(\mathrm{OR}=0.78 ; 95 \% \mathrm{CI}=0.61-0.99)$ genotypes [97]. In the Health Professionals Follow-up Study (HPFS) [99, 109], and Prostate, Lung, Colon and Ovarian Cancer Screening Trial (PLCO) Study [99], inheritance of TLR10 (rs11096955, rs1 1096957) had no association with PCA risk among European Americans. However, there were null findings for TLR1 rs4833095, TLR10 (rs11096955, rs11096957) in relation to PCA susceptibility among men of African descent in the PLCO study. 
Consistent with our study, five independent studies reported null findings in relation to prostate cancer risk and possession of TLR1 rs46224663 and TLR6 (rs5743814, rs5743810, rs1039559, rs3821985) variant alleles [97, 99, 106, 109]. Inheritance of one or more minor alleles was associated with either an increase [TLR1 rs5743604 (OR = $1.28 ; 95 \% \mathrm{CI}=1.12-1.44), \operatorname{TLR} 10 \operatorname{rs} 4274855(\mathrm{OR}=1.21 ; 95 \% \mathrm{CI}=1.03-1.39)][99$, 106] or decrease [TLR1 rs5743595 CC ( $\mathrm{OR}=0.63 ; 95 \% \mathrm{CI}=0.42-0.93), T L R 1$ $r s 2149356(\mathrm{OR}=0.83 ; 95 \% \mathrm{CI}=0.67-0.99), T L R 4 r s 1927911(\mathrm{OR}=0.79 ; 95 \% \mathrm{CI}=$ 0.62-0.96)] $[97,99,107]$ in the risk of developing prostate cancer among Caucasians in three separate observational studies. However, several studies including our study found that the previously mentioned sequence variants were not significantly related to prostate cancer among men of African and European descent [99, 103 , 105,109$]$. Song and associates (2009) observed that the TLR4 rs1927911 CC genotype was linked to an increase in prostate cancer risk in a Korean population case-control study (143 controls, 157 cases) [98]; whereas, another study did not reveal a statistically significant relationship among Korean men (223 controls, 240 cases) [104]. Discrepant findings for these two studies may be attributed to differences in methods used for allelic discrimination [98, 104]. For instance, the RFLP-PCR method used in the 2009 study [98] may not have the same capacity to discern between homozygous and heterozygous genotypes, relative to fluorescence polarization detection, a more advance method used by Kim and co-workers (2012) [104]. Other explanations for differences in prostate cancer risk estimates for the aforementioned $T L R$-related SNPs may include: inadequate statistical power to detect significant differences between prostate cancer cases and controls among Koreans [98, 104]; failure to adjust for multiple hypothesis testing [97- 
99, 104-109]; and unknown environmental exposures/lifestyle factors (e.g., pathogens, environmental toxins, antioxidants) [97-99, 103-109].

The functional impact and biological activity of TLR genes are greatly affected by the inheritance of their associated sequence variants. For instance, TLR6 rs 2381289 located in 3'UTR and TLR2 rs 1898830 located in intron 1 may affect transcriptional regulation of $T L R$ genes. TLRs 2 and 6 are controlled by the master regulatory transcription factor p53 [176]. TLR-associated SNPs may alter p53 interactions with TLR genes. In silico tools revealed that IRAK4 rs4251545 codes for a change from Ala to Thr in mRNA splicing, which in turn may influence mRNA stability of IRAK4 kinase activity, as well as TLR signaling protein-protein interactions. Such alterations may lead to biochemical conditions that favor cell death, decreases in matrix metalloproteinases linked to cell migration, decreases in pro-inflammatory cytokines/chemokines and ultimately abrogation of tumor growth. Yeyeodu and associates (2013) identified that IRAK4 rs 4251545 resides in a transcription enhancer/silencer region and codes for a phosphorylation site and non-synonymous mutation at position 428 [177]. It was speculated inheritance of the IRAK4 rs4251545 TT genotype was associated with a 4.5 fold increase in breast cancer susceptibility among African-American women relative to those with the referent genotype[177]. In addition, this high susceptibility may have been attributed to alteration of IRAK4 phosphorylation. This change may influence the transcriptional level of IRAK4 and impair TLR3 regulated apoptosis in breast cancer cells [177].

Lastly, we examined the combined effects of TLR-associated SNPs as predictors of prostate cancer using age-adjusted MDR analysis to determine the best gene-gene 
interaction models. In the total population, MDR analysis revealed a significant threefactor (TLR10 rs1 1096957-TLR6 rs2381289-IRF3 rs2304206) interaction model as a good predictor of PCA risk (Permutation testing p-value $=0.001$ ). Among U.S. men of African descent, the best predictor of PCA risk was the two-factor gene-gene interaction model between IRAK4 rs4251545 and TLR2 rs 1898830 (Permutation testing $\mathrm{p}$-value $=$ 0.001). However, only the TLR6 rs 2381289 SNP for the Jamaican population remained statistically significant after adjusting for age and multiple hypothesis testing (Permutation testing $\mathrm{p}$-value $=0.018)$. However, there are no published reports on the TLR-associated sequence variants observed in our gene-gene interaction study. The strengths and limitations of our approach were considered in our research findings. Although nominal relationships between TLR-associated SNPs and PCA risk were observed, we cannot rule out the possibility that other TLR sequence variants within the innate immune pathway may still influence PCA risk and disease prognosis. Consequently, future studies will enable us to evaluate the relationship between TLR SNPs and Gleason score, tumor stage, biochemical/disease recurrence, as well as overall/disease specific mortality. Multi-center pooled genetic studies with thousands of cases and controls may enable us to confirm and validate our findings. Moreover, PCA susceptibility may also be influenced by polymorphisms of some genes even further downstream of the TLR signaling pathway, including caspases (CASP 3, 7, 8, and 10), mitogen-activated protein kinases (MAPKs), inflammatory cytokines, and chemokines. In fact, selected cytokine- and chemokine-associated sequence variants have been evaluated in relation to PCA susceptibility among men of African descent in published reports by our lab $[35,36]$. 
Future studies will assess whether selected TLR-related SNPs may alter TLR signaling, miRNA and/or protein expression or relative expression activity of downstream targets. The genetic admixture among African-American men, as documented by other published reports, may modify the relationship between TLR SNPs and prostate cancer risk. Adjustment of our risk models for West African Ancestry ultimately had no significant bearing on calculated risk estimates among AfricanAmerican men. Our gene-gene interaction analyses were controlled for multiple hypothesis testing with permutation testing. Given the high prediction accuracy (i.e., $61.9 \%$ ) between $T L R 2$ and IRAK4, our study findings require replication within independent study sets. However, recent simulation studies demonstrate that even modest disparities in genotype frequencies among study participants of independent study sets may interfere with the capacity to replicate complex interactions [178]. Consequently, to replicate our findings, it is critical that future replicate studies have the same genetic architecture (i.e., ancestry identification markers and TLR SNPs) as the African-Americans in the current study. Caution is recommended in the interpretation of our study findings due to a modest marginal effect between $T L R$ signaling sequence variants and PCA risk. However, enthusiasm for the relationship between PCA and the innate immune signaling pathway was slightly elevated in our exhaustive 2- and 3-way interactions. In particular, our exploratory analysis revealed a synergistic relationship between IRAK4 and TLR2 as significant PCA markers among men of African descent in the U.S. (Table 10b). We speculate genetic variations in TLR-related genes may influence the PCA risk by modulating cell survival, proliferation and/or inflammation. To corroborate these findings and explore the functional consequences of $T L R$-related SNPs 
on PCA development, we plan to overexpress both IRAK4 and TLR2, individually and IRAK4-TLR2 in combination in PCA cell lines. Such studies may help us understand the role of the IRAK4-TLR2 axis in the PCA phenotype, including cell death, proliferation, migration, colony formation and invasion. In addition, these modified cell lines could be implanted into mice to observe their effect on PCA tumor growth and metastasis. The combination of our genetic variation analysis of $T L R$-related polymorphisms with biological studies will aid in the accurate prediction and eventual offset of genetic risk factors that predispose men of African descent to PCA. 


\section{CHAPTER 4}

\section{CHEMOKINE LIGAND 5 (CCL5) AND CHEMOKINE RECEPTOR(CCR5) GENETIC}

\section{VARIANTS AND PROSTATE CANCER RISK AMONG MEN OF AFRICAN}

Chemokine and chemokine receptors play an essential role in tumorigenesis.

Chemokine-associated single nucleotide polymorphisms (SNPs) are associated with various cancers. However, their impact on prostate cancer (PCA) among men of African descent is unknown. Consequently, we evaluated main and combined effects of 43 chemokine-associated SNPs in germ-line DNA samples from 814 African-American and Jamaican men (279 PCA cases and 535 controls) in relation to PCA risk using the Illumina's Goldengate genotyping system, multivariate logistic regression and entropybased MDR. We hypothesized that inheritance of variant chemokine-associated alleles may lead to alterations in PCA susceptibility, presumably due to variations in antitumor immune responses. For the total population, inheritance of CCL5 rs2107538 (AA, $\mathrm{GA}+\mathrm{AA}$ ) and $r s 3817655$ (AA, AG, AG+AA) genotypes were linked with a 34-48\% reduction in PCA risk [35]. The recessive and dominant models for CCR5 rs1799988 and CCR7 rs3136685 were associated with a 1.52-1.73 fold increase in PCA risk. Upon stratification, only CCL5 rs3817655 and CCR7 rs3136685 remained significant for the Jamaican and U.S. subgroups, respectively [35]. In summary, CCL5 (rs2107538, rs3817655) and CCR5 rs 1799988 sequence variants significantly modified PCA susceptibility among men of African descent, even after adjusting for age and multiple 
comparisons. Our findings require further evaluation and validation in relation to prostate cancer risk and ultimately disease progression, biochemical/disease recurrence and mortality in larger high-risk subgroups. Such efforts will help to identify genetic markers capable of explaining disproportionately high prostate cancer incidence, mortality, and morbidity rates among men of African descent.

\section{Results}

\section{Prevalence of minor alleles/genotype frequency comparing men of African Descent} from the U.S. and Jamaica

Overall, the chemokine-related SNPs were fairly common among disease-free individuals from the entire sub-population of U.S. and Jamaica, with average minor frequencies of $26-27 \%$ and a standard deviation of $14 \%$, respectively (data not shown). Thirty-eight SNPs had minor allele frequencies $\geq 5 \%$. For exploratory purposes, five rare SNPs (CCR9 rs12721497, CCL17 rs11076191, CCL11 rs4795896, CCL21 rs11574916, CXCL12 rs 1801157) were analyzed with minor allele frequencies ranging between 0.015-0.490. The minor allele frequency comparing controls from the U.S. and Jamaica were strongly correlated $\left(R^{2}=0.957\right)$. Only 5 out of the 43 SNPs analyzed were discordant comparing men of African descent from the U.S. to men from Jamaica (pvalue $\leq$ 0.0487), namely CCL17 rs11076191, CCL21 rs11574916, CCR7 rs3136685, CCR7 rs3136687, and CCR9 rs12721497 [35].

\section{Relationship between chemokine sequence variants and prostate cancer risk}

Among all men of African descent, five sequence variants were significantly associated with the risk of developing prostate cancer, as summarized in Table 11a. Possession of the CCL5 rs $2107538 \mathrm{GA}+\mathrm{AA}\left(\mathrm{OR}_{\text {unadjusted }}=0.59 ; 95 \% \mathrm{CI}=0.44,0.80\right)$ or 
CCL5 rs $3817655 \mathrm{GA}+\mathrm{AA}\left(\mathrm{OR}_{\text {unadjusted }}=0.54 ; 95 \% \mathrm{CI}=0.40,0.74\right)$ genotype was linked with a 41-46\% reduction in PCA risk in the unadjusted LR models. These effects remained significant for both $C C L 5 \mathrm{SNPs}$ after adjusting for age. The recessive genetic model for $C C R 5$ rs $1799988\left(\mathrm{OR}_{\text {age-adjusted }}=1.52 ; 95 \% \mathrm{CI}=1.02,2.26\right)$ as well as the dominant models for $C C R 7$ rs $3136685\left(\mathrm{OR}_{\text {age-adjusted }}=1.66 ; 95 \% \mathrm{CI}=1.09,2.54\right)$ and $C C R 7$ rs3136687 $\left(\mathrm{OR}_{\text {age-adjusted }}=1.14 ; 95 \% \mathrm{CI}=1.12,1.16\right)$, respectively, were associated with a significant 1.14-1.66 fold increase in PCA risk within the age adjusted LR models. After controlling for multiple comparisons, the dominant genetic models for the two CCL5 SNPs (rs2107538, rs3817655) remained significant with false-discovery rates $($ FDR $) \leq 0.015$; whereas, the recessive model for CCR5 rs 1799988 was statistically significant $(\mathrm{FDR}=0.0494)$. 
Table 11a. Relationship between Chemokine-associated SNPs and PCA Risk Among men of African Descent.

\begin{tabular}{|c|c|c|c|c|c|c|c|c|}
\hline $\begin{array}{c}\text { Gene } \\
\text { (Allele, } \\
\text { position, } \\
\text { function) }\end{array}$ & Genotype & $\begin{array}{l}\text { Cases } \\
\text { n }(\%)\end{array}$ & $\begin{array}{c}\text { Controls } \\
\text { n (\%) }\end{array}$ & $\begin{array}{l}\text { Unadjusted OR } \\
\qquad(95 \% \mathrm{CI})\end{array}$ & $\begin{array}{l}\text { Adjusted OR } \\
\qquad(95 \% \mathrm{CI})\end{array}$ & $\begin{array}{c}\text { Chi-square }\left(\chi^{2}\right) \\
\text { p-value }\end{array}$ & p-trend & FDR \\
\hline CCR5 & AA & 85 (30.7) & 194 (36.7) & 1.00 (referent) & 1.00 (referent) & 0.0050 & 0.004 & 0.068 \\
\hline rs1799988 & AG & 107 (38.6) & 227 (43.9) & $1.08(0.76,1.52)$ & $0.83(0.55,1.25)$ & 0.6760 & & \\
\hline 5'UTR & GG & $85(30.7)$ & $108(20.4)$ & $1.80(1.23,2.63)$ & $1.38(0.87,2.17)$ & 0.0030 & & \\
\hline \multirow[t]{2}{*}{ TFBS } & $\mathrm{AG}+\mathrm{GG}$ & $192(69.3)$ & $335(63.3)$ & $1.31(0.96,1.78)$ & $1.01(0.70,1.46)$ & 0.0900 & & 0.482 \\
\hline & GG vs $(A A+A G)$ & & & $1.73(1.24,2.40)$ & $1.52(1.02,2.26)$ & 0.0013 & & 0.049 \\
\hline CCL5 & GG & $111(39.8)$ & $150(28.1)$ & 1.00 (referent) & 1.00 (referent) & 0.0020 & 0.001 & 0.049 \\
\hline$r s 2107538$ & GA & $124(44.4)$ & $270(50.6)$ & $0.62(0.45,0.86)$ & $0.72(0.49,1.06)$ & 0.0040 & & \\
\hline 5' near gene & $\mathrm{AA}$ & $44(15.8)$ & $114(21.4)$ & $0.52(0.34,0.80)$ & $0.53(0.32,0.89)$ & 0.0030 & & \\
\hline \multirow[t]{2}{*}{ TFBS } & $\mathrm{GA}+\mathrm{AA}$ & $168(60.2)$ & 384 (71.9) & $0.59(0.44,0.80)$ & $0.66(0.46,0.96)$ & 0.0007 & & 0.015 \\
\hline & $\mathrm{AA}$ vs $(\mathrm{GG}+\mathrm{GA})$ & & & $0.83(0.57,1.20)$ & $0.74(0.47,1.16)$ & 0.0570 & & 0.474 \\
\hline$C C L 5$ & GG & $114(41.0)$ & $147(27.5)$ & 1.00 (referent) & 1.00 (referent) & 0.0040 & 0.002 & 0.019 \\
\hline rs3817655 & GA & 115 (41.4) & $278(52.0)$ & $0.53(0.38,0.74)$ & $0.57(0.38,0.84)$ & 0.0002 & & \\
\hline Intron 2 & AA & $49(17.6)$ & $110(20.5)$ & $0.57(0.38,0.87)$ & $0.54(0.32,0.89)$ & 0.0009 & & \\
\hline \multirow[t]{2}{*}{ TFBS } & $\mathrm{GA}+\mathrm{AA}$ & $164(59.0)$ & $388(72.5)$ & $0.54(0.40,0.74)$ & $0.56(0.39,0.81)$ & 0.0001 & & 0.004 \\
\hline & $\mathrm{AA}$ vs $(\mathrm{GG}+\mathrm{GA})$ & & & $0.83(0.57,1.20)$ & $0.74(0.47,1.16)$ & 0.3170 & & 1.000 \\
\hline \multirow{5}{*}{$\begin{array}{c}C C R 7 \\
\text { rs3136685 } \\
\text { Intron } 1\end{array}$} & $\mathrm{AA}$ & $55(19.7)$ & $151(28.3)$ & 1.00 (referent) & 1.00 (referent) & 0.0290 & 0.031 & 0.308 \\
\hline & $\mathrm{AG}$ & $139(49.8)$ & 237 (44.4) & $1.61(1.11,2.34)$ & $1.86(1.18,2.92)$ & 0.0120 & & \\
\hline & GG & $85(30.5)$ & $146(27.3)$ & $1.60(1.06,2.40)$ & $1.39(0.85,2.28)$ & 0.0240 & & \\
\hline & $\mathrm{AG}+\mathrm{GG}$ & $224(80.3)$ & 383 (71.7) & $1.61(1.13,2.28)$ & $1.66(1.09,2.54)$ & 0.0080 & & 0.599 \\
\hline & GG vs $(A A+A G)$ & & & $1.16(0.85,1.60)$ & $0.92(0.62,1.35)$ & 0.3480 & & 0.161 \\
\hline \multirow{5}{*}{$\begin{array}{c}C C R 7 \\
\text { rs3136687 } \\
\text { Intron } 1\end{array}$} & GG & $84(30.1)$ & $173(32.4)$ & 1.00 (referent) & 1.00 (referent) & 0.0410 & 0.458 & 0.352 \\
\hline & GA & $153(54.8)$ & $249(46.5)$ & $1.26(0.91,1.76)$ & $1.45(0.97,2.16)$ & 0.1611 & & \\
\hline & AA & $42(15.1)$ & $113(21.1)$ & $0.77(0.49,1.19)$ & $0.96(0.57,1.62)$ & 0.2340 & & \\
\hline & $\mathrm{GA}+\mathrm{AA}$ & $195(69.9)$ & $362(67.6)$ & $1.11(0.81,1.52)$ & $1.14(1.12,1.16)$ & 0.5162 & & 0.716 \\
\hline & $\mathrm{AA}$ vs $(\mathrm{GG}+\mathrm{GA})$ & & & $0.66(0.45,0.98)$ & $0.76(0.49,1.20)$ & 0.0372 & & 0.509 \\
\hline
\end{tabular}

The chi-square $(\chi 2)$ test $p$-values were used to determine the difference in the genotype frequencies between cases and controls. *Fisher's p-values were calculated when expected genotype counts were < 5 for either cases and controls. Significant odd ratios (ORs) and 95\% confidence interval (CI) are indicated in boldface. Abbreviations: TFBS, transcription factor binding site; FDR, false discovery rate. 
In an exploratory analysis, we evaluated risk estimates for all 43 chemokine targets for each racial/ethnic group, as depicted in Table 11b. Among U.S. men, CCR5 rs1799988, CCL5 (rs2107538, rs2280789, rs3817655), CCL25 rs2032887, and CXCR7 rs1045879 were associated with PCA risk. Inheritance of the CCL25 rs2032887 AG+GG $\left(\mathrm{OR}_{\text {unadjusted }}=0.66 ; 95 \% \mathrm{CI}=0.46,0.96\right)$, CCL5 rs $2107538 \mathrm{GA}+\mathrm{AA}\left(\mathrm{OR}_{\text {unadjusted }}=0.52\right.$; $95 \% \mathrm{CI}=0.36,0.76), C C L 5 r s 2280789 \mathrm{AG}+\mathrm{GG}\left(\mathrm{OR}_{\text {unadjusted }}=0.60 ; 95 \% \mathrm{CI}=0.41\right.$, 0.89), and CCL5 rs3817655 GA+AA $\left(\mathrm{OR}_{\text {unadjusted }}=0.46 ; 95 \% \mathrm{CI}=0.32,0.68\right)$ genotypes were significantly associated with a $34-54 \%$ reduction in the risk of developing PCA with chi-square p-values ranging from 0.0001-0.027. Although the magnitude of the reduction in PCA risk for CCL5 rs2107538 GA+AA, CCL5 rs3817655 GA+AA and CCL25 rs2032887 AG+GG genotypes remained practically unchanged after adjusting for age, the findings only remained significant for CCL5 rs3817655 SNP after the adjustment $\left(\mathrm{OR}_{\text {unadjusted }}=0.46, \mathrm{OR}_{\text {age-adjusted }}=0.51\right)$. The 1.5-1.6 fold increase in PCA susceptibility was associated with the CCR5 rs 1799988 recessive model $\left(\mathrm{OR}_{\text {unadjusted }}=1.62\right.$; $95 \% \mathrm{CI}=1.08,2.42)$ and the $C X C R 7 r s 1045879 \mathrm{AG}+\mathrm{GG}$ genotype $\left(\mathrm{OR}_{\text {unadjusted }}=1.54\right.$; $95 \% \mathrm{CI}=1.07,2.22 ; \mathrm{P}=0.02)$ was lost in the age adjusted risk models.

For the Jamaican population, there was a two-fold increase in PCA susceptibility associated with the $C C R 5 r s 1799987 \mathrm{AA}\left(\mathrm{OR}_{\text {unadjusted }}=2.18 ; 95 \% \mathrm{CI}=1.04,4.58\right), C C R 5$ $r s 1799988 \mathrm{GG}\left(\mathrm{OR}_{\text {unadjusted }}=2.25 ; 95 \% \mathrm{CI}=1.08,4.71\right)$, and $C C R 7 r s 3136685 \mathrm{AG}+\mathrm{GG}$ $\left(\mathrm{OR}_{\text {unadjusted }}=2.3 ; 95 \% \mathrm{CI}=1.05,5.07\right)$ genotypes, with corresponding chi-square $\mathrm{P}$ values ranging from 0.02-0.037. Additionally, a 54\% reduction in PCA risk was observed for individuals who possessed the CCR9 rs $1488371 \mathrm{CA}+\mathrm{AA}$ genotype $\left(\mathrm{OR}_{\text {unadjusted }}=0.46 ; 95 \% \mathrm{CI}=0.23,0.94\right)$. Out of the 4 markers, the $C C R 7$ rs 3136685 
SNP remained significant after adjusting for age. Notably, the magnitude of PCA risk estimates did not change for the CCR5, CCL5, and CCR9 SNPs, comparing the adjusted and unadjusted risk models. However, only CCL5 (rs2107538, rs3817655) sequence variants survived multiple hypothesis testing among U.S. men of African descent (Bonferroni Correction p-value $<0.0012$ ). 
Table 11b. Relationship between Chemokine-associated SNPs and PCA Risk stratified by racial ethnic group.

\begin{tabular}{|c|c|c|c|c|c|c|c|c|c|}
\hline $\begin{array}{l}\text { Gene (Allele, } \\
\text { position, function) }\end{array}$ & Genotype & $\begin{array}{c}\text { Unadjusted } \\
\text { OR (95\%CI) } \\
\text { US Men }\end{array}$ & $\begin{array}{c}\text { Unadjusted } \\
\text { OR (95\% CI) } \\
\text { Jamaican Men }\end{array}$ & $\begin{array}{c}\text { Age-Adjusted } \\
\text { OR (95\% CI) } \\
\text { US Men }\end{array}$ & $\begin{array}{c}\text { Age-Adjusted } \\
\text { OR (95\%CI) } \\
\text { Jam Men }\end{array}$ & $\begin{array}{c}\chi^{2} \\
\text { p-value } \\
\text { US Men }\end{array}$ & $\begin{array}{l}\text { p-trend } \\
\text { US Men }\end{array}$ & $\begin{array}{l}\chi^{2} \\
\text { p-value }{ }^{*} \\
\text { Jam Men }\end{array}$ & $\begin{array}{l}\text { p-trend } \\
\text { Jam Men }\end{array}$ \\
\hline $\begin{array}{l}\text { CCR5 } \\
\text { rs1799988 } \\
\text { 5'UTR } \\
\text { TFBS }\end{array}$ & $\begin{array}{c}\text { AA } \\
\text { AG } \\
\text { GG } \\
\text { AG+GG } \\
\text { GG vs }(\mathrm{AA}+\mathrm{AG})\end{array}$ & $\begin{array}{l}1.00 \text { (referent) } \\
0.95(0.62,1.44) \\
1.58(0.99,2.49) \\
1.15(0.79,1.68) \\
\mathbf{1 . 6 2}(\mathbf{1 . 0 8 , 2 . 4 2})\end{array}$ & $\begin{array}{l}1.00 \text { (referent) } \\
1.26(0.66,2.40) \\
\mathbf{2 . 2 5}(\mathbf{1 . 0 8 ,}, \mathbf{4 . 7 1}) \\
1.56(0.86,2.82) \\
\mathbf{1 . 9 6}(\mathbf{1 . 0 4 , 3 . 7 0 )}\end{array}$ & $\begin{array}{l}1.00 \text { (referent) } \\
0.68(0.42,1.12) \\
1.06(0.60,1.85) \\
0.80(0.52,1.26) \\
1.28(0.78,2.12) \\
\end{array}$ & $\begin{array}{l}1.00 \text { (referent) } \\
1.23(0.60,2.52) \\
2.23(0.99,5.00) \\
1.55(0.81,2.98) \\
1.98(0.98,3.98)\end{array}$ & $\begin{array}{l}0.063 \\
0.808 \\
0.053 \\
0.453 \\
\mathbf{0 . 0 2 0} \\
\end{array}$ & 0.076 & $\begin{array}{l}0.085 \\
0.484 \\
0.031 \\
0.142 \\
\mathbf{0 . 0 3 7} \\
\end{array}$ & 0.034 \\
\hline $\begin{array}{l}\text { CCL5 } \\
r s 2107538 \\
5 ' \text { near gene } \\
\text { TFBS }\end{array}$ & $\begin{array}{c}\text { GG } \\
\text { GA } \\
\text { AA } \\
\text { GA+AA } \\
\text { AA vs }(\mathrm{GG}+\mathrm{AG})\end{array}$ & $\begin{array}{l}1.00 \text { (referent) } \\
\mathbf{0 . 5 4}(\mathbf{0 . 3 6 , 0 . 8 0}) \\
\mathbf{0 . 4 8}(\mathbf{0 . 2 8}, \mathbf{0 . 8 2}) \\
\mathbf{0 . 5 2}(\mathbf{0 . 3 6 , 0 . 7 6 )} \\
0.68(0.42,1.11) \\
\end{array}$ & $\begin{array}{l}1.00 \text { (referent) } \\
0.75(0.40,1.40) \\
0.53(0.24,1.16) \\
0.68(0.38,1.23) \\
0.64(0.32,1.26) \\
\end{array}$ & $\begin{array}{l}1.00 \text { (referent) } \\
0.67(0.42,1.08) \\
0.53(0.28,1.01) \\
\mathbf{0 . 6 3}(\mathbf{0 . 4 0 , 0 . 9 9 )} \\
0.66(0.37,1.20) \\
\end{array}$ & $\begin{array}{l}1.00 \text { (referent) } \\
0.82(0.40,1.64) \\
0.52(0.22,1.22) \\
0.72(0.37,1.40) \\
0.58(0.28,1.24) \\
\end{array}$ & $\begin{array}{l}\mathbf{0 . 0 0 3} \\
\mathbf{0 . 0 0 3} \\
\mathbf{0 . 0 0 7} \\
\mathbf{0 . 0 0 1} \\
0.125 \\
\end{array}$ & 0.002 & $\begin{array}{l}0.286 \\
0.375 \\
0.116 \\
0.204 \\
0.192 \\
\end{array}$ & 0.116 \\
\hline $\begin{array}{l}\text { CCL5 } \\
r s 2280789 \\
\text { Intron } 1 \\
\text { TFBS }\end{array}$ & $\begin{array}{c}\text { AA } \\
\text { AG } \\
\text { GG } \\
\text { AG+GG } \\
\text { GG vs }(\mathrm{AA}+\mathrm{AG})\end{array}$ & $\begin{array}{l}1.00 \text { (referent) } \\
\mathbf{0 . 6 0}(\mathbf{0 . 4 0 , 0 . 9 0 )} \\
0.62(0.24,1.56) \\
\mathbf{0 . 6 0}(\mathbf{0 . 4 1 , 0 . 8 9 )} \\
0.72(0.28,1.82) \\
\end{array}$ & $\begin{array}{l}1.00 \text { (referent) } \\
1.20(0.66,2.18) \\
0.59(0.18,1.89) \\
1.06(0.61,1.86) \\
0.55(0.18,1.80) \\
\end{array}$ & $\begin{array}{l}1.00 \text { (referent) } \\
\mathbf{0 . 6 0}(\mathbf{0 . 3 7}, \mathbf{0 . 9 7}) \\
1.00(0.34,2.99) \\
0.64(0.40,1.01) \\
1.14(1.12,1.18) \\
\end{array}$ & $\begin{array}{l}1.00 \text { (referent) } \\
1.48(0.76,2.89) \\
0.42(0.12,1.46) \\
1.18(0.63,2.20) \\
0.36(0.10,1.27) \\
\end{array}$ & $\begin{array}{l}\mathbf{0 . 0 3 9} \\
\mathbf{0 . 0 1 5} \\
\mathbf{0 . 3 0 9} \\
\mathbf{0 . 0 1 1} \\
0.488 \\
\end{array}$ & 0.018 & $\begin{array}{r}0.508 \\
0.549 \\
0.373 \\
0.82 \\
0.313 \\
\end{array}$ & 0.823 \\
\hline $\begin{array}{l}\text { CCL5 } \\
r s 3817655 \\
\text { Intron } 2 \\
\text { TFBS }\end{array}$ & $\begin{array}{c}\text { GG } \\
\text { GA } \\
\text { AA } \\
\text { GA+AA } \\
\text { AA vs }(\mathrm{GG}+\mathrm{GA})\end{array}$ & $\begin{array}{l}1.00 \text { (referent) } \\
\mathbf{0 . 4 4}(\mathbf{0 . 2 9}, \mathbf{0 . 6 5}) \\
\mathbf{0 . 5 6}(\mathbf{0 . 3 4}, \mathbf{0 . 9 2}) \\
\mathbf{0 . 4 6}(\mathbf{0 . 3 2}, \mathbf{0 . 6 8}) \\
0.88(0.55,1.40) \\
\end{array}$ & $\begin{array}{l}1.00 \text { (referent) } \\
0.72(0.38,1.34) \\
0.53(0.24,1.16) \\
0.66(0.36,1.20) \\
0.66(0.34,1.28) \\
\end{array}$ & $\begin{array}{l}1.00 \text { (referent) } \\
\mathbf{0 . 4 9}(\mathbf{0 . 3 0}, \mathbf{0 . 8 0}) \\
0.54(0.29,1.02) \\
\mathbf{0 . 5 1}(\mathbf{0 . 3 2}, \mathbf{0 . 8 0}) \\
0.80(0.46,1.42) \\
\end{array}$ & $\begin{array}{l}1.00 \text { (referent) } \\
0.74(0.36,1.50) \\
0.50(0.22,1.20) \\
0.66(0.34,1.28) \\
0.61(0.28,1.27) \\
\end{array}$ & $\begin{array}{r}\mathbf{0 . 0 0 0 2} \\
<\mathbf{0 . 0 0 0 1} \\
\mathbf{0 . 0 2 2} \\
<\mathbf{0 . 0 0 0 1} \\
0.577 \\
\end{array}$ & 0.003 & $\begin{array}{r}0.275 \\
0.302 \\
0.115 \\
0.167 \\
0.22 \\
\end{array}$ & 0.11 \\
\hline $\begin{array}{l}C C L 25 \\
r s 2032887 \\
\text { Exon } 3 \\
\text { ESE/ESS, nsSNP } \\
\text { probably damaging } \\
\text { missense R }>\mathrm{H}\end{array}$ & $\begin{array}{c}\text { AA } \\
\text { AG } \\
\text { GG } \\
\text { AG+GG } \\
\text { GG vs (AA+AG) }\end{array}$ & $\begin{array}{l}1.00 \text { (referent) } \\
\mathbf{0 . 6 7}(\mathbf{0 . 4 6 , 0 . 9 9 )} \\
0.61(0.29,1.28) \\
\mathbf{0 . 6 6}(\mathbf{0 . 4 6 , 0 . 9 6 )} \\
0.71(0.34,1.47)\end{array}$ & $\begin{array}{l}1.00 \text { (referent) } \\
1.42(0.80,2.48) \\
1.10(0.36,3.38) \\
1.37(0.80,2.36) \\
0.93(0.32,2.75)\end{array}$ & $\begin{array}{l}1.00 \text { (referent) } \\
0.70(0.44,1.11) \\
0.57(0.22,1.42) \\
0.68(0.44,1.05) \\
0.65(0.26,1.60)\end{array}$ & $\begin{array}{l}1.00 \text { (referent) } \\
1.54(0.82,2.88) \\
0.84(0.24,2.88) \\
1.42(0.78,2.60) \\
0.68(0.20,2.24)\end{array}$ & $\begin{array}{l}0.084 \\
0.404 \\
0.196 \\
\mathbf{0 . 0 2 7} \\
0.357\end{array}$ & 0.034 & $\begin{array}{r}0.474 \\
0.225 \\
0.86 \\
0.253 \\
0.898\end{array}$ & 0.379 \\
\hline $\begin{array}{l}\text { CCR5 } \\
\text { rs } 1799987 \\
\text { Intron } 1 \\
\text { TFBS }\end{array}$ & $\begin{array}{c}\text { GG } \\
\text { GA } \\
\text { AA } \\
\text { GA+AA } \\
\text { AA vs }(\mathrm{GG}+\mathrm{GA}) \\
\end{array}$ & $\begin{array}{l}1.00 \text { (referent) } \\
1.29(0.88,1.92) \\
0.84(0.48,1.48) \\
1.18(0.80,1.70) \\
0.72(0.44,1.21) \\
\end{array}$ & $\begin{array}{l}1.00 \text { (referent) } \\
1.28(0.68,2.44) \\
\mathbf{2 . 1 8}(\mathbf{1 . 0 4}, \mathbf{4 . 5 8}) \\
1.56(0.86,2.82) \\
1.88(0.99,3.56) \\
\end{array}$ & $\begin{array}{l}1.00 \text { (referent) } \\
0.89(0.56,1.44) \\
0.58(0.29,1.14) \\
0.81(0.52,1.26) \\
0.61(0.32,1.15) \\
\end{array}$ & $\begin{array}{l}1.00 \text { (referent) } \\
1.25(0.61,2.56) \\
\mathbf{2 . 2 0}(\mathbf{0 . 9 8 ,}, \mathbf{4 . 9 4}) \\
1.55(0.81,2.98) \\
1.92(0.96,3.88) \\
\end{array}$ & $\begin{array}{l}0.197 \\
0.191 \\
0.558 \\
0.399 \\
0.222 \\
\end{array}$ & 0.951 & $\begin{array}{l}0.107 \\
0.442 \\
\mathbf{0 . 0 3 9} \\
0.142 \\
0.051 \\
\end{array}$ & 0.041 \\
\hline $\begin{array}{l}C C R 7 \\
r s 3136685 \\
\text { Intron } 1\end{array}$ & $\begin{array}{c}\text { AA } \\
\text { AG } \\
\text { GG } \\
\text { AG+GG } \\
\text { GG vs (AA+AG) }\end{array}$ & $\begin{array}{l}1.00 \text { (referent) } \\
1.32(0.86,2.02) \\
1.07(0.65,1.76) \\
1.23(0.82,1.84) \\
0.90(0.59,1.36) \\
\end{array}$ & $\begin{array}{l}1.00 \text { (referent) } \\
2.24(0.98,5.16) \\
2.38(1.02,5.58) \\
\mathbf{2 . 3 0}(\mathbf{1 . 0 5}, \mathbf{5 . 0 7}) \\
1.28(0.74,2.25) \\
\end{array}$ & $\begin{array}{l}1.00 \text { (referent) } \\
1.58(0.94,2.66) \\
1.02(0.56,1.86) \\
1.36(0.83,2.21) \\
0.76(0.46,1.26) \\
\end{array}$ & $\begin{array}{l}1.00 \text { (referent) } \\
2.78(1.09,7.08) \\
2.52(0.97,6.52) \\
\mathbf{2 . 6 6}(\mathbf{1 . 1 0 , 6 . 4 2}) \\
1.16(0.62,2.15) \\
\end{array}$ & $\begin{array}{l}0.381 \\
0.197 \\
0.778 \\
0.305 \\
0.622 \\
\end{array}$ & 0.731 & $\begin{array}{l}0.103 \\
0.056 \\
\mathbf{0 . 0 4 5} \\
\mathbf{0 . 0 3 7} \\
0.372 \\
\end{array}$ & 0.086 \\
\hline $\begin{array}{l}\text { CCR7 } \\
r s 3136687\end{array}$ & $\begin{array}{l}\text { GG } \\
\text { GA }\end{array}$ & $\begin{array}{l}1.00 \text { (referent) } \\
\mathbf{1 . 8 1}(\mathbf{1 . 1 6}, \mathbf{2 . 8 0})\end{array}$ & $\begin{array}{l}1.00 \text { (referent) } \\
0.98(0.55,1.75)\end{array}$ & $\begin{array}{l}1.00 \text { (referent) } \\
\mathbf{1 . 7 3}(\mathbf{1 . 0 3}, \mathbf{2 . 9 3})\end{array}$ & $\begin{array}{l}1.00 \text { (referent) } \\
1.13(0.60,2.14)\end{array}$ & $\begin{array}{l}0.022 \\
0.008\end{array}$ & 0.294 & $\begin{array}{l}0.229 \\
0.459\end{array}$ & 0.218 \\
\hline
\end{tabular}




\begin{tabular}{|c|c|c|c|c|c|c|c|c|c|}
\hline Intron 1 & $\begin{array}{c}\text { AA } \\
\text { GA+AA } \\
\text { AA vs }(G G+G A)\end{array}$ & $\begin{array}{l}1.27(0.74,2.18) \\
\mathbf{1 . 6 3}(\mathbf{1 . 0 7}, \mathbf{2 . 4 9}) \\
0.86(0.55,1.32)\end{array}$ & $\begin{array}{l}0.46(0.18,1.18) \\
0.85(0.49,1.48) \\
0.46(0.19,1.14)\end{array}$ & $\begin{array}{l}1.18(0.63,2.20) \\
1.53(0.96,2.53) \\
\mathbf{1 . 1 5}(\mathbf{1 . 1 2}, \mathbf{1 . 1 8}\end{array}$ & $\begin{array}{l}0.74(0.25,2.17) \\
1.06(0.57,1.95) \\
0.69(0.25,1.91)\end{array}$ & $\begin{array}{l}0.380 \\
0.023 \\
0.482\end{array}$ & & $\begin{array}{l}0.106 \\
0.573 \\
0.092\end{array}$ & \\
\hline $\begin{array}{l}\text { CCR9 } \\
\text { rs } 1488371 \\
\text { Intron } 2\end{array}$ & $\begin{array}{c}\text { CC } \\
\text { CA } \\
\text { AA } \\
\text { CA+AA } \\
\text { AA vs (AA+CA) }\end{array}$ & $\begin{array}{l}1.00 \text { (referent) } \\
0.94(0.62,1.40) \\
1.57(0.50,4.90) \\
0.98(0.66,1.44) \\
1.60(0.52,4.97)\end{array}$ & $\begin{array}{l}1.00 \text { (referent) } \\
0.52(0.26,1.08) \\
\mathbf{0 . 4 6}(\mathbf{0 . 2 3}, \mathbf{0 . 9 4})\end{array}$ & $\begin{array}{l}1.00 \text { (referent) } \\
0.88(0.54,1.42) \\
0.92(0.22,3.80) \\
0.88(0.54,1.40) \\
0.95(0.23,4.00)\end{array}$ & $\begin{array}{l}1.00 \text { (referent) } \\
0.60(0.26,1.31) \\
0.48(0.22,1.04)\end{array}$ & $\begin{array}{l}\mathbf{0 . 0 1 3} \\
0.747 \\
0.435 \\
0.901 \\
0.414 \\
\end{array}$ & 0.902 & \begin{tabular}{r|}
$\mathbf{0 . 0 0 3}$ \\
0.08 \\
0.984 \\
$\mathbf{0 . 0 3 4}$ \\
0.984 \\
\end{tabular} & 0.018 \\
\hline $\begin{array}{l}\text { CXCR7 } \\
r s 1045879 \\
\text { Exon 1 } \\
\text { synSNP } \\
\mathrm{L}>\mathrm{L} \\
\end{array}$ & $\begin{array}{c}\text { AA } \\
\text { AG } \\
\text { GG } \\
\text { AG+GG } \\
\text { GG vs }(\mathrm{AA}+\mathrm{AG}) \\
\end{array}$ & $\begin{array}{l}1.00 \text { (referent) } \\
\mathbf{1 . 5 4}(\mathbf{1 . 0 6}, \mathbf{2 . 2 6}) \\
1.53(0.84,2.79) \\
\mathbf{1 . 5 4}(\mathbf{1 . 0 7}, \mathbf{2 . 2 2}) \\
1.21(0.69,2.13)\end{array}$ & $\begin{array}{l}1.00 \text { (referent) } \\
1.38(0.77,2.48) \\
0.86(0.34,2.16) \\
1.24(0.72,2.14) \\
0.76(0.31,1.84)\end{array}$ & $\begin{array}{l}1.00 \text { (referent) } \\
1.30(0.82,2.04) \\
1.02(0.47,2.20) \\
1.24(0.80,1.93) \\
0.88(0.42,1.84)\end{array}$ & $\begin{array}{l}1.00 \text { (referent) } \\
1.30(0.68,2.50) \\
0.74(0.27,2.04) \\
1.15(0.62,2.10) \\
0.67(0.25,1.80)\end{array}$ & $\begin{array}{r}0.065 \\
\mathbf{0 . 0 2 5} \\
0.166 \\
\mathbf{0 . 0 2} \\
0.499 \\
\end{array}$ & 0.038 & $\begin{array}{l}0.459 \\
0.279 \\
0.756 \\
0.431 \\
0.538 \\
\end{array}$ & 0.762 \\
\hline
\end{tabular}

The chi-square $\left({ }^{(2)}\right.$ test $\mathrm{p}$-values were used to determine the difference in the genotype frequencies between cases and controls.

*Fisher's p-values were calculated when expected genotype counts were $<5$ for either cases and controls. Significant associations are indicated in boldface. Abbreviations: UTR, untranslated region; TFBS, transcription factor binding site; ESE exonic splicing enhancer; ESS, exonic splicing silencers; synSNP, synonymous coding SNP; Jam, Jamaican. 


\section{Analysis of gene-gene interactions using Multi-factor Dimensionality Reduction}

MDR modeling was utilized to evaluate and validate gene-gene interactions among 43 chemokine-associated sequence variants in relation to PCA risk. The top ageadjusted one-, two- and three-factor gene-gene interaction models for the total population, including men of African descent from Jamaica and the U.S., were statistically significant with $100 \%$ cross validation consistency (CVC), 59-67\% average testing accuracy (ATA) and permutation testing p-values of 0.001, as shown in Table 12a. The three-factor interaction model consisting of CCR7 rs3136685, CCL5 rs3817655, and CCR9 rs41289608 was the best predictor of PCA risk among men of African descent, based upon the highest ATA value of $66.5 \%$. This three-factor interaction model was driven by theThe mutual information gain score of CCL5 $r s 3817655(\mathrm{IG}=2.8 \%)$ (Figure 10). However, none of the pairwise interactions of the three-factor interaction model yielded more information than each SNP considered alone.

Analysis of age-adjusted gene-gene interactions among U.S. men of African descent yielded statistically significant one-, two- and three-factor interaction models with $100 \%$ CVC, 58-68\% ATA values, and permutation testing p-values of 0.001-0.003 (Table 12b). In addition, the best one-factor MDR model (CCL5 rs3817655) was a persistent predictor of PCA risk in the total population and U.S. men, as shown in Tables 12a and 12b, respectively. Yet, the three-factor gene-gene interaction model (CCR6 rs3093024-CCL5 rs3817655-CCR9 rs41289608) was selected as the best predictor of PCA risk among U.S. men based upon its high ATA value of 68.7\% (Permutation testing p-value $=0.001)$. However, this 3-way interaction was dominated by CCL5 rs3817655 (Data not shown). 
Upon stratification of age-adjusted MDR analyses for Jamaican men, the threefactor gene-gene interaction model of CCR6 rs3093024, CCR4 rs6550178 and CXCR7 rs7559855 was statistically significant and the overall best predictor of PCA susceptibility (Permutation testing p-value $=0.017)($ Table 12c). The three-factor model was selected as the best predictor of risk due to its association with an extremely high ATA score of $70 \%$ among Jamaican men. This interaction model was moderately synergistic (orange line) and primarily driven the main effect of CCR4 rs6550178 (IG = 8.2\%) and the pairwise interaction between CCR6 and CXCR7 $(\mathrm{IG}=3.41 \%)$ (Figure 11). Thus far, CCR4 rs6550178 had the highest individual information gain score among all of the sequence variants included in this study. 
Table 12a. Interactions and main effects of Chemokine-associated SNPs as predictors of PCA using age-adjusted MDR among men of African Descent.

\begin{tabular}{|c|c|c|c|c|}
\hline $\begin{array}{l}\text { Best Model } \\
\text { (dbSNPID\#) }\end{array}$ & Interactions & $\begin{array}{c}\text { Cross } \\
\text { Validation } \\
\text { Consistency } \\
\text { (CVC) }\end{array}$ & $\begin{array}{l}\text { Average } \\
\text { Testing } \\
\text { Accuracy } \\
\text { (ATA) }\end{array}$ & $\begin{array}{c}\text { Permutation } \\
\text { Testing } \\
p \text {-value }\end{array}$ \\
\hline$\frac{\text { One Factor }}{C C L 5 \text { rs3817655 }}$ & 43 & $10 / 10$ & 0.595 & 0.001 \\
\hline $\begin{array}{l}\frac{\text { Two Factor }}{C C L 5 \text { rs3817655 }} \\
\text { CCR4 rs6550178 }\end{array}$ & 903 & $10 / 10$ & 0.628 & 0.001 \\
\hline $\begin{array}{l}\text { Three Factor } \\
\text { CCR7 rs3136685 } \\
\text { CCL5 rs3817655 } \\
\text { CCR9 rs41289608 }\end{array}$ & 12,341 & $10 / 10$ & 0.665 & 0.001 \\
\hline
\end{tabular}

*Analysis was restricted to 279 cases and 535 controls. Interaction models were adjusted for multiple hypothesis testing with 1,000 permutations. 


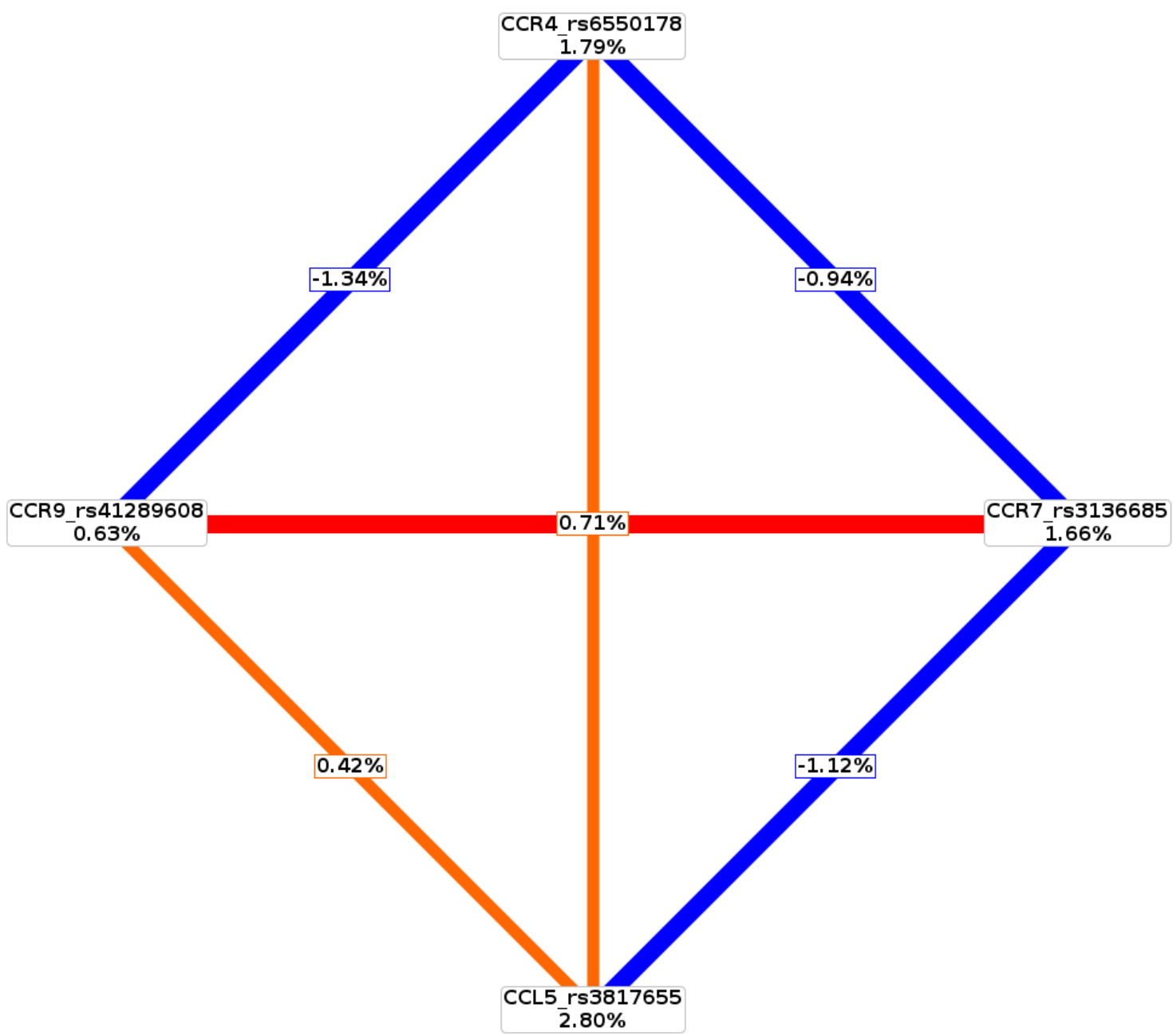

Figure 10. Entropy graph of Chemokine gene-gene interactions among U.S. and Jamaican men of African Descent. The mutual gain scores for all the pairwise combinations for the best 2- and 3-factor MDR models did not exceed the information gain scores of the individual loci. Consequently the selected genegene interaction models were not informative and predominantly driven by a strong single SNP effect from CCL5 rs3817655 (IG = 2.8\%). 
Table 12b. Interactions and main effects of Chemokine-associated SNPs as predictors of PCA using age-adjusted MDR among U.S. men of African Descent.

\begin{tabular}{|c|c|c|c|c|}
\hline $\begin{array}{l}\text { Best Model } \\
\text { (dbSNPID\#) }\end{array}$ & Interactions & $\begin{array}{c}\text { Cross } \\
\text { Validation } \\
\text { Consistency } \\
\text { (CVC) }\end{array}$ & $\begin{array}{c}\text { Average } \\
\text { Testing } \\
\text { Accuracy } \\
\text { (ATA) }\end{array}$ & $\begin{array}{c}\text { Permutation } \\
\text { Testing } \\
p \text {-value }\end{array}$ \\
\hline$\frac{\text { One Factor }}{C C L 5 \text { rs3817655 }}$ & 43 & $10 / 10$ & 0.584 & 0.001 \\
\hline $\begin{array}{c}\text { Two Factor } \\
\text { CCL5 rs3817655 } \\
\text { CCR5 rs } 1799988\end{array}$ & 903 & $10 / 10$ & 0.619 & 0.003 \\
\hline $\begin{array}{l}\text { Three Factor } \\
\text { CCR6 rs3093024 } \\
\text { CCL5 rs3817655 } \\
\text { CCR9 rs41289608 }\end{array}$ & 12,341 & $10 / 10$ & 0.687 & 0.001 \\
\hline
\end{tabular}

*Analysis was restricted to 279 cases and 535 controls. Interaction models were adjusted for multiple hypothesis testing with 1,000 permutations. 
Table 12c. Interactions and main effects of Chemokine-associated SNPs as predictors of PCA using age-adjusted MDR among Jamaican men of African Descent.

\begin{tabular}{|c|c|c|c|c|}
\hline $\begin{array}{l}\text { Best Model } \\
\text { (dbSNPID \#) }\end{array}$ & Interactions & $\begin{array}{c}\text { Cross } \\
\text { Validation } \\
\text { Consistency } \\
(\text { CVC })\end{array}$ & $\begin{array}{l}\text { Average } \\
\text { Testing } \\
\text { Accuracy } \\
\text { (ATA) }\end{array}$ & $\begin{array}{c}\text { Permutation } \\
\text { Testing } \\
p \text {-value }\end{array}$ \\
\hline$\frac{\text { One Factor }}{C C R 9 r s 2286486}$ & 43 & $10 / 10$ & 0.606 & 0.061 \\
\hline $\begin{array}{c}\text { Two Factor } \\
\text { CCR9 rs2286486 } \\
\text { CCR7 rs3136687 }\end{array}$ & 903 & $10 / 10$ & 0.637 & 0.329 \\
\hline $\begin{array}{c}\text { Three Factor } \\
\text { CCR6 rs3093024 } \\
\text { CCR4 rs6550178 } \\
\text { CXCR7 rs } 7559855\end{array}$ & 12,341 & $9 / 10$ & 0.704 & 0.017 \\
\hline
\end{tabular}

*Analysis was restricted to 279 cases and 535 controls. Interaction models were adjusted for multiple hypothesis testing with 1,000 permutations. 


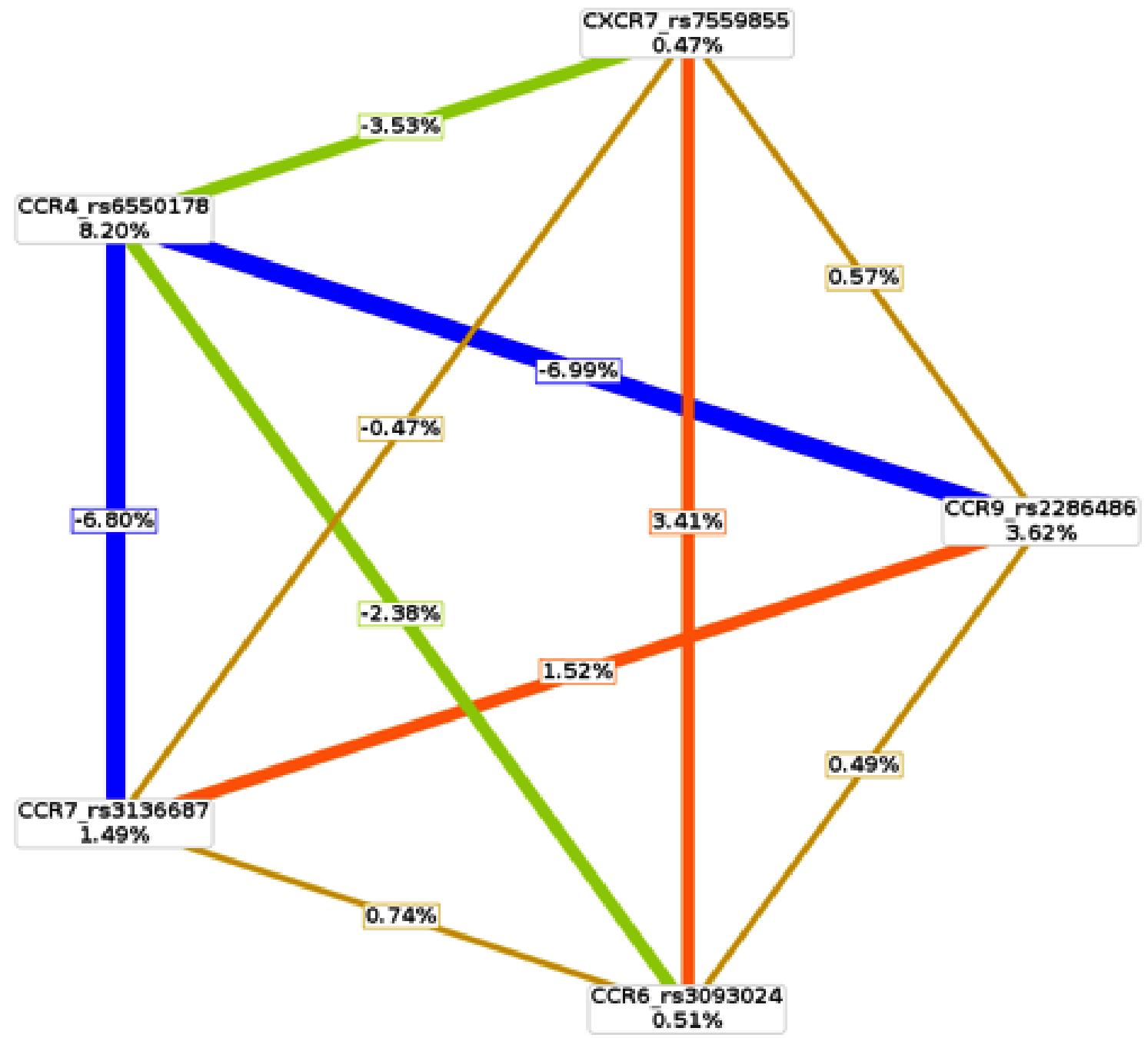

Figure 11. Entropy graph of Chemokine gene-gene interactions among Jamaican men of African Descent. MDR analysis revealed that only the threefactor (CCR6 rs3093024-CXCR7 rs7559855-CCR4 rs6550178) survived multiple hypothesis testing with $90 \% \mathrm{CVC}$ and $70.4 \%$ ATA values (Permutation p-value=0.017). However, a moderately synergistic (orange line) interaction between $C C R 6$ and $C X C R 7$ associated with a pairwise mutual information gain score of $3.41 \%$, which is higher than the mutual information gain scores of each SNP. In addition, the three-factor interaction model was predominantly driven by CCR4 rs6550178 ( $\mathrm{IG}=8.2 \%)$. 


\section{Discussion}

Chemotaxis is an important process required for tumor growth and metastasis $[179,180]$. It is regulated by a complex network of chemokines, chemokine receptors and downstream targets that synergistically regulate immune and inflammatory responses [180]. Recent molecular studies have demonstrated that over expression of selected chemokines and chemokine receptors are related to aggressive cancer phenotypes, including lung, breast and prostate cancer [181-185]. Some observational studies suggest inheritance of susceptibilities detected in chemokine-associated genes may alter the risk of developing cancer [116-120]. However, to our knowledge, there are no published reports on the impact of inheriting multiple functional variants in relation to prostate cancer among men of African Descent. Therefore, the current study evaluated the individual and combined effects of 43 chemokine associated sequence variants on PCA risk among 279 cases and 535 disease-free men of African descent from the U.S and Jamaica using LR and MDR modeling. Five SNPs detected in CCL5, CCR5 and CCR7 were significantly associated with prostate cancer risk among all study participants; however, only three markers survived adjustments for potential confounders and multiple hypothesis testing [35]. Notably, inheritance of at least one CCL5 rs3817655 A or CCL5 rs2107538 A loci was linked with a 34-44\% decrease in PCA susceptibility among all men of African Descent. In addition, the recessive genetic model for CCR5 rs 1799988 was associated with a 52-73\% increase in PCA risk. We also observed significant main effects for the CCL5 rs3817655 and CCR7 rs3136685 SNPs among U.S. and Jamaican men, respectively. 
MDR analysis revealed several significant chemokine-associated gene-gene interactions among men of African descent. In the total population, a three factor model interaction model was selected as the best prostate cancer predictor for the total population (CCR7 rs3136685-CCL5 rs3817655-CCR9 rs41289608) as well as the African-Americans from the U.S. (CCR6 rs3093024- CCL5 rs3817655-CCR9 rs41289608) with $\mathrm{CVC}=100 \%$ ATA $=66.5-68.7$ and Permutation-testing $\mathrm{p}$-value $=$ 0.001. $(\mathrm{CVC}=100 \% ; \mathrm{ATA}=66.5 \%$ value; Permutation testing $\mathrm{p}$-value $=0.001)$ However, upon closer inspection, these 3-way interactions were primarily driven by CCL5 rs3817655 none of the interactions within the three-factor model were informative. Interestingly, a significant three-factor interaction model (CCR6 rs3093024CCR4 rs6550178- CXCR7 rs7559855) for Jamaican men had the highest ATA value (70.4\%) compared to the total population and U.S men interaction models (Permutation p-value $=0.017)$. This interaction model was moderately synergistic due to the major main effect of $C C R 4$ rs6550178 $(\mathrm{IG}=8.2 \%)$ and a pairwise interaction between CCR6 rs3093024 and CXCR7 rs7559855 ( $\mathrm{IG}=3.41 \%)$. In fact, the pairwise mutual information gain score of CCR6 rs3093024 and CXCR7 rs7559855 was higher than information gain scores of the individual variants. However, the other interaction models among Jamaican men did not survive multiple hypothesis testing.

Several cancer cells, including PCA cells, express chemokines and their cell surface bound receptors. Chemokine ligand 5 (RANTES) is a small molecule with a strong capacity to induce cellular migration of inflammatory cells and production of its receptor (CCR5) in human PCA cell lines $[73,75]$. The CCL5/CCR5 axis induces PCA cell proliferation and invasion [74]. It's speculated that once CCL5 binds to CCR5, it 
serves as an autocrine factor and activates cellular responses involved in cancer progression [73]. In the current study, possession of the CCL5 rs3817655 A or CCL5 rs2107538 A loci was linked with a protective effect in relation to prostate cancer risk among all men of African descent from the U.S. and Jamaica combined. The directionality of the risk estimates persisted when we stratified by racial/ethnic group; however, the findings were only statistical significant for the U.S. men. In addition, findings for the total and U.S. subgroups remained significant even after adjusting for age and multiple hypothesis testing. The observed protective effects associated with the two aforementioned CCL5 SNPs ( $r s 3817655, r s 2107538)$ may be attributed to a reduction in transcriptional activation, reduced protein levels, and ultimately reduced tumorigenic capacity. To our knowledge, there are no published reports on the impact of the CCL5 rs3817655 SNP on prostate cancer susceptibility or its functional consequence on genes/proteins. On the other hand, the CCL5 rs $2107538 \mathrm{G}-403 \mathrm{~A}$ promoter SNP is associated with a decrease in protein expression detected in serum collected from Type II diabetic and disease-free subjects [186]. In addition, this locus has been evaluated in two independent prostate cancer studies. In a study involving 607 Caucasian male residents of Spain (297 cases, 3011 controls), Saenz-Lopez and co-workers (2008) observed a 1.44-fold increase in PCA risk among carriers of the CCL5 rs2107538 GA+AA genotype $(p$-value $=0.039)[116]$. However, this finding did not corroborate with a larger null report consisting of 1553 Caucasian men (i.e., 815 PCA cases, 738 controls) from Australia [187]. Our findings of a protective effect against PCA among our study participants is consistent with other published reports that reveal a decrease in the risk of developing gastric cancer, lymphoma, and type 1 diabetes [113, 186, 188]. Within a 
multi-ethnic pancreatic case-control study, the prevalence of the "A" allele was more frequent among disease-free Asian and African-Americans relative to pancreatic cases [118]; however, this allele was more prevalent among Caucasian pancreatic cases relative to controls. Collectively, these findings may suggest inheritance of genetic susceptibilities detected in the $C C L 5$ gene may vary across different racial/ethnic groups.

The functional impact of $C C L 5$ sequence variants is complicated by the high degree of linkage disequilibrium within both the promoter and intron 1 region. An and co-workers (2006), evaluated the impact of three SNPs detected in the promoter region (rs2280788 -28C/G, rs2107538 -405 G/A) and intron 1 of CCL5 rs2280789 [189]. They demonstrated that transcriptional regulation of $C C L 5$ was primarily governed by an intron 1.1 A/G SNP (rs2280789). Intron $1.1 \mathrm{G}$ allele corresponded with a strong decrease in transcriptional activity of RANTES; whereas, the $-28 \mathrm{G}$ allele had a modest up-regulation in human cell lines. In our stratified analysis, the intron 1.1 CCL5 rs $2280789 \mathrm{AG}$ or $\mathrm{AG}+\mathrm{GG}$ genotypes were associated with a marginal $36-41 \%$ decrease in PCA risk among men of African descent from the U.S.; however, these findings require further evaluation in a larger study set. The CCL5 rs $2280788-28 \mathrm{C} / \mathrm{G}$ was not evaluated in the current study, since the $\mathrm{C}$ allele frequency is $0 \%$ for African-American men, as reported in NCBI. The functional consequence of SNPs detected in CCL5 is further perplexed by their interaction with downstream receptors.

The biological activity mediated by CCL5 is facilitated through its interaction with chemokine receptors (CCR1, CCR2, CCR3, and CCR5). However, relative to CCR1-3, CCR5 plays a more important role in CCL5-mediated cell migration [190]. CCR5, a member of the beta chemokine receptor family, is a seven transmembrane 
protein, which is expressed by T cells and macrophages. Over expression of CCR5 has been detected in aggressive prostate cancer tissue relative to benign prostatic hyperplasia [75]. The CCR5 rs $1799988 \mathrm{C}$ allele is significantly associated with viral load set point (i.e., decreased time from asymptomatic $\mathrm{HIV}^{+}$to AIDS and increased infectiousness) and AIDS progression [191]; however, there are no published reports for this 5'UTR SNP in relation to prostate cancer or other inflammatory/immune response-related diseases. In the current study, we observed a 1.52-1.75 fold increase in the risk of developing prostate cancer among all men of African descent who possessed the CCR5 rs $1799988 \mathrm{CC}$ genotype. However, the impact of this SNP in relation to PCA risk was more pronounced among men of African descent from Jamaica relative to U.S. men. This increased risk may have an impact on transcriptional activity, which may result in increased protein levels of CCR5; however, this requires confirmation using ex vivo, in vitro, and micro-dissected tumor tissue-based assays.

The functional consequence of intronic sequence variants, CCR6 rs3093024, CCR4 rs6550178 and CXCR7 rs7559855, is unknown for any cancer. However, our lab observed a significant 3-factor gene-gene interaction (CCR6 rs3093024-CCR4 rs6550178-CXCR7 rs7559855) model, which was the best predictor of PCA risk among Jamaican men $($ Permutation testing $\mathrm{p}$-value $=0.017)$. Although these chemokine sequence variants have not been studied in relation to PCA in the literature, the genes in which these variants reside are associated with PCA. Several published reports have implicated that the expression of CCR6, CCR4 and CXCR7 plays a role in prostate cancer progression. Ghadjar and co-workers (2008) showed the CCR6 protein was expressed in over $50 \%$ of prostatic tumors and strongly associated with aggressive 
prostate cancer, according to gleason score $(\mathrm{p}$-value $=0.003)$ and tumor stage $(\mathrm{p}<$ 0.0005) [192]. For CXCR7, Wang and associates (2008) demonstrated that CXCR7/RDC1 protein expression increases gradually from PIN to localized and metastatic PCA [86]. CXCR7/RDC1 targets cadherin-11 and influences the expression of pro-angiogenic VEGF and IL8 in prostate cancer, which may contribute to tumor growth. In addition, CXCR7 is a direct target of hypermethylated in cancer 1 (HIC1), a gene that regulates proliferation migration and invasion [193]. The promoter of HIC1 is hypermethylated in prostate cancer cells. Restoration of HIC1 in prostate cancer cell lines, PC3 and C4-2B, inhibited cellular proliferation, migration and invasion via down regulation of MMP2/3 protein expression. A study by Derhovanessian and colleagues (2009) observed that hormone-resistant prostate cancer patients with IL17+ T cells lacking the expression of CCR4 were strongly associated with a poor prognosis [194]. CCR4 expression may have a protective effect against prostate cancer progression.

The strengths, limitations and future directions were considered in relation to our findings on PCA susceptibility among men of African descent. Forty-three sequence variants were evaluated in relation to prostate cancer risk among men of African descent from the U.S. and Jamaica [35]. A strong correlation between the minor allele frequencies between these two study populations enabled us to pool genetic data to identify relationships that would have remained undetected if we evaluated the populations separately. As a result of pooling, we identified three SNPs (i.e., CCL5 rs3817655, CCL5 rs2107538, CCR5 rs1799988) that were significantly associated with prostate cancer in the total population even after adjusting for age and multiple hypothesis testing. Upon stratification by study center, we cannot rule out the possibility 
that race/ethnic specific sequence variants may track with disease progression or prognosis. Consequently, future targeted sequencing will allow us to identify, evaluate and validate novel and commonly reported chemokine-associated SNPs as tumor classification and prognostication tools among African-American, Caribbean, African and European men. Such efforts will require pooled data from multi-center studies that seek to identify the genetic signatures related to prostate cancer health disparities domestically and globally. In addition, molecular biological studies are needed to understand the functional consequence of the CCL5 and CCR5 sequence variants on: mRNA expression/stability, or protein expression, structure and/or function. This will require observational studies that allow us to consider lifestyle, geographical, environmental, or cultural differences that may interact with genetic susceptibilities and subsequently modify PCA outcomes. In future studies, we will evaluate the mRNA and protein expression of CCL5 and CCR5 in metastatic and non-metastatic prostate cancer cell lines compared to normal prostate cells using qRT-PCR and western blot analysis. We will also examine the impact of coding and non-coding SNPs in CCL5 and CCR5 on cellular migration, proliferation and invasion in selected prostate cancer cell lines to determine the functional mechanism of selected SNPs. We will also evaluate the protein expression of CCL5 and CCR5 in tumor tissue collected from men of African and European descent to determine any unique expression profiles between ethnic groups. Lastly, study participants self-identified themselves as African-American, Caribbean, African, or Jamaican. Population admixture, which commonly occurs among men of African descent, may bias risk estimates. After adjusting risk estimates for West African Ancestry, risk estimates did not significantly vary when compared to unadjusted risk 
models (data not shown). Statistical power greater than $80 \%$ was used to observe effect sizes of $\geq 1.5$ (or $\leq 0.67)$ and 1.55 (or $\leq 0.64$ ) for the total and U.S. populations, respectively. All p-values were adjusted for multiple hypotheses testing to minimize false positive results using the false discovery rate and Bonferroni Correction. Despite these efforts, we cannot rule out the possibility that the significant relationships observed for the U.S. (CCL5 rs3817655) and total populations (CCL5 rs2107538, CCL5 rs3817655, CCR5 rs1799988) are suggestive and warrant further validation in larger studies. Future studies in our laboratory will focus on high-throughput targeted sequencing to evaluate the impact of novel and commonly reported CCL5 (rs2107538, rs3817655) and CCR5 (rs 1799988) sequence variants on PCA susceptibility and disease prognosis among men of African descent. Even modest variations in genotype allele frequencies among men of African descent can reduce the chances of replicating single SNP effects within and between independent and validation study sets. To ensure reproducibility within future and ongoing studies, extreme care is needed to select study sets with comparable ancestry and genetic backgrounds. 


\section{CHAPTER 5}

\section{THE IMPACT OF GENETIC VARIANTS IN INFLAMMATORY-RELATED GENES ON PROSTATE CANCER RISK AMONG MEN OF AFRICAN DESCENT}

Although case-control studies have evaluated the role of variant inflammatoryrelated loci in prostate cancer, their impact is virtually unknown among men of African descent. To address this, we evaluated the impact of inflammatory cytokine single nucleotide polymorphisms (SNPs) on prostate cancer risk for men of African descent. Forty-four SNPs in inflammatory cytokine-associated genes in germ-line DNA were evaluated among 814 African-American and Jamaican men (279 prostate cancer cases and 535 controls) using Illumina's Golden gate genotyping system, logistic regression and entropy-based MDR. Four SNPs were modestly associated with prostate cancer after adjusting for age. In the total population, inheritance of the IL1R2 rs11886877 AA, IL8RB rs $11574752 \mathrm{AA}$, TNF rs1800629 GA + AA, and TNF rs673 GA genotypes modestly increased prostate cancer risk by 1.45 to 11.7 -fold relative to the referent genotype. Among U.S. men, age-adjusted dominant, recessive and additive genetic models for the $I L 1 R 2$ rs 11886877 locus were linked to an increase in prostate cancer susceptibility. However, these main effects did not persist after adjusting for multiple hypothesis testing. Our preliminary data does not strongly support the hypothesis that inflammatory-related sequence variants influence prostate cancer risk among men of African descent. However, further evaluation is needed to assess whether other variant inflammatory-related genes may contribute to prostate cancer risk and disease 
progression in larger and ethnically diverse multi-center studies. Findings from our study will help to fill in the gaps in information pertinent to prostate cancer among men of African descent.

\section{Results}

Prevalence of inflammatory-associated sequence variants among men of African

\section{Descent}

Inheritance of variant inflammatory-related loci was fairly common among African-American men in the current study. Specifically, the minor allele frequencies of 44 sequence variants ranged from $3 \%$ to $48 \%$, as depicted in Table 8 . Notably, the observed genotype frequency distribution among controls did not significantly deviate from expected counts according to the Hardy Weinberg equilibrium. With the exception of three loci (IL1RN rs4251961, IL10RB rs999788, and TNF rs673), the observed genotype frequencies in the current study corroborated with values for individuals of African-American/African ancestry, reported in the NCBI's SNP entrez Table 8 (p-value $=0.081-0.975)$.

\section{Relationship between inflammatory sequence variants and prostate cancer risk}

Seven out of 44 sequence variants detected in inflammatory-related genes were modestly associated with prostate cancer risk among 814 men of African descent (279 cases and 535 controls) [36]. For unadjusted risk models, elevations in prostate cancer susceptibility were observed among carriers of $I L 1 R 2$ rs 1188687 (AA, GA+AA), IL8RB rs11574752 (AA, GA+AA), TNF rs1800629 (GA, GA+AA), TNF rs673 (GA), IL1A (rs17561 AA, rs2856836 GG) and IL10RA rs4252243 AA genotypes with risk estimates ranging from 0.17-11.7 among men of African descent. Only half of these loci remained 
significant after adjusting for age, namely the $I L 1 R 2$ rs 1188687 (AA, GA+AA), IL8RB rs 11574752AA, and TNF rs673GA markers (Table 13a). Inheritance of $I L 1 R 2$ $r s 1188687$ [AA $\left(\mathrm{OR}_{\text {age-adjusted }}=1.92 ; 95 \% \mathrm{CI}=1.11-3.32\right), \mathrm{GA}+\mathrm{AA}\left(\mathrm{OR}_{\text {age-adjusted }}=1.46\right.$; $95 \% \mathrm{CI}=1.01-2.10)]$, IL8RB rs $11574752\left[\mathrm{AA}\left(\mathrm{OR}_{\text {age-adjusted }}=38.4 ; 95 \% \mathrm{CI}=3.86-\right.\right.$ 382.8), recessive genetic model $\left.\left(\mathrm{OR}_{\text {age-adjusted }}=39.2 ; 95 \% \mathrm{CI}=3.94-390\right)\right], T N F$ $r s 1800629\left[\mathrm{GA}\left(\mathrm{OR}_{\text {age-adjusted }}=1.54 ; 95 \% \mathrm{CI}=1.06-2.24\right), \mathrm{GA}+\mathrm{AA}\left(\mathrm{OR}_{\text {age-adjusted }}=1.53\right.\right.$; $95 \% \mathrm{CI}=1.06-2.20)]$ and $T N F r s 673\left[\mathrm{GA}\left(\mathrm{OR}_{\text {age-adjusted }}=1.50 ; 95 \% \mathrm{CI}=1.04-2.16\right)\right]$ genotypes were associated with an increase in PCA risk among men of African descent (Table 13a). However, IL1R2 rs 11886877 marker was the only genetic susceptibility factor that was significant under the additive genetic model, indicative of a significant dose-response effect in relation to the number of inherited minor allele $(\mathrm{P}-$ trend $=0.010)$. The aforementioned markers were not classified as important prostate cancer predictors after adjusting for multiple comparisons bias using the Bonferroni correction, with a significance cut-off of 0.0011 . 
Table 13a. Relationship between Inflammatory-associated SNPs and PCA Risk among men of African Descent.

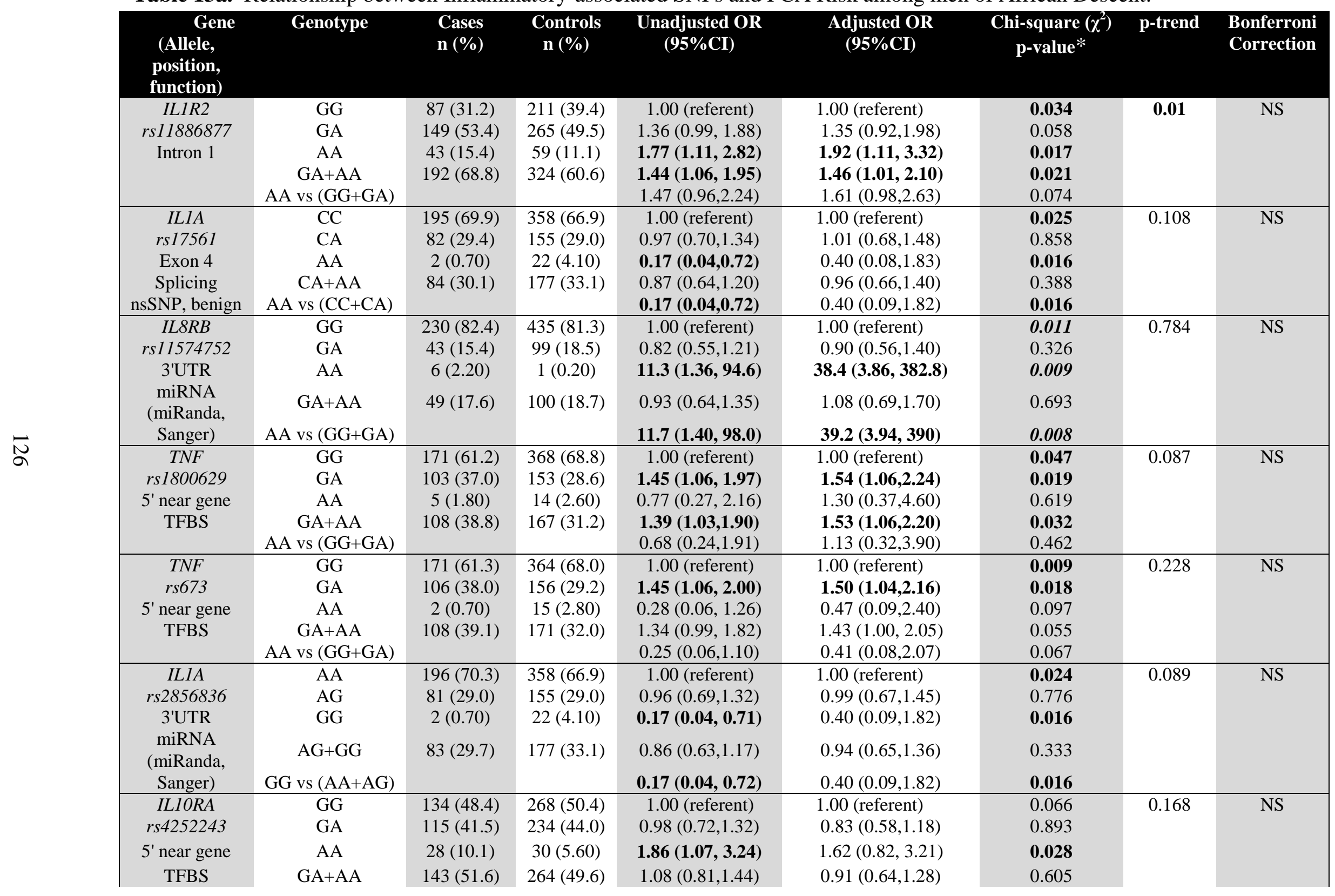


The chi-square $(\chi 2)$ test $\mathrm{p}$-values were used to determine the difference in the genotype frequencies between cases and controls. *Fisher's p-values were calculated when expected genotype counts were $<5$ for either cases and controls. Significant odd ratios (ORs) and 95\% confidence interval (CI) are indicated in boldface. Abbreviations: UTR, untranslated region; TFBS, transcription factor binding site; ESE exonic splicing enhancer; ESS, exonic splicing silencers; nsSNP, non-synonymous coding SNP; miRNA, microRNA binding site. 
Upon stratification by sub-population, modestly significant prostate cancer predictors varied by racial/ethnic group in the unadjusted and adjusted risk models. Possession of the RNASEL $r$ s $1213524 \mathrm{AG}\left(\mathrm{OR}_{\text {age-adjusted }}=2.10 ; 95 \% \mathrm{CI}=1.04-4.24\right)$ genotype was associated with a 2.10-fold increase in the risk of developing prostate cancer among Jamaican men (Table 13b). However, this loci was not significant in the dominant, recessive or additive genetic models. Similar to the total population, inheritance of sequence variants in ILIR2, ILIORA and TNF among U.S. men were linked with an increase in prostate cancer risk. Among U.S. men, four inflammatory-related sequence variants, IL1R2 rs 11886877 (GA, GA+AA, AA), TNF rs673 GA, TNF rs1800629 (GA, GA+AA), IL10RA rs4252243 AA were associated with 1.4-2.34 fold increase in prostate cancer risk; whereas, reductions were observed among carriers of IL1B rs1071676 GC+CC, IL1B rs1143634 GA+AA, and IL1A rs1800587 AA genotypes within unadjusted risk estimate models ( $\mathrm{p}$-value $\geq 0.028$ ). Out of these 7 markers, most of the genetic models for the IL1R2 loci remained significant after adjusting for age. Possession of ILIR2 rs11886877 variant alleles under the dominant/co-dominant [AA $\left(\mathrm{OR}_{\text {age-adjusted }}=2.75 ; 95 \% \mathrm{CI}=1.38-5.50\right), \mathrm{GA}+\mathrm{AA}\left(\mathrm{OR}_{\text {age-adjusted }}=1.82 ; 95 \% \mathrm{CI}=1.82-\right.$ 2.88), ILIR2 rs 11886877 recessive genetic $\left.\left(\mathrm{OR}_{\text {age-adjusted }}=2.05 ; 95 \% \mathrm{CI}=1.10-3.80\right)\right]$ and IL10RA rs4252243 recessive genetic $\left(\mathrm{OR}_{\text {age-adjusted }}=2.49 ; 95 \% \mathrm{CI}=1.08-5.72\right)$ models were associated with an elevation in PCA susceptibility among U.S. men of African descent. In the stratified analysis, none of the aforementioned markers survived correction for multiple hypothesis testing according to the new significance level among U.S. and Jamaican men (Bonferroni Correction p-value $\geq 0.004$ and $p$-value $\geq 0.018$ ), respectively. 
Table 13b. Relationship between Inflammatory-associated SNPs and PCA Risk stratified by racial ethnic group.

\begin{tabular}{|c|c|c|c|c|c|c|c|c|c|}
\hline $\begin{array}{l}\text { Gene (Allele, } \\
\text { location, } \\
\text { function) }\end{array}$ & Genotype & $\begin{array}{l}\text { Unadjusted } \\
\text { OR (95\%CI) } \\
\text { US men }\end{array}$ & $\begin{array}{l}\text { Age-Adjusted } \\
\text { OR }(95 \% \mathrm{CI}) \\
\text { US men }\end{array}$ & $\begin{array}{l}\text { Unadjusted } \\
\text { OR }(95 \% \text { CI }) \\
\text { Jam men }\end{array}$ & $\begin{array}{l}\text { Age-Adjusted OR } \\
(95 \% \mathrm{CI}) \\
\text { Jam men }\end{array}$ & $\begin{array}{c}\chi^{2} \\
\text { p-value* } \\
\text { US men }\end{array}$ & $\begin{array}{c}\chi^{2} \\
\text { p-value* } \\
\text { Jam men }\end{array}$ & $\begin{array}{l}\mathrm{p} \text { trend } \\
\text { US men }\end{array}$ & $\begin{array}{l}\mathrm{p} \text { trend } \\
\text { Jam men }\end{array}$ \\
\hline$I L 1 B$ & GG & 1.00 (referent) & 1.00 (referent) & 1.00 (referent) & 1.00 (referent) & 0.050 & 0.550 & \multirow[t]{5}{*}{0.022} & \multirow[t]{5}{*}{0.276} \\
\hline$r s 1071676$ & $\mathrm{GC}$ & $0.72(0.48,1.10)$ & $0.70(0.42,1.14)$ & $1.39(0.71,2.70)$ & $1.28(0.62,2.64)$ & 0.124 & 0.338 & & \\
\hline UTR'3 & $\mathrm{CC}$ & $0.16(0.02,1.25)$ & $0.19(0.02,2.00)$ & $2.02(0.18,22.8)$ & $1.15(0.10,14.6)$ & 0.081 & 0.568 & & \\
\hline $\begin{array}{l}\text { miRNA } \\
\text { (miRanda. }\end{array}$ & $\mathrm{GC}+\mathrm{CC}$ & $0.66(0.44,1.00)$ & $0.66(0.40,1.10)$ & $1.42(0.74,2.72)$ & $1.26(0.62,2.60)$ & 0.050 & 0.294 & & \\
\hline Sanger) & $\mathrm{CC}$ vs $(\mathrm{GG}+\mathrm{GC})$ & $0.18(0.02,1.36)$ & $0.21(0.02,2.18)$ & $1.89(0.16,21.1)$ & $1.10(0.08,13.7)$ & 0.096 & 0.606 & & \\
\hline$I L 1 B$ & GG & 1.00 (referent) & 1.00 (referent) & 1.00 (referent) & 1.00 (referent) & 0.051 & 0.447 & \multirow[t]{5}{*}{0.016} & \multirow[t]{5}{*}{0.203} \\
\hline rs1143634 & GA & $0.67(0.44,1.01)$ & $0.65(0.40,1.06)$ & $1.51(0.76,3.00)$ & $1.37(0.64,2.90)$ & 0.058 & 0.243 & & \\
\hline Exon 4 & AA & $0.21(0.02,1.60)$ & $0.24(0.02,2.86)$ & $2.05(0.18,23.0)$ & $1.16(0.10,14.6)$ & 0.131 & 0.561 & & \\
\hline $\begin{array}{c}\text { Splicing } \\
\text { (ESE/ ESS) }\end{array}$ & $\mathrm{GA}+\mathrm{AA}$ & $0.63(0.42,0.95)$ & $0.62(0.38,1.02)$ & $1.54(0.78,3.00)$ & $1.36(0.65,2.82)$ & 0.028 & 0.208 & & \\
\hline $\begin{array}{c}\text { cds- } \\
\text { synonmous }\end{array}$ & AA vs(GG+GA) & $0.23(0.02,1.80)$ & $0.27(0.02,3.20)$ & $1.89(0.16,21.1)$ & $1.10(0.08,13.7)$ & 0.157 & 0.606 & & \\
\hline \multirow{5}{*}{$\begin{array}{l}\text { IL1R2 } \\
\text { rs11886877 } \\
\text { Intron } 1\end{array}$} & GG & 1.00 (referent) & 1.00 (referent) & 1.00 (referent) & 1.00 (referent) & 0.007 & 0.889 & \multirow[t]{5}{*}{0.002} & \multirow[t]{5}{*}{0.631} \\
\hline & GA & $1.60(1.08,2.40)$ & $1.63(1.00,2.64)$ & $0.92(0.50,1.68)$ & $0.94(0.48,1.80)$ & 0.020 & 0.782 & & \\
\hline & AA & $2.34(1.31,4.16)$ & $2.75(1.38,5.50)$ & $0.82(0.36,1.86)$ & $0.94(0.38,2.30)$ & 0.004 & 0.633 & & \\
\hline & $\mathrm{GA}+\mathrm{AA}$ & $1.72(1.18,2.52)$ & $1.82(1.14,2.88)$ & $0.89(0.50,1.58)$ & $0.94(0.50,1.74)$ & 0.005 & 0.700 & & \\
\hline & AA vs $(\mathrm{GG}+\mathrm{GA})$ & $1.76(1.04,2.96)$ & $2.05(1.10,3.80)$ & $0.86(0.40,1.80)$ & $0.97(0.43,2.20)$ & 0.033 & 0.691 & & \\
\hline \multirow{5}{*}{$\begin{array}{c}R N A S E L \\
r s 12135247 \\
\text { UTR'3 } \\
\text { TFBS, } \\
\text { miRNA }\end{array}$} & AA & 1.00 (referent) & 1.00 (referent) & 1.00 (referent) & 1.00 (referent) & 0.820 & 0.025 & \multirow[t]{5}{*}{0.909} & \multirow[t]{5}{*}{0.216} \\
\hline & AG & $1.06(0.72,1.58)$ & $1.14(0.71,1.84)$ & $2.17(1.14,4.12)$ & $2.10(1.04,4.24)$ & 0.756 & 0.018 & & \\
\hline & GG & $0.77(0.30,1.96)$ & $0.70(0.24,2.10)$ & $0.45(0.08,2.40)$ & $0.28(0.04,1.70)$ & 0.570 & 0.344 & & \\
\hline & $\mathrm{AG}+\mathrm{GG}$ & $1.02(0.70,1.50)$ & $1.07(0.68,1.68)$ & $1.81(0.99,3.30)$ & $1.68(0.88,3.24)$ & 0.906 & 0.053 & & \\
\hline & GG vs (AG+AA) & $0.76(0.30,1.92)$ & $0.67(0.22,1.97)$ & $0.36(0.06,1.91)$ & $0.22(0.04,1.35)$ & 0.555 & 0.232 & & \\
\hline \multirow{5}{*}{$\begin{array}{c}T N F \\
r s 1800629 \\
5 ' \text { near gene } \\
\text { TFBS }\end{array}$} & GG & 1.00 (referent) & 1.00 (referent) & 1.00 (referent) & 1.00 (referent) & 0.101 & 0.782 & \multirow[t]{5}{*}{0.113} & \multirow[t]{5}{*}{0.549} \\
\hline & GA & $1.50(1.03,2.20)$ & $1.52(0.96,2.42)$ & $1.21(0.68,2.12)$ & $1.41(0.78,2.63)$ & 0.034 & 0.518 & & \\
\hline & AA & $0.90(0.28,2.80)$ & $1.51(0.36,6.24)$ & $1.00(0.06,16.3)$ & $1.00(0.06,17.2)$ & 0.842 & 1.000 & & \\
\hline & $\mathrm{GA}+\mathrm{AA}$ & $1.44(0.99,2.10)$ & $1.53(0.97,2.40)$ & $1.20(0.68,2.10)$ & $1.40(0.75,2.60)$ & 0.050 & 0.525 & & \\
\hline & AA vs $(\mathrm{GG}+\mathrm{GA})$ & $0.78(0.25,2.42)$ & $1.32(0.32,5.40)$ & $0.94(0.06,15.2)$ & $0.88(0.05,15.0)$ & 0.666 & 0.962 & & \\
\hline \multirow{5}{*}{$\begin{array}{c}I L 1 A \\
\text { rs1800587 } \\
\text { UTR'5 } \\
\text { TFBS, } \\
\text { Splicing } \\
\text { (ESE } \text { or } \text { ESS) }\end{array}$} & GG & 1.00 (referent) & 1.00 (referent) & 1.00 (referent) & 1.00 (referent) & 0.088 & 0.450 & \multirow[t]{5}{*}{0.028} & \multirow[t]{5}{*}{0.224} \\
\hline & GA & $0.75(0.50,1.10)$ & $0.68(0.42,1.08)$ & $1.38(0.76,2.50)$ & $1.42(0.74,2.72)$ & 0.119 & 0.297 & & \\
\hline & AA & $0.56(0.32,0.96)$ & $0.78(0.40,1.53)$ & $1.56(0.69,3.50)$ & $1.64(0.70,4.00)$ & 0.038 & 0.279 & & \\
\hline & $\mathrm{GA}+\mathrm{AA}$ & $0.70(0.48,1.00)$ & $0.70(0.45,1.10)$ & $1.42(0.80,2.50)$ & $1.47(0.80,2.72)$ & 0.053 & 0.222 & & \\
\hline & AA vs $(\mathrm{GG}+\mathrm{GA})$ & $0.66(0.40,1.10)$ & $0.96(0.52,1.80)$ & $1.30(0.62,2.70)$ & $1.34(0.60,3.00)$ & 0.105 & 0.478 & & \\
\hline \multirow{5}{*}{$\begin{array}{c}\text { IL10RA } \\
r s 4252243 \\
5 \text { ' near gene } \\
\text { TFBS }\end{array}$} & GG & 1.00 (referent) & 1.00 (referent) & 1.00 (referent) & 1.00 (referent) & 0.062 & 0.632 & \multirow[t]{5}{*}{0.275} & \multirow[t]{5}{*}{0.329} \\
\hline & GA & $0.92(0.63,1.33)$ & $0.70(0.44,1.10)$ & $1.24(0.70,2.20)$ & $1.21(0.64,2.28)$ & 0.648 & 0.448 & & \\
\hline & AA & $2.02(1.04,3.95)$ & $2.10(0.90,4.98)$ & $1.50(0.54,4.26)$ & $1.04(0.34,3.20)$ & 0.038 & 0.436 & & \\
\hline & $\mathrm{GA}+\mathrm{AA}$ & $1.03(0.72,1.50)$ & $0.81(0.52,1.30)$ & $1.28(0.74,2.21)$ & $1.15(0.64,2.10)$ & 0.863 & 0.328 & & \\
\hline & AA vs (GG+GA) & $2.11(1.10,4.02)$ & $2.49(1.08,5.72)$ & $1.37(0.50,3.74)$ & $1.02(0.40,2.98)$ & 0.023 & 0.539 & & \\
\hline$T N F$ & GG & 1.00 (referent) & 1.00 (referent) & 1.00 (referent) & 1.00 (referent) & 0.027 & 0.452 & 0.279 & 0.874 \\
\hline$r s 673$ & GA & $1.50(1.02,2.20)$ & $1.46(0.92,2.30)$ & $1.22(0.70,2.14)$ & $1.41(0.76,2.62)$ & 0.025 & 0.498 & & \\
\hline
\end{tabular}




\begin{tabular}{|c|c|c|c|c|c|c|c|}
\hline 5' near gene & AA & $0.24(0.03,1.84)$ & $0.54(0.06,4.44)$ & $0.33(0.03,3.24)$ & $0.40(0.03,4.70)$ & 0.178 & 0.340 \\
TFBS & GA+AA & $1.38(0.95,2.00)$ & $1.40(0.88,2.20)$ & $1.14(0.66,2.00)$ & $1.33(0.72,2.46)$ & 0.087 & 0.635 \\
& AA vs (GG+GA) & $0.21(0.02,1.60)$ & $0.47(0.06,3.91)$ & $0.31(0.03,2.98)$ & $0.35(0.03,4.08)$ & 0.132 & 0.308 \\
\hline
\end{tabular}

The chi-square $\left(\chi^{2)}\right.$ test p-values were used to determine the difference in the genotype frequencies between cases and controls.

*Fisher's p-values were calculated when expected genotype counts were <5 for either cases and controls. Significant odd ratios (ORs) and 95\% confidence interval (CI) are indicated in boldface. Abbreviations: UTR, untranslated region; TFBS, transcription factor binding site; ESE exonic splicing enhancer; ESS, exonic splicing silencers; nsSNP, non-synonymous coding SNP; Jam, Jamaican. 


\section{Analysis of gene-gene interactions using Multi-factor Dimensionality Reduction}

MDR analyses revealed that the one-, two- and three-factor interaction models survived multiple hypothesis testing with a 90-100\% CVC and a 58-61\% ATA values among men of African descent, as shown in Table 14a (Permutation p-value $=0.001$ 0.013). TNF rs673 was selected as the best one-factor model among men of African descent, based on the highest information gain score relative to the other cytokineassociated sequence variants $(\mathrm{IG}=2.08 \%)$ (Figure 12). For the two-factor interaction model (IL10RA rs4252243, IL10RB rs8178433), the MDR entropy-based graph revealed no informative pairwise mutual information gain score for the interaction (Figure 12). The three-factor gene-gene interaction model (IL1R2 rs11886877, IL10 rs1800896, IL10RA rs4252243) was selected as the best predictor of PCA susceptibility among men of African descent based on its association with the highest ATA value (ATA $=61 \%$ ). This three-factor interaction model was primarily driven by a highly synergistic (red line) pairwise interaction between IL10 and IL1R2 associated with a mutual information gain score of $0.86 \%$. This pairwise interaction was more informative than each individual SNP when considered alone (Figure 12).

Upon stratification by ethnic group, the one- and three-factor interaction models were statistically significant with $100 \%$ CVC and 60-67\% ATA values among U.S. men $($ Permutation testing p-value $=0.001-0.005)($ Table 14b). IL10 rs4252243 was selected as the best one-factor predictor of prostate cancer, based on a $100 \% \mathrm{CVC}$ and $59.7 \%$ ATA. Perhaps MDR allows us to detect important prostate cancer predictors that we were unable to observe under the Bonferroni adjusted LR models. The three-factor interaction model (IL1B rs 1143627, IL1A rs 1800587, IL1RN rs315951) was selected as 
the best predictor of PCA risk due to its high CVC value of 100\% and ATA score of 67\% among U.S. men (Permutation testing p-value $=0.001$ ). The synergy of this interaction model was driven by a highly synergistic interaction between IL1B rs 1143627 and IL1A rs 1800587 with an informative IG score of $1.93 \%$ (Data not shown). Among Jamaican men, the two-factor (ILIRN rs315951 and ILIRI rs949963) interaction model associated with a 100\% CVC value and 65\% ATA score remained significant after adjustment for multiple hypothesis testing $($ Permutation testing $\mathrm{p}$-value $=0.008)$. This two-factor interaction model was highly synergistic due to its informative pairwise mutual information gain score of $4.77 \%$ (Data not shown). 
Table 14a. Interactions and main effects of Inflammatory-associated SNPs as predictors of PCA using age-adjusted MDR among men of African Descent.

\begin{tabular}{|c|c|c|c|c|}
\hline $\begin{array}{l}\text { Best Model } \\
\text { (dbSNPID \#) }\end{array}$ & Interactions & $\begin{array}{c}\text { Cross } \\
\text { Validation } \\
\text { Consistency } \\
(\mathrm{CVC})\end{array}$ & $\begin{array}{l}\text { Average } \\
\text { Testing } \\
\text { Accuracy } \\
\text { (ATA) }\end{array}$ & $\begin{array}{c}\text { Permutation } \\
\text { Testing } \\
p \text {-value }\end{array}$ \\
\hline$\frac{\text { One Factor }}{\text { TNF rs673 }}$ & 44 & $10 / 10$ & 0.580 & 0.001 \\
\hline $\begin{array}{l}\text { Two Factor } \\
\text { IL10RA rs } 4252243 \\
\text { IL10RB rs } 8178433\end{array}$ & 946 & $9 / 10$ & 0.598 & 0.013 \\
\hline $\begin{array}{l}\text { Three Factor } \\
\text { IL1R2 rs } 11886877 \\
\text { IL10 rs } 1800896 \\
\text { IL10RA rs } 4252243\end{array}$ & 13,244 & $9 / 10$ & 0.610 & 0.003 \\
\hline
\end{tabular}

*Analysis was restricted to 279 cases and 535 controls. Interaction models were adjusted for multiple hypothesis testing with 1,000 permutations. 


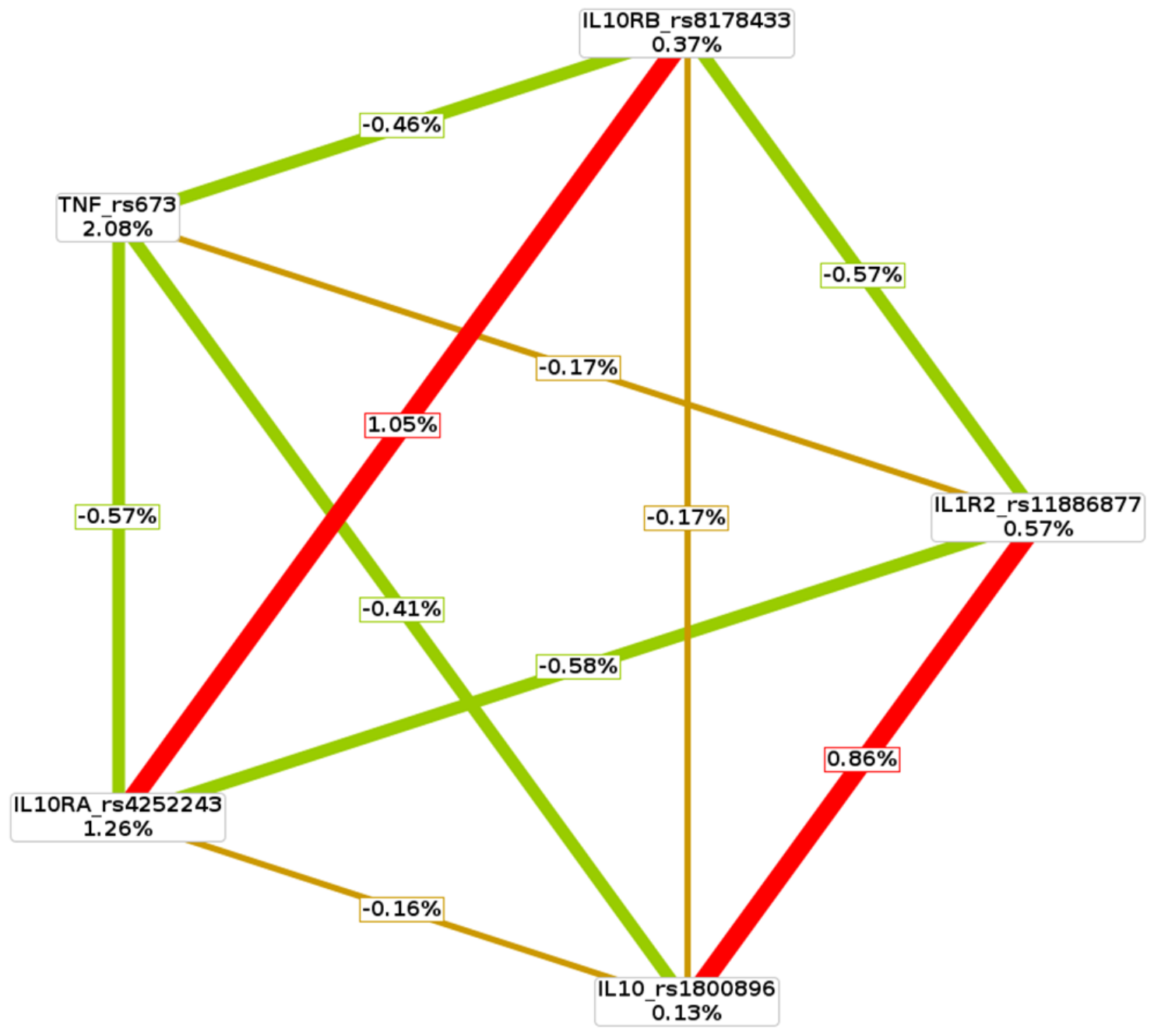

Figure 12. Entropy graph of Cytokine gene-gene interactions among U.S. and Jamaican men of African Descent. MDR analysis revealed that 1-, 2- and 3-factor interaction models survived multiple hypothesis testing with a $90-100 \% \mathrm{CVC}$ and 58-61\% ATA values (Permutation p-value $=0.001-0.013$ ). The three-factor genegene interaction model (IL1R2 rs11886877, IL10 rs1800896, IL10RA rs4252243) was the best predictor of PCA risk among men of African descent. The synergy of this model was based on interaction information gain score of $0.86 \%$ for IL10 and IL1R2 that is higher than the mutual information gain scores of each variant. 
Table 14b. Interactions and main effects of Inflammatory-associated SNPs as predictors of PCA using age-adjusted MDR among U.S. men of African Descent.

\begin{tabular}{|c|c|c|c|c|}
\hline $\begin{array}{l}\text { Best Model } \\
(\text { dbSNPID \#) }\end{array}$ & Interactions & $\begin{array}{c}\text { Cross } \\
\text { Validation } \\
\text { Consistency } \\
(\text { CVC) }\end{array}$ & $\begin{array}{c}\text { Average } \\
\text { Testing } \\
\text { Accuracy } \\
\text { (ATA) }\end{array}$ & $\begin{array}{c}\text { Permutation } \\
\text { Testing } \\
p \text {-value }\end{array}$ \\
\hline$\frac{\text { One Factor }}{\text { IL10RA rs } 4252243}$ & 44 & $10 / 10$ & 0.597 & 0.005 \\
\hline $\begin{array}{l}\text { Two Factor } \\
\text { IL10RA rs4252243 } \\
\text { IL10RB rs } 8178433\end{array}$ & 946 & $10 / 10$ & 0.627 & 0.084 \\
\hline $\begin{array}{l}\text { Three Factor } \\
\text { IL1B rs } 1143627 \\
\text { IL1A rs } 1800587 \\
\text { IL1RN rs315951 }\end{array}$ & 13,244 & $10 / 10$ & 0.665 & 0.001 \\
\hline
\end{tabular}

*Analysis was restricted to 279 cases and 535 controls. Interaction models were adjusted for multiple hypothesis testing with 1,000 permutations. 
Table 14c. Interactions and main effects of Inflammatory-associated SNPs as predictors of PCA using age-adjusted MDR among Jamaican men of African Descent.

\begin{tabular}{|lcccc|}
\multicolumn{1}{|c}{$\begin{array}{c}\text { Best Model } \\
\text { (dbSNPID \#) }\end{array}$} & Interactions & $\begin{array}{c}\text { Cross } \\
\text { Validation } \\
\text { Consistency } \\
\text { (CVC) }\end{array}$ & $\begin{array}{c}\text { Average } \\
\text { Testing } \\
\text { Accuracy } \\
\text { (ATA) }\end{array}$ & $\begin{array}{c}\text { Permutation } \\
\text { Testing } \\
\text { p-value }\end{array}$ \\
\hline $\begin{array}{l}\text { One Factor } \\
\text { IL1R2 rs4141134 }\end{array}$ & 44 & $10 / 10$ & 0.577 & 0.243 \\
\hline $\begin{array}{l}\text { Two Factor } \\
\text { IL1RN rs315951 }\end{array}$ & 946 & $10 / 10$ & 0.653 & 0.008 \\
IL1R1 rs949963 & & & & \\
\hline Three Factor & 13,244 & $10 / 10$ & 0.657 & 0.060 \\
\hline $\begin{array}{l}I L 1 A \text { rs } 1304037 \\
\text { IL10 rs } 1800872\end{array}$ & & & & \\
IL1RN rs315951 & & & & \\
\hline
\end{tabular}

*Analysis was restricted to 279 cases and 535 controls. Interaction models were adjusted for multiple hypothesis testing with 1,000 permutations. 


\section{Discussion}

Chronic inflammation has been associated with tumor development and metastasis in cancer progression. Inflammatory response is regulated through a complex network of cytokines, cytokine receptors and downstream targets that synergistically regulate innate/humoral immune and inflammatory processes. Recent molecular and genetic epidemiology studies have demonstrated that chronic inflammation and susceptibilities in inflammatory-associated genes are related to aggressive cancer phenotypes, including lymphoma, and gastric and prostate cancer [101, 122, 195-197]. However, to our knowledge, there are limited published reports on the impact of inheriting multiple cytokine-related functional sequence variants in relation to prostate cancer among men of African Descent. Therefore, our current study evaluated the individual and combined effects of 44 inflammatory associated sequence variants on prostate cancer risk among 279 cases and 535 disease-free men of African descent from the U.S and Jamaica [36]. Cytokine-associated sequence variants (IL1R2 rs 11886877 AA, IL10RA rs4252243 AA) were associated with a 2.11-2.34-fold increase in risk of developing prostate cancer among men of Descent from the U.S. However, these sequence variants did not survive multiple hypothesis testing. MDR analysis revealed significant and highly synergistic age adjusted two-factor (ILIORB rs8178433 and IL10RA rs4252243) pairwise and three-factor (IL1R2 rs11886877, IL10 rs1800896, IL10RA rs4252243) interaction models associated with prostate cancer risk among men of African descent. Nevertheless, the three-factor interaction was selected as the overall best predictor of prostate cancer susceptibility among men of African based upon an informative information gain score and high ATA value (Permutation p-value $=0.003$ ). 
Our findings show a modest increase in prostate cancer risk for unadjusted and adjusted logistic regression models for ILIR2 rs11886877 among men of African descent. Although this sequence variant did not survive multiple hypothesis testing, the additive, dominant and recessive genetic models of this variant were significant. The ILIR2 rs 11886877 SNP is located 2415 base pairs from the transcription start site. Its close proximity to the regulatory region of the $I L 1 R 2$ gene suggests it may have a high likelihood of regulating $I L I R 2$ gene expression. Currently, there are no published reports on the relationship between $I L 1 R 2$ rs 11886877 and prostate cancer for any population. Although there is no evidence of the impact of this sequence variant on prostate cancer risk among European- and African-American men, the relationship between the ILIR2 gene expression and prostate cancer has been demonstrated through published reports [140, 198, 199]. However, Ricote and colleagues (2004) observed high protein expression of IL1R2 in high and low gleason score prostatic tumor tissue compared to normal prostatic tissue [140]. The study findings suggest that high expression of IL1R2 is in result of the absence of IL1Ra (antagonist of IL1) to mute the pro-inflammatory effect of IL1 $\alpha$ in prostate cancer. However, IL1 $\alpha$ does not have a high affinity to bind to IL1R2. Additionally, other studies also suggest that IL1R2 may function as a decoy receptor or natural inhibitor of IL1 $[139,140]$. Moreover, Leshem and colleagues found that the promoter region of $I L 1 R 2$ possesses putative binding motifs for the TMPRSS2/ERG fusion gene, which is highly expressed in aggressive prostate cancer [198]. When the expression of $I L I R 2$ was knocked down using small interfering RNAs, it resulted in the reduction of ZEB2 mRNA expression in hTERT/shp53/CyclinD-CDK4 overexpressing cells exposed to TMPRSS2/ERG [198]. The TMPRSS2/ERG fusion gene indirectly up- 
regulates $Z E B 2$, a facilitator of the epithelial to mesechymal transition (EMT), by binding to $I L 1 R 2$ to increase prostate cancer tumorigenesis [200]. Further investigation of $I L 1 R 2$ in relation to PCA risk is needed to determine the effect of $I L I R 2$ expression on prostate cancer tumorigenesis.

Additionally, MDR analyses revealed other inflammatory-related sequence variants associated with PCA susceptibility. Within a three-factor interaction model, the inheritance of ILIR2 rs11886877 combined with IL10 rs1800896 and IL1ORA rs4252243 was significantly associated with PCA susceptibility based upon an informative IG of 0.86\% for the pairwise interaction (IL1R2 rs11886877, IL10 rs1800896), individual IG score of $1.26 \%$ (IL10RA rs4252243) and ATA score of $61 \%$ among men of African descent. IL10 is a major anti-inflammatory cytokine and IL10RA (interleukin 10 receptor alpha) is a known mediator of its signaling in immunosuppression. For instance, Stearns and associates (2003) observed that IL10 treatment down-regulates the gene and protein expression of MMP2 and membrane type 1 MMP in non-immortalized primary prostate cancer cells (HPCA-10c) via its receptor IL10R [201]. Moreover, Cardillo and colleagues (2006) observed an increase in the protein expression of IL10 in the epithelium of prostatic tissue compared to normal prostatic tissue [202]. Based upon LR modeling, the inheritance of IL10 rs 1800896 and IL10RA rs425224 was associated with a marginal increase in PCA susceptibility among men of African from the U.S. men. This increase in PCA risk may be attributed to these genetic alterations within these genes (IL1O and IL10RA), which can impair gene function of these anti-inflammatory cytokines.

Out of 44 inflammatory-related sequence variants, 7 SNPs included in our study were evaluated in relation to prostate cancer outcomes within 4 independent 
observational studies $[121,122,125,126]$. Commensurate with our findings, two observational studies demonstrated that sequence variants detected in IL10 ( $r$ s1800871, rs 1800872) and IL8 rs4073 were not significantly related to prostate cancer risk [122, 126]. Inheritance of TNF rs 1800629 AA genotype was associated with a significant 1.8 fold increase in prostate cancer risk among North Indian men in a small study (150 cases, 150 controls); however, this marker resulted in null findings in a larger study (484 cases, 484 controls) $[121,122]$. In our preliminary analyses inheritance of one or more TNF rs1800629 A alleles was marginally associated with a 1.5-fold increase in prostate risk; however, this relationship did not survive adjustment after multiple hypothesis testing. Lastly, IL10 rs $1800896 \mathrm{G}$ and ILIB rs $1143627 \mathrm{C}$ alleles had protective effects in two separate Caucasian sub-populations. However, neither of these markers served as important prostate cancer predictors among African American men in the current study. Casey and colleagues (2002) showed a 2-fold increase in prostate cancer susceptibility linked to inheritance of the RNASEL rs486907 AA genotype among men of European descent [125]. However, this loci was not related to prostate cancer risk among African Americans in the current study. This may be due to differences in minor allele frequencies, prevalence of the sequence variants, environment exposures, failure to adjust findings for multiple hypothesis testing or inadequate sample size.

We considered the strengths, limitations and future directions of our study. Fortyfour sequence variants were evaluated in relation to prostate cancer risk among men of African descent from the U.S. and Jamaica. Upon stratification by study center, we identified race/ethnicity specific inflammatory-associated sequence variants associated with prostate cancer risk. However, selected inflammatory-related sequence variants did 
not show a robust relationship with prostate cancer susceptibility. Population admixture, which commonly occurs among men of African descent, may bias risk estimates. However, adjustment of risk estimates by West African Ancestry and/or age did not modify the directionality of observed risk estimates among men from the U.S. (Data not shown). Although, the sample statistical size of this study population is small, we ensured that we had ample power to accurately detect risk estimates. Our findings do not support the hypothesis that inflammatory related sequence variants are associated with prostate cancer among men of African descent. However, we cannot eliminate the possibility that ILIR2 and other inflammatory-related sequence variants not included in this study may influence the risk of prostate cancer development or aggressive tumor behavior. In larger studies, the impact of individual or interaction between inflammatory cytokine-associated SNPs in relation to prostate cancer tumor grade, biochemical or disease recurrence, and mortality will undergo evaluation using targeted sequencing, in vitro studies, in silico and bioinformatics tools. Such efforts will help to identify genetic markers linked to disproportionately high prostate cancer incidence, mortality, and morbidity rates among men of African descent. 


\section{CHAPTER 6}

\section{CONCLUSION AND SUMMARY}

The literature on the contribution of chronic inflammation to prostate cancer (PCA) development and progression has increasingly grown over the past decade. Many reports discuss how inflammatory-related genes (e.g., TLRs, chemokines, cytokines) and genetic alterations of these genes play a pivotal role in PCA pathogenesis. Toll-like receptors (TLRs), which are major mediators in innate immunity serve as a surveillance system. In the presence of pathogens, TLRs are activated and trigger the inflammatory response via innate immunity. Inflammation is a critical response in innate immunity that leads to tissue repair and attracts innate immune cells via production of cytokines/chemokines. Repetitive damage to prostatic tissue leads to chronic inflammation in the prostate. Genetic polymorphisms within the inflammatory and immune response pathway may lead to an imbalance in pro-and anti- inflammatory signals and result in prolonged chronic inflammation. Some inflammatory and immune response related sequence variants have been previously studied in relation to PCA risk; however, most of these studies focus on European and Asian sub-populations. Furthermore, the contribution of gene-gene interactions on PCA susceptibility has not been well studied. Failure to include gene-gene interactions may greatly limit the detection of markers that influence PCA susceptibility.

To address these gaps in the literature, we evaluated 119 single nucleotide polymorphisms (SNPs) within inflammatory and immune response-related genes (i.e., 
TLRs, chemokines and cytokines) among men of African descent [31, 35, 36 ]. Logistic regression (LR) analyses did not reveal any significant associations with PCA susceptibility that survived multiple hypothesis testing among toll-like receptor -related sequence variants. Interestingly after adjustment for multiple hypothesis testing of LR models, possession of CCL5 (rs2107538, rs3817655), CCR5 rs1799988 and IL1R2 rs11886877 sequence variants were strongly and/or marginally associated with PCA susceptibility among men of African descent. CCL5 [(rs2107538 (GA, AA), rs3817655 (GA, AA)] genotypes showed a decrease in PCA risk, primarily driven by the U.S. population. However, the variant alleles of IL1R2 rs11886877 A and CCR5 rs $1799988 \mathrm{G}$ were associated with an increase in PCA susceptibility among men of African descent.

Among the inflammatory and immune response associated gene-gene interactions, we observed several highly synergistic interactions. A highly synergistic three-factor (TLR10 rs11096957, TLR6 rs2381289 and IRF3 rs2304206) interaction model was observed with a high CVC value and ATA score among men of African descent from the U.S. and Jamaica (Permutation testing p-value $=0.001$ ). Additionally, this three-factor interaction model was the best predictor of PCA risk was primarily driven by pairwise interaction between TLR10 rs11096957 and IRF3 rs2304206 (IG = $1.32 \%)$ and the main effect of TLR6 rs $2381289(\mathrm{IG}=1.71 \%)$. Among U.S. men, the two-factor (TLR2 rs1898830, IRAK4 rs4251545) interaction model was selected as the best predictor of PCA risk, based on an informative pairwise mutual IG score (IG = $2.33 \%$ ) that exceeded main effects (Permutation testing $\mathrm{p}$-value $=0.001$ ). Chemokine associated interactions resulted in a three-factor (CCR6 rs3093024, CXCR7 rs7559855, and CCR4 rs6550178) interaction model as the best predictor of PCA risk among 
Jamaican men $($ ATA $=70.4 \%$; Permutation testing $p$-value $=0.017)$. The synergy of this interaction model was primarily based upon the informative pairwise mutual interaction information gain score between CCR6 rs309302 and CXCR7 rs7559855 (IG = 3.41\%) and the main effect of CCR4 rs6550178 (IG = 8.2\%). Lastly, cytokine-associated interaction models yielded a highly synergistic three-factor (ILIR2 rs11886877, IL10 rs1800896, IL10RA rs4252243) interaction model, primarily driven by IL1ORA $r s 4252243(\mathrm{IG}=1.26 \%)$ coupled with the IL1R2 rs11886877 -IL10 rs1800896 axis (IG $=0.86 \%)$ among men of African $($ ATA $=61 \%$; Permutation testing p-value $=0.003$ ). Collectively, our findings suggest that the inheritance of main [CCL5 (rs2107538, rs3817655), IL1R2 rs11886877] and joint [(TLR10 rs11096957, TLR6 rs2381289, and IRF3 rs2304206), (TLR2 rs1898830, IRAK4 rs4251545), (CCR6 rs3093024, CXCR7 rs7559855, and CCR4 rs6550178)] effects modify the PCA susceptibility among men of African descent.

Further investigation of these sequence variants will further elucidate the role of inflammatory and immune response-related genes on PCA development and aggressive phenotype associated with men of African descent. Future studies will evaluate the following: (1) the impact of CCL5, CCR5 and IL1R2 expression on prostate cancer tumorigenesis via knockout and/or knockin in vitro and in vivo models; and (2) the association of inflammatory and immune response-associated sequence variants in relation to PCA tumor grade, biochemical or disease recurrence, and mortality among men of African descent. 
In the U.S., 17\% of men will develop PCA in their lifetime. Once PCA metastasizes, it is associated with a 5 year survival rate of $29 \%$. Current conventional therapies are not very effective against PCA metastatic disease. Moreover, AfricanAmerican and Caribbean men are disproportionately affected by this disease compared to their European-American counterparts. Therefore, it is imperative that we study the biological underpinnings responsible for PCA development and progression. Our published reports evaluated the contribution of genetic alterations in the inflammatory and immune response pathway to PCA development. The investigation of sequence variants within inflammatory and immune response-associated genes involved in prostate cancer will help to improve the overall detection, prognosis, diagnosis, and clinical management of PCA among men. For clinicians and physicians, the prostate serum antigen (PSA) test and DRE (digital rectum exam) are unreliable PCA screening prognostication tools. Infact, the U.S. Preventive Services Task Force (USPSTF) and American Urological Association (AUA) highly recommend against the use of the PSA test for PCA detection due to its lack of specificity and sensitivity. Moreover, PCA detection cannot solely depend on DRE findings, since this test must always be performed in combination with another test. Consequently, clinicians and physicians are unable to make reliable PCA prognostic and diagnostic decisions for patients without the use of invasive procedures such as prostate biopsies. Even after dozens of painful needle core biopsies, tumors may still remain undetected. As a result of the USPSTF's and AUA's recommendations, many clinicians and urologists have experienced a significant loss financially due to their inability to highly recommend the PSA test to their patients. The identification of genetic alterations that either reduce or enhance the prostate cancer 
aggressive phenotype may serve as a potential solution to the issues associated the PSA test. These genetic alterations will help in the design of PCA specific genetic marker (SNP) panels and therapeutic agents against PCA metastatic disease. Clinicians and physicians may use these panels as non-invasive PCA prognostic and/or diagnostic tools to determine disk risk due to the high detectability of SNPs in DNA isolated from human blood specimens. Sequence may replace the PSA test and DRE as robust and reliable screening tools for PCA detection. Ultimately, genetic markers may improve personalize medicine and explain the disproportionate effect on prostate cancer incidence, mortality, and morbidity rates among men of African descent. 


\section{REFERENCES}

1. American Cancer S: Cancer Facts and Figures 2014. In. Atlanta, GA: American Cancer Society; 2014.

2. American Cancer S: Cancer Treatment and Survivorship Facts and Figures 20142015. In. Altanta, GA: American Cancer Society; 2014.

3. Pienta KJ, Loberg R: The "emigration, migration, and immigration"of prostate cancer. Clin Prostate Cancer 2005, 4(1):24-30.

4. Logothetis CJ, Millikan R: Chemotherapy for advanced prostate cancer: 25 years later. J Clin Oncol 2008, 26(15):2423-2424.

5. Madan RA, Arlen PM: Recent advances revolutionize treatment of metastatic prostate cancer. Future Oncol 2013, 9(8):1133-1144.

6. Viville C: [Local recurrence after radical prostatectomy for prostatic cancer]. Annales d'urologie 2000, 34(1):53-57.

7. Grups JW: [Long-term results of radical prostatectomy]. Der Urologe Ausg A 1988, 27(6):348-351.

8. Ritch CR, Morrison BF, Hruby G, Coard KC, Mayhew R, Aiken W, Benson MC, McKiernan JM: Pathological outcome and biochemical recurrence-free survival after radical prostatectomy in African-American, Afro-Caribbean (Jamaican) and CaucasianAmerican men: an international comparison. BJU Int 2013, 111(4 Pt B):E186-190. 
9. Bradley CJ, Yabroff KR, Dahman B, Feuer EJ, Mariotto A, Brown ML:

Productivity costs of cancer mortality in the United States: 2000-2020. J Natl Cancer Inst 2008, 100(24):1763-1770.

10. Stokes ME, Black L, Benedict A, Roehrborn CG, Albertsen P: Long-term medical-care costs related to prostate cancer: estimates from linked SEER-Medicare data. Prostate Cancer Prostatic Dis 2010, 13(3):278-284.

11. Roehrborn CG, Black LK: The economic burden of prostate cancer. BJU Int 2011, 108(6):806-813.

12. Crawford ED, Black L, Eaddy M, Kruep EJ: A retrospective analysis illustrating the substantial clinical and economic burden of prostate cancer. Prostate Cancer Prostatic Dis 2010, 13(2):162-167.

13. Glover FE, Jr., Coffey DS, Douglas LL, Russell H, Cadigan M, Tulloch T, Wedderburn K, Wan RL, Baker TD, Walsh PC: Familial study of prostate cancer in Jamaica. Urology 1998, 52(3):441-443.

14. Sfanos KS, De Marzo AM: Prostate cancer and inflammation: the evidence. Histopathology 2012, 60(1):199-215.

15. Kristal AR, Arnold KB, Neuhouser ML, Goodman P, Platz EA, Albanes D, Thompson IM: Diet, supplement use, and prostate cancer risk: results from the prostate cancer prevention trial. Am J Epidemiol 2010, 172(5):566-577.

16. Schut HA, Snyderwine EG: DNA adducts of heterocyclic amine food mutagens: implications for mutagenesis and carcinogenesis. Carcinogenesis 1999, 20(3):353-368. 17. Joshi AD, Corral R, Catsburg C, Lewinger JP, Koo J, John EM, Ingles SA, Stern MC: Red meat and poultry, cooking practices, genetic susceptibility and risk of prostate 
cancer: results from a multiethnic case-control study. Carcinogenesis 2012, 33(11):21082118.

18. Toxicology PN: Report on Carcinogens In: Heterocyclic Amines (Selected. 13th edn; 2014: 1-3.

19. Russo G, Mischi M, Scheepens W, De la Rosette JJ, Wijkstra H: Angiogenesis in prostate cancer: onset, progression and imaging. BJU Int 2012, 110(11 Pt C):E794-808.

20. Prostate cancer [http://www.ncbi.nlm.nih.gov/pubmedhealth/PMH0001418/]

21. Ames BN, Gold LS, Willett WC: The causes and prevention of cancer. Proc Natl Acad Sci U S A 1995, 92(12):5258-5265.

22. Coussens LM, Werb Z: Inflammation and cancer. Nature 2002, 420(6917):860867.

23. Cheng I, Witte JS, Jacobsen SJ, Haque R, Quinn VP, Quesenberry CP, Caan BJ, Van Den Eeden SK: Prostatitis, sexually transmitted diseases, and prostate cancer: the California Men's Health Study. PLoS One 2010, 5(1):e8736.

24. MacLennan GT, Eisenberg R, Fleshman RL, Taylor JM, Fu P, Resnick MI, Gupta S: The influence of chronic inflammation in prostatic carcinogenesis: a 5-year followup study. J Urol 2006, 176(3):1012-1016.

25. Prostatitis - bacterial

[http://www.nlm.nih.gov/medlineplus/ency/article/000519.htm]

26. Habermacher GM, Chason JT, Schaeffer AJ: Prostatitis/chronic pelvic pain syndrome. Annu Rev Med 2006, 57:195-206.

27. American Cancer S: Cancer Facts and Figures for African Americans. In. Altanta, GA: American Cancer Society; 2013. 
28. Kleier JA: Prostate cancer in black men of African-Caribbean descent. Journal of cultural diversity 2003, 10(2):56-61.

29. Bunker CH, Patrick AL, Konety BR, Dhir R, Brufsky AM, Vivas CA, Becich MJ, Trump DL, Kuller LH: High prevalence of screening-detected prostate cancer among Afro-Caribbeans: the Tobago Prostate Cancer Survey. Cancer Epidemiol Biomarkers Prev 2002, 11(8):726-729.

30. Rebbeck TR, Devesa SS, Chang BL, Bunker CH, Cheng I, Cooney K, Eeles R, Fernandez P, Giri VN, Gueye SM et al: Global patterns of prostate cancer incidence, aggressiveness, and mortality in men of african descent. Prostate cancer 2013, 2013:560857.

31. Rogers EN, Jones DZ, Kidd NC, Yeyeodu S, Brock G, Ragin C, Jackson M, McFarlane-Anderson N, Tulloch-Reid M, Sean Kimbro K et al: Toll-like receptorassociated sequence variants and prostate cancer risk among men of African descent. Genes Immun 2013, 14(6):347-355.

32. Eastham JA, May RA, Whatley T, Crow A, Venable DD, Sartor O: Clinical characteristics and biopsy specimen features in African-American and white men without prostate cancer. J Natl Cancer Inst 1998, 90(10):756-760.

33. Winters SJ, Brufsky A, Weissfeld J, Trump DL, Dyky MA, Hadeed V:

Testosterone, sex hormone-binding globulin, and body composition in young adult African American and Caucasian men. Metabolism: clinical and experimental 2001, 50(10):1242-1247.

34. deVere White RW, Deitch AD, Jackson AG, Gandour-Edwards R, Marshalleck J, Soares SE, Toscano SN, Lunetta JM, Stewart SL: Racial differences in clinically 
localized prostate cancers of black and white men. J Urol 1998, 159(6):1979-1982; discussion 1982-1973.

35. Kidd LR, Jones DZ, Rogers EN, Kidd NC, Beache S, Rudd JE, Ragin C, Jackson M, McFarlane-Anderson N, Tulloch-Reid M et al: Chemokine Ligand 5 (CCL5) and chemokine receptor (CCR5) genetic variants and prostate cancer risk among men of African Descent: a case-control study. Hereditary cancer in clinical practice 2012, 10(1):16.

36. Jones DZ, Ragin C, Kidd NC, Flores-Obando RE, Jackson M, McFarlaneAnderson N, Tulloch-Reid M, Kimbro KS, Kidd LR: The impact of genetic variants in inflammatory-related genes on prostate cancer risk among men of African Descent: a case control study. Hereditary cancer in clinical practice 2013, 11(1):19.

37. Benford ML, VanCleave TT, Lavender NA, Kittles RA, Kidd LR: 8q24 sequence variants in relation to prostate cancer risk among men of African descent: a case-control study. BMC Cancer 2010, 10:334.

38. Kidd LR, Brock GN, VanCleave TT, Benford ML, Lavender NA, Kruer TL, Wittliff JL: Angiogenesis-associated sequence variants relative to breast cancer recurrence and survival. Cancer Causes Control 2010, 21(10):1545-1557.

39. Lavender NA, Rogers EN, Yeyeodu S, Rudd J, Hu T, Zhang J, Brock GN, Kimbro KS, Moore JH, Hein DW et al: Interaction among apoptosis-associated sequence variants and joint effects on aggressive prostate cancer. BMC Med Genomics 2012, 5:11. 40. VanCleave TT, Moore JH, Benford ML, Brock GN, Kalbfleisch T, Baumgartner RN, Lillard JW, Jr., Kittles RA, Kidd LC: Interaction among variant vascular endothelial 
growth factor (VEGF) and its receptor in relation to prostate cancer risk. Prostate 2010, 70(4):341-352.

41. Wallace TA, Prueitt RL, Yi M, Howe TM, Gillespie JW, Yfantis HG, Stephens RM, Caporaso NE, Loffredo CA, Ambs S: Tumor immunobiological differences in prostate cancer between African-American and European-American men. Cancer Res 2008, 68(3):927-936.

42. Reams RR, Agrawal D, Davis MB, Yoder S, Odedina FT, Kumar N, Higginbotham JM, Akinremi T, Suther S, Soliman KF: Microarray comparison of prostate tumor gene expression in African-American and Caucasian American males: a pilot project study. Infect Agent Cancer 2009, 4 Suppl 1:S3.

43. Balistreri CR, Candore G, Lio D, Carruba G: Prostate cancer: from the pathophysiologic implications of some genetic risk factors to translation in personalized cancer treatments. Cancer gene therapy 2014, 21(1):2-11.

44. Woenckhaus J, Fenic I: Proliferative inflammatory atrophy: a background lesion of prostate cancer? Andrologia 2008, 40(2):134-137.

45. Vykhovanets EV, Maclennan GT, Vykhovanets OV, Gupta S: IL-17 Expression by macrophages is associated with proliferative inflammatory atrophy lesions in prostate cancer patients. International journal of clinical and experimental pathology 2011, 4(6):552-565.

46. Feghali CA, Wright TM: Cytokines in acute and chronic inflammation. Frontiers in bioscience : a journal and virtual library 1997, 2:d12-26.

47. Klink JC, Miocinovic R, Magi Galluzzi C, Klein EA: High-grade prostatic intraepithelial neoplasia. Korean journal of urology 2012, 53(5):297-303. 
48. Prostate Cancer

[http://www.cancer.org/cancer/prostatecancer/detailedguide/prostate-cancer-what-isprostate-cancer]

49. de Visser KE, Eichten A, Coussens LM: Paradoxical roles of the immune system during cancer development. Nature reviews Cancer 2006, 6(1):24-37.

50. Janeway CA, Travers, P., Walport, M., Schlomchik, M.: Principles of innate and adaptive immunity. In: Immunobiology: The Immune System in Health and Disease. 5 edn. New York: Taylor \& Francis; 2001.

51. Sato Y, Goto Y, Narita N, Hoon DS: Cancer Cells Expressing Toll-like Receptors and the Tumor Microenvironment. Cancer microenvironment : official journal of the International Cancer Microenvironment Society 2009, 2 Suppl 1:205-214.

52. Galli R, Starace D, Busa R, Angelini DF, Paone A, De Cesaris P, Filippini A, Sette C, Battistini L, Ziparo E et al: TLR stimulation of prostate tumor cells induces chemokine-mediated recruitment of specific immune cell types. J Immunol 2010, 184(12):6658-6669.

53. Luster AD: The role of chemokines in linking innate and adaptive immunity. Curr Opin Immunol 2002, 14(1):129-135.

54. Esche C, Stellato C, Beck LA: Chemokines: key players in innate and adaptive immunity. J Invest Dermatol 2005, 125(4):615-628.

55. Striz I, Brabcova E, Kolesar L, Sekerkova A: Cytokine networking of innate immunity cells: a potential target of therapy. Clin Sci (Lond) 2014, 126(9):593-612. 56. Alberts B, Johnson, A., Lewis, J., Raff, M., Roberts, K., Walter, P.: Molecular Biology of the Cell, 4 edn. New York, NY: Taylor and Francis Group; 2002. 
57. Nishimura M, Naito S: Tissue-specific mRNA expression profiles of human tolllike receptors and related genes. Biological \& pharmaceutical bulletin 2005, 28(5):886892.

58. Varambally S, Yu J, Laxman B, Rhodes DR, Mehra R, Tomlins SA, Shah RB, Chandran U, Monzon FA, Becich MJ et al: Integrative genomic and proteomic analysis of prostate cancer reveals signatures of metastatic progression. Cancer cell 2005, $8(5): 393-406$.

59. Chin AI, Miyahira AK, Covarrubias A, Teague J, Guo B, Dempsey PW, Cheng G: Toll-like receptor 3-mediated suppression of TRAMP prostate cancer shows the critical role of type I interferons in tumor immune surveillance. Cancer Res 2010, 70(7):2595-2603.

60. Gonzalez-Reyes S, Fernandez JM, Gonzalez LO, Aguirre A, Suarez A, Gonzalez JM, Escaff S, Vizoso FJ: Study of TLR3, TLR4, and TLR9 in prostate carcinomas and their association with biochemical recurrence. Cancer immunology, immunotherapy : CII 2011, 60(2):217-226.

61. Gatti G, Quintar AA, Andreani V, Nicola JP, Maldonado CA, Masini-Repiso AM, Rivero VE, Maccioni M: Expression of Toll-like receptor 4 in the prostate gland and its association with the severity of prostate cancer. Prostate 2009, 69(13):1387-1397.

62. Han JH, Park SY, Kim JB, Cho SD, Kim B, Kim BY, Kang MJ, Kim DJ, Park

JH: TLR7 expression is decreased during tumour progression in transgenic adenocarcinoma of mouse prostate mice and its activation inhibits growth of prostate cancer cells. Am J Reprod Immunol 2013, 70(4):317-326. 
63. Marin-Aguilera M, Codony-Servat J, Kalko SG, Fernandez PL, Bermudo R, Buxo E, Ribal MJ, Gascon P, Mellado B: Identification of docetaxel resistance genes in castration-resistant prostate cancer. Mol Cancer Ther 2012, 11(2):329-339.

64. Kumar DM, Patil V, Ramachandran B, Nila MV, Dharmalingam K, Somasundaram K: Temozolomide-modulated glioma proteome: role of interleukin-1 receptor-associated kinase-4 (IRAK4) in chemosensitivity. Proteomics 2013, 13(14):2113-2124.

65. Zhu L, Wang L, Luo X, Zhang Y, Ding Q, Jiang X, Wang X, Pan Y, Chen Y: Tollip, an intracellular trafficking protein, is a novel modulator of the transforming growth factor-beta signaling pathway. J Biol Chem 2012, 287(47):39653-39663.

66. Kubiczkova L, Sedlarikova L, Hajek R, Sevcikova S: TGF-beta - an excellent servant but a bad master. J Transl Med 2012, 10:183.

67. Levy L, Hill CS: Alterations in components of the TGF-beta superfamily signaling pathways in human cancer. Cytokine Growth Factor Rev 2006, 17(1-2):41-58. 68. Benckert C, Jonas S, Cramer T, Von Marschall Z, Schafer G, Peters M, Wagner K, Radke C, Wiedenmann B, Neuhaus $\mathrm{P}$ et al: Transforming growth factor beta 1 stimulates vascular endothelial growth factor gene transcription in human cholangiocellular carcinoma cells. Cancer Res 2003, 63(5):1083-1092.

69. Zhao H, Kim Y, Wang P, Lapointe J, Tibshirani R, Pollack JR, Brooks JD: Genome-wide characterization of gene expression variations and DNA copy number changes in prostate cancer cell lines. Prostate 2005, 63(2):187-197.

70. Kim IY, Ahn HJ, Zelner DJ, Shaw JW, Lang S, Kato M, Oefelein MG, Miyazono K, Nemeth JA, Kozlowski JM et al: Loss of expression of transforming growth factor 
beta type I and type II receptors correlates with tumor grade in human prostate cancer tissues. Clin Cancer Res 1996, 2(8):1255-1261.

71. Kato T, Fujita Y, Nakane K, Mizutani K, Terazawa R, Ehara H, Kanimoto Y, Kojima T, Nozawa Y, Deguchi T et al: CCR1/CCL5 interaction promotes invasion of taxane-resistant PC3 prostate cancer cells by increasing secretion of MMPs 2/9 and by activating ERK and Rac signaling. Cytokine 2013, 64(1):251-257.

72. Itoh Y, Nagase H: Matrix metalloproteinases in cancer. Essays in biochemistry 2002, 38:21-36.

73. Vaday GG, Peehl DM, Kadam PA, Lawrence DM: Expression of CCL5 (RANTES) and CCR5 in prostate cancer. The Prostate 2006, 66(2):124-134.

74. Manes S, Mira E, Colomer R, Montero S, Real LM, Gomez-Mouton C, JimenezBaranda S, Garzon A, Lacalle RA, Harshman K et al: CCR5 expression influences the progression of human breast cancer in a p53-dependent manner. J Exp Med 2003, 198(9):1381-1389.

75. Konig JE, Senge T, Allhoff EP, Konig W: Analysis of the inflammatory network in benign prostate hyperplasia and prostate cancer. The Prostate 2004, 58(2):121-129. 76. Huang X, Su K, Zhou L, Shen G, Dong Q, Lou Y, Zheng S: Hypoxia preconditioning of mesenchymal stromal cells enhances PC3 cell lymphatic metastasis accompanied by VEGFR-3/CCR7 activation. J Cell Biochem 2013, 114(12):2834-2841. 77. Takanami I: Overexpression of CCR7 mRNA in nonsmall cell lung cancer: correlation with lymph node metastasis. Int J Cancer 2003, 105(2):186-189. 
78. Mashino K, Sadanaga N, Yamaguchi H, Tanaka F, Ohta M, Shibuta K, Inoue H, Mori M: Expression of chemokine receptor CCR7 is associated with lymph node metastasis of gastric carcinoma. Cancer Res 2002, 62(10):2937-2941.

79. Ou DL, Chien HF, Chen CL, Lin TC, Lin LI: Role of Twist in head and neck carcinoma with lymph node metastasis. Anticancer Res 2008, 28(2B):1355-1359.

80. Killian PH, Kronski E, Michalik KM, Barbieri O, Astigiano S, Sommerhoff CP, Pfeffer U, Nerlich AG, Bachmeier BE: Curcumin inhibits prostate cancer metastasis in vivo by targeting the inflammatory cytokines CXCL1 and -2. Carcinogenesis 2012, 33(12):2507-2519.

81. Benelli R, Stigliani S, Minghelli S, Carlone S, Ferrari N: Impact of CXCL1 overexpression on growth and invasion of prostate cancer cell. Prostate 2013, 73(9):941951.

82. Roy I, Zimmerman NP, Mackinnon AC, Tsai S, Evans DB, Dwinell MB: CXCL12 chemokine expression suppresses human pancreatic cancer growth and metastasis. PLoS One 2014, 9(3):e90400.

83. Goguet-Surmenian E, Richard-Fiardo P, Guillemot E, Benchetrit M, GomezBrouchet A, Buzzo P, Karimdjee-Soilihi B, Alemanno P, Michiels JF, Schmid-Alliana A et al: CXCR7-mediated progression of osteosarcoma in the lungs. Br J Cancer 2013, 109(6):1579-1585.

84. Liu C, Pham K, Luo D, Reynolds BA, Hothi P, Foltz G, Harrison JK: Expression and functional heterogeneity of chemokine receptors CXCR4 and CXCR7 in primary patient-derived glioblastoma cells. PLoS One 2013, 8(3):e59750. 
85. Singh RK, Lokeshwar BL: The IL-8-regulated chemokine receptor CXCR7 stimulates EGFR signaling to promote prostate cancer growth. Cancer Res 2011, 71(9):3268-3277.

86. Wang J, Shiozawa Y, Wang Y, Jung Y, Pienta KJ, Mehra R, Loberg R, Taichman RS: The role of CXCR7/RDC1 as a chemokine receptor for CXCL12/SDF-1 in prostate cancer. J Biol Chem 2008, 283(7):4283-4294.

87. Sun YX, Pedersen EA, Shiozawa Y, Havens AM, Jung Y, Wang J, Pienta KJ, Taichman RS: CD26/dipeptidyl peptidase IV regulates prostate cancer metastasis by degrading SDF-1/CXCL12. Clinical \& experimental metastasis 2008, 25(7):765-776. 88. Singh S, Singh UP, Stiles JK, Grizzle WE, Lillard JW, Jr.: Expression and functional role of CCR9 in prostate cancer cell migration and invasion. Clin Cancer Res 2004, 10(24):8743-8750.

89. Dinarello CA: Historical insights into cytokines. Eur J Immunol 2007, 37 Suppl $1: \mathrm{S} 34-45$.

90. Lowry SF: Cytokine mediators of immunity and inflammation. Arch Surg 1993, 128(11):1235-1241.

91. Immune System [http://www.niaid.nih.gov/topics/immunesystem/immunecells/Pages/cytokines.aspx] 92. Salman H, Ori Y, Bergman M, Djaldetti M, Bessler H: Human prostate cancer cells induce inflammatory cytokine secretion by peripheral blood mononuclear cells. Biomedicine $\&$ pharmacotherapy = Biomedecine $\&$ pharmacotherapie 2012, 66(5):330333. 
93. Wikstrom P, Stattin P, Franck-Lissbrant I, Damber JE, Bergh A: Transforming growth factor beta1 is associated with angiogenesis, metastasis, and poor clinical outcome in prostate cancer. Prostate 1998, 37(1):19-29.

94. Rodriguez-Berriguete G, Sanchez-Espiridion B, Cansino JR, Olmedilla G, Martinez-Onsurbe P, Sanchez-Chapado M, Paniagua R, Fraile B, Royuela M: Clinical significance of both tumor and stromal expression of components of the IL-1 and TNFalpha signaling pathways in prostate cancer. Cytokine 2013, 64(2):555-563.

95. Chung TD, Yu JJ, Spiotto MT, Bartkowski M, Simons JW: Characterization of the role of IL-6 in the progression of prostate cancer. Prostate 1999, 38(3):199-207. 96. Erb HH, Langlechner RV, Moser PL, Handle F, Casneuf T, Verstraeten K, Schlick B, Schafer G, Hall B, Sasser K et al: IL6 sensitizes prostate cancer to the antiproliferative effect of IFNalpha2 through IRF9. Endocr Relat Cancer 2013, 20(5):677-689.

97. Stevens VL, Hsing AW, Talbot JT, Zheng SL, Sun J, Chen J, Thun MJ, Xu J, Calle EE, Rodriguez C: Genetic variation in the toll-like receptor gene cluster (TLR10TLR1-TLR6) and prostate cancer risk. Int J Cancer 2008, 123(11):2644-2650.

98. Song J, Kim DY, Kim CS, Kim HJ, Lee DH, Lee HM, Ko W, Lee G: The association between Toll-like receptor 4 (TLR4) polymorphisms and the risk of prostate cancer in Korean men. Cancer Genet Cytogenet 2009, 190(2):88-92.

99. Lindstrom S, Hunter DJ, Gronberg H, Stattin P, Wiklund F, Xu J, Chanock SJ, Hayes R, Kraft P: Sequence variants in the TLR4 and TLR6-1-10 genes and prostate cancer risk. Results based on pooled analysis from three independent studies. Cancer Epidemiol Biomarkers Prev 2010, 19(3):873-876. 
100. Vasto S, Carruba G, Candore G, Italiano E, Di Bona D, Caruso C: Inflammation and prostate cancer. Future Oncol 2008, 4(5):637-645.

101. Zabaleta J, Lin HY, Sierra RA, Hall MC, Clark PE, Sartor OA, Hu JJ, Ochoa AC: Interactions of cytokine gene polymorphisms in prostate cancer risk. Carcinogenesis 2008, 29(3):573-578.

102. Zabaleta J, Su LJ, Lin HY, Sierra RA, Hall MC, Sartor AO, Clark PE, Hu JJ, Ochoa AC: Cytokine genetic polymorphisms and prostate cancer aggressiveness. Carcinogenesis 2009, 30(8):1358-1362.

103. Cheng I, Plummer SJ, Casey G, Witte JS: Toll-like receptor 4 genetic variation and advanced prostate cancer risk. Cancer EpidemiolBiomarkers Prev 2007, 16(2):352355.

104. Kim HJ, Bae JS, Chang IH, Kim KD, Lee J, Shin HD, Lee JY, Kim WJ, Kim W, Myung SC: Sequence variants of Toll-like receptor 4 (TLR4) and the risk of prostate cancer in Korean men. World journal of urology 2012, 30(2):225-232.

105. Zheng SL, Augustsson-Balter K, Chang B, Hedelin M, Li L, Adami HO, Bensen J, Li G, Johnasson JE, Turner AR et al: Sequence variants of toll-like receptor 4 are associated with prostate cancer risk: results from the CAncer Prostate in Sweden Study. Cancer Res 2004, 64(8):2918-2922.

106. Sun J, Wiklund F, Zheng SL, Chang B, Balter K, Li L, Johansson JE, Li G, Adami HO, Liu W et al: Sequence variants in Toll-like receptor gene cluster (TLR6TLR1-TLR10) and prostate cancer risk. J NatlCancer Inst 2005, 97(7):525-532. 
107. Chen YC, Giovannucci E, Lazarus R, Kraft P, Ketkar S, Hunter DJ: Sequence variants of Toll-like receptor 4 and susceptibility to prostate cancer. Cancer Res 2005, 65(24):11771-11778.

108. Sun J, Wiklund F, Hsu FC, Balter K, Zheng SL, Johansson JE, Chang B, Liu W, Li T, Turner AR et al: Interactions of sequence variants in interleukin-1 receptorassociated kinase4 and the toll-like receptor 6-1-10 gene cluster increase prostate cancer risk. Cancer EpidemiolBiomarkers Prev 2006, 15(3):480-485.

109. Chen YC, Giovannucci E, Kraft P, Lazarus R, Hunter DJ: Association between Toll-like receptor gene cluster (TLR6, TLR1, and TLR10) and prostate cancer. Cancer Epidemiol Biomarkers Prev 2007, 16(10):1982-1989.

110. Stark JR, Wiklund F, Gronberg H, Schumacher F, Sinnott JA, Stampfer MJ, Mucci LA, Kraft P: Toll-like receptor signaling pathway variants and prostate cancer mortality. Cancer Epidemiol Biomarkers Prev 2009, 18(6):1859-1863.

111. Chang CC, Chen SC, Hsieh YH, Chen YC, Chen TY, Chu YH, Ma HJ, Chou MC, Tsai HT, Yang SF: Stromal cell-derived factor-1 but not its receptor, CXCR4, gene variants increase susceptibility and pathological development of hepatocellular carcinoma. Clin Chem Lab Med 2009, 47(4):412-418.

112. Hirata H, Hinoda Y, Kikuno N, Kawamoto K, Dahiya AV, Suehiro Y, Tanaka Y, Dahiya R: CXCL12 G801A polymorphism is a risk factor for sporadic prostate cancer susceptibility. Clinical cancer research : an official journal of the American Association for Cancer Research 2007, 13(17):5056-5062. 
113. Liou JM, Lin JT, Huang SP, Wu CY, Wang HP, Lee YC, Chiu HM, Shun CT, Lin MT, Wu MS: RANTES-403 polymorphism is associated with reduced risk of gastric cancer in women. Journal of gastroenterology 2008, 43(2):115-123.

114. Vindrieux D, Escobar P, Lazennec G: Emerging roles of chemokines in prostate cancer. Endocr Relat Cancer 2009, 16(3):663-673.

115. Soria G, Ben-Baruch A: The CCL5/CCR5 Axis in Cancer. New York: Human Press; 2009.

116. Saenz-Lopez P, Carretero R, Cozar JM, Romero JM, Canton J, Vilchez JR, Tallada M, Garrido F, Ruiz-Cabello F: Genetic polymorphisms of RANTES, IL1-A, MCP-1 and TNF-A genes in patients with prostate cancer. BMC Cancer 2008, 8:382.

117. Weng CJ, Chien MH, Lin CW, Chung TT, Zavras AI, Tsai CM, Chen MK, Yang SF: Effect of CC chemokine ligand 5 and CC chemokine receptor 5 genes polymorphisms on the risk and clinicopathological development of oral cancer. Oral Oncol 2010, 46(10):767-772.

118. Duell EJ, Casella DP, Burk RD, Kelsey KT, Holly EA: Inflammation, genetic polymorphisms in proinflammatory genes TNF-A, RANTES, and CCR5, and risk of pancreatic adenocarcinoma. Cancer epidemiology, biomarkers \& prevention : a publication of the American Association for Cancer Research, cosponsored by the American Society of Preventive Oncology 2006, 15(4):726-731.

119. Enjuanes A, Benavente Y, Bosch F, Martin-Guerrero I, Colomer D, PerezAlvarez S, Reina O, Ardanaz MT, Jares P, Garcia-Orad A et al: Genetic variants in apoptosis and immunoregulation-related genes are associated with risk of chronic lymphocytic leukemia. Cancer research 2008, 68(24):10178-10186. 
120. Purdue MP, Lan Q, Menashe I, Zheng T, Zhang Y, Yeager M, Hosgood HD, 3rd, Zahm SH, Chanock SJ, Rothman N et al: Variation in innate immunity genes and risk of multiple myeloma. Hematol Oncol 2011, 29(1):42-46.

121. Berhane N, Sobti RC, Melesse S, Mahdi SA, Kassu A: Significance of Tumor necrosis factor alpha-308 (G/A) gene polymorphism in the development of prostate cancer. Mol Biol Rep 2012, 39(12):11125-11130.

122. Dluzniewski PJ, Wang MH, Zheng SL, De Marzo AM, Drake CG, Fedor HL, Partin AW, Han M, Fallin MD, Xu J et al: Variation in IL10 and other genes involved in the immune response and in oxidation and prostate cancer recurrence. Cancer Epidemiol Biomarkers Prev 2012, 21(10):1774-1782.

123. Lin DW, FitzGerald LM, Fu R, Kwon EM, Zheng SL, Kolb S, Wiklund F, Stattin $\mathrm{P}$, Isaacs WB, Xu J et al: Genetic variants in the LEPR, CRY1, RNASEL, IL4, and ARVCF genes are prognostic markers of prostate cancer-specific mortality. Cancer Epidemiol Biomarkers Prev 2011, 20(9):1928-1936.

124. Alvarez-Cubero MJ, Saiz M, Martinez-Gonzalez LJ, Alvarez JC, Lorente JA, Cozar JM: [RNASEL study of genetics of prostate cancer and its relation to clinical staging]. Actas urologicas espanolas 2012, 36(5):306-311.

125. Casey G, Neville PJ, Plummer SJ, Xiang Y, Krumroy LM, Klein EA, Catalona WJ, Nupponen N, Carpten JD, Trent JM et al: RNASEL Arg462Gln variant is implicated in up to $13 \%$ of prostate cancer cases. Nat Genet 2002, 32(4):581-583.

126. Kesarwani P, Ahirwar DK, Mandhani A, Singh AN, Dalela D, Srivastava AN, Mittal RD: IL-10 -1082 G>A: a risk for prostate cancer but may be protective against 
progression of prostate cancer in North Indian cohort. World journal of urology 2009, 27(3):389-396.

127. Tindall EA, Severi G, Hoang HN, Southey MC, English DR, Hopper JL, Giles GG, Hayes VM: Interleukin-6 promoter variants, prostate cancer risk, and survival. Prostate 2012, 72(16):1701-1707.

128. Tindall EA, Severi G, Hoang HN, Ma CS, Fernandez P, Southey MC, English DR, Hopper JL, Heyns CF, Tangye SG et al: Comprehensive analysis of the cytokinerich chromosome 5q31.1 region suggests a role for IL-4 gene variants in prostate cancer risk. Carcinogenesis 2010, 31(10):1748-1754.

129. Fernberg P, Chang ET, Duvefelt K, Hjalgrim H, Eloranta S, Sorensen KM, Porwit A, Humphreys K, Melbye M, Ekstrom Smedby K: Genetic variation in chromosomal translocation breakpoint and immune function genes and risk of non-Hodgkin lymphoma. Cancer Causes Control 2010, 21(5):759-769.

130. Liu L, Yang X, Chen X, Kan T, Shen Y, Chen Z, Hu Z: Association between TNF-alpha polymorphisms and cervical cancer risk: a meta-analysis. Mol Biol Rep 2012, 39(3):2683-2688.

131. Gorouhi F, Islami F, Bahrami H, Kamangar F: Tumour-necrosis factor-A polymorphisms and gastric cancer risk: a meta-analysis. Br J Cancer 2008, 98(8):14431451.

132. Pooja S, Francis A, Bid HK, Kumar S, Rajender S, Ramalingam K, Thangaraj K, Konwar R: Role of ethnic variations in TNF-alpha and TNF-beta polymorphisms and risk of breast cancer in India. Breast Cancer Res Treat 2011, 126(3):739-747. 
133. de Oliveira JG, Rossi AF, Nizato DM, Miyasaki K, Silva AE: Profiles of gene polymorphisms in cytokines and Toll-like receptors with higher risk for gastric cancer. Digestive diseases and sciences 2013, 58(4):978-988.

134. Gaudet MM, Egan KM, Lissowska J, Newcomb PA, Brinton LA, Titus-Ernstoff L, Yeager M, Chanock S, Welch R, Peplonska B et al: Genetic variation in tumor necrosis factor and lymphotoxin-alpha (TNF-LTA) and breast cancer risk. Hum Genet 2007, 121(3-4):483-490.

135. Danforth KN, Rodriguez C, Hayes RB, Sakoda LC, Huang WY, Yu K, Calle EE, Jacobs EJ, Chen BE, Andriole GL et al: TNF polymorphisms and prostate cancer risk. Prostate 2008, 68(4):400-407.

136. White KL, Schildkraut JM, Palmieri RT, Iversen ES, Jr., Berchuck A, Vierkant RA, Rider DN, Charbonneau B, Cicek MS, Sutphen R et al: Ovarian cancer risk associated with inherited inflammation-related variants. Cancer Res 2012, 72(5):10641069.

137. Balasubramanian SP, Azmy IA, Higham SE, Wilson AG, Cross SS, Cox A, Brown NJ, Reed MW: Interleukin gene polymorphisms and breast cancer: a case control study and systematic literature review. BMC Cancer 2006, 6:188.

138. Han W, Kang SY, Kang D, Park SK, Lee JY, Kim H, Park AK, Noh DY:

Multiplex genotyping of 1107 SNPs from 232 candidate genes identified an association between IL1A polymorphism and breast cancer risk. Oncol Rep 2010, 23(3):763-769.

139. Colotta F, Re F, Muzio M, Bertini R, Polentarutti N, Sironi M, Giri JG, Dower SK, Sims JE, Mantovani A: Interleukin-1 type II receptor: a decoy target for IL-1 that is regulated by IL-4. Science 1993, 261(5120):472-475. 
140. Ricote M, Garcia-Tunon I, Bethencourt FR, Fraile B, Paniagua R, Royuela M: Interleukin-1 (IL-1alpha and IL-1beta) and its receptors (IL-1RI, IL-1RII, and IL-1Ra) in prostate carcinoma. Cancer 2004, 100(7):1388-1396.

141. Zheng Y, Humphry M, Maguire JJ, Bennett MR, Clarke MC: Intracellular interleukin-1 receptor 2 binding prevents cleavage and activity of interleukin-1alpha, controlling necrosis-induced sterile inflammation. Immunity 2013, 38(2):285-295.

142. Di Paolo NC, Shayakhmetov DM: Interleukin-1 receptor 2 keeps the lid on interleukin-1alpha. Immunity 2013, 38(2):203-205.

143. Friedman JH, Roosen CB: An introduction to multivariate adaptive regression splines. Stat Methods Med Res 1995, 4(3):197-217.

144. Lemon SC, Roy J, Clark MA, Friedmann PD, Rakowski W: Classification and regression tree analysis in public health: methodological review and comparison with logistic regression. Annals of behavioral medicine : a publication of the Society of Behavioral Medicine 2003, 26(3):172-181.

145. Moore JH, Hill, D.P., Fisher, J.M., Lavender, N., Kidd, L.R.: Human-Computer Interaction in a Computational Evolution System for the Genetic Analysis of Cancer. In: Genetic Programming Theory and Practice IX. Ann Arbor, MI, USA: Springer; 2011: $153-171$.

146. Hahn LW, Ritchie MD, Moore JH: Multifactor dimensionality reduction software for detecting gene-gene and gene-environment interactions. Bioinformatics 2003, 19(3):376-382.

147. Xu J, Lowey J, Wiklund F, Sun J, Lindmark F, Hsu FC, Dimitrov L, Chang B, Turner AR, Liu W et al: The interaction of four genes in the inflammation pathway 
significantly predicts prostate cancer risk. Cancer EpidemiolBiomarkers Prev 2005, 14(11 Pt 1):2563-2568.

148. Rizzato C, Canzian F, Rudnai P, Gurzau E, Stein A, Koppova K, Hemminki K, Kumar R, Campa D: Interaction between functional polymorphic variants in cytokine genes, established risk factors and susceptibility to basal cell carcinoma of skin. Carcinogenesis 2011, 32(12):1849-1854.

149. Lin GT, Tseng HF, Yang CH, Hou MF, Chuang LY, Tai HT, Tai MH, Cheng YH, Wen CH, Liu CS et al: Combinational polymorphisms of seven CXCL12-related genes are protective against breast cancer in Taiwan. Omics 2009, 13(2):165-172. 150. Jones DZ, Ragin, C., Jackson, M., McFarlane-Anderson, N., Morrison, S., FloresObando, R.,Kimbro, K.S., Kidd, L.R.: Chemokine-associated Genetic Variants as Predictors of Prostate Cancer Risk among men of African Descent. In: American Association for Cancer Research: The Science of Cancer Health Disparities in Racial/Ethnic Minorities and the Medically Underserved Conference: 2011; Washington, D.C.; 2011.

151. Sohn KC, Li ZJ, Choi DK, Zhang T, Lim JW, Chang IK, Hur GM, Im M, Lee Y, Seo YJ et al: Imiquimod induces apoptosis of squamous cell carcinoma (SCC) cells via regulation of A20. PLoS One 2014, 9(4):e95337.

152. Vaisanen MR, Vaisanen T, Jukkola-Vuorinen A, Vuopala KS, Desmond R, Selander KS, Vaarala MH: Expression of toll-like receptor-9 is increased in poorly differentiated prostate tumors. Prostate 2010, 70(8):817-824. 
153. Vaisanen MR, Jukkola-Vuorinen A, Vuopala KS, Selander KS, Vaarala MH: Expression of Toll-like receptor-9 is associated with poor progression-free survival in prostate cancer. Oncology letters 2013, 5(5):1659-1663.

154. Di JM, Pang J, Pu XY, Zhang Y, Liu XP, Fang YQ, Ruan XX, Gao X: Toll-like receptor 9 agonists promote IL-8 and TGF-beta1 production via activation of nuclear factor kappaB in PC-3 cells. Cancer Genet Cytogenet 2009, 192(2):60-67.

155. Ochoa-Callejero L, Perez-Martinez L, Rubio-Mediavilla S, Oteo JA, Martinez A, Blanco JR: Maraviroc, a CCR5 antagonist, prevents development of hepatocellular carcinoma in a mouse model. PLoS One 2013, 8(1):e53992.

156. Velasco-Velazquez M, Jiao X, De La Fuente M, Pestell TG, Ertel A, Lisanti MP, Pestell RG: CCR5 antagonist blocks metastasis of basal breast cancer cells. Cancer Res 2012, 72(15):3839-3850.

157. Kidd LC, Vancleave TT, Doll MA, Srivastava DS, Thacker B, Komolafe O, Pihur V, Brock GN, Hein DW: No association between variant N-acetyltransferase genes, cigarette smoking and Prostate Cancer susceptibility among men of African descent. Biomark Cancer 2011, 2011(3):1-13.

158. Jackson MD, Walker SP, Simpson-Smith CM, Lindsay CM, Smith G, McFarlaneAnderson N, Bennett FI, Coard KC, Aiken WD, Tulloch T et al: Associations of wholeblood fatty acids and dietary intakes with prostate cancer in Jamaica. Cancer causes \& control : CCC 2012, 23(1):23-33.

159. Manolio TA, Collins FS, Cox NJ, Goldstein DB, Hindorff LA, Hunter DJ, McCarthy MI, Ramos EM, Cardon LR, Chakravarti A et al: Finding the missing heritability of complex diseases. Nature 2009, 461(7265):747-753. 
160. McCarthy MI, Abecasis GR, Cardon LR, Goldstein DB, Little J, Ioannidis JP, Hirschhorn JN: Genome-wide association studies for complex traits: consensus, uncertainty and challenges. Nature reviews Genetics 2008, 9(5):356-369.

161. Steemers FJ, Gunderson KL: Illumina, Inc. Pharmacogenomics 2005, 6(7):777782.

162. Giri VN, Egleston B, Ruth K, Uzzo RG, Chen DY, Buyyounouski M, Raysor S, Hooker S, Torres JB, Ramike T et al: Race, genetic West African ancestry, and prostate cancer prediction by prostate-specific antigen in prospectively screened high-risk men. Cancer PrevRes(Phila Pa) 2009, 2(3):244-250.

163. Tian C, Hinds DA, Shigeta R, Kittles R, Ballinger DG, Seldin MF: A genomewide single-nucleotide-polymorphism panel with high ancestry information for African American admixture mapping. AmJHumGenet 2006, 79(4):640-649.

164. Falush D, Stephens M, Pritchard JK: Inference of population structure using multilocus genotype data: linked loci and correlated allele frequencies. Genetics 2003, 164(4):1567-1587.

165. Menashe I, Rosenberg PS, Chen BE: PGA: power calculator for case-control genetic association analyses. BMC Genet 2008, 9:36.

166. Gui J, Andrew AS, Andrews P, Nelson HM, Kelsey KT, Karagas MR, Moore JH: A simple and computationally efficient sampling approach to covariate adjustment for multifactor dimensionality reduction analysis of epistasis. Hum Hered 2010, 70(3):219225. 
167. Greene CS, Penrod NM, Kiralis J, Moore JH: Spatially uniform relieff (SURF) for computationally-efficient filtering of gene-gene interactions. BioData mining 2009, $2(1): 5$.

168. Moore JH, Asselbergs FW, Williams SM: Bioinformatics challenges for genomewide association studies. Bioinformatics 2010, 26(4):445-455.

169. Moore JH, Gilbert JC, Tsai CT, Chiang FT, Holden T, Barney N, White BC: A flexible computational framework for detecting, characterizing, and interpreting statistical patterns of epistasis in genetic studies of human disease susceptibility. JTheorBiol 2006, 241(2):252-261.

170. Jakulin A, Bratko I, Smrike D, Demsar J, Zupan B: Attribute interactions in medical data analysis. In. Protarus: Cyprus; 2003: 229-238-238.

171. Jakulin A, Bratko I: Analyzing attribute interations. Lecture Notes in Artificial Intelligence 2003, 2838:229.

172. McGill WL: Multivariate information transmission. In: Psychometrika. vol. 19; 1954: $97-116$.

173. Mramor M, Leban G, Demsar J, Zupan B: Visualization-based cancer microarray data classification analysis. Bioinformatics 2007, 23(16):2147-2154.

174. De Marzo AM, Platz EA, Sutcliffe S, Xu J, Gronberg H, Drake CG, Nakai Y, Isaacs WB, Nelson WG: Inflammation in prostate carcinogenesis. Nature reviews Cancer 2007, 7(4):256-269.

175. Huang QX, Cheng XY, Mao ZC, Wang YS, Zhao LL, Yan X, Ferris VR, Xu RM, Xie BY: MicroRNA discovery and analysis of pinewood nematode Bursaphelenchus xylophilus by deep sequencing. PLoS One 2010, 5(10):e13271. 
176. Menendez D, Shatz M, Azzam K, Garantziotis S, Fessler MB, Resnick MA: The Toll-like receptor gene family is integrated into human DNA damage and p53 networks. PLoS Genet 2011, 7(3):e1001360.

177. Yeyeodu ST, Kidd LR, Oprea-Ilies GM, Burns BG, Vancleave TT, Shim JY, Kimbro KS: IRAK4 and TLR3 Sequence Variants may Alter Breast Cancer Risk among African-American Women. Frontiers in immunology 2013, 4:338.

178. Greene CS, Penrod NM, Williams SM, Moore JH: Failure to replicate a genetic association may provide important clues about genetic architecture. PLoS One 2009, 4(6):e5639.

179. Negus RP, Balkwill FR: Cytokines in tumour growth, migration and metastasis. World journal of urology 1996, 14(3):157-165.

180. Balkwill FR: The chemokine system and cancer. J Pathol 2012, 226(2):148-157.

181. Miotto D, Boschetto P, Bononi I, Milani G, Legorini C, Cavallesco G, Lo Cascio N, Zeni E, Fabbri LM, Mapp CE: CC ligand 2 levels are increased in LPS-stimulated peripheral monocytes of patients with non-small cell lung cancer. Respiratory medicine 2007, 101(8):1738-1743.

182. Hinton CV, Avraham S, Avraham HK: Role of the CXCR4/CXCL12 signaling axis in breast cancer metastasis to the brain. Clinical \& experimental metastasis 2010 , 27(2):97-105.

183. Walser TC, Fulton AM: The role of chemokines in the biology and therapy of breast cancer. Breast disease 2004, 20:137-143. 
184. Darash-Yahana M, Pikarsky E, Abramovitch R, Zeira E, Pal B, Karplus R, Beider K, Avniel S, Kasem S, Galun E et al: Role of high expression levels of CXCR4 in tumor growth, vascularization, and metastasis. FASEB J 2004, 18(11):1240-1242.

185. Waugh DJ, Wilson C, Seaton A, Maxwell PJ: Multi-faceted roles for CXCchemokines in prostate cancer progression. Frontiers in bioscience : a journal and virtual library 2008, 13:4595-4604.

186. Zhernakova A, Alizadeh BZ, Eerligh P, Hanifi-Moghaddam P, Schloot NC, Diosdado B, Wijmenga C, Roep BO, Koeleman BP: Genetic variants of RANTES are associated with serum RANTES level and protection for type 1 diabetes. Genes Immun 2006, 7(7):544-549.

187. Petersen DC, Severi G, Hoang HN, Padilla EJ, Southey MC, English DR, Hopper JL, Giles GG, Hayes VM: No association between common chemokine and chemokine receptor gene variants and prostate cancer risk. Cancer epidemiology, biomarkers \& prevention : a publication of the American Association for Cancer Research, cosponsored by the American Society of Preventive Oncology 2008, 17(12):3615-3617.

188. Bracci PM, Skibola CF, Conde L, Halperin E, Lightfoot T, Smith A, Paynter RA, Skibola DR, Agana L, Roman E et al: Chemokine polymorphisms and lymphoma: a pooled analysis. Leuk Lymphoma 2010, 51(3):497-506.

189. An P, Nelson GW, Wang L, Donfield S, Goedert JJ, Phair J, Vlahov D, Buchbinder S, Farrar WL, Modi W et al: Modulating influence on HIV/AIDS by interacting RANTES gene variants. Proceedings of the National Academy of Sciences of the United States of America 2002, 99(15):10002-10007. 
190. Blanpain C, Buser R, Power CA, Edgerton M, Buchanan C, Mack M, Simmons G, Clapham PR, Parmentier M, Proudfoot AE: A chimeric MIP-1alpha/RANTES protein demonstrates the use of different regions of the RANTES protein to bind and activate its receptors. J Leukoc Biol 2001, 69(6):977-985.

191. Fellay J, Ge D, Shianna KV, Colombo S, Ledergerber B, Cirulli ET, Urban TJ, Zhang K, Gumbs CE, Smith JP et al: Common genetic variation and the control of HIV-1 in humans. PLoS genetics 2009, 5(12):e1000791.

192. Ghadjar P, Loddenkemper C, Coupland SE, Stroux A, Noutsias M, Thiel E, Christoph F, Miller K, Scheibenbogen C, Keilholz U: Chemokine receptor CCR6 expression level and aggressiveness of prostate cancer. J Cancer Res Clin Oncol 2008, 134(11):1181-1189.

193. Zheng J, Wang J, Sun X, Hao M, Ding T, Xiong D, Wang X, Zhu Y, Xiao G, Cheng G et al: HIC1 modulates prostate cancer progression by epigenetic modification. Clin Cancer Res 2013, 19(6):1400-1410.

194. Derhovanessian E, Adams V, Hahnel K, Groeger A, Pandha H, Ward S, Pawelec G: Pretreatment frequency of circulating IL-17+ CD4+ T-cells, but not Tregs, correlates with clinical response to whole-cell vaccination in prostate cancer patients. Int $\mathrm{J}$ Cancer 2009, 125(6):1372-1379.

195. Song N, Han S, Lee KM, Choi JY, Park SK, Jeon S, Lee Y, Ahn HS, Shin HY, Kang HJ et al: Genetic variants in interleukin-2 and risk of lymphoma among children in Korea. Asian Pac J Cancer Prev 2012, 13(2):621-623.

196. Lin HC, Liu CC, Kang WY, Yu CC, Wu TT, Wang JS, Wu WJ, Huang CH, Wu MT, Huang SP: Influence of cytokine gene polymorphisms on prostate-specific antigen 
recurrence in prostate cancer after radical prostatectomy. Urologia internationalis 2009, 83(4):463-470.

197. Gonzalez CA, Sala N, Capella G: Genetic susceptibility and gastric cancer risk. Int J Cancer 2002, 100(3):249-260.

198. Leshem O, Madar S, Kogan-Sakin I, Kamer I, Goldstein I, Brosh R, Cohen Y, Jacob-Hirsch J, Ehrlich M, Ben-Sasson S et al: TMPRSS2/ERG promotes epithelial to mesenchymal transition through the ZEB1/ZEB2 axis in a prostate cancer model. PLoS One 2011, 6(7):e21650.

199. Chang SY, Su PF, Lee TC: Ectopic expression of interleukin-1 receptor type II enhances cell migration through activation of the pre-interleukin 1alpha pathway. Cytokine 2009, 45(1):32-38.

200. King JC, Xu J, Wongvipat J, Hieronymus H, Carver BS, Leung DH, Taylor BS, Sander C, Cardiff RD, Couto SS et al: Cooperativity of TMPRSS2-ERG with PI3-kinase pathway activation in prostate oncogenesis. Nat Genet 2009, 41(5):524-526.

201. Stearns ME, Wang M, Hu Y, Garcia FU, Rhim J: Interleukin 10 blocks matrix metalloproteinase-2 and membrane type 1-matrix metalloproteinase synthesis in primary human prostate tumor lines. Clin Cancer Res 2003, 9(3):1191-1199.

202. Cardillo MR, Ippoliti F: IL-6, IL-10 and HSP-90 expression in tissue microarrays from human prostate cancer assessed by computer-assisted image analysis. Anticancer Res 2006, 26(5A):3409-3416. 


\section{CURRICULUM VITAE}

\section{Dominique Zilpha Jones, B.A.}

Email:dzjone01@exchange. louisville.edu

\section{A. EDUCATION}

University of Louisville, Louisville, KY

2011-Present

M.S. and Ph.D., Pharmacology and Toxicology

Smith College, Northampton, MA

2006-2010

B.A., Biochemistry

B. AWARDS

- Alice Eaves Barns Award, University of Louisville

- Dean's Citation, University of Louisville

- Southern Regional Education Board Doctoral Scholar Fellowship, University of Louisville

- Integrated Programs in Biomedical Sciences Fellowship (IPIBS), University of Louisville

2011-2012

- Dean's List, Smith College

2009-2010

- Jackie Robinson Foundation Scholar

2006-2010

- American Chemical Society Scholar

2006-2010

C. RESEARCH EXPERIENCE

Graduate Research Assistant, Department of Pharmacology 
and Toxicology

University of Louisville, Louisville, KY

PI: Dr. LaCreis Kidd

- Investigated inflammatory and immune response related genetic variants linked to prostate cancer risk through logistic regression and multi-factor dimensionality reduction $(\mathrm{MDR})$ modeling

- Received training in statistical analysis software (SAS) and Linux operating system programming

- Evaluated miRNA expression profiles in prostate cancer serum and cell lines as

- potential prognostic tools for prostate cancer diagnosis

- Utilized molecular cloning techniques to examine the impact of microRNA expression on cellular behavior in normal prostate and prostate cancer cells.

Summer Intern, James Graham Brown Cancer Center

06/2011-08/2011

University of Louisville, Louisville, KY

PI: Dr. LaCreis Kidd

- Completed Collaborative Institutional Training Initiative (CITI) in Human Research and Health Insurance Portability and Accountability Act (HIPPA) Privacy Training

- Received training on the operation of a Linux Operation System and Multifactor Dimensionality Reduction program, Statistical Analysis Software (SAS) programming and Golden Helix SNPs Variation Software 
- Completed a summer research project titled "Chemokine-associated Genetic Variants as Predictors of Prostate Cancer Risk among men of African Descent"

Research Technician, Biomedical and Biotechnology 11/2010-05/2011 Research Institute

North Carolina Central University, Durham, NC

PIs: Dr. Maxwell Gyamfi and Dr. Sean Kimbro

- Examined concentrations of proteins involved in the synthesis and metabolism of the SAM pathway through a BCA Assay, and Western Blotting Analysis

- Performed a lipid profile to determine the levels of glucose, triglycerides, HDL, LDL, and VDL in mice serum samples, a lipid extraction technique on hepatic tissue, and RNA extraction

- Received American Association for Laboratory Animal Science (AALAS) certification training in animal care for research and education through the AALAS Learning Library

Undergraduate Research Fellow, Department of Biochemistry 08/2009-05/2010 Smith College, Northampton, MA

PI: Professor Lale Burk

- Observed the biosynthesis of Dehydrodiisoeugenol (DDIE) from eugenol and isoeugenol in an acidic, basic and neutral buffer environment through thin layer chromatography and successfully synthesized coupled product DDIE in a neutral buffer system 
- Submitted a Special Studies research paper entitled "Investigation of Natural Products: The Oxidation of Olefins with Horseradish Peroxidase IV in Buffering Environments" to the Department of Biochemistry

- Presented a poster "Felix Haurowitz: His Life and Contributions to Biochemistry" on Haurowitz's research: first isolation of fetal hemoglobin, the change in crystallized deoxyhemoglobin's conformation during the absorption of oxygen and the theory of antibody formation

- Analyzed the impact of Haurowitz's publications (350 papers and 11 books between 1918-1966) on modern biochemistry and immunology

Teacher Assistant, Department of Biochemistry

Smith College, Northampton,MA

PI: Dr. Amy Burnside

- Prepared laboratory for weekly experiments; amylase purification, activity assay and SDS-gel electrophoresis

- Made chemical stock solutions, distributed and organized laboratory equipment

- Assisted instructor in perfecting lab experiments and students with problem-solving of their laboratory projects and assignments

- Reviewed and offered constructive criticism on laboratory notebooks of students

- Managed laboratory lock-up and clean up

Student Research Fellow, Biomanufacturing Research Institute

and Technology Enterprise

Department of Pharmaceutical Sciences

North Carolina Central University, Durham, NC 
PI: Dr. Dayami Lopez

- Performed a protein quantitative analysis with BCA on a Beckman Du Spectrophotometer, a Real-time PCR using SYBR Green on the 7500 Fast Real-Time PCR System, and data analysis to determine the effects of polarization and zaragozic acid (ZA) on the expression of the LDL receptor and PCSK9 proteins in hepatocytes

- Prepared cell culture and passed cells for C3A cell line (subclone of HepG2 cell line)

- Audited a North Carolina Central University graduate school course entitled Metabolic Diseases

\section{PEER-REVIEWED MANUSCRIPTS}

- Kidd L.R., Jones D.Z., Beache S., Rogers E.N., Ragin C., Jackson M., McFarlaneAnderson N., Tulloch-Reid M, Flores-Obando R., Barve S.S., Rudd J.E., and Kimbro K.S.. Chemokine Ligand 5 (CCL5) and Chemokine Receptor (CCR5) Genetic Variants and Prostate Cancer Risk among men of African Descent. Hereditary Cancer in Clinical Practice, 10(1):16, 2012.

- Rogers E.N., Jones D.Z., Yeyeodu, S.T, Ragin C., Jackson M.,McFarlane-Anderson N., Tulloch-Reid M, Kimbro K.S., and Kidd L.R. Toll-like Receptor (TLR)Associated Sequence Variants as Predictors of Prostate Cancer Risk Among Men of African Descent. Genes and Immunity, 10.1038/gene.2013.22, 2013.

- Kidd, L.R., Rogers, E.N., Yeyeodu, S.T., Jones, D.Z., Kimbro, K.S. Contribution of Toll-like Receptor Signaling Pathways to Breast Tumorigenesis and Treatment. Breast Cancer: Targets and Therapy, 10.2147/BCTT.S29172, 2013.

- Jones D.Z., Ragin C., Jackson M.,Kidd N.C., Flores-Obando R.E.McFarlaneAnderson N., Tulloch-Reid M, Kimbro K.S., and Kidd L.R. The Impact of Genetic 
Variants in Inflammatory-related Genes on Prostate Cancer Risk among men of African Descent. Hereditary Cancer in Clinical Practice, 11(1):19, 2013.

- Spruiell K., Jones D.Z., Cullen J.M., Awumey E.M., Gonzalez F. J., and Gyamfi, M.A. Role of human pregnane $\mathrm{X}$ receptor in high fat diet-induced obesity in premenopausal female mice. Biochemical Pharmacology, 2014 Apr 7. pii: S00062952(14)00207-X. doi: 10.1016/j.bcp.2014.03.019.

\section{E. ABSTRACTS AND POSTER PRESENTATIONS: NATIONAL/LOCAL}

\section{MEETINGS}

- Jones D.Z., Burk L. Felix Haurowitz: His Life and Contributions to Biochemistry. Celebrating Collaborations, Smith College, Northampton, Massachusetts, April 2010.

- Jones D.Z., Ragin C., Jackson M., McFarlane-Anderson N., Morrison S., FloresObando F., Kimbro K.S., and Kidd, L.R. Chemokine-associated genetic variants as predictors of prostate cancer risk among men of African Descent. Research Louisville!, University of Louisville, Kentucky, October 11, 2011.

- Kidd L.R., Jones D.Z., Ragin C., Jackson M., McFarlane-Anderson N., Morrison S., Flores-Obando F., Kimbro K.S. Chemokine-associated genetic variants as predictors of prostate cancer risk among men of African Descent. AACR Cancer Health Disparities, Washington, D.C. September 18, 2011.

- Kidd L.R., Jones D.Z., Ragin C., Jackson M., McFarlane-Anderson N., Morrison S., Flores-Obando F., Kimbro K.S. Chemokine-associated Loci and Prostate Cancer Among Men of African Descent. AACR Annual Meeting, Chicago, IL, March 31, 2011. 
- Jones D.Z., Anene D., Aloway A., Anene P., Avila D.V., Gobejishvili L., Barve S.S., McNally L.R., and Kidd L.R. Potential micro-RNA Biomarkers Associated with Cell Migration and Metastasis. Research Louisville!, Louisville, Kentucky, September 18, 2012.

- Anene D., Jones D.Z., Aloway A., Anene P., Avila D.V., Gobejishvili L., Barve S.S., McNally L.R., and Kidd L.R. Are Cell Adhesion Associated Micro-RNAs Linked With Metastatic Prostate Cancer? Research Louisville!, Louisville, Kentucky, September 18, 2012.

- Aloway A., Jones D.Z., Anene D., Anene P., Avila D.V., Gobejishvili L., Barve S.S., McNally L.R., and Kidd L.R. Cell Survival miRNAs (29a,29c,and 221) and Premetastatic Prostate Cancer ? Research Louisville!, Louisville, Kentucky, September $18,2012$.

- Jones D.Z., Anene D., Aloway A., Anene P., Avila D.V., Gobejishvili L., Barve S.S., McNally L.R., and Kidd L.R. Potential micro-RNA Biomarkers Associated with Cell Migration and Metastasis. James Graham Brown Cancer Center Retreat, Louisville, Kentucky, October 26, 2012.

- Anene D., Jones D.Z., Aloway A., Anene P., Avila D.V., Gobejishvili L., Barve S.S., McNally L.R., and Kidd L.R. Are Cell Adhesion Associated Micro-RNAs Linked With Metastatic Prostate Cancer? The Kentucky Honors Roundtable, Murray State University, Murray, Kentucky, October 27, 2012.

- Jones D.Z., Anene D., Aloway A., Anene P., Avila D.V., Gobejishvili L., Barve S.S., McNally L.R., and Kidd L.R. Reduced Expression of miR-342-3p in stage I, III, and IV Prostate Cancer. AACR Annual Meeting, Washington, D.C., April 8, 2013. 
- Jones D.Z., Linder J., Avila D.V., Gobejishvili L., Barker D., Schmidt L., Hobbing K., Clark G., and Kidd L.R. TGF-beta Signaling in prostate cancer cell lines derived from European- and African-American men. Research Louisville!, Louisville, Kentucky, September 24, 2013.

- Jones D.Z., Linder J., Avila D.V., Gobejishvili L., Barker D., Schmidt L., Hobbing K., Clark G., and Kidd L.R. TGF-beta Signaling in prostate cancer cell lines derived from European- and African-American men. James Graham Brown Cancer Center Retreat, Louisville, Kentucky, October 25, 2013.

- Jones D.Z., Hobbing K., Schmidt M.L., Clark G., and Kidd L.R. The Effect of miR186 Inhibition on Cell Viability and Colony Formation in Prostate Cancer. Research Louisville!, Louisville, Kentucky, September 16, 2014.

- Jones D.Z., Hobbing K., Schmidt M.L., Clark G., and Kidd L.R. The Effect of miR186 Inhibition on Cell Viability and Colony Formation in Prostate Cancer. James Graham Brown Cancer Center Retreat, Louisville, Kentucky, October 17, 2014.

\section{F. PROFESSIONAL MEMBERSHIP AND LEADERSHIP}

- School of Medicine Diversity Committee, Student Member, 2014-Present Society of Toxicology, 2014-Present

- Black Biomedical Graduate Student Organization (BBGSO), President, 2012-Present

- Golden Key International Honor Society, Member, 2012-Present

- American Association of Cancer Research (AACR), Member, 2012-Present

- Sigma Xi, The Scientific Research Society, Member, 2010

\section{G. SCIENTIFIC MEETINGS, WORKSHOPS, TRAINING}


- University of Louisville Pharmacology and Toxicology Departmental Seminars, 2011-Present

- American Association for Cancer Research, National Meeting, 2012-Present

- UofL Grant Writing Academy, Participant, 2013 